Transforming LGBTQ Lives

\title{
QUEER ROMA
}

Lucie Fremlova

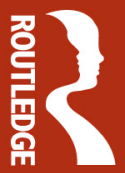




\section{Queer Roma}

This book offers in-depth insight into the lives of queer Roma, thus providing rich evidence of the heterogeneity of Roma. The lived experiences of queer Roma, which are very diverse regionally and otherwise, pose a fundamental challenge to one-dimensional, negative misrepresentations of Roma as homophobic and antithetical to European and Western modernity.

The book platforms Romani agency and voices in an original and novel way. This enables the reader to feel the individuals behind the data, which detail stories of rejection by Romani families and communities, and nonRomani communities; and unfamiliar, ground-breaking stories of acceptance by Romani families and communities. Combining intersectionality with queer theory innovatively and applying it to Romani Studies, the author supports her arguments with data illustrating how the identities of queer Roma are shaped by antigypsyism and its intersections with homophobia and transphobia.

Thanks to its theoretical and empirical content, and its location within a book series on LGBTIQ lives that appeals to an international audience, this authoritative book will appeal to a wide range of readers. It will a be useful resource for libraries, community and social service workers, third-sector Romani and LGBTIQ organisations, activists and policymakers; an invaluable source of information for scholars, teachers and students of bigger modules in undergraduate, graduate and postgraduate courses in a cross section of academic disciplines and subject areas. These include, but are not limited to, LGBTIQ/Queer Studies; Women's, Gender and Sexuality Studies; Romani Studies; Sociology; Anthropology; Human Geography; Area Studies; Cultural Studies; Social Movement Studies; Media Studies; Psychology; Heath Science; Social Science; Political Science.

Lucie Fremlova is an independent researcher who works at the interface between academia, social movements and policy. Her close-up, transdisciplinary research focuses on ethnic, 'racial', sexual and gender identities, particularly in relation to queer Roma. In her innovative theoretical approach, she combines intersectionality with queer theory. Her article 'LGBTIQ Roma and queer intersectionalities: the lived experiences of LGBTIQ Roma', published by the European Journal of Politics and Gender in 2019, won the Council for European Studies Gender and Sexuality Research Network Best Article Award for 2019. Her article 'Non-Romani researcher positionality and reflexivity: queer(y)ing one's privilege' was the most-read article published in 2019 in volume 1, number 2 of the Critical Romani Studies Journal. 


\section{Transforming LGBTQ Lives}

\section{Series Editors:}

Katherine Johnson (University College Dublin, Ireland)

Kath Browne (RMIT University, Australia)

Transforming LGBTQ Lives hosts the best international scholarship on contemporary lesbian, gay, bi, trans and queer (LGBTQ) issues. Innovative, interdisciplinary and intersectional, the series showcases theoretical and empirical research that fosters debate, pushes disciplinary boundaries and shapes activism. Extending feminist and queer scholarship through attention to a wide set of disciplinary influences (sociology, psychology, human geography, media and cultural studies, social policy, leisure studies, sports studies, political science) topics address the diversity of LGBTQ lives.

Recent titles in series:

The Everyday Lives of Gay Men

Autoethnographies of the Ordinary

Edited by Edgar Rodríguez-Dorans and Jason Holmes

Queer Roma

Lucie Fremlova

For more information about this series, please visit: www.Routledge.com/ Transforming-LGBTQ-Lives/book-series/LGBTQLIVES 


\section{Queer Roma}

\section{Lucie Fremlova}


First published 2022

by Routledge

2 Park Square, Milton Park, Abingdon, Oxon OX14 4RN

and by Routledge

605 Third Avenue, New York, NY 10158

Routledge is an imprint of the Taylor \& Francis Group, an informa business

(C) 2022 Lucie Fremlova

The right of Lucie Fremlova to be identified as author of this work has been asserted by her in accordance with sections 77 and 78 of the Copyright, Designs and Patents Act 1988.

The Open Access version of this book, available at www.taylorfrancis.com, has been made available under a Creative Commons Attribution-Non Commercial-No Derivatives 4.0 license.

Trademark notice: Product or corporate names may be trademarks or registered trademarks, and are used only for identification and explanation without intent to infringe.

British Library Cataloguing-in-Publication Data

A catalogue record for this book is available from the British Library

Library of Congress Cataloging-in-Publication Data

Names: Fremlova, Lucie, author.

Title: Queer Roma / Dr. Lucie Fremlova.

Description: Milton Park, Abingdon, Oxon ; New York, NY :

Routledge, 2022. I

Series: Transforming LGBTQ lives I Includes bibliographical

references and index.

Identifiers: LCCN 2021031123 (print) | LCCN 2021031124 (ebook) |

ISBN 9780367422059 (hardback) I ISBN 9781032138244

(paperback) I ISBN 9780367822699 (ebook)

Subjects: LCSH: Sexual minorities, Romani.

Classification: LCC HQ76.27.R66 F74 2022 (print) I

LCC HQ76.27.R66 (ebook) I DDC 306.7608914/97--dc23

LC record available at https://lccn.loc.gov/2021031123

LC ebook record available at https://lccn.loc.gov/2021031124

ISBN: 978-0-367-42205-9 (hbk)

ISBN: 978-1-032-13824-4 (pbk)

ISBN: 978-0-367-82269-9 (ebk)

DOI: $10.4324 / 9780367822699$

Typeset in Sabon

by MPS Limited, Dehradun 


\section{Contents}

List of figures vi

Acknowledgements vii

Introduction 1

1 Understanding Romani identities beyond ethnic and binary frames

2 'Perverse' and 'deviant' queer sexualities, genders, ethnicities and 'racialities'

3 'We're here, we're Roma and queer!' 98

4 Visibility in spaces between difference and sameness $\quad 125$

5 Queer belonging 150

6 Towards non-stereotypical understandings of Romani identities

References $\quad 192$

Index 218 


\section{Figures}

0.1 Queer Roma 1

6.1 Myth and reality 180

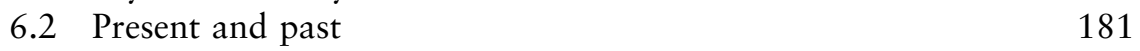

$\begin{array}{ll}6.3 \text { Everyday couple } & 182\end{array}$

6.4 Everyday household 182

6.5 On my skin $1 \quad 183$

6.6 On my skin 2 


\section{Acknowledgements}

Around 2014, the slogan 'Nothing about us without us' was particularly salient in the Roma rights movement and Romani Studies. Increasingly, Roma, including queer Roma, were expressing their frustration at being written about by others who often failed to invite them to the table. In this spirit, I would like to thank everyone who shared their lived experiences with me. It would have been impossible for me to write this book without the contributions of all the queer Roma who participated in the doctoral research, on which the book is based.

I wrote the largest part of this book in 2020, at a very specific juncture. I left academia, and the COVID-19 pandemic had started. Literally everything was being turned upside down within a very short period of time. While it was not always easy to put aside what was happening and to concentrate fully on writing the book, I had all the time in the world to do so. My special thanks go to my wife, Carol Simmons, who helped make this possible with her love and support. She was also the first person to read my book and to give me invaluable feedback and constructive observations that helped me substantially.

Transforming a doctoral thesis into a book is a tall order; yet, many people have done so before me. I have benefited from the plentiful experiences of Dr Aidan McGarry, who provided me with thorough, insightful comments and has been a source of support and inspiration for me ever since I started my doctorate. I also want to thank my mum Lucie, my sister Vendula, her partner David and my nephews Hubert and Marian for providing me with love and emotional support. 


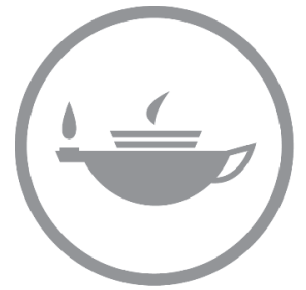

Taylor \& Francis
Taylor \& Francis Group http://taylorandfrancis.com 


\section{Part one: Introduction}

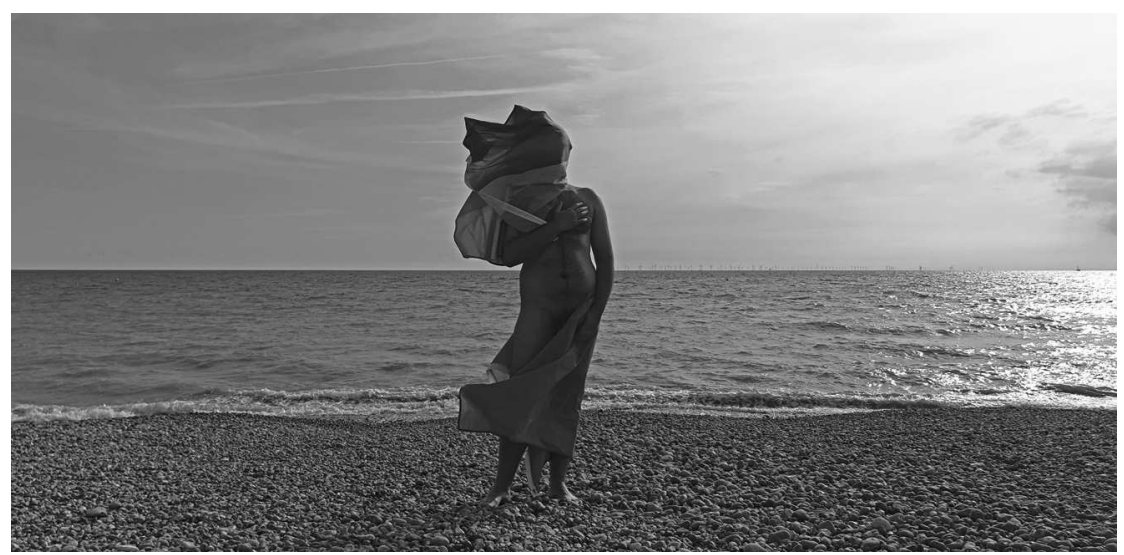

Figure 0.1 Queer Roma.

The book that you are about to read is a qualitative exploration of the lived experiences of queer Roma across and beyond Europe. 'But who are Roma?', you may ask. Roma are a diverse, heterogeneous, transnational ethnic minority scattered across continents as varied as Europe, North and South Americas, Australia, Africa and, according to some scholars, even Asia (Hancock 2002, xx). Roma are often referred to as a nation without a territory or a state. In the European Union (EU) alone, Roma are estimated to number between 10 and 12 million: this makes Roma the largest ethnic/ 'racial' minority group. Roma differ significantly from continent to continent; from country to country; from region to region. This heterogeneity is also reflected in the different names coming under the umbrella term 'Roma': 1 Vlach Rom, Rumungro Rom, Kalderash, Sinti, Lavari, Manouche, Ashkali, Boyash, Tattare, Kale, Ursari, Luri, Romanishals or Romany Gypsies, ${ }^{2}$ Yenish, Gitanos and many more.

Historically, there has been an often-unacknowledged proximity between Roma and lesbian, gay, bi, trans, intersex and queer (LGBTIQ) people, 


\section{Introduction}

reflected not just in a social, but also a linguistic affinity between queer argots such as Polari used by gay men and drag queens in the United Kingdom $(\mathrm{UK})^{3}$ or a Lubunca and Kaliardà used by LGBTIQ communities in Turkey and Greece, respectively. Apart from borrowing from other languages, these queer argots both use elements of the Romani language (Barrett 2018). Despite this queer-Roma proximity, grounded in common experiences of stigmatisation and persecution of both groups discussed in Chapter Two, until very recently, queer Roma were not visible; or certainly not as visible as has been the case over the past decade. During this time, a discernible LGBTIQ Roma movement has emerged and mobilised across Europe: the latter section of this introductory chapter discusses this mobilisation. The visible presence of queer Roma at Pride events in European capitals and other cities, such as Prague, Cologne, Berlin, Madrid, Valencia, Strasbourg, Bucharest, Kyiv, Budapest or London, which came to a temporary halt in 2020 due to the ongoing global COVID-19 pandemic, is another aspect of the enormous diversity among Roma of multiple, intersecting identities - whether they are linked to ethnicity/'race', sexuality, gender identity or other categories of identification.

As this book will show, contrary to so-called popular beliefs and opinions, Roma of minority sexual and gender identities, who identify as queer, have always been present within the social matrix of the various subgroups and in all walks of life. And not just that: the rich, multi-faceted lived experiences of queer Roma presented in this book dispel myths about the presumed compulsory heterosexuality, homophobia and sexual backwardness of Roma.

Yet, despite this ever-present heterogeneity among Roma, non-Roma and majority societies have historically seen and treated Roma as a homogeneous ethnic monolith, to whom they have attributed a negative group identity. Given this overwhelmingly negative treatment of Roma by nonRoma throughout the history, it is not a coincidence that even in the 21st century, Roma remain one of the most discriminated against ethnic/'racial' minority groups in Europe (FRA 2018). Roma continue to face high levels of ethnic/'racial' discrimination, socio-economic marginalisation and exclusion also in other parts of the world, for instance, the United States (US). ${ }^{4}$ In countries as varied as Slovakia, Romania, Bulgaria and Denmark, the COVID-19 pandemic has served as a magnifying glass, uncovering the actual extent of racial inequalities and anti-Romani racism; and the discrimination that Roma are subject to at the hands of majority societies. ${ }^{5}$ For instance, lack of running water in many, often overcrowded Romani settlements, ghettos and dwellings across Europe has meant that Roma have been contracting COVID-19 at a higher rate than non-Roma. This has led to an increased number of arbitrary acts of over-policing by law enforcement agencies and the army, as well as cases of police brutality. ${ }^{6}$

The response to Roma by non-Romani individuals, institutions, organisations, governments and even academia has tended to be very polarised. As 
I will discuss later in this book, in the popular imagination of non-Roma, Roma have either been portrayed as villains or romanticised 'bon sauvages'. This dichotomy of vilifying representations on the one hand and romanticising ones on the other has been instrumental in generating and maintaining stereotypical and damaging misrepresentations and perceptions of Roma among non-Roma, as well as a stigmatised, fixed ethnic identity. This is reminiscent of Adichie's (2009) danger of a single story. The danger lies in that stereotypical portrayals that flatten a particular people and their experiences by constantly showing them as only one thing over and over again turn the people into a single story: an incomplete stereotype which robs them of dignity by emphasising how distinct and different they are. Such historically flattened portrayals and representations of Roma have led to social stigmatisation of Roma whom non-Roma perceive as fundamentally distinct, different from the white, non-Romani majority and the rest of society both in terms of biology and culture. Over the past decades, there has been a lot of extreme negative media coverage of Roma. These single, flattened stories about 'Roma leaving rubbish and stealing stuff' have become a source of television entertainment in the form of reality TV shows and investigative documentaries that spread misinformation about Roma, ${ }^{7}$ produced by commercial channels across Europe ${ }^{8}$ and the US, ${ }^{9}$ as well as by European public service broadcasters such as Czech Television ${ }^{10}$ or the BBC. ${ }^{11}$ Since many Roma do not want to be associated with such negative portrayals for fear of being stigmatised and racially persecuted even further, they often decline to be identified, hide or deny their ethnicity altogether.

Non-Roma have tended to see and treat Roma as a threat, risk to personal safety and societal, national and trans-national security. Within the neoliberal market-oriented political arena, with its emphasis on free trade, deregulation, privatisation, public service cuts due to austerity measures since the 2008 financial crises and the COVID-19 pandemic starting at the turn of 2019 and 2020, nation states have often tended to make Roma hyper-visible and used them as bargaining chips, or the proverbial sacrificial lambs to generate feelings of solidarity, collective identity and belonging among non-Roma. As this book will show, even in academia, scholars, very often non-Roma, have incorrectly theorised Roma as an object of cultural essentialism stuck in time, anachronistic and antithetical to modernity, or even post-modernity; and trapped within a purely ethnic frame of reference. Such a collective conception of ethnic identity has engendered an approach whereby members of this group have been reduced to possessing the same or similar sets of assumed characteristics and values determined by a fixed ethnic identity. However, such a conceptualisation has never reflected the everyday lived realities of Roma; and, for that matter, those of queer Roma even less so. 


\section{Introduction}

\section{Locating queer Roma}

Despite an abundance of literature on Roma, queer Roma have barely existed in academic and other literature. Queer Roma have also been absent from the vast literature on LGBTIQ people. Consequently, information about the experiences of queer Roma is still almost non-existent or scarce. I have been aware of the presence of queer Roma within the Roma rights movement ever since I started to be involved in Roma rights advocacy and research around 2000 in the Czech Republic and then around 2004 internationally. In the early to mid-2000s, sex, sexuality and gender identity were still taboo topics in some of the Czech non-Roma and Roma families that I was friends with and in organisations that I cooperated with. I knew of individuals and had friends, acquaintances and colleagues who were queer Roma but only self-identified as Roma. They would disclose their sexuality only in private, imploring me not to tell anyone.

In the late 1990s and early 2000s, due to rising levels of racial prejudice towards Roma after the collapse of Communism in 1989, the presence of Roma in non-Roma straight spaces was quite unusual in the Czech Republic. This is not to say that it never happened; but in gay and lesbian venues, despite occasional arguments with some LGBTIQ non-Roma who held prejudicial views on Roma, there seemed to be a somewhat greater sense of acceptance, solidarity and belonging among members of the two marginalised groups: Roma and LGBTIQ. I would see not only gay, lesbian and bi Roma, but also other non-heteronormative - queer - Roma. There were some supportive, often female Romani colleagues who were happy to go to a gay club with a group of closeted Romani gays. I saw similar expressions of support and solidarity from straight Romani women in several gay clubs in the city of Brno in the early to mid-2000s: around midnight, a group of Romani cross-dressers and trans people would arrive, accompanied by straight Romani women. Based on these observations, I came to the conclusion that just like queer non-Roma, some queer Roma were experiencing acceptance, while others had to deal with rejection. Simultaneously, I was fascinated and shocked by the complete invisibility and lack of acknowledgement of queer Roma in everyday interactions.

\section{From researching segregation in education to researching sexualities}

Around 2004 and 2005, I started to work as a researcher primarily in the third sector, researching the discrimination against Roma. Several other field researchers and I conducted a background study concerning the segregation of Romani pupils in Czech education. The data were then used as evidence for the ground-breaking judgement D.H and others v. the Czech Republic regarding indirect discrimination against Roma in Czech education, delivered by the European Court of Human Rights in $2007 .{ }^{12}$ It was 
then that I was beginning to understand the importance of qualitative data in the absence of hard, statistical data. I learnt that where one was able to identify a pattern, but there was no objective evidence readily available, one had to go actively searching for it; and that doing so allowed one to come up with innovative, critical approaches. I repeated a similar approach in 2008 when undertaking a mapping survey of Roma who had moved from other European Union member states to England (Fremlova/European Dialogue 2009). In 2010, on the back of the mapping survey and my previous research, I designed and conducted an innovative pilot research study. It looked at the achievement of Romani children studying in mainstream education in the UK, some of whom had been previously largely segregated into special - or practical - schools or classes for the mentally challenged with reduced curricula in Central and Eastern European school systems (Fremlova et al. 2011). The pilot study was my first scholarly effort to deessentialise Roma. What do I mean by that? The study endeavoured to show that under different sets of circumstances, in a different schooling system and a different socio-cultural context, the performance, achievement and attainment of Romani pupils did not differ from the school achievement of non-Romani ones. Where there were differences in achievement, it was due to structural obstacles and systemic inadequacies posed by the educational system: the root cause of underachievement did not lie in the ethnic/'racial' heritage of Romani pupils, but in the quality of teaching.

Living, working and doing research in the UK opened my eyes to other social phenomena related to how identities are impacted and shaped by new environments after migrating. Many of the Roma whom I interviewed had moved to the UK over the past three decades, blended in, became ordinary, more comfortable and, indeed, proud to self-identify as Roma. Naturally, moving to the UK was not without challenges, but the Roma reported this ethnic 'coming out' to be a major factor, impacting positively on their children's academic achievement. Importantly, much has changed following the 2010 General Election in the UK. This resulted in austerity measures, budget cuts, deteriorating community race relations, increasing levels of racism (Fremlova/Fundamental Rights Agency 2012) and eventually in the 2016 European Union referendum and the UK's withdrawal from the EU in January 2020. The positives reported by the Roma respondents made me reflect on the role that relatively higher levels of acceptance of ethnic/'racial' identities of colour and non-heteronormative sexualities play in different contexts; and how this acceptance discursively shapes and forms identities. While doing research on the educational experiences of Roma in the UK, I also began to notice changes in relation to perceptions of sexuality among Roma, as well as queer Roma starting to come out of the closet more frequently than I had previously seen. A key question was how to capture these experiences in a situation where the very topic of any potential research inquiry concerned possibly the most intimate aspects of one's private life and still a social taboo in some Romani families and communities. 


\section{Introduction}

I was aware of an MA thesis on the Queer Gypsy (Baker 2002) but it was not until around 2009 and 2010 that I started to perceive gradual changes whereby some queer Roma started to feel comfortable enough to come out of the closet as LGBTIQ. In that period, the film Roma Boys (2009), Jovanovic's article The Difference that Makes a Difference: We Need More Guts! (2009) about the experience of being a gay Roma, Brooks' article (Mis)recognitions: Romanies, Sexualities, Sincerities (2009), an academic article on Romani women, skin colour, sexuality, gay pride and passing (Horváth 2010); Mikey Walsh's book Gypsy boy (2010) came out, followed by the 2011 sequel Gypsy boy on the run; and Berná's two articles on queer Roma in Spanish (Berná 2011a, 2011b). In 2010, I set up a private Facebook group that brings together queer Roma, their friends and allies where the topic of sexual and gender identity can be broached. Initially, it had about 50 members, mostly from my circles of queer Roma friends and acquaintances, as well as a number of like-minded LGBTIQ non-Roma and other allies. Currently, the group has 500 members, spanning over 15 different countries across Europe, North and South America.

In early 2013, the Council of Europe launched a study on young Roma's experiences of multiple discrimination: for the first time, it included sexuality and gender identity. I became involved as a researcher and the main editor. The study was eventually published under the title Barabaripen: Young Roma speak about multiple discrimination (Fremlova and Georgescu 2014). Despite being innovative, the study, which was designed as a learning resource for young people, had a limited scope: it offered a glimpse into the lived experiences of one lesbian Roma and two gay Roma. It was mainly thanks to this study that I started to cooperate closely with the Czech-based, predominantly LGBTIQ Romani organisation ARA ART. In 2014, it launched a counselling service for queer Roma and held a national workshop. In 2015 and 2016, we organised the first and second International Roma LGBT conferences in Prague.

In the meantime, more accounts of queer Romani experiences had been published: Tesăr's (2012) Becoming Rom (male), becoming Romni (female) among Romanian Cortorari Roma: on body and gender; a blog about a Czech Romani young man living openly as gay in the UK (Leeming 2012); the Serbian version of Dzuvljarke: Roma Lesbian Existence (Kurtic 2013), followed by an English translation (ERRC 2014); a Czech television programme about a trans Roma (2013); ${ }^{13}$ a volume entitled Nothing about us without us (ERRC 2015); and a transnational interdisciplinary research project New bybrid and sexualised Roma identities (2015-2017). ${ }^{14}$ The experiences and multiple ethnic/'racial', sexual and gender identities of queer Roma started to become more visible. There was also anecdotal evidence suggesting that Romani communities were accepting of queer Roma; and that queer Roma experienced hostility and rejection from non-Roma LGBTIQ people, grounded in antigypsyism (Fremlova and Georgescu 2014). A number of journal articles (Baker 2015; Máté 2015; Fremlova 2018; Fremlova 2019) 
appeared between 2015 and 2020; the now-renowned theatre piece Roma Armee has been staged since 2017 at the Berlin-based Gorki Theatre (Pabijanek 2018, Heljić 2019); and the Gypsy, Romani and Traveller LGBTQ+ Spoken History Archive has been launched (2021). ${ }^{15}$

Over the past two decades, two books on Romani sexuality have been published in English: a volume of texts by Romani authors writing on the topic of Roma and sexuality, edited by Nirenberg (2011); and Gay y Blasco's monograph on Roma in Madrid (1999). Both books remain silent on the topic of queer Roma. Recently, two book chapters about queer Roma have appeared (Corradi 2017; Fremlova and McGarry 2018); and a Spanish book on Roma, politics, self-representations, activisms, gender and sexuality (Andrés and Masó 2018). However, to the present day, apart from the aforementioned publication about Roma lesbian women in Serbia (Kurtic 2013), no monograph has been published, which would offer an intersectional, regionally and otherwise diverse account of the lived experiences of queer Roma. Corradi's book (2017) touches upon the topic of Roma who enact and display non-heterosexual orientations, transgender and intersexual diversities being excluded from Roma families, communities and clans due to the topics being still taboo. That is only one side of the story, though. By providing also the other side of the story, this book aspires to complement the previous narratives.

\section{The book and its structure}

The starting point for this book is the question: 'What are the experiences of queer Roma in and beyond Europe?'. This transdisciplinary book is the first one of its kind to offer in-depth insight into the lives and experiences of queer Roma. It illustrates how, for queer Roma, life is inextricably linked to being seen and defined through the lens of ethnicity/'race', sex/gender, sexuality and gender identity. It also demonstrates how antigypsyism in non-Romani communities is a key aspect that often dominates and eclipses the lived experiences of queer Roma. Offering a breadth of empirical evidence attesting to the enormous diversity and heterogeneity of identities among Roma, the book details the more familiar stories of rejection or partial acceptance by nuclear and extended families and communities, along with particular strategies queer Roma use to negotiate such situations. Importantly, in Chapters Three, Four and Five, you will find the less familiar and at times entirely unfamiliar stories of acceptance of queer Roma by families, communities and other kinship structures, and experiences of antigypsyism in - and exclusion from - LGBTIQ non-Romani communities. The rich, multi-layered lived experiences of queer Roma contained in this book pose a fundamental challenge to stereotypical, onedimensional, negative representations of Roma that are often racist. As such, they defy dominant homogenising portrayals of Roma as anachronistic and antithetical to modernity and Europeanness. 


\section{Introduction}

The book consists of an introduction and six chapters and is divided into two parts, which are meant to be read together, but they can also be read separately, independently of one another. The current, first part is a theoretical as well as methodological excursion, setting the scene and introducing the main concepts. Thus far, this introductory chapter has located queer Roma - who have barely existed in research on LGBTIQ and Roma on the societal and scholarly map and discussed my trajectory from researching the educational segregation of Roma to doing research on, with and for queer Roma. The following section of this introduction discusses the choice of vocabulary used in this book, provides a brief historical overview of Roma and offers an outline of the emergence of the queer Roma movement over the past decade. This societal phenomenon has occurred against the backdrop of the rising levels of antigypsyism vis-à-vis an increased societal acceptance and enhanced legal protections of LGBTIQ people not only in Europe but also in many other parts of the world. This dichotomy in public perception of what are often considered two of the most stigmatised and pathologised collective social identities (explored in detail in Chapter Two) - LGBTIQ, Roma and their intersections - in Europe provides an important social context, within which the multiple, intersectional lives and experiences of queer Roma unfold.

Chapter One, 'Understanding Romani identities beyond ethnic and binary frames', is the longest chapter, which provides the theoretical and methodological backbone of the book. It discusses understandings of Romani identity in Romani Studies scholarship. It goes on to consider conceptualisations of Romani identity in relation to Stuart Hall's concept of 'new ethnicities' as encapsulating ethnicity/'race', sex/gender, class, sexuality, gender identity and other categories of identification, paving the way for queer research-informed conceptualisations of Romani identities. The chapter discusses the relevance of concepts emanating from queer theory and queer of colour critique to conceptualisations of ethnic/'racial', sexual and gender identities; and the benefits of 'queer intersectionalities'. It demonstrates the centrality of queer intersectional scholarship to understanding the intersectional nexus of ethnicity/'race', sex/gender, sexuality, gender identity, class, age, disability and so on. These artificially created social divisions are a symptom of inequitable hegemonic power relations. The chapter goes on to discuss the methods and methodology used during the qualitative, ethnography-informed research. It offers a methodological reflection on access to participants, data collection and data analysis, and critically examines queer non-Romani researcher positionality and reflexivity.

Chapter Two, "Perverse" and "deviant" queer sexualities, genders, ethnicities and "racialities"', expands on the notion that certain types of non-normative ethnic/'racial' identities, for example, Black, Romani, Jewish, as well as sexual and gender identities, for example, lesbian, gay, bi, transgender, intersex, have come to be seen as perverse, pathological, deviant, abject, socially stigmatised and stigmatising markers for their bearers. 
It examines the construction of gendered and sexed, or sexualised, ethnicities/'racialities', as well as the construction of ethnicised and 'raced', or 'racialised', sexual and gender identities. The chapter explores what are, within the European context, often considered two of the most stigmatised and pathologised collective social, ethnic/'racial', sexual and gender identities - Roma, queer and their intersections: queer Romani identities. Just like non-normative sexualities and gender identities are often closets for queer people, Romani identity has become a kind of ethnic/'racial' closet due to being a negative, socially stigmatising marker for many Roma.

The second part of the book explores the empirical findings. Using a very diverse pool of rich empirical evidence, Chapter Three, 'We're here, we're Roma and queer'!, considers how the intersectional experiences of queer Roma are informed and shaped by different relations, contexts and material realities. The chapter goes on to examine the lived experiences of queer Roma at the intersection of antigypsyism, homophobia, lesbophobia (homophobia thereafter), transphobia, sexism and other forms of oppression. It goes on to look at how the lived experiences of queer Roma are shaped through family and communities. The chapter explores the role that gender plays in relation to the societal position of women, men and trans Roma, particularly in terms of the asymmetrical power relations impacting on the position of Romani lesbian women, Romani gay men and bi and trans Roma. Gender identity is considered with respect to the ways in which some trans Roma are ethnicised/'racialised', sexed and gendered as opposed to cisgender Roma and non-Roma. The chapter goes on to consider ethnic/ 'racial' and queer visibility, invisibility and hyper-visibility.

Chapter Four, 'Visibility in spaces between difference and sameness', explores the lived experiences of queer Roma vis-à-vis different degrees of ethnic/'racial' and queer visibility, including invisibility and hyper-visibility; their links to acceptance - or lack thereof; and being located within and in between sets of social relations and contexts. It considers the ethnic/'racial' closet, the queer closet and passing resulting from various degrees of ethnicised, 'racialised', sexed and gendered visibility as strategies responding to and protecting their queer Roma users from antigypsyism, homophobia, transphobia, sexism and intersectional oppression. It also demonstrates how as mediators, bridges and in-betweens, some queer Roma seek to create commonality, and indeed, strategic sameness - a conscious, strategic, subversive take on passing as non-Roma and straight - to unsettle and challenge marked essentialist ethnic/'racial', sexual and gender 'difference'. Finally, the chapter considers the notion that spaces which enable queer Roma to live and enact their intersecting ethnic/'racial' and queer identities are vital to being seen, heard, understood and feeling emotionally safe.

Chapter Five, 'Queer belonging', explores the notion of queer belonging as a non-normative positionality vis-à-vis the queer intersectional specificity that queer Roma experience due to possessing negatively valued, stigmatised, pathologised and often hyper-visible ethnic/'racial', sexual and gender 
identities. This has consequences for queer Roma's sense of belonging to majority white-normative, heteronormative and cisnormative societies, as well as Romani and LGBTIQ communities. Queer (non-normative) belonging in turn impacts on the identifications and disidentifications made. Queer Roma may identify with certain aspects of ethnic/'racial', sexual and gender identities while disidentifying with dominant socio-cultural scripts, values and norms that are hostile, threatening or oppressive. The chapter discusses how queer belonging epitomises a strategic response to the 'queer identity dilemma'.

Chapter Six, 'Towards non-stereotypical understandings of Romani identities', the concluding chapter, summarises key milestones in understanding Romani identities; and those understandings engendered by the lived experiences of queer Roma, explored throughout Parts One and Two of this book and facilitated by the concept of queer intersectionalities. These understandings unsettle and challenge persisting dominant, essentialising conceptualisations of Romani identities at the core of stereotypical representations of Roma that are generated, used and maintained most often by non-Roma. The chapter proceeds to consider the importance of innovative methods in conducting impactful transdisciplinary research at the interface between community organising, activism, policy and academic scholarship; co-producing knowledge that brings about social change; and the heterogeneity and plurality inherent to the lived experiences and visual self-representations of queer Roma. Contemplating the use of strategic essentialism and queer intersectional feminism in social movements, the book concludes by reflecting on possible future directions for the Roma rights movement.

\section{Terminology}

As for the terminology used: the umbrella term 'Roma', along with the adjective 'Romani' ${ }^{16}$ used in this book, is an endonym adopted by the first World Romani Congress in London exactly half a century ago, in 1971. Along with the Romani flag and the Romani anthem, ${ }^{17}$ its adoption marks a significant milestone in the emancipation of Roma. Nonetheless, its usage is not without problems. Members of some communities, for instance, those who ascribe as Romani Gypsy or Traveller in the UK, have argued that the term 'Roma' has been imposed on them by political and other structures in continental Europe. Other critics believe that its frequent use is partially responsible for perpetuating the stereotypical image of Roma as a homogenous group. At the same time, many Central and Eastern European Roma consider the use of the word 'Gypsy' a racial slur. It is an exonym that has been historically imposed on Roma by the dominant non-Romani societies and is associated with racial persecution and the Nazi atrocities committed against Roma during WW2 Romani Holocaust. Proponents of 'Roma' and 'Romani' believe the terms best reflect the heterogeneity of the various 
diverse populations, as well as the inclusive nature of the adjective to encompass Roma of Central and Eastern European heritage, Romani Gypsies and Travellers of Romani heritage. As a non-Roma, I respect the fundamental importance of every individual's right to self-identify. That is why the terms 'Roma/Romani/Romany', 'Gypsy' and 'Traveller' are used where the persons at issue self-identify as such; or they refer to other members of the same, similar or related groups. The terms 'Gadjo' (singular) and 'Gadje' (collective) are used to refer to non-Roma. Some of the conceptual problems associated with the use of the term 'Gypsy' also inform my choice of terminology to refer to a specific form of racism against Roma, antigypsyism, associated with historic stigmatisation and other key assumptions: orientalism, nomadism, rootlessness and backwardness (Rostas 2019). I use the term in line with the following definition proposed by the Alliance against Antigypsyism (2016) to signify a historically constructed, persistent complex of customary racism against social groups identified under the stigma 'gypsy' or other related terms, and it incorporates: a homogenising and essentializing perception and description of these groups; the attribution of specific characteristics to them; discriminating social structures and violent practices (...), which have a denigrating and ostracising effect and which reproduce structural disadvantages. (...) The term antigypsyism - in citing the majority's projections of an imagined outgroup of 'gypsies' which simultaneously constructs an imagined in-group is analytically more accurate and makes clear that other groups - Sinti, Travellers, manouches [sic], Egyptians - are equally affected. (Alliance against Antigypsyism 2016, 5-6; emphasis added)

The acronym 'LGBTIQ' is used throughout this book to reflect how each of the participants self-identified. However, its use is not unproblematic either. Whatever form it takes, such as LGB, LGBT, LGBTI, LGBTQ or when, as in this book, the umbrella term 'queer' is used to refer to lesbian, gay, bisexual, trans, intersex and queer people, it purports to encompass a given set of sexualities or gender identities. As Chapter One will show, this fixity is antithetical to queer theorising's understanding of queer as a 'positionality vis-à-vis the normative' (Halperin 1995, 62). In a similar vein, it has been argued that, for example what is sometimes a tokenistic inclusion of the ' $\mathrm{T}$ ' for trans is a way of appropriating and assuming trans people's experiences often without involving them. These observations are highly topical given the current culture wars waged, largely within the UK context, by a small number of gender-critical, trans-exclusionary feminists over trans women.

\section{Who are Roma? A brief historic overview of Roma in Europe}

Many members of the diverse Roma groups and subgroups living transnationally have maintained aspects of a shared culture and dialects of the Romani language since the 11th and 12th centuries. Starting with 


\section{Introduction}

comparative philologists such as Grellmann (1783), a consensus has been established amongst scholars and linguists, including Romani ones such as Hancock (2002), Horváthová (2002), Le Bas (2010) and Lee (2009). According to the consensus, the ancestors of European Roma are believed to have been a mixture of Indian Rajput troops (Kshatriya) and their camp followers, composed of castes, sub-castes and social tiers (jatis). Roma are believed to have left present-day northern India in several stages and waves (Hancock 2002) sometime between 3rd and 9th-10th centuries, during a series of raids led by Mahmud of Ghazni between 1000 and 1027 AD in an attempt to spread Islam. Nonetheless, the exact timing, manner and circumstances of Roma's departure from India and arrival into Europe remain unknown (Horváthová 2002, Matras 2015, 159). There are clues to be found in the vocabulary of the Romani language, which shares its earliest and most basic words such as water (pani) or house (kher), as well as warfare and military-related words with other Indian languages such as Hindi, Panjabi, Gujarati, Nepali, Bengali, and many more (Lee 1998; Hancock 2002), including Greek (Horváthová 2002) and Persian (cited in McGarry 2010). Importantly though, as I will discuss later, anthropologists such as Okely (1983), Willems (1997) and Lucassen et al. (1998) have challenged the legacy of the linguistic perspective.

Historical evidence suggests that Roma arrived in the Byzantine Constantinople between 810 and 1050 AD (Groome 1908, 485) - with evidence of a Romani presence in a document from Constantine XI Palaiologos dating from 1283 (Hancock 2002, 15) - and later in other parts of Europe in the 14th and 15th centuries (Liégeois 1986; Hancock 2002). For example the first official record of the presence of Egyptians ${ }^{18}$ - hence Gypsies - in Scotland is from 1505 and in England from 1513/1514 (Kenrick and Clark 1995, 24) where these groups are at times referred to as Travellers. The Church, the state and trade guilds introduced and maintained antiRomani measures and laws in the 16th, 17th and 18th centuries. In 1568, Pope Pius V expelled Roma from the Holy Roman Church (Hancock 2002). From the 14th century through 1855 in Moldavia and 1856 in Wallachia (Matras 2015), Roma were not expelled but enslaved (Liégeois 1983; Hancock 2002). In south-eastern Moravia, Roma first started to settle at the end of the 17 th century thanks to the local aristocracy's toleration, which meant that only a few Roma were exempted from the so-called anti-Gypsy laws. This was conditioned by the tolerated individuals stopping all contact with their families and abandoning Romani culture, traditions and language (Horváthová 2002). In Hungary under Maria Theresa's reign, in the 18th century, Roma were settled as part of her project of assimilation and sedentarization. Roma were prohibited from speaking Romani or wearing traditional clothes. Romani children were often taken away from their families. In Spain, Roma were forcibly settled and enslaved, especially from the second half of the 18th century as part of the so-called great round-up in Andalusia in 1749 (Liégeois 1983; Horváthová 2002). 
The actual situation and living conditions of Roma across 19th-century Europe differed substantially. In the Czech lands, for example many Roma who remained unsettled, hence itinerant, were punished for their vagrancy in line with a number of Austro-Hungarian anti-Romani decrees and laws. This was the case especially with the ordinance of the Viennese interior ministry on wandering Gypsies No. 14015/1887 of 14 September 1888 (Zel'ová et al. 1994). As a result, vagrant Roma were apprehended, prosecuted, jailed, expelled or conscripted into the Hungarian military. In the meantime, in the neighbouring region of southern and south-eastern Moravia, many Roma succeeded in establishing permanent settlements as the foundations for integration and settlement had been laid since the 17th century through assimilation (Horváthová 2002, 39). Meanwhile, as mentioned above, in Moldavia and Wallachia (present-day Romania), Roma were enslaved for 500 years until 1855-1856.

Over the past two centuries, Roma have continued to face rejection, marginalisation, oppression, forced assimilation, racism, persecution and, in the most extreme cases, extermination. In the first half of the 20th century, drawing upon the aforementioned 19th-century Austro-Hungarian anti-Romani measures, Central European states were resorting to repressive measures regulating the movement of Roma, such as introducing gypsy identity cards - a special document that included the holder's fingerprints instead of a photograph, as well as draconian laws against Gypsy nomadism, adopted in France in 1912, in Bavaria in 1926 or Czechoslovakia in 1927 (Liégeois 1983; Horváthová 2002). On 14 July 1927, the Chamber of Deputies of the Czechoslovak National Assembly adopted Act No. 117/ 1927 Coll. on vagrant Gypsies, defined as 'Gypsies wandering from place to place and other vagabonds avoiding work who live the Gypsy way of life' customarily replaced by the general term of 'Gypsies' which, at that time, did not have an ethnic meaning only - requiring persons aged 14 and older to carry with them at all times and produce upon request their gypsy identification card (Horváthová 2002, 43). It prohibited the residence of foreign Roma and regulated attitudes by the state administration towards travelling, which was considered an inborn instinct or even a 'racial' feature of all Roma. The act also empowered local authorities to ban Roma from designated places, impacting partly on settled Roma, too, and resulting in the establishment of the Centre for Registering Nomadic Gypsies in Prague by Government Decree No. 68/1928 (IOM 2003, 8). This shows that across the region, these long-term continuities go back to the shared AustroHabsburg legacy and the interwar period. This is a useful way of disconnecting the association of repression of Roma with regimes such as fascism or communism only (Donert 2017, 2020). ${ }^{19}$ We have seen the example of Czechoslovakia, with its interwar law on the regulation of the movement of nomadic 'Gypsies' and the introduction of special passports that was also a practice used by various west European states such as France. 


\section{Introduction}

Across Europe, similar repressive policies led to the Romani Holocaust, 'O Baro Porajmos' ('Porrajamos', 'Pharrajimos'), the 'Great Devouring', also known as 'Samudaripen' during the Second World War. It refers to the annihilation of hundreds of thousands of Roma - including 'Gypsy halfbreeds' and those perceived as Roma - across Central and Eastern Europe. Estimates of the numbers of victims range from 220,000 (Milton 1991) to 1,500,000 (Hancock 2005). Extermination in some countries was thorough: for example in the Protectorate of Bohemia and Moravia, only approximately one-tenth of the 5000 Bohemian and Moravian Roma survived (Schneider et al. 2009, 283). The rest were murdered in Auschwitz, resulting in the dialects becoming almost extinct. At the inauguration of the Sinti and Roma Memorial in Berlin in October 2012 - that is, 30 years after Germany officially recognized the racially based motives for the annihilation of the Sinti and Roma - Romani Rose, head of the German Council of Sinti and Roma, a prominent Sinto who lost 13 members of his family at Auschwitz-Birkenau, said: 'There is not a single family of Sinti and Roma in Germany who has not lost immediate family members. It shapes our identity to this day'. ${ }^{20}$ Though the Romani victims of these atrocities must never be forgotten, since 2015 when the European Parliament declared 2nd August as the European Roma Holocaust Memorial Day, ${ }^{21}$ commemoration has also focused on Romani agency and resistance through celebrating the Romani Resistance Day. ${ }^{22}$

In the second half of the 20th century, Roma throughout Western Europe faced both covert and overt discrimination due to what majority societies perceived as a nomadic lifestyle (Liégeois 1983, 117-122). Meanwhile, across the Eastern socialist bloc after WW2, communist governments continued to assimilate Roma. Some of the policies and measures included coordinated dispersal, resettlement - for example within former Czechoslovakia, resettlement from Slovakia to the Czech lands - and sedentary settlement in line with Act No. 74/1958 ${ }^{23}$; social engineering; eugenics in healthcare (especially the coercive sterilisation of Romani women without proper consent); segregated schooling, including special schools; and labour through state enterprise (Liégeois 1983; Horváthová 2002; McGarry 2010). Across the former Soviet bloc, there was a tension between assimilation and regulation of movement, the liquidation of the settlements starting in the 1960s and an effort to move Roma to cities. This was reflected in the 'racialised' language used to describe Roma: in former Czechoslovakia, from the mid-1960s, demographers were using the classification of nomadic, semi-nomadic and assimilated Roma; and referred to a-social behaviour to describe nomadic Roma (Donert 2020). These assimilation policies were aimed at uprooting the Romani language, centuries of cultural and spiritual traditions, customs, values and practices (Hübschmannová 1979; Horváthová 2002; Stewart 1997, 87). Different communist states across the former Soviet bloc applied different approaches to Roma. However, there was a common underlying attitude to Roma who 
were believed not to meet the criteria of an ethnic or national minority such as common language, territory, economy, beliefs and culture (Puxon 1973, 13). Roma tended to be seen through a social lens as a social group, or more precisely as an object of social policy before 1989 (Kusá 2014). In the period that followed the end of Communism, this resulted in the newly emerging democratic states often overlooking the dimension of ethnicity/ 'race', hampering the process of understanding the workings of antigypsyism and of finding effective remedies.

The political, social and economic changes associated with the collapse of Communism in 1989 gave rise to unprecedented social mobilisation for emancipation by Central and Eastern European Roma (Horváthová 2002, Vermeersch 2006, McGarry 2010). Nonetheless, pressures following the economic transformation started to weigh very heavily on the most vulnerable segments of Central and Eastern European societies, including Roma. The post-1989 transition to democracy saw many Roma, who had previously worked in various state-owned steel factories, plants and enterprises such as the coal mining industry or agriculture for decades, lose their employment. Roma were amongst the first workers who were sacked. As a result of the dire economic situation, race relations started to deteriorate rapidly: Roma were gradually pushed out of work, into poverty, ending up on the margins of society. The real extent of previously suppressed and hidden racist and discriminatory, biased attitudes towards Roma and the visible 'other' such as ethnic/'racial' and sexual minorities started to resurface in early 1990 with free speech and the rise of neo-Nazi movements and ideologies. This left many Roma in situations of vulnerability and danger. The late Václav Havel, the first president of Czechoslovakia that was democratically elected at the end of December 1989 , called the tenuous position of Roma within the post-communist societies transitioning to democracy a 'litmus test'. ${ }^{24}$ Thirty-one years on, it is clear that his timely observation still applies globally to all neoliberal democratic societies, in which Roma live.

Across the former communist bloc, the newly emerging democratic governments found it challenging to tackle decades-long issues inherited from the previous regimes such as segregated schooling, eugenics within healthcare, social engineering and socialist housing policies that became diametrically different within a span of several years. This was due to a series of factors, including sky-rocketing prices of basic commodities and housing. Institutional racism and hostile attitudes held towards Roma by non-Roma became even more deeply ingrained. The confluence of these negative factors made it difficult for many Roma to access key services such as employment, housing, education, healthcare or social services (European Roma Rights Centre 2007). Roma were effectively pushed out of mainstream education, the labour market and housing into the margins of society, thus hampering the participation of Roma in social, economic, political and public life. For instance, some authors refer to the ghettoisation and institutional 
segregation of Romani cultural heritage and contemporary Romani art as a parallel to the spatial segregation and ghettoisation of Roma in urbanist planning in the Central and Eastern European region (Moravčíková 2020). In his article the 'Ethnic representation of Roma in Hungary' (2015), Andras Kallai speaks of the ethnic stigmatisation of artistic production by artists of Romani heritage. Thereby, Romani art is institutionally separate, categorised on the basis of the artists' ethnicity and labelled by stereotypical concepts that constructs its racially coded traits. These orientalist stereotypes are professionally unfounded, according to Kallai. They are also a metaphor for the lack of representation, as well as the kind of representation that accentuates, re-inscribes and 'orientalises' the assumed cultural difference (cf. Moravčíková 2020).

As the social and racial tensions kept rising, the 1990s and the first decade of the 21st century - also marked by the financial crisis from 2008 - saw a dramatic increase in the numbers of racially motivated assaults, killings and murders of Roma across Central and Eastern Europe. National governments implemented a few effective measures to stop the rise of far-right ideologies, political parties and movements; indeed, some actively nurtured their emergence. Consequently, many Roma ended up seeking asylum in Canada and prior to EU accession, ${ }^{25}$ in the Western European countries such as the UK but did not always receive a warm welcome: in fact, some media portrayed them as a 'Gypsy invasion', a 'Romani criminal conspiracy', a threat (Clark and Campbell, 2000, 37). Against the background of this state of affairs, the Czech Republic, Estonia, Hungary, Latvia, Lithuania, Poland, the Slovak Republic and Slovenia as well as Cyprus and Malta started the accession process, eventually joining the EU in 2004, followed by Romania and Bulgaria in 2007. Very little has changed until the present day, as noted regularly by the EU's European Commission, the Council of Europe, the Organisation for Security and Cooperation in Europe or the European Union Agency for Fundamental Rights (FRA).

\section{Turn of the 20th and 21st centuries: Rising antigypsyism vis-à-vis increasing acceptance of LGBTIQ people}

In Western Europe, specifically in the EU, the 1980s and early 1990s saw key developments with respect to legislating legal provisions aimed at the protection of and equality for LGBTIQ people. Despite legislation ${ }^{26}$ such as Section 28, enacted in 1988 and repealed in 2000 in Scotland and in 2003 in England and Wales, that sought to prevent local education authorities from promoting homosexuality, LGBTIQ activists and advocates contributed, albeit informally, to the drafting of a report for the European Parliament (EP), calling for equal rights for gays and lesbians, including same-sex marriage (Kollman 2009). The subsequent annual EP reports on the state of human rights dwelt on the issue of sexual orientation, thus putting LGBTIQ rights firmly on the table in the European Commission 
and EU Council (Ibid). These initiatives eventually resulted in the inclusion of an anti-discrimination clause in the first legally binding international treaty to include sexual orientation as a protected characteristic: the 1997 Amsterdam Treaty. It came into force in 1999, thus helping to set the stage for the adoption of the 2000 Employment Equality Directive (also referred to as Directive 2000/78/EC), which prohibits discrimination on the basis of religion and belief, age, disability and sexual orientation.

Meanwhile, following the fall of the Berlin Wall across Central and Eastern Europe and the Balkans, in 1989, openness about one's sexuality and gender identity was still quite rare despite communist countries such as Czechoslovakia and Hungary having decriminalised homosexuality in 1962. ${ }^{27}$ Although the World Health Organisation (WHO) declassified homosexuality as a mental disorder in 1990, it did not remove transgender identity from the list of mental disorders until $2019 .{ }^{28}$ Prior to the collapse of Communism in 1989, with some exceptions, non-normative, or queer, sexualities and gender identities had not been visibly expressed or performed in the public; in the wake of 1989, non-heteronormative people were slowly starting to become more visible. This, in turn, resulted in rising levels of homophobia throughout the 1990s. Nonetheless, in the course of the 2000s, from a legal and societal point of view, the situation of LGBTIQ people was improving at least to a certain extent (FRA 2009, 2010). This was the case especially in the run-up to the EU enlargement on 1 May 2004 when the eight Central and Eastern European countries were in the process of bringing their legislation in line with EU law, transposing EU directives and incorporating the acquis Communautaire into their domestic law in order to meet the Copenhagen criteria. Despite the lack of progress regarding the adoption of the Horizontal Directive first proposed in $2008,{ }^{29}$ a key milestone has been the adoption in November 2020 of the first-ever strategy on LGBTIQ equality in the EU by the European Commission. ${ }^{30}$

At a national level, in the Czech Republic, for instance, the registered partnership act was adopted in 2005, entering into force in 2006. This was an important development that has contributed to positive changes in the general public's perception of LGBTIQ people, same-sex relationships and unions (FRA 2009). Nevertheless, the positive developments with respect to LGBTIQ - or more precisely LGB - people were not matched by the worsening life conditions and segregation of many Roma. In the late 1990s and mid-2000s, Roma were increasingly relegated to the edges of society in the Czech Republic (Honusková and Šturma 2010; Matoušek and Sýkora 2011; Toušek 2011). Some 300 Roma ghettos had emerged there by 2009 (Gabal Analysis \& Consulting 2006, 2009). The situation kept worsening despite the delayed adoption of the anti-discrimination law in 2009, 5 years after the Czech Republic joined the EU in 2004.

The fate of Roma living in the other post-communist states followed a similar trajectory. For example in Slovakia, due to the collapse of the socialist economy, the rise of unemployment from 0 to $10 \%$ (Gallová- 
Kriglerová and Chudžiková 2013, 169-170; Grill 2015, 161) and increasing, at times total dependence on social welfare benefits, the situation of Roma deteriorated rapidly. This was the case particularly in the east of the country where the most sizeable communities of Roma live. Most Roma were living under the poverty line as joblessness resulted in the vast majority of Roma having no income and relying on social welfare benefits. Civil unrest took place in Eastern Slovakia in 2004 after the Slovak government had halved weekly unemployment benefits and abolished child benefit $^{31}$ in a move that triggered one of the largest civil disturbance since the fall of Communism. Slovakia was due to join the EU in 2 months. The unrest, in which many Roma got involved, resulted in one of the largest deployments of the police and armed forces since the fall of Communism in 1989. To quell the riots, the prime minister sent 20,000 extra police and 1,000 soldiers to Eastern Slovakia. ${ }^{32}$ Sixteen years on,

[t] he housing and accommodation situation of Roma seriously lags behind the situation of the general population' and is characterised by 'lack of access to adequate housing across the EU'; in fact, 'the problem of residential segregation of Roma remains among the main shortcomings of the Roma inclusion policies. (CEU 2020, 29)

Over the past three decades, many Roma left Central and Eastern Europe to start their lives over in Western states primarily within the EU but also in Canada. In the 1990s, Roma did so as refugees and asylum seekers; following the two EU accessions in 2004 and 2007, Roma used their right as EU citizens to move freely within the EU. This was met with an almost immediate backlash against freedom of movement, including anti-Romani measures such as expulsions, evictions, deportations, ethnic profiling and/or fingerprinting by the authorities in Italy in 2008; France in 2010 and the UK in 2012-2013. For instance, during the Italian Roma crisis in 2007 and 2008, Roma became targets of discriminatory policies, including fingerprinting and ethnic profiling, which constructed images of Roma as distinct from the Italian nation (McGarry 2011, 2017). In the run-up to the June 2016 EU referendum and the final date of Brexit (January 2020), freedom of movement by economically weaker EU citizens, including Roma, from poorer EU states to more affluent Western EU states was a key topic in debates on whether the UK should stay in the EU.

At the time of writing this book in 2019-2021, the UK, the rest of Europe and, for that matter, the rest of the world had been experiencing a major backlash against discourses regarding equality, minority ethnic, LGBTIQ, women's and human rights for quite some time. Against the backdrop of the COVID-19 pandemic, Poland's Andrzej Duda won the presidential elections in July 2020 by dehumanising LGBTIQ people as an ideology and non-human in his campaign. In April 2020, Hungary passed a law ending trans people's legal recognition. On 16 June 2020, the Romanian 
Parliament passed a bill banning educational institutions from promoting theories and opinions on gender according to which gender is a separate concept from biological sex. In October 2020, Polish and Slovak legislators pushed for radical restrictions on abortion. ${ }^{33}$ These alarming developments have disproportionately impacted on the lives of individuals with multiple, intersecting identities, including queer Roma. Whether the impact of the EU Anti-racism Action Plan 2020-2025 $5^{34}$ and the new EU Roma strategic framework, ${ }^{35}$ launched by the Commission in September and October 2020, respectively, and the Council of the EU Recommendation on Roma equality, inclusion and participation, ${ }^{36}$ adopted in March 2021, will be more than symbolic remains to be seen.

\section{The emergence of the LGBTIQ Roma movement}

Over the past decade, queer Roma have mobilised, creating a visible LGBTIQ Roma movement. Queer Roma have become more visible individually and collectively thanks to the emergence of organisations such as ARA ART (Czech Republic); Queer Roma (Germany); Ververipen: Roma por la Diversidad; Asociación Gitanas Feministas por la Diversidad (Spain); Romani Cultural and Arts Centre and Traveller Pride (UK). Numerous LGBTIQ Roma-related events have taken place since 2014: the first national Roma LGBT workshop (May 2014); the Council of Europe conference 'United for dignity' (June 2014); the first, second and third International Roma LGBT conferences (Prague 2015-2016; Strasbourg 2017); Prague Pride with an LGBTIQ Roma float and music stage (2014-2019); Budapest, Madrid, Valencia Prides (2015-2019); Christopher Street Day in Cologne with an LGBTIQ Roma float (2015-2019), Traveller Pride (London 2019), to name a few.

Queer Roma have been gaining visibility in public spaces and at gay Prides across Europe, thus making a strategic political claim to be acknowledged and recognised by majority societies, LGBTIQ and Romani communities, and the LGBTIQ and Roma rights movements. Queer Roma have been celebrating pride, often framed by experiences of antigypsyism, homophobia and transphobia, by displaying the Romani flag next to the rainbow flag. In 2015, a Romani LGBTIQ group, in which I was present as well, participated in the Prague Pride march with its own float and a DJ. It was accompanied by approximately 40 people, including Romani crossdressers and drag queens, queer Roma, as well as some non-Romani and straight people and a traditional dance group of Romani women. At one point, the group, which carried a huge rainbow flag and a big Romani flag, was approached by a man who started yelling religiously motivated, homophobic slurs in the Romani language, suggesting that homosexuality is a sin against God. In this important moment, the queer Roma and nonRoma LGBTIQ allies came together in one voice and answered back to him in unison: 'Opre Roma!' [Rise, Roma!]. 
In the aftermath and during the subsequent events that took place between 2015 and 2017, Romani presence at gay Prides has been criticised, at times fiercely, by proponents of the notion that Romani ethnic identity is and may be - heterosexual only. Various critics of queer Roma have proposed different rules governing when, how and by whom the Romani flag can be displayed. According to some, the Romani flag should not be displayed by queer Roma because of their 'promiscuous lifestyle' which they believe contradicts and disrespects Romani purity laws. ${ }^{37}$ Others opined that queer Roma may display the Romani flag, provided they 'behave properly'; ${ }^{38}$ or that queer Roma should make their own rainbow flag incorporating elements of the Romani flag so that it was clear that not all Roma are 'faggots' ${ }^{39}$ In extreme situations, queer Roma have received threats of physical violence or even death threats. Visibility was key: the presence and representation of queer Roma became visible in particular social, geographical, relational, material and temporal contexts. This visibility generated some interesting, albeit problematic discussions about identity, its boundaries, difference and sameness, as well as belonging: for example, who can and cannot belong with, in or to Roma and under what circumstances. It became the linking proxy, establishing a relationship between the non-normative (queer) ethnic/'racial', sexual and gender identities as experienced by queer Roma.

At the time of writing this book, in late 2020, I came upon an article about Pope Francis' accepting attitude towards same-sex unions. ${ }^{40}$ In it, the director of an LGBTIQ Romani organisation, a gay Roma, welcomed the Pope's words. The discussion under the story, in which mostly Roma participated, was homophobic. For a moment, I started having doubts about finishing this book because I did not want to expose the queer Romani research participants to potential abuse. Then, I said to myself that only a few people engaged in this behaviour online: there are bigoted people in every group. I reminded myself of the responsibility I had towards the people who shared their lived experiences with me. They did so in order for their powerful personal testimonies to see the light of day and to challenge this kind of abuse: a moral duty I have to honour.

\section{Notes}

1 'Roma' is understood here in line with the Council of Europe's definition adopted in 2010. It encompasses numerous groups and subgroups: 'The term "Roma" (...) refers to Roma, Sinti, Kale and related groups in Europe, including Travellers and the Eastern groups (Dom and Lom), and covers the wide diversity of the groups concerned, including persons who identify themselves as Gypsies' (Council of Europe 2012, 4).

2 In Central and Eastern Europe, the word 'Gypsy' is considered a racial slur.

3 'Polari: The Code Language Gay Men Used to Survive', accessed 13 January 2021, https://www.bbc.com/culture/article/20180212-polari-the-code-languagegay-men-used-to-survive. 
4 'Why Is Discrimination against America Roma Ignored?', 13 January 2021, accessed 13 January 2021, https://www.opendemocracy.net/en/whydiscrimination-against-american-roma-ignored/.

5 'Magnifying Inequalities for the Roma during the COVID-19 Pandemic', 29 June 2020, accessed 23 November 2020, https://rwi.lu.se/2020/06/magnifyinginequalities-for-the-roma-during-the-covid-19-pandemic/.

6 'In Bulgaria, at least seven Roma settlements have been shut off from the rest of society at various points since March, despite low rates of confirmed infections in most of them. Officials in one town even sprayed disinfectant on a Roma settlement from a plane. Five Roma towns were cordoned off in Slovakia. In Romania, Serbia, Slovakia, the Netherlands and North Macedonia, there have been 15 incidents of police violence against Roma since Europe's lockdowns began, including against young children', accessed on 23 November 2020, https://www.nytimes.com/2020/07/06/world/europe/coronavirus-roma-bulgaria.html.

7 'I Make Shiny Things', Romatopia, accessed 7 December 2020, https:// romatopia-podcast.podigee.io/2-1-i-make-shiny-things-with-daniel-baker.

8 Channel 4's 'The Truth about Traveller Crime' made explicit links between crime and Roma/Travellers, accessed on 23 November 2020, https:// www.channel4.com/programmes/the-truth-about-traveller-crime.

9 'My Big Fat American Gypsy Wedding', https://www.tlc.com/tv-shows/my-bigfat-american-gypsy-wedding/.

10 In an episode broadcast in September 2013, the moderator referred to Roma's 'negative social features' as a pretext for racist marches, accessed 23 November 2020, https://www.ceskatelevize.cz/porady/10175540660-mate-slovo-s-mjilkovou/213411030520020/.

11 'This World - Gypsy Child Thieves' was broadcast in September 2009. 'BBC Documentary about Roma Children Sparts Outrage'. Institute of Race Relations, 2009, https://irr.org.uk/article/bbc-documentary-about-roma-children-sparksoutrage/, accessed 23 November 2020.

12 Case of D.H. and others v. the Czech Republic. HUDOC. European Court of Human Rights, 13 November 2007, http://hudoc.echr.coe.int/eng\#\%7B\%22 appno\%22:[\%2257325/00\%22]\%7D, accessed 13 September 2020.

13 'Queer: A Story for Trannies', Czech Republic, 2013, accessed on 23 November 2020, http://www.ceskatelevize.cz/porady/10520528904-queer/21356221 0900015-roman-pro-transky/.

14 New views on the community/new hybrid and sexualised Roma identities, accessed 1 February 2021, https://www.ub.edu/adhuc/en/node/3992.

15 'The Gypsy, Roma and Traveller LGBTQ + Spoken History Archive', Romani Cultural \& Arts Company, 2021, accessed 1 February 2021, http:// www.romaniarts.co.uk/voices/grt-lgbtq-spoken-history-archive/.

16 'Roma' functions as an adjective in idioms such as 'Roma rights' or the 'Roma rights movement'.

178 April was officially declared the International Roma Day during the International Romani Union's 4th World Romani Congress in 1990 in Serock, Poland.

18 'Kosovo recognised Roma, Ashkali and Egyptians', accessed on 23 November 2020, https://www.osce.org/mission-in-kosovo/443587; https://minorityrights.org/ minorities/roma-9/.

19 Roma Sovieticus: Roma Experience under Communism by Dr Ciprian Necula October 13, 2020. European Roma Institute for Arts and Culture Barvalipe Roma Online University, accessed 23 November 2020, https:/www.facebook.com/ watch/live/?v=2412445202396593\&ref=watch_permalink. 


\section{Introduction}

20 Remembrance and Beyond. Dr Ethel Brooks: Remembering the Dead, Documenting Resistance, Honouring the Heroes, accessed 23 November 2020, https://www.un.org/sites/un2.un.org/files/vol_3_web.pdf.

21 'European Roma Holocaust Memorial Day: Statement by President von der Leyen, Vice-President Jourová and Commissioner Dalli', 31 July 2020, accessed 10 December 2020, https://ec.europa.eu/commission/presscorner/detail/en/statement_2 0_1423.

22 Statement on Romani Resistance Day. Council of Europe. 16 May 2020, accessed 10 December 2020, https://rm.coe.int/romani-resistance-day-16-may/1 6809 e4ece.

23 'February Marks the $62^{\text {nd }}$ Anniversary of Communist Czechoslovakia Forcibly Sedentarizing Roma', accessed 1 February 2021, http://www.romea.cz/en/news/ world/february-marks-the-62nd-anniversary-of-communist-czechoslovakia-forcibly-sedentarizing-romani-people\#.

24 'Havel Calls the Gypsies "Litmus Test"', New York Times, 10 December 1993, accessed 10 December 2020, https://www.nytimes.com/1993/12/10/world/ havel-calls-the-gypsies-litmus-test.html.

25 Within the EU, asylum cannot be granted to an EU citizen as all EU Member States are deemed safe countries of origin, accessed 1 February 2021, https:// www.refworld.org/docid/55bf55094.html.

26 Denmark decriminalised same-sex acts in 1933, Sweden in 1944, England in 1967, West Germany in 1969, Austria in 1971, Finland in 1971, Norway in 1972, Spain in 1979, Ireland in 1993. France (and Andorra) decriminalised homosexual activity between consenting adults in 1791, with the adoption of the new penal code (it did not recognise homosexuality itself though).

27 Bulgaria and East Germany decriminalised homosexuality in 1968, Croatia, Montenegro and Slovenia already in 1977 (then Yugoslavia). Other former Yugoslav republics made homosexuality legal only after the collapse of Yugoslavia in 1991: Serbia in 1994, Macedonia in 1996 and Bosnia and Herzegovina in 2002. In the 1980s homosexuality was illegal in Kosovo but legal in Vojvodina, both being autonomous provinces within the Republic of Serbia, which belonged to Yugoslavia. Albania legalised homosexuality in 1977 although it retained other laws criminalising same-sex acts until 1995. Romania decriminalised both male and female homosexuality in 1996. (N.B. the new Polish penal code of 1932 decriminalised consensual same-sex acts, which have not been recriminalised since.) Russia decriminalised homosexuality in 1993, after the Soviet Union's fall in 1991, in order to join the Council of Europe. Russia had decriminalised male homosexuality in 1922; however, in 1933, Stalin recriminalised it. Other former Soviet republics decriminalised homosexuality after 1991 or still have not done so: Ukraine (1991), Estonia and Latvia (1992), Lithuania (1993), Belarus (1994), (1995), Kyrgyzstan, Kazakhstan and Tajikistan (1998), Azerbaijan and Georgia (2000), Armenia (2003); male same-sex acts remain illegal in Turkmenistan (up to 5 years imprisonment) and Uzbekistan (up to 3 years imprisonment).

28 'WHO Drops Being Transgender from List of Mental Disorders', TIME, 28 May 2019, accessed 10 December 2020, https://time.com/5596845/worldhealth-organization-transgender-identity/.

29 'COM (2008) 426: Proposal for a Council Directive on Implementing the Principle of Equal Treatment Between Persons Irrespective of Religion or Belief, Disability, Age or Sexual Orientation \{SEC(2008) 2180\} \{SEC(2008) 2181\}', accessed on 23 November 2020, https://eur-lex.europa.eu/legal-content/en/ HIS/? uri=CELEX\%3 A 52008PC0426\&fbclid=IwAR01A5r6ZZmrdQSC5 AJ7U2vsiobHX1feOAXimio-hpzVrDe-rgS8E7HQqvo. 
30 'Union of Equality: The Commission Presents Its First-Ever Strategy on LGBTIQ Equality in the EU'. 12 November 2020, accessed on 23 November 2020, https://ec.europa.eu/commission/presscorner/detail/en/ip_20_2068? fbclid= IwAR2yGQMtPaxcYVmm644ZQyrLbzM_-NCFXzqMPesbOkC1gr1xXaEj4 aFoGAQ.

31 'Dusan Dirda from Levoca will have to feed his 11 children on $£ 69$ a month, the maximum any family can expect under tough new rules. Until 1 January, Dirda could expect between 1,000 and 1,600 Slovak crowns for each of his children, plus 2,900 crowns for each unemployed adult'. 'Roma Face Starvation in the Slums of Slovakia'. The Guardian, accessed 23 November 2020, www.guardian. co.uk/world/2004/feb/29/theobserver.

32 'On the evening of Tuesday February 24, 2004, the Slovak government ordered the largest mobilisation of its police and armed forces since 1989, in order to address the problem of unrest and a threatened state-wide strike among Roma in Slovakia. Although figures varied according to reports, according to information available as of February 26, on the territories of Košice, Prešov and Banska Bystrica Counties, approximately 1600 police officers and 650 members of the army had been mobilised, with a further 350 soldiers put on active alert. Minister of the Interior Vladimir Palko was quoted by domestic media as having stated on the evening of February 24, "All police officers have had holidays suspended until further notice. At issue is the largest engagement of police forces since 1989. [...] Yesterday for the first time since 1989 water cannons were deployed and used." That week Slovak press has been dominated by headlines such as "This is War!"'. 'Extreme Rights Deprivation among Roma in Slovakia Leads to Unrest', European Roma Rights Centre, 28 May 2004, accessed 23 November 2020, http://www.errc.org/cikk.php?cikk=1884.

33 'Abortion Restriction Botes Succeed in Poland, Fail in Slovakia... Just', accessed 23 November 2020, https://balkaninsight.com/2020/10/23/democracy-digestabortion-restriction-votes-succeed-in-poland-fail-in-slovakia-just/.

34 'The EU Anti-racism Action Plan 2020-2025', accessed 23 November 2020, https:/ec.europa.eu/info/policies/justice-and-fundamental-rights/combattingdiscrimination/racism-and-xenophobia/eu-anti-racism-action-plan-2020-2 025_en.

35 'The New EU Roma Strategic Framework for Equality, Inclusion and Participation', accessed on 23 November 2020, https://ec.europa.eu/info/ publications/new-eu-roma-strategic-framework-equality-inclusion-and-participation-full-package_en?fbclid=IwAR3R_mphgmvwp38GhF41A9S2zRGdhhEJ1 h6Pxc63zJaAD11J3UY5qCqq5Ds.

36 https://eur-lex.europa.eu/legal-content/EN/TXT/HTML/?uri=CELEX:32021 $\mathrm{H} 0319(01) \&$ from=EN

37 'Renata Berkyová: Gays, Hands Off the Romani Flag!', August 2016, accessed 23 November 2020, http://www.romea.cz/en/news/czech/renata-berkyova-gayshands-off-the-romani-flag.

38 'Čeněk Růžička: It's Strange for LGBT People to Hold the Rainbow and Romani Flags while Speaking of Roma Pride', June 2017, accessed 23 November 2020, http://www.romea.cz/en/news/czech/cenek-ruzicka-it-s-strange-for-lgbt-peopleto-hold-the-rainbow-and-romani-flags-while-speaking-of-roma-pride.

39 One of the public comments read as follows: 'It is quite important to know when I am allowed to use the Romani flag and I certainly wouldn't use it for your kind of representation. You have yours and if you like, you can make a joint international one where only lesbians and faggots will be represented together, I don't mind you but as of late I have a feeling that all of your events are a kind of promotion ... and it is becoming widespread, there are many more boys and 


\section{Introduction}

girls who joined your group. Does it serve as recruitment? You can make your own T-shirts and wear them BUT DO NOT ABUSE THE ROMA FLAG FOR YOUR PURPOSES EVEN THOUGH YOU ARE ROMA! IT IS DISRESPECTFUL OF THE VALUE OF OUR ANCESTORS AND THOSE WHO HAVE IT AS A SYMBOL OF THE NATION!!!' (original emphasis).

40 'Pope Supports Registered Partnership for Same-Sex Couples, Romani Community Member in the Czech Republic Calls It Progress', ROMEA, 30 October 2020, accessed on 23 November 2020, http://www.romea.cz/en/news/ czech/pope-supports-registered-partnership-for-same-sex-couples-romani-community-member-in-the-czech-republic-calls-it-progress. 


\section{Understanding Romani identities beyond ethnic and binary frames}

This chapter starts by offering a theoretical account of a number of ways of understanding identity. This serves as a springboard to discussing identity, based primarily on insights from the work of Stuart Hall as a leading theorist of culture, 'race' and ethnicity in British Cultural Studies. I then proceed to apply these conceptualisations to understandings of identity in Romani Studies. Starting with conceptualisations of Romani identity primarily along ethnic lines, I go on to explore understandings of Romani identities facilitated by concepts such as hybridity, super-diversity, intersectionality and concepts emanating from queer theory and queer of colour critique. That is why there is an oscillation between the singular 'Romani identity' and the plural 'Romani identities' throughout this chapter and the book. These concepts cross-cut identity categories such as ethnicity/'race', sex/gender, ${ }^{1}$ sexuality, gender identity, class, age, social status, religion and so on, thus facilitating alternative understandings of Romani identities. Importantly, queer theoretical concepts - and queer assemblages in particular - make it possible to attend to the multifaceted fluidity of Romani identities, including queer Romani identities, due to being non-normative, anti-essentialist and applicable to conceptualisations of ethnic/'racial', sexual and gender identities, as well as capable of disrupting dominant homogenising, binary and fixed accounts of identities. Having examined the advantages and pitfalls of intersectionality and queer theoretical concepts, I go on to argue in favour of reading queer assemblages in conjunction with intersectionality, or queer intersectionalities. This enables us to attend to the workings of asymmetrical hegemonic power relations whilst being able to see identities as multifaceted, fluid, always in the process of becoming. In the final section of this chapter, I discuss the methods and methodology used during the qualitative, ethnography-informed research and I provide a methodological reflection on access to participants, data collection and data analysis, as well as on critically examining non-Romani researcher positionality and reflexivity. 


\section{Theoretical considerations: Individual and collective social identities}

There is no one perfect, all-encompassing recipe for understanding the complexity of people's identities. Whatever society, population, community, group or another social unit one comes from, there is no conceptual magic wand that one can wave to understand the ontological what - that is, what exactly we understood about people's identities - and the epistemological how - that is, how we understand them. This is mainly because identity has always been fraught with much complexity. It has been debated particularly in the social sciences and humanities in relation to a series of fundamental social changes and structural transformations that have affected modern and postmodern societies: industrialisation, urbanisation, the division of labour, globalisation, democracy, the (neo)liberal nation state, social movements, the advent of the internet and social media, the global rise of populism and right-wing extremism, the COVID-19 pandemic and many more. In the 1950 s, identity was an 'essentially contested concept' (Gallie 1956) as much as it is in the first decade of the 21st century. Every era presents our understanding of identity with new challenges. This has been the case, particularly during the past decade when we have witnessed a major backlash against ethnic/'racial', sexual and gender identities, minority and human rights and equality discourses across the globe. This backlash has seen the strengthening of views, ideologies and movements based on the essentialist notions of biological givenness and the natural. The following lines will illustrate what exactly I mean by that.

From the earliest moments of our lives, we are taught to make sense of our role in the social world around us as individuals and as members of our respective societies, communities, families and other social and relational units. At the level of individual identity, or self-identity, this may entail what Stuart Hall referred to as 'the old logics of identity: a notion of our true self, some real self inside there' $(2000,42)$. It may seem perfectly natural to us to think that this true, originary 'real self' is our essential, biologically given identity that makes us 'us'. We may believe that we develop our identity intuitively while discovering it almost as if it were in store for us somewhere in the future. This conception of identity is reminiscent of the Enlightenment's ideas about the Cartesian subject being selfdetermining, self-evident, self-sustaining, coherent, rational and stable. This sense of ourselves, of who we really are, is shaped by our contact with " "significant others" who mediate to the subject the values, meanings and symbols - the culture - of the world [they] inhabit' (Hall 1992, 275). We are almost constantly faced, consciously or unconsciously, with the questions 'Who am I?' and 'Where do I belong?'. As we get older, we become more aware of our social identities: according to Hall, social identities are aspects of our identities arising from our belonging to distinct cultures formed along ethnic/'racial', linguistic, religious, national and other lines. 
How we move about in the world as individuals has implications for our individual identity, as well as for the collective social identities that we identify ourselves with. According to Hall (1996a), identity is inseparable from the discursive practice of identification. Identity is a product, albeit evolving - a temporary halt in an ongoing series of constructions (Munnik $2001,96)$ - as much as it is part of the ongoing process of identity formation or identification; it is constantly reproduced and reconstructed. "It is not determined in the sense that it can always be "won" or "lost", sustained or abandoned' (Hall 1996a, 2). This notion is contrary to previous Cartesian essentialist understandings of identity as integral, originary and unified. These philosophical views relied upon the Enlightenment's previous theorising about the Cartesian subject. The inner core, with which the subject was endowed at birth, grew but remained essentially the same.

\section{Ethnicity/'race' and 'new ethnicities'}

Roma, as well as LGBTIQ people, were among the millions of people, mainly Jews, murdered and exterminated because the Nazi ideology thought of them as 'racially' impure, inferior to the Aryan 'race', deviant and anti/asocial. As I discuss in Chapter Two, following the atrocities committed in the name of 'racial purity' during WW2, most European states have treated 'race' as a taboo, moving towards using ethnicity rather than 'race'. Yet, in the 21st century, 'race' still matters (Lentin 2020). Even though we know scientifically that 'race', or for that matter, ethnicity, does not exist - that is, it is not biologically, genetically or physically defined and despite frequent claims that we live in post-racial times, 'race' - similar to class - still functions as a key means of social classification that determines and maintains order by putting people into different groups. Simultaneously, due to the role of the modern nation states in creating the myth of 'a pure, original people, or "folk"' (Hall 1996c, 615; original emphasis), 'imagined communities' (Ibid, 616) are formed along ethnic/ 'racial' and national lines. Later in this chapter, as well as in Chapter Two, I discuss the impact on Roma of the 'racialising' dynamics of antigypsyism/ Romaphobia, generated by neoliberal nation states in order to create the 'imagined' non-Romani majority by marking out Roma as 'racially' distinct, different inadaptable, anti/asocial, abject, backward. In this dynamic, national cultures construct identities by producing unified symbols, meanings and narratives about the primordial nation, its history, including origins, memories, foundational myths, invented traditions, customs, desire of togetherness and belonging, and continuity of its cultural heritage in the present and the future, with which people can identify. The essentialist logic of ethnic/'racial' identity is then conceptualised along similar lines of mythical unity.

Ethnicity/'race' is a discursive category, a unit of meaning. It is contextual, relational and subject to constant redefinition and reconstruction at 
different moments in time, in different regional and cultural contexts. Ethnicity/'race' is constructed historically, culturally, politically, even socioeconomically. It is grounded in the discourse of racism (Hall 1996b, 446); in 'class [a]s the modality in which race is lived' (Hall [1978] 1996); and in coloniality and colonialism. Hall insisted on using 'race' and ethnicity as 'the whole social formation which is racialized, not as a kind of subcategory' (Grossberg 2007, 101). He also insisted on the internality of 'race' in all social processes and, in turn, on seeing 'race' as a lens, through which broader structures can be explored, rather than a thing in and of itself (Lewis 2000; Grossberg 2007). This is how I understand and use the ethnicity/'race' nexus, which I discuss in Chapter Two: "Perverse" and "deviant" queer sexualities, genders, ethnicities and "racialities"'.

National and ethnic/'racial' identities are not something that we are born with; rather, they are sets of cultural values, symbols, meanings and systems of cultural representation we are born into. We know what it means and entails to be a member of a specific national group - for example, English, Japanese, Czech or member of an ethnicised/'racialised' group, for example, Roma - based on how that meaning and its signifier have come to be represented to us, often through what they exclude. ${ }^{2}$

As part of the process of identification, we are in a constant dialogical relationship with these sets of meanings, negotiating our identities. Hall believed that as collective social identities, ethnicity/'race', sex/gender, sexual and gender identities, class and religion stood at the root of organising people's thinking. They came to represent the most fundamental units, or systems, of the social order through which people made sense of and gave meaning to their individual identities and the social world surrounding them. These collective social identities that were part of essential, universal, homogenous, unified 'already-produced stabilities and totalities' (Hall 2000, 45) have been fundamentally transformed, giving rise to new types of collective social, or cultural identities. These new identities yield a much greater degree of plurality and fragmentation, offering a glimpse of a politics which is

able to address people through the multiple identities which they have understanding that those identities do not remain the same, (...) that they cross-cut one another, that they locate us differently at different moments (...) and do not stitch us in place, locate us, in the way they did in the past. (Hall 2000, 59, 63)

Elaborating extensively on a significant shift in conceptualising the term 'black' in black cultural politics in the United Kingdom (UK), Hall ushered in a new approach to conceptualising ethnic/'racial' identities, or 'new ethnicities' as multiple, multifaceted, fluid and intersecting. 'Black' did not cease to denote the specific experiences of individuals who identified as black; however, it was necessary to account for other aspects of identity, or 
categories of identification, predicated on an assumed difference from 'social norms'. These locate each post-modern subject differently within different social and cultural systems, paradigms and discourses. This new logic of identity grounded in difference and diversity enables each subject to

speak from a particular place, out of a particular history, out of a particular experience, a particular culture. (...) We are all, in that sense, ethnically located and our ethnic identities are crucial to our subjective sense of who we are (Hall 1996b, 447; original emphasis).

While ethnicity/'race' may be one of the aspects of this location within the different social and cultural discourses, gender, sexuality and class must be attended to as well. As we shall see later in this chapter, this new understanding of identities is in line with intersectional feminism, lesbian and gay studies and queer theory.

Hall argued that the loss of the Cartesian fantasy of a stable 'sense of self' in the latter part of the 20th century resulted in 'de-centering individuals both from their place in the social and cultural world, and from themselves - (...) a "crisis of identity" (Hall 1992, 275); and in the emergence of the post-modern subject and the shifting of personal identities. Consequently, the post-modern subject was reconceptualised as fragmented, having 'no fixed, essential, permanent identity, (...) composed not of a single, but of several sometimes contradictory or unresolved identities' (Ibid, 276); 'never singular but multiply constructed across different, often intersecting and antagonistic, discourses, practices and positions' (1996a, 4). This type of subject is also a sociological one: a modern, interactive conception of identity and the self, formed in relation to people and surrounding cultural systems. This reconceptualisation helped to spell out the contextual side of identities: that is, the discourses, systems and paradigms, within which the post-modern subject operates, and their effects, through which the post-modern subject is constantly determined, shaped and transformed. It also revolutionised the way we understand the content and function of identities. The above shifts in grasping ethnic/'racial' identities have been key to conceptualisations of Romani identity - or, indeed, identities - in Romani Studies, discussed in the following section.

\section{Reconciling binary essentialist and constructionist understandings of Romani identity}

Roma are a very heterogeneous, transnational ethnic minority grouping of numerous sub-groups. Though citizens of nation states - except for Romani refugees and internally displaced persons - Roma are regarded, and at times regard themselves, as a nation without a state: a notion that was first clearly articulated in the 'Declaration of a Roma Nation' (2000) asserting a right to self-determination as a non-territorial nation but making no claims to a 
territory (Acton and Klímová 2001). Even though numerous members of these diverse sub-groups speak various versions and dialects of the Romani language (Matras 2002, 2013) and engage in similar cultural practices and customs (Acton and Mundy 1997), Roma are not united by one common language, religion, cultural practice, geographical location, occupation, physical appearance or lifestyle (McGarry 2010; Surdu and Kovats 2015). Contrary to this complex reality, Roma and Romani identity have been subject to a plethora of misrepresentations and stereotypes. More often than not, Roma have been represented as a homogenous ethnic group along essentialist lines, whose members' physiognomic features and behavioural traits are deemed genetic, thus allegedly determined before/at birth by virtue of their ethnic/'racial' identity. A word of caution is required here since the above objective external circumstances are often referred to as the common properties or attributes of Roma; unfortunately, some academic discourses are not an exception. Historically, stereotyping misrepresentations externally imposed on Roma, often by non-Roma, have been instrumental in generating and maintaining negative perceptions and single-story notions held by non-Roma about who Roma are. The actual lives of Roma with multiple identities, one of which happens to be Roma, have thus been hijacked by distorted narratives and stereotypical images of 'Gypsiness', the 'Gypsy' and a 'Gypsy fetish' (Gay y Blasco 2008, 298). Coupled with historical suppression of Romani cultural identity (McGarry 2010), these misrepresentations have come to be intrinsically associated with Romani identity, seen as essential, defining, in-born markers of Roma, and turned into common knowledge, informing the views, beliefs and values of nonRoma, and at times those of Roma through internalised racism. This powerful negative, or pathological, valuation of Romani identity has not only put Roma in 'double jeopardy' (Vermeersch 2006) when trying to frame Romani identity in a positive way to mobilise around it in the face of negative narratives relating to Romani ethnicity. This negative valuation has also been fuelling antigypsyism even further, thereby facilitating the process of creating a stigmatised, as well as 'closeted' Romani identity, explored more in detail in Chapter Two.

In Romani Studies, scholars have leaned towards two distinctive, divisive, though not mutually exclusive conceptualisations of Romani identity. The essentialist - or primordial - approach, has tended to define Roma as a historic ethnic diaspora and an unassimilated ethnic group that shares a common origin, language, history and culture (Fraser 1992; Lee 1998; Hancock 2002; Horváthová 2002). A more radical form of this conceptualisation, which some authors view as a separate conceptualisation, concentrates on the issue of biological kinship, accentuating the notion of natural tribal bonds and genetic, or phenotypic, characteristics (Hancock 1992, 2002; Lee 1998). Some of these theories have been supported by developments in genetics, with scholars asserting that molecular genetic studies concerning European Roma unequivocally confirm the linguistic 
theory of the Indian origin of Roma (Iovita and Schurr 2004; Comas Martínez-Cruz et al. 2015; Font-Porterias et al. 2019). However, biological theories related to Romani identity are problematic (Vermeersch 2006) considering the devastating impact that racist ideologies, particularly the Nazi racial ideology and eugenics, have had on Europe, as well as the United States (US) because of their claim that Roma are biologically 'deficient' due to having the so-called 'Romani gene'. At the heart of essentialism lies a belief that people have a set of certain innate, enduring characteristics - or essence - because of their biological or genetic make-up. Complementing biological essentialism, cultural essentialism, which has been referred to as the new racism since the 1980s, is based 'not on the ideas of innate biological superiority, but on the supposed incompatibility of cultural traditions' (Donald and Rattansi 1992, 2). Whether biological or cultural, essentialism is problematic because it ignores and plays down the role of history, society and cultural environment. As we have seen so far, Hall's anti-essentialist theoretical formulation sought to re-conceptualise ethnicity without relying on biological or cultural essentialism.

The social constructionist - or culturalist - conceptualisation has largely focused on issues concerning lifestyle and behaviour. It elaborates on the idea that Roma share a common culture and cultural practices such as elements of religion, habits, purity laws, travelling, a set of beliefs, sometimes referred to as Romipen or Romanipen, the Romani identity; and that Roma occupy specific niches, particularly in the changing division of labour (Okely 1983). Lucassen et al. (1998) have argued that Roma are related to one another exclusively by their behaviour as they choose to be selfemployed, work with their family and lead an itinerant lifestyle; as a result, Roma are an interest group rather than an ethnic minority with common roots and culture (Lucassen et al. 1998, 171). Other scholars such as Jakoubek and Poduška (2003), Jakoubek (2004) have made similar, albeit highly controversial claims suggesting that the common traits that Roma share are 'culture of poverty' and loyalty to kinship: this, in their opinion, does not constitute the principle of ethnicity or nationality. However, the legitimacy and validity of these radical versions of constructionism have been questioned by a number of Czech academics (Barša 2005; Elš́l 2004) due to the implications and politically detrimental impact the research has had on Czech Romani communities, particularly at the local and regional level.

Some Romani Studies scholars have positioned themselves within the remit of the diasporic, or primordial, conceptualisation of Romani identity while others have been critical of it. However, the distinction between the two conceptualisations is not always so clear-cut. Some scholars associated with - and at times critiqued for - their essentialising approach have moved between the two approaches. Certain scholars such as Hancock use the term 'strategic essentialism', coined by Spivak in 1984 (Chakraborty 2010): the notion that some socially, politically or otherwise subordinate, 


\section{Understanding Romani identities}

marginalised or discriminated against groups temporarily put aside group differences in order to forge a sense of stable, fixed collective identity, through which they band together into political or social movements. (N.B., I discuss strategic essentialism in relation to identity politics in detail in Chapters Five and Six). As for those scholars who have been critical of the primordial conceptualisation, Okely (1983), for instance, suggests that focusing on the Indian origin of Roma was a form of Orientalism, exoticising Roma by setting them apart as non-European. ${ }^{3}$ Willems (1997) claims that current ideas about Roma as an ethnic diaspora are part of a deliberate fabrication by 'gypsyologists' of Gypsies as a separate ethnicity in the 18th century. Belton (2005) argues that an ethnic and 'racial' focus on Roma has given rise to a narrative of Romani identity whereby Roma only see themselves through an ethnic/'racial' lens; instead, 'this group is made up of a melting of people from a diverse range of backgrounds and, as such, does not constitute an ethnic or racial whole' (Belton 2005, 3). Mayall (2004) points to inconsistencies within the current non-Roma scholarship on Roma (for instance referring to Liégeois' manner of treating the issue of the Indian origin of Roma), concluding that 'Roma are and have been whoever people have wanted them to be' (Mayall 2004, 276-278). According to Mayall, non-Roma have constructed the group by setting boundaries and providing it with its own images. This, however, does not mean that Romani identity is not real: the process of constructing borders can facilitate identity building and provide a basis for a strong, distinct collective identity (Mayall 2004). Le Bas warns of some of the dangers of overaccentuating the idea of Roma as a people living in diaspora, asserting that such an approach leads to perpetuating the image of 'the truest and purest Gypsies who never left India' (2010, 67-68). To sum up, whatever difference of opinion there has been among scholars as to the significance of the 'origin' of Roma, it must be remembered that the archetype of the 'pure,' 'true,' 'mythic' and/or 'eternal Gypsy' (Tremlett 2009; Willems 1997, 46) never existed in the first place.

\section{Romani identities across disciplines}

Efforts to understand Romani identity have been generally freighted with differences of opinion among scholars who disagree about what constitutes Romani identity. This is not only because of the contested Indian, allegedly non-European, origin of Roma, but also due to Roma having a 'contested ethnic identity' (McGarry 2010) characterised by heterogeneity, fragmentation and difference in sub-group identity around which Roma nonetheless unite. In Romani Studies, there have been tensions not just because of the aforementioned duality of epistemological approaches - that is, essentialism and social constructionism that have at times overlapped - but also due to academic affiliations and disciplines. The following section focuses on some of the debates, themes and overlaps in relation to how Romani identity has 
been understood by academics in the various disciplines of Romani Studies: Linguistics, Anthropology, Sociology and Political science. Naturally, as with all disciplines, the boundaries between the individual disciplines are often blurred. Indeed, much Romani Studies scholarship is interdisciplinary. For ease of reference, I list them separately.

\section{Linguistics}

Due to there being very few known documented records of the Roma's migration westwards in medieval times, Romani Studies linguists have traditionally relied on linguistic evidence to support the theory that Roma originated in and migrated from India, particularly the region of Punjab in the North-west of India. Linguists have based their scholarship on 18thcentury linguistic investigations and research by, most notably, Rüdiger (1782) and Grellmann (1783) who were the first ones to establish a link between the Romani language and the Indo-Aryan languages of India (Fraser 2000, 21). Grellmann's work went on to become much better known, translated and more widely disseminated than Rüdiger's despite his interpretation of Romani communities being deviant and having a deficit subculture. Importantly, their texts impacted contemporary academic debate by establishing alternative images of Roma and conceptualisations of Romani identity (van Baar 2011). Together with Borrow's work (1857), they are regarded as the 'forefathers' of the Gypsy Lore Society founded in 1888 , which has, to date, maintained a problematic link with the presentday Romani Studies. It has tended to 'oscillate around classical themes of anthropology (rituals, identities, religions, music and other cultural expressions), linguistics or historical research' (Mirga-Kruszelnicka 2015, 41). Romani Studies are seen as the Gypsy Lore Society's inheritor and the legacy, characterised by a hierarchical attitude to the researched and affiliation to established centres of power (Brooks 2015). In her view, 'the relation of the re-named Romani Studies journal to the present-day Gypsy Lore Society calls into question any temporal shifts or sea changes in Romani Studies as a field of inquiry' (Brooks 2015, 58). Apart from the early 'gypsyologists', Matras (2002) draws attention to the discussion on the presence of various populations of Indian origin outside of India, as well as to the debates in which scholars such as Pott (1844), Grierson (1922) and others elaborated on the possibility of a direct connection between the Roma and castes of commercial itinerant populations in India. Another key contribution to Romani linguistics was Sampson's monograph on Welsh Romani from 1926 (Matras 1999, 89). Modern understanding of the Romani language and its historical development has been reliant on reconstructing and comparing it with other Indo-Aryan idioms and the contact languages (Matras 2006, 2), as well as on reconstructing and reinterpreting history by speculatively putting together accounts of events (Matras 2002). For instance, Hancock's linguistic scholarship is based on 
his theory, according to which the ancestors of present day were members of the military caste, who left India with their camp followers around 1000-1250 AD in response to a series of Islamic invasions led by Mahmud of Ghazni $(2000,1)$. The linguistic approach to Romani Studies (including sociolinguistics) has traditionally enjoyed a prominent position in the 20th century in central and eastern European countries, with linguists such as Hübschmannová, Elš́k, Friedman, and others (Bakker and Matras 2003). However, it is worth pointing out that linguists have not restricted their inquiry strictly to linguistics since scholars such as Hancock, Matras and others have also written about Romani history, culture and identity.

The evidence obtained thanks to linguistics continues to reveal historic routes of certain groups (Matras 2002). Inevitably, though, this direct relationship between linguistics and history often puts Romani Studies linguists into opposition to some anthropologists, sociologists and political scientists. This is most often due to the aforementioned difference of opinion between, on the one hand, the proponents of the essentialist approach, and supporters of the constructionist approach, on the other. Linguists have also levelled criticism at Romani Studies scholars in other disciplines. For example, Matras has been critical of Okely's refusal to 'engage with the linguistic argument' (Matras 2013, 4), as well as of Stewart, Gay y Blasco or Jakoubek for the same reason (Ibid, 5-5). He has also critiqued the Dutch constructionist approach represented by Cottaar, Lucassen and Willems mainly in terms of their 'de-construction' of the Indian origin and rejection of Romani groups as ethnic minority groups (Ibid, 4-5). At the same time, Matras has criticised Liégeois for his essentialising definition of 'Roma, Gypsies and Travellers' produced for the Council of Europe: not only does it define Roma as outsiders and institutionalises the image of a fictional 'Gypsy' but it also 'avoids a partition between socioeconomic organisation in peripatetic communities and Roma as an ethnic-linguistic minority' (Ibid, 7). However, this multiple critique of the anthropological, sociological and political scientific lines of inquiry have not offered a solution to the ongoing dispute between essentialism and social constructionism.

\section{Anthropology}

The social constructionist approach has generally informed the anthropologic inquiry. This includes some valid points made by the Dutch school critiquing the 18th-century nationalist framing of heterogeneous itinerant groups as one homogenous, non-European people originating in India: Roma. Anthropologists have generally steered clear of making 'an absurd social constructivist claim that "Roma do not exist"" (Stewart 2010, 2) except for the aforementioned claim by Jakoubek and Poduška (2003). Anthropologists writing on Roma have traditionally studied aspects of Romani culture and identity. They have focused on strategies of mobilising cultural resources, by which Roma subvert majority social, cultural and 
economic structures and hierarchies through a continual process of articulating, constructing and maintaining distinctive identities - the 'Gypsy-way' or 'Gypsiness' - and semi-autonomous cultural space grounded in Roma's assumed difference from non-Roma, as well as from other Romani subgroups (Okely 1983; Sutherland 1986; Stewart 1997; Gay y Blasco 1999; Lemon 2000). By so doing, anthropologists have helped to understand ethnic groups as the result of social and political processes of categorisation and ethnicity as a form of social organisation rather than objective group characteristics or common properties. By extension, anthropologists have demonstrated that Romani identity is not a primordial common cultural content. Instead, Romani identity is socially constructed and relational (Durst 2010). According to the essentialist approach, Roma had been an isolated tribe whose migration from India contaminated their once intact culture. Contrary to this, anthropologists such as Okely have contended that Roma are a people whose culture constructs its internal coherence alongside and in opposition to other dominant cultures in the same geographical and political space' (1994, 2010). This implies that Romani identity is 'a product of classification struggles involving both classifiers and those classified as Roma' (Vermeersch 2006, 13). Okely (1983) opposes the notion that Romani Gypsies are exotic outsiders who moved into and remained unassimilated in European societies. She argues that instead of referring to the pre-supposed Indian origin, scholars should attend to the socio-economic dynamics and processes at the time of their arrival in Britain $(1983,12)$. Anthropologists such as Gay y Blasco $(1999,50)$ or Stewart $(1997,28)$ have stated similar disinterest in the Indian-origin theory.

Despite the aforementioned contributions to existing scholarship on Roma achieved by anthropology, the discipline itself has not remained above criticism. Some sociologists have criticised anthropologists for being too focused on the assumed cultural difference of Roma from non-Roma rather than on the dynamics of similarities across populations. This focus has contributed to reifying the assumed groupness of Roma, Romani culture as coherent, as well as producing a romanticised image of the originary Roma in a situation where everyday poverty and other attendant social issues facing Roma are much more critical (Tremlett 2014b, 836, 837). For instance, despite the indisputable contribution made by her monograph, some of the observations made by Gay y Blasco (1999) contribute to perpetuating and re-inscribing the assumed marked essentialist ethnic/'racial' difference of Roma. The Romani female body is conceptualised as radically different from that of other Spaniards, 'Gypsy' men and women as enacting their superiority over 'non-Gypsies' and the 'Gitano social order' as 'impermanent'. It is worth remembering, though, that personhood being always sexed and gendered is a social process not unique to Roma. In fact, it is common to all societies. The idea that personhood is constructed as sexed and gendered is key to queer theory, which is discussed later in this chapter and in Chapter Two. Queer theory critically challenges this notion. 
Anthropology has been critiqued for "its focus on "culture" as the starting premise of its analysis' (Brooks 2015, 57); and for methodologically resting on accounts by individual anthropologists of their fieldwork conducted in Romani communities or 'a [Romani] person an as exemplar and performer of Gypsy/Roma distinctiveness' (Gay y Blasco 2011, 445) and being prone to critique for its selective subjectivity as being 'merely personal' (Okely 2010). Oprea (2004) has critiqued anthropological accounts of Romani communities, often written by non-Roma, that result in 'turning a blind eye' to patriarchal practices, excusing them as the others' culture, neglecting the daily realities of Romani women, and perpetuating a romanticised notion of Romani existence (30-31). These academic critiques suggest that there is a need for attending to the disconnect they perceive to exist between anthropologists' conceptualisations of Romani identities and the realities of multiple everyday Romani identities and lived experiences on the ground. The discipline has been facing the above critiques, including the criticism that 'the all-pervasive methodological nationalism of anthropological and other social scientific approaches produces false and misleading accounts of Roman[i] lives in Europe today' Stewart 2010, 2). In light of this, Stewart poses a constructive challenge to Romani Studies by suggesting that 'rich and honest analysis of Roma[ni] lives demands that authors transcend the "ethnic" frame of reference' $(2010,2)$. How this plea has been responded to is discussed below.

\section{Sociology}

A substantial part of the sociological inquiry in Romani Studies has been informed by writing about the situation of Roma throughout Central and Eastern Europe, particularly in relation to poverty. A wide scope of sociological research initiatives and projects have stressed the growing hardship, marginalisation, oppression of, and persisting discrimination against Roma across the board (in housing, healthcare, education, employment social services). Sociologists have also written about Romani identity. For instance, Ladányi and Szelényi (2006) have taken a socio-historical approach to investigating the status and labelling of Romani minorities by suggesting the concept of a racialised and gendered 'underclass' as a suitable term to define the situation of Roma minorities today in Central and Eastern European countries. Csepeli and Simon (2004) note the various constructions of Romani identity, including as an ethnic group, a cultural group and a social class. Guy (2001) observes that whereas communist policies framed the Roma question as a social one, the post-communist approach to the social issues facing Roma was to ethnicise Roma. In this connection, Gheorghe (1997) previously suggested that in the wake of the collapse of communism, Roma and Romani identity, which had been seen as social and largely negative, succeeded in ascending - at least to a certain degree - to a position of enhanced social respectability through 
'ethnogenesis' (Gheorghe and Acton 1992, 2001; Gheorghe 1997; Mirga and Gheorghe 1997; Acton and Klímová 2001). Ethnogenesis is a process whereby

a social group, previously occupying a despised and inferior position, moving from this position to some kind of respectability with a sort of equality with other social groups in the hierarchy of social stratification on the basis of a revised perception of their identity. The achievement of this movement is a project for us because of Gypsy experience of marginalization, of inferior social positions, of carrying a stigmatised identity in society. (Gheorghe 1997, 158)

Guy (2001) goes on to argue that Romani identity is social rather than ethnic, derived from the Roma's subordinate position within the wider economy and society. Yet, the two aspects are not 'necessarily dichotomised opposites for population groups in human society have overlapping social and ethnic dimensions' (2001, 4, 8). Guy claims that the dominant experience of Roma as Europeans has been the continued persecution and discrimination Roma have suffered, which, in turn, has shaped perception of Roma by others and has stigmatised Roma self-perception as having a 'pariah social identity' $(2001,5)$. At the same time, he proposes that Romani identity and 'culture,' understood broadly, are not unique, isolated, fixed entities despite showing some characteristic elements: they are constantly shaped and (re)constructed 'out of and [in] response to the nature of the symbiotic relationship between Roma and the wider majority communities' $(2001,7)$. Such scholarship has provided a very constructive sociological insight: on the one hand, it succeeded in acknowledging the historical reality of many Roma; on the other, by taking more of a social constructionist approach, it recognised the importance of the process of identity construction within the larger social fabric.

While making an important commentary on the current state of affairs in the changing political terrains of post-communist countries moving towards neoliberalism (Emigh and Szelényi 2001; Ladányi and Szelényi 2006), some of these accounts have come to be seen as objective descriptors of the social reality and common properties of the lives of sizeable numbers of Roma. The inequalities suffered predominantly by Roma at the hands of the majority, non-Romani societies - and hence attributed to Roma rather than non-Roma - have been documented and publicised so widely that they have become 'common knowledge' (Vermeersch 2006). At the same time, some Romani Studies scholars, including anthropologists, sociologists and demographers refer to Roma as a 'hard to see' (Stewart 2010,1) or 'invisible' (Okely 2010) minority. Sociological research and demographic data collection have been used, at times successfully, by sociologists, human rights and Roma rights organisations. They have contributed to documenting aspects of the current socio-economic situation of Roma across Europe such 
as lack of equality of opportunity in accessing mainstream education; accounting for some of the underlying socio-economic reasons; and litigating breaches of fundamental rights before domestic and European courts. However, 'difficulties [...] mark all attempts at conceptualising [Romani] identity as an objective property' (Vermeersch 2006, 20, 23).

Critique from sociologists was levelled at anthropologists mainly due to their focus on culture as an allegedly common property of Roma. In turn, sociologists writing in Romani Studies have faced similar criticism from anthropologists for their focus on poverty as a defining feature of Roma. In Tremlett's view, '[t]his is an important debate as it pivots on whether culture has been dismissed as poverty or whether poverty becomes the overwhelming feature of a community' (2014b, 837; see also 2009 and 2017). Tremlett adds that despite the premises of the two disciplines being historically divergent, a similar effect is achieved in both cases in terms of conceptualising Romani identity though an 'ethnic lens.' Irrespective of the level of social constructionism that has informed sociological and anthropologic inquiries, both end up producing essentialist conceptualisations ${ }^{4}$ of Romani identity, 'centred on asking what the most important feature is that makes up Roma people's characters and experiences of their lives' (Ibid, 831). Tremlett goes on to remark that

these debates, whilst appearing to be arguing different positions, actually end up in a similar ideological place... a heterogeneous approach to diversity that still keeps the notion of an overall 'group'.... [W]e need to re-think simplistic ethnicity-focused approaches that fall into the danger of reifying ethnicity as an essentialised, fixed-group concept [that misses] out on the inclusion of a range of other types of diversities, for example: gender, socio-economic positioning (or class contexts), generation, sexuality, legal status, local and national contexts. (2014b, 831-840)

In a nutshell, this binary approach has trapped Romani Studies scholarship in culturally essentialist ways of understanding Roma and Romani identities.

\section{Political science}

Informed by both the essentialist and social constructionist perspectives, political science has made its mark on Romani Studies by taking stock of scholarship generated by all of the above academic disciplines and bringing a fresh perspective. Political scientists have explored Romani identity as a 'racial' category in everyday bureaucratic practices (Plájás et al. 2019); a politicised, ethnicised/'racialised' conception in post-communist, neoliberal European nation states where state reforms create new mechanisms of Romani marginalisation in the context of political discourses on Roma (van Baar and Kóczé 2020). They have also paid attention to contemporary 
socio-economic and political conditions. Amidst these circumstances, Romani identity becomes an ideological, as well as institutional politicalexpert construction along ethnic/'racial' lines. This construction maintains and reinforces exclusionary practices and policies targeting Roma, poor and deprived ones in particular (Surdu and Kovats 2015, 7-8). Van Baar (2011), for example, has examined the Europeanisation of Romani representation at a time of the re-emergence of nationalist and populist rhetoric and movements across Europe, security measures vis-à-vis Roma (2015) and the importance of recognising the Romani Holocaust in the process of Romani identity formation at a transnational level (2010). Vermeersch (2006) and McGarry (2010, 2017) have examined the issues of Europeanisation and transnationality with respect to the situation of Romani communities in selected Central and Eastern European countries. They have studied the relationship between, on the one hand, Romani communities and non-governmental organisations representing and speaking for the Roma - that is, the Romani social and political movement; and, on the other, the recently emerged political structures such as national and international governing bodies, institutions and organisations. Vermeersch makes an important observation in relation to the paradoxical discourse of exoticising and orientalising Romani identity as non-European whilst, simultaneously, the actual interests, or concerns of Romani communities are labelled negatively as issues, or problems and panEuropeanised (2006, 172-174). This implies the notion that at a general societal level, Roma are being conceptualised homogeneously and constructed as 'un-European strangers' and 'non-citizens'. At the same time, European nation states and majority societies support the negative narrative of Roma being a drain on their resources.

Political scientists have acknowledged the challenges facing Roma, especially in terms of the deeply embedded marginalisation, discrimination and racism targeting Roma - or antigypsyism ${ }^{5}$ - along ethnic/'racial' lines that are endemic to most European societies. They have investigated Romani ethnic identity and the role it has played in the process of Romani ethnic mobilisation and unity since the early 1990s (Vermeersch 2006; McGarry 2010). They have also studied the significance of a common ethnic identity as a prerequisite for legitimate interest articulation and representation by the transnational Romani movement (McGarry 2010). Political scientists have been writing from a predominantly social constructionist viewpoint. While acknowledging that 'Romani identity is (...) "real"' (Vermeersch 2006, 5), they have argued that identity 'always works in relationship to and interacts with other social processes and variables' (McGarry 2010, 51); and 'is clearly dependent on social and political negotiation' (Vermeersch 2006, 5). Importantly, this perspective has not denied Roma the reality of lived experiences as a result of identifying or being identified as Roma. At the same time, this vantage point refrained from seeing marginalisation, exclusion and discrimination as objective properties 
of Roma, Romani identity or, indeed, as part of Romani culture. Instead, it has offered insightful commentaries on the socially constructed dynamics of the current political discourses in Europe and their impact on the process of identity construction vis-à-vis Roma rights in Europe.

For example, McGarry (2010) details two theoretical approaches that have informed citizenship rights and governmental, as well as international policy towards Roma: the 'social integration' and the 'racial discrimination' schools of thought. According to the former, which has its roots in Enlightenment, Roma are 'un-integrated' and framed as 'primitive natives' in need of being uplifted from their dire circumstances by 'civilised Westerners' whose moral duty it is to make them become full citizens by forcing them to go to school and work. Communism hoped to transform Roma through assimilation; these days, social integration has been replaced by the euphemism 'social inclusion', including through the work of neoliberal initiatives such as the World Bank, Open Society Foundations, and at the level of the European Union. The latter approach has its roots in Romanticism, emphasising Roma's liberty of culture and lifestyle. According to this approach, Roma are framed as Rousseau's 'bon sauvage' - that is, the 'good savage' uncorrupted by non-Romani society - and are victims of underrepresentation, marginalisation and discrimination due to negative perceptions of their socially stigmatised group identity. These analyses have facilitated a better understanding of the role of social inclusion discourses and policies that are devised, implemented and promoted by European political institutions and transnational - often Romani organisations to help uplift, emancipate and empower Roma, in the construction of a particular conceptualisation of Romani identity as a politicised, ethnicised and 'racialised' construct. The perpetuation of this essentialised conception of Romani identity engenders toxic relations between non-Roma and Roma and a vicious cycle that continues to marginalise Roma.

Political scientists have also interrogated previously largely overlooked understandings of Romani identity defined by members of Romani communities and Romani grassroots politics as a separate, non-territorial nation without a kin state (whose members have never demanded their own state); a national minority within nation states (protected by minority and human rights instruments), and an 'ethnoclass', that is, an ethnic group resembling a class at the bottom of the socioeconomic ladder (Vermeersch 2006, 160-166). Those who understood Romani identity as an ethnoclass tend to stress the precarious social circumstances of Roma; as a result, the main focus of these scholars has been on social rights such as education, housing and employment (Vermeersch 2006, 166). The concept, as described by Vermeersch, is particularly interesting when considered as an escape mechanism used by Roma to avoid association with the generally negatively perceived, hence stigmatising Romani ethnic identity, which is also highly visibilised - or hyper-visible - in political discourses and the 
media (N.B., I discuss hyper-visibility in Chapters Three, Four and Five). Some scholars used ethnoclass as an alternative understanding of Romani identity due to the conflation of Romani identity with pathological, abject and objectionable behaviour. Consequently, Romani identity has become an ethnic 'closet'. Some Roma who would declare their ethnic identity in private would not do so in public for fear of being associated with the 'Romani problem' (Vermeersch 2006, 182), they would sometimes downplay Romani ethnicity or would at times try to pass as non-Romani. Sexual, gender and ethnic/'racial' identities are distinct and separate: as such, they entail very different histories, materialities and lived experiences that cannot be equated. However, the distinct processes of exclusion have some important parallels. Consequently, the notion of stigmatised, closeted and pathologised Romani identities and queer identities, which I discuss in Chapter Two, is particularly salient.

This thorough, multi-disciplinary insight into the various conceptualisations of Romani identities has led political scientists towards establishing an understanding of Romani identities as contested, not cohesive, 'constantly shaped and reconstructed in and across political contexts'; a consequence of social processes where ethnicity plays the role of 'a unifying agent', gelling Roma who are otherwise not united across religious, cultural, occupational and linguistic lines (McGarry 2010, 42,141). The conceptualisation of Romani identity construction as a 'complex process of labelling, categorisation and self categorisation' (Vermeersch 2006, 3) is very much in line with the perspective proposed by the present book, especially as it also allows for the inclusion of other perspectives such as those offered by intersectionality and queer theoretical concepts.

\section{Romani individual and collective identities}

As we have seen thus far, the binary academic approach to Romani identities has often understood Roma in a narrow, culturally essentialist sense. This approach has sometimes slipped - often unwittingly - into perpetuating homogenising, two-dimensional stereotypes, tropes and clichés about Roma. Accentuation of shared aspects of collective ethnic identity has at times led to Romani individuals being conflated with Romani communities and with Romani kinship: an important concept explored in Romani Studies (San Roman 1975; Okely 1975; Gay y Blasco 1999; Martin and Gamella 2005; Budilová and Jakoubek 2007; Cahn 2009; Tesăr 2012), which Chapter Three discusses in relation to the lived experiences of queer Roma. In this collective conception of Romani ethnic identity, the assumed characteristics of unspecified, amorphous Romani communities represent and speak for all Romani individuals. Broadly speaking, those who selfidentify or are identified as Roma get associated with the stigmatised group identity always through the proxy of Romani communities. Identity thus becomes a means of reducing all members of a group to possessing the same 
set of assumed characteristic traits and values. Consequently, Romani identities and those individuals who are believed to possess them have come to be understood as belonging to an over-ethicised/'racialised', homogenous group identity, as a problem that is both pan-European and non/unEuropean. This has serious consequences for belonging, which I discuss in detail in Chapters Two and Five.

Romani communities have been theorised as a group or collectivity along ethnic lines, that is, 'essentially distinct' and 'different' from non-Romani communities in almost every respect: birth rates, life expectancy, infant mortality rate, the division of labour, economy, travelling patterns, selfascription, political groupings, marriage choices, upbringing and gender divisions, education (and lack thereof), engagement with service providers, accounts of structural oppression and so on. I say this fully aware that some of my previous research on coercive sterilisation (Fremlova 2006), segregated education (Fremlova and Ureche 2009; Fremlova et al. 2011) and multiple discrimination (Fremlova et al. 2014) could be interpreted that way, too. Undoubtedly, such studies are important when describing structural inequality and possible remedies. However, the often-unintended effect is that they, too, may contribute to re-inscribing the marked essentialist difference attributed to Roma. Consequently, these processes stigmatise, or mark, Romani identities. Yet, there is evidence within research that Roma possess identities characterised by hybridity, super-diversity (Tremlett 2009, 2014b), intersectionality (Kóczé 2009) and queerness (Baker 2015; Máté 2015; Fremlova 2017, 2018, 2019). As in the case of queer Roma, being Roma may not necessarily be the most pertinent category of identification. That is why it is important for research to attend to ways in which individuals may identify as Roma but may simultaneously experience other categories of identification as more important; and to how Romani ethnic identity can be experienced in ordinary, mundane ways (Tremlett and McGarry 2013). This approach to research helps to facilitate more nuanced understandings of both individual and collective Romani identities. It also helps to demonstrate how Romani communities ordinarily operate outside the scope of marked essentialist ethnic/'racial' difference that often frames discourses on antigypsyism and discrimination. For instance, ways in which Romani communities function as important social units and fundamental safety nets to support each other through good, as well as bad times, including providing support to their LGBTIQ members, which I discuss in Chapters Three, Four and Five. Such research ultimately gives rise to knowledge production that does not construct Roma as an ethnicised/'racialised' other, 'distinct' from the majority and 'marked out' as 'essentially different'.

Having outlined some of the key challenges faced by Romani Studies for ending up perpetuating - often unintentionally - homogenising and culturally essentialist misrepresentations of Roma, the following section looks at alternative ways of understandings Romani identities beyond ethnicity/ 
'race'. These alternatives allow for conceptualisations of Romani identities across numerous facets of identity and at their intersections.

\section{Transcending the 'ethnic' frame? Alternative conceptualisations of Romani identities}

For some time now, Romani Studies has been experiencing a critical turn (Bogdan et al. 2018) in knowledge production, leading to the emergence of Critical Romani Studies. The discipline has been at a crossroads, particularly in relation to the essentialist versus social constructionist dichotomy discussed earlier in this chapter, as well as in terms of the process of knowledge production and its decolonisation. Though not for the first time, the need for a new, critical direction was emphasised at the October 2014 conference Nothing about us without us (Dunajeva, Kóczé and Cemlyn 2015). That Romani Studies as an academic field has been on the verge of an existential crisis became quite clear at the turn of 2014 and 2015 when plans for the launch of the European Roma Institute of Arts and Culture ${ }^{6}$ were announced. Some scholars hailed it as 'the radical and fundamental paradigm shift that has been long time coming in Romani Studies' (Clark 2015), expressing the hope that new voices, Romani voices would be heard. Others were cautious (Kovats 2015), pessimistic (Matras 2015) or wary that this may lead to 'the dangers of a closed society research paradigm' (Stewart, 2017). What emanated from the widely publicised discussions was that there were numerous Romani Studies scholars, including those of Romani heritage, who welcomed the prospect of a paradigm shift in knowledge production. Still, others were less reluctant to admit that Romani Studies - a subject area historically dominated by non-Romani, often male, straight, cisgender scholars, lacking in plurality of voices and limited geographically, methodologically and paradigmatically - needs to change. Decolonising the process of producing knowledge about Roma would ultimately entail accommodating the long excluded - at times unwittingly - and much-needed authoritative Romani voices.

Knowledge production and ownership in Romani Studies, as well as the question of control, power and who exercises it, are, indeed, critical ones since they determine which authoritative voices are included and which ones are not. Romani Studies has lacked a critical perspective from within Romani communities as Romani scholars, 'the outsiders within' are still underrepresented despite their numbers having increased significantly over the past two decades (Mirga-Kruszelnicka 2015). Both non-Romani and Romani scholars have expressed similar concerns at Romani Studies' reluctance to engage critical views, including from Romani scholarship: that is, scholarship by academics of Romani heritage. For instance, in her paper Towards "Critical Whiteness" in Romani Studies, Vajda (2015) raises fundamental questions about the structural positionality of white/nonRomani scholars in a monological and monocultural vacuum without the 
input of those most acutely affected, that is Romani scholars. Consequently, in its current form, Romani Studies actively contributes to recentering hegemonic white power structures, as well as setting up a framework of research that is academically exclusionary and potentially heteronormative. Echoing Spivak's (1987) 'epistemic violence,' Brooks (2015), for instance, uses the term 'epistemological erasure/invisibility' to refer to the absence of Romani subjects, Romani communities, Romani knowledge and its production, whose silence, or allegedly 'inexpert status', continue to conserve the West as Subject $(2015,57,61)$. Brooks makes the following proposal:

If we are to salvage Romani Studies from its Gypsylorist origins, it is crucial that we take on the hierarchies that are implicit when Romani 'culture' is seen as bounded, and outside of, the subject of the West... $(2015,58)$.

The revolutionary voices, and not just the Romani ones, from within Romani Studies call into question the nature of Romani Studies, which has not made a clean break with the essentialist legacy of the Gypsy Lore Society. The notion that in Romani Studies, Roma 'are [still] seen only as objects and subject of analysis, rather than as producers of knowledge about Roma and about non-Roma alike' (Brooks 2015, 58), dominated by Western, white ethnocentric and paternalistic epistemology, means that this field of inquiry in its current form cannot be - and is not - an adequate reflection of and response to the plurality, heterogeneity and diversity of the lives and identities of Roma, including those within academia. To adequately attend to the pluralist, multidimensional identifications that members of the various heterogeneous groups and sub-groups of Roma make, it is inevitable that Romani Studies acquires a plurality of voices, including Romani, non-Romani, feminist, intersectional, as well as queer ones.

\section{Understanding Romani identities through hybridity and super-diversity}

The previous sections have examined the essentialist/social constructionist dichotomy in grasping Romani identities in Romani Studies, which has led to the coexistence of two distinctive, divisive, though not mutually exclusive, conceptualisations of Romani identities. Such a dichotomous, or dual, approach is not unique: let us recall Hall's proposition that the old collective social identities, including ethnic/'racial' identities, have not disappeared. Instead, they have undergone a fundamental transformation, giving rise to 'new ethnicities' existing within the context of a dichotomy of old and new identities. New ethnicities are predicated on difference, diversity and a non/anti-essentialist and non/anti-identitarian approach to identities. These are central tenets of queer theory discussed later in this chapter, which highlights the relational, fluid nature of identities while 
disrupting fixed identity categories, socially constructed binary hierarchies and social norms and normativities. This includes white-normativity, heteronormativity, cisnormativity and patriarchy where being white, heterosexual, cisgender and male is a neutral, unmarked state: or the 'norm'.

Hall wrote primarily about the black experience in the UK. However, his theoretical insights are relevant to the experiences of Roma all over Europe, particularly in terms of the duality of old and new Romani identities. Brubaker (2016) describes this duality in understanding identities as 'a sharpened tension between idioms of givenness, essence, objectivity, and nature on the one hand and idioms of choice, autonomy, subjectivity, and self-fashioning on the other' (15). One way to avoid the trap of cultural essentialism is to bring the concept of hybrid identities to heterogeneity (Tremlett 2009). Hybridity helps to account for the multifaceted diversity of the various Romani identities, 'effectively mov[ing] away from homogenising terms', in which Roma end up being portrayed. Tremlett argues that hybridity entails recognising that a Romani person may be deeply engaged with the cultural practices of their group, yet they may be, at the same time, undertaking activities considered typical for the majority culture. In different situations, they may also be influenced by their age, gender, sex, class, nationality, sexuality, social status etc. This means that hybridity may be potentially considered useful for conceptualising the multiple identifications that Roma make across groups and formations, including at the intersection of ethnicity/'race', sex/gender, sexuality, gender identity and other categories of identification.

Other Romani Studies scholars had previously considered employing hybridity. Okely (1994) was careful to use hybridity in relation to Roma 'because it carries with it the suggestion of incongruity' (62). Silverman (2012) discusses the viability, as well as the more problematic nature of using hybridity to conceptualise Romani identities, culture and music:

The fact that Roma embrace hybridity and that Romani music is hybrid is perhaps obvious, but if the concept is to have any validity, we must show how this hybridity works, why it exists, and how it differs from other explanatory models. (...) Hybridity, however, can be a problematic concept because of its vagueness and its theoretical positioning. (...) Hybridity also brings up the problem of antecedent purity. (...) Either hybridity is everywhere, thus losing its theoretical force, or else it exists in specific places and is contrasted with the nonhybrid. $(2012,42)$

Elaborating on the notion of hybrid identities, Tremlett (2014b) suggests that 'super-diversity' best encapsulates the much-needed shift in how ethnicity, heterogeneity and diversity are currently used in Romani Studies, "still leaving the potential of limiting talk about "the collective world view" of "the Gypsies" that can easily slip into essentialised talk' (2014, 838). 
Super-diversity is a concept coined and introduced by Steven Vertovec (2007) as a means of looking beyond ethnicity. Writing about the experiences of migrants and immigrants to the UK, Vertovec (2007) defines superdiversity as

a notion intended to underline a level and kind of complexity surpassing anything the [UK] has previously experienced (...), distinguished by a dynamic interplay of variables among an increased number of new, small and scattered, multiple-origin, transnationally connected, socio-economically differentiated and legally stratified immigrants who have arrived over the last decade. (...) Such additional variables include differential immigration statuses and their concomitant entitlements and restrictions of rights, divergent labour market experiences, discrete gender and age profiles, patterns of spatial distribution, and mixed local area responses by service providers and residents. Rarely are these factors described side by side. The interplay of these factors is what is meant here, in summary fashion, by the notion of 'super-diversity' (2007, 1-2).

Just like members of other constituencies, Roma form a part of postmodern societies: as such, Roma are constituents of a plethora of 'neotribes and elective communities' (Belton 2005, referring to Hetherington 2000, 93). Super-diversity, according to Tremlett (2014b), epitomises a shift away from previous multiculturalist perspectives focused primarily on ethnic groups. These perspectives were inadequate in capturing the new patterns of ways people are living (Vertovec, 2007, 2010) and towards a focus on hybrid group dynamics, as well as the problematic nature of group categorisation. Super-diversity has a 'potential to engage more deeply with the diverse life experiences and structural positionings of people' (Tremlett 2014b, 831). Whilst seeing the above benefits of using super-diversity to help better understand Romani identities, some of the problematic aspects of applying this concept to Roma are linked to its provenance: that is, specific to British contexts, realities and histories; the challenge looking beyond ethnicity may entail in terms of losing sight of ethnicity; its potential to reify the stereotypical image of Roma as nomadic by focusing on immigration; and super-diversity's lack of theoretical territory as being potentially problematic since the concepts of 'race' and ethnicity are over-used and under-discussed in Romani Studies (2014b, 838-40). This means that even though both ethnicity and 'race' are overarching concepts, ethnicity is referred to as a defining, essential feature of Roma - or, for that matter, of all ethnic minorities - when in fact it can be considered a universal denominator for everyone as all people are ethnically located. Tremlett goes on to make a strong case for applying super-diversity to conceptualisations of Romani identities. 


\section{Understanding Romani identities through intersectionality}

This section examines intersectionality and its application to Romani identities in Romani Studies. Later in this chapter, this will allow me to sketch out ideas as to how queer theory, and particularly Puar's (2007) concept of queer assemblages, can be read in conjunction with intersectionality to better attend to and account for the multifaceted complexity and fluidity of Romani identities.

Compared with super-diversity, intersectionality has been in use as a concept and an analytic since the 1990s. As a theoretical and methodological paradigm, a lens for political interventions and a framework for studies of social positioning (Cho, Crenshaw and McCall 2013), intersectionality has navigated numerous different theoretical, analytical and empirical terrains. Intersectionality has a long history, particularly in the US. It is important to acknowledge the roots of intersectionality going back to enslaved woman Sojourner Truth's political statement 'Ain't I a Woman?' (1850). Fundamentally shaking up and challenging essentialist notions of womanhood - and black womanhood in particular - the rhetorical question and the book capture all key aspects of intersectionality. As a concept, intersectionality was first used in academic discourse advanced within Critical Race Studies (the Combahee River Collective 1977; hooks 1981; Lorde 1984). Intersectionality, especially its popularisation, is largely attributed to Crenshaw's two essays published in 1989 and 1991 respectively. Within legal and antidiscrimination scholarship, Crenshaw's conception of intersectionality presented a proposition that the experiences of black women and other women of colour, particularly in the field of (un) employment, were not sufficiently served by existing feminist theorising, and thus demanded new paradigms. This new analytic frame disrupted the tendency to treat 'race' and sex/gender as two mutually exclusive identity categories. Compared with the multidimensional and multi-layered nature of Black women's experiences,

[t]his single-axis framework erases Black women in the conceptualization, identification and remediation of race and sex discrimination by limiting inquiry to the experiences of otherwise-privileged members of the group. (...) The intersectional experience is greater than the sum of racism and sexism [and] any analysis that does not take intersectionality into account cannot sufficiently address the particular manner in which Black women are subordinated. (Crenshaw 1989, 140)

Intersectionality is fundamental to understanding the workings of hegemonic power relations that exist in inequitable ways. Intersectionality signifies 'the complex, irreducible, varied, and variable effects which ensue when multiple axis $[s i c]$ of differentiation - economic, political, cultural, psychic, subjective and experiential - intersect in historically specific 
contexts' (Brah and Phoenix 2004, 76). Intersectionality is 'both a normative theoretical argument and an approach to conducting empirical research that emphasizes the interaction of categories of difference' (Hancock 2007, 64, original emphasis). The concept 'refers to aspects of identity and how they interact and affect equality' (Franken et al. 2009, 9). It was devised to tackle ways in which the various axes of difference and social divisions intersect; and to explore how 'race, class, gender, sexuality, ethnicity, nation, ability and age operate not as unitary, mutually exclusive categories but as reciprocally constructing phenomena that shape complex social inequalities' (Hill Collins, 2015: 2). As Johnson (2014) cautions, 'there is nothing "natural" about these divisions (...), rather, they emerge through institutionalized practices and processes that label and position particular "others"' $(2014,84)$. A key assertion of intersectionality is that the various axes of differentiation and the ensuing forms of oppression intersect, interlock and interact with each other. They do not exist in isolation or act independently of each other, nor can they be separated out into discrete and pure strands. Consequently, they are transformed at and through their intersections.

Some intersectional scholars such as Crenshaw focus specifically on the situation of Black women and women of colour; others concentrate on the intersectional workings of social divisions more generally, insisting that intersectionality refers to all subject positions since they are all fundamentally constituted by the interplay of ethnicity/'race', sex/gender, sexuality, class and other identity categories. Nash (2008) believes that the overwhelming majority of intersectional scholarship has centred on the particular positions of multiply marginalised subjects, 'obscur[ing] the question of whether all identities are intersectional or whether only multiply marginalised subjects have an intersectional identity' (2008, 9). YuvalDavis develops this idea further in her concept of situated intersectionality (2014; Yuval-Davis et al. 2017a): the notion that intersectional analysis

should be applied to all people and not just to marginalized and racialized women, with whom the rise of Intersectionality theory is historically linked, so as to avoid the risk of exceptionalism and of reifying and essentializing social boundaries (Yuval-Davis et al. 2017a, 1050).

According to Crenshaw, 'women of color experience racism in ways not always the same as those experienced by men of color' (Crenshaw 1991, 1252). This results in 'dominant conceptions of antiracism and feminism [being] limited' (Ibid). Some scholars argue that ethnicity/'race', raciality (Kuntsman and Mikaye 2008) - and by extension racism and antigypsyism have been submerged and silenced within queerness when in fact they should always be interrogated together. Others have taken this claim further, arguing that certain gay white men may benefit from oppressive mechanisms in 
societies that depend upon white-normativity, heteronormativity, cisnormativity and patriarchy (Nast 2002).

Different intersectionality scholars and theorists have also interpreted intersectionality either as a constitutive ${ }^{7}$ or as an additive process: for example, Crenshaw's imagery of a crossroad and traffic. Crenshaw (1993) nonetheless differentiates between structural and political intersectionality. The former refers to 'the ways in which the location of women of colour at the intersection of race and gender make our actual experience of domestic violence, rape and remedial reform quantitatively different from that of white women'. The latter pertains to how 'both feminist and antiracist politics have functioned in tandem to marginalize the issue of violence against women of colour' (1993, 3). Yuval-Davis (2006) differentiates between four types, or forms of social divisions: organisational, intersubjective, experiential and representational. These different forms affect how scholars theorise each of these four types per se, as well as the connections and interconnections between them. Social divisions such as class, ethnicity/'race', gender, sexuality, age and ability tend to be 'naturalised,' or essentialised on the basis of biology, or 'genetic pools' (Yuval-Davis 2006, 199). This, according to her, entails the homogenisation of these social categories, i.e. treating people who belong to a particular social category as sharing equally those natural attributes and setting the criteria of exclusion/ inclusion accordingly. Yet, Yuval-Davis opines, for some people, social divisions such as gender, age, ethnicity/'race' and class may be more important than others in constructing specific positionings as they tend to shape most people's lives in most social locations, while others (caste, indigenous status, being a refugee) tend to affect fewer people. However, while individual social divisions are 'constructed/intermeshed with each other, (...) they are irreducible to each other' (Yuval-Davis 2006, 200). As Chapter Three will show, in different cultural, socio-economic, political, and historical contexts, individual queer Roma may occupy specific social positions because of any one social division: that is, sexuality, gender or ethnicity/'race'). A particular axis of inequality such as ethnicity/'race' and the resulting oppression, for instance, antigypsyism, may become a key aspect of their specific positioning - or intersectionalities - despite still being impacted by, for instance, homophobia, transphobia, misogyny and their intersection.

Over the past two decades, intersectionality has been gaining ground in Romani Studies. According to Mügge et al. (2018), 'the issue of race and its (dis)appearance in relation to intersectionality is brought into sharp focus as intersectionality is operationalised on the European mainland' (Ibid, 20). By contrast, in Romani Studies, predominantly Romani intersectional feminist scholars have used intersectionality as a 'comprehensive theorising of various power relations' (Erel et al. 2008) to theorise the multidimensional, intersecting and interlocking power relations impacting on the experiences of Romani women and their multiple values (Máté 2015). This 
has included 'race' (Emigh and Szelényi 2001; Kóczé 2009) since 'the interaction between gender and 'race' creates a double disadvantage for Roma women' (Emigh et al. 2001, 22). The intersectional analytic frame has thus disrupted the tendency to treat ethnicity/'race' and gender as mutually exclusive identity categories.

In Romani Studies, an intersectional approach to understanding Romani women's experiences was first heralded by Oprea (2004). Kóczé (2009) argued that 'Romani women' are not a monolithic group: they encompass single Roma mothers, young Romani women from traditional communities, educated Romani women, Romani women professionals, older Romani women, disabled Romani women and so on. Thus, Kóczé develops her intersectional approach as she suggests that ethnicity/'race' and 'gender' may not be enough as other, multiple and intersecting aspects of identity such as class, age, (dis)ability, social and economic status, sexuality and religion determine Romani women's position in society. Kóczé suggests that as a tool, intersectionality bests accounts for the notion that Romani women activists are at the intersection of two or more identity categories such as ethnicity/'race', gender and class; and brings more inclusive discourses and transforms internal discourses within the Romani movement.

As an originally legal concept, intersectionality has been gaining ground particularly among those Romani rights advocates and lawyers who are interested in the legal aspects and definitions of multiple discrimination (Fremlova et al. 2014). Notwithstanding, intersectionality is still missing ${ }^{8}$ from Romani Studies. Dunajeva et al. (2015), who reiterate assertions previously made by Oprea (2005), Kóczé (2009), Brooks (2012), Gelbart (2012) and Schultz (2012), comment on the issue of lacking intersectional analysis plaguing Romani feminist scholars. Yet, it is much needed, given 'the intense marginalisation of Romani women and the oppression they experience both from the dominant society and within communities (...) alongside their absence within mainstream feminist and anti-racist discourse' (Dunajeva et al. 2015). In the same volume, Vajda (2015) notes that a critical approach to whiteness would perhaps entail a more intersectional approach to Romani Studies. Jovanovic and Daróczi (2015) provide an outline of the essence of intersectionality as a concept and method, as well as its benefits and relevance to Romani Studies. They go on to argue that 'the Romani movement must incorporate an intersectional approach to a higher extent in order to avoid a narrow Romani identity politics that assumes national identity as having exclusive relevance to experiences of Romani people at any given time' $(2015,79-80)$. In their view, intersectionality makes it possible to look at how the dominant discourse ignores contexts, in which certain groups of Roma. They give the example of boys, vulnerable men or young women who have been institutionalised and are vulnerable to specific forms of trafficking in human beings. These omissions result in a failure to examine gender relations, socioeconomic status, ethnic belonging, age, sexuality and so on. As a postcolonial 
critique, intersectionality has challenged the role of non-Romani identity, whiteness and patriarchy in the production of knowledge on Roma; and Romani Studies' focus on certain Romani subjects vis-à-vis the lack of attention it has paid to others. It has also focused on the gender difference and the multi-faceted, intersecting experiences of predominantly Romani women, as well as other Roma who have been historically left out of Romani academic and activist discourses. By so doing, intersectionality has slowly paved the way for the inclusion of issues pertaining to sexuality and gender identity, previously deemed a social taboo, and extending it, in due course, to Roma who self-identify as LGBTIQ. Nonetheless, until quite recently, sexuality as a specific category of identification has been omitted, at times avoided within Romani Studies scholarship.

The above alternative conceptualisations of Romani identities facilitated by hybridity, super-diversity and intersectionality have contributed to ushering in a significant paradigm shift: paraphrasing Hall (1996b), these mark the end of the innocent notion of the essentialist Romani subject. There is one last thing that needs to be said about intersectionality, though. Crenshaw's 1991 article revisited intersectionality in relation to identity politics, emphasising the claim that intersectionality should not be understood as 'some new, totalizing theory of identity'. Instead, it was meant to encapsulate 'the need to account for multiple grounds of identity when considering how the social world is constructed' (1991, 1244-5). This is a key point to remember, especially given the contested relationship between intersectionality, queer theory and queer theoretical concepts, which I discuss in the following section.

\section{'Queerness' and queer (of colour) theoretical concepts}

Just like the word 'Gypsy', which is still seen by many as a racial slur, the word 'queer', which used to be a homophobic and transphobic slur, has a complicated history. This is reflected in the different meanings that it has assumed over time ${ }^{9}$. Since non-heterosexual and non-cisgender people have reclaimed queer, it no longer has the connotation of a slur. As mentioned in the introduction, in contemporary usage, queer often refers to nonheteronormative sexual and non-cisgender people and their identities. In so doing, it purports to encompass a given set of stable sexual or gender identities. This fixity of identities is, however, antithetical to queer theory's understanding of queer: in queer theory, the term takes on a non/antinormative and non/anti-essentialist meaning proposed by Hall, discussed in the previous section. Halperin describes queer ${ }^{10}$ as 'an identity without an essence (...), demarcat[ing] (...) a positionality vis-à-vis the normative - a positionality that is not restricted to lesbians and gay men' $(1995,62)$.

Though it may seem hard to describe or categorise queer precisely because, by default, it is a positionality, its key function is non-normativity. 
Therefore, queer is also subversive to that which is normal, normalised and normative. According to Gamson,

[q]ueerness in its most distinctive forms shakes the ground on which gay and lesbian politics has been built, taking apart the idea of a 'sexual minority,' and a 'gay community,' indeed of 'gay' and 'lesbian' and even 'man' and 'woman'. It builds on central difficulties of identitybased organising: the instability of identities both individual and collective, their made-up, yet necessary character. It exaggerates and explodes these troubles, haphazardly attempting to build a politics from the rubble of deconstructed collective categories. This debate, and other related debates in lesbian and gay politics, is not only over the content of collective identity (whose definition of ' $g a y$ ' counts?), but over the everyday viability and political usefulness of sexual identities (is there and should there be such a thing as 'gay,' 'lesbian,' 'man,' 'woman'?). (1995, 390)

With this in mind, queer theory can then be understood as a critical nonnormative and non/anti-essentialist theoretical approach to grasping individual and collective identities. Queer theory has been the main thrust of scholarship on sexual and gender identities since the late 1980s and early 1990s. This vein of academic inquiry emerged within a very particular context in the social sciences and humanities. There, the social constructionist approach to interrogating sexual orientation and gender had succeeded in producing scholarship premised on an anti-essentialist understanding of the 'sexual subject'. The social constructionist scholarship on sexuality that came to be known as Lesbian and Gay Studies (e.g. D’Emilio 1983; Duberman et al. 1990; Halperin 1990; Faderman 1991) challenged medical, psychiatric, sexological and sociobiological essentialist approaches to sexual orientation and gender - i.e. the Foucauldian concept of the 'medicalised homosexual' - in the late 19th and the 20th centuries. Simultaneously, the lesbian and gay experience preceding gay liberation that this vein of scholarship set out to capture, explain and theorise was characterised and formed by deeply engrained prejudice and repression. As a consequence, Lesbian and Gay Studies scholars tended to understand the sexual subject as historically specific, contingent on social norms and cultural scripts, liberating the 'modern homosexual' (Plummer 1981; Jagose 1996; Weeks 2012) from the constraints of its historic and modern erasure. Here, we can see the emergence of a kind of dilemma, or 'queer dilemma' around 'the instability of identities, their made-up, yet necessary character' (Gamson 1995, 390). This can be seen also at a more general level as an 'identity dilemma' (McGarry and Jasper 2015; see also, Fremlova and McGarry 2018) discussed in Chapter Five: the notion that fixed identity categories, and political mobilisation around them, are the basis for political power, but also the basis of oppression. This dilemma is somewhat 
reminiscent of the essentialist/constructionist dichotomy in understanding Romani identities discussed above in the section 'Reconciling binary essentialist and constructionist understandings of Romani identity'. The social constructionist approach to understanding the lesbian and gay subject still ended up unwittingly producing essentialised conceptualisations that "treated its object of study as a fait accompli; (...) a kind of "shored up" sexual subject position ...' (Green 2007, 28): that is, as a fixed, stable set of sexualities and gender identities. It was against this backdrop and within the context of the social constructionist and poststructuralist schools of thought, ${ }^{11}$ including feminist poststructuralist scholarship, that queer theorists moved away from reifications of the status quo regulatory social norms and hegemonic power relations (de Lauretis 1991; Fuss 1991; Butler 1993) to embracing an approach that saw sexualities and gender identities as socially constructed, unstable and fluid; an approach that was fundamentally critical of essentialising conceptualisations of identities. As Weeks (2012) argues, ${ }^{12}$ though, it is important to acknowledge that the work of queer theorists, who built on the work of their predecessors, would have been impossible without the major paradigm shift attained by Lesbian and Gay Studies in the 1970s and 1980s. ${ }^{13}$

Informed by scholarship emanating from poststructuralism, feminism, Lesbian and Gay Studies, as well as by reconceptualisations of identity as discussed in the previous section in relation to Hall's notion of new ethnicities, queer theory interrogates fixed identity categories, discursively produced binary social categories such as man/woman, straight/ gay, cis/ trans (Gamson 1995; Browne, Lim and Brown 2007) and their deployment in maintaining social norms, dominant orthodoxies and dualisms. This critical approach makes it possible to understand identity categories as social constructs, shaped by histories, practices, taboos, social rules, customs and traditions, which are necessary, viable and politically useful (Gamson 1995). Butler (1990) uses the expression 'regulatory fictions' $(1990,32)$ : fixed identity categories and binary social norms - or rules - are real in that they exist and regulate all aspects of people's lives in society, especially the lives of those who trespass or breach them. Yet, just like fiction, these rules are written, or constructed as the result of a consensus among people within particular histories, in different societies and power structures at different times. Queer theory critically analyses and deconstructs dominant hierarchies of power: '[q]ueering what counts as nature (...), specific normalised categories (...)' (Haraway 1994, 60), taking them 'beyond the heterosexual/homosexual binary to a usage of queer theory as an approach that critiques the class, race and gender specific dimensions of heteronormativities as well as homonormativities (...) that does not simply describe and reify the spaces of sexual "others" (Oswin 2008, 96). The fundamental premise of queer theory lies in problematising the ways in which norms and categories classifying that which is normal as opposed to abnormal/not normal are constituted, deployed, maintained and reinforced. 
Queer theory explores and unpicks how identities are constructed through the process of identification. Hall (2000) calls for an antiessentialist 'politics of recognising that all of us are composed of multiple social identities (...) through their diversity of identifications' $(2000,57)$, in which identity becomes a 'movable feast' always (trans)formed by how we are represented and addressed in the surrounding cultural systems (1996c, 598). Similarly, Butler (1993) suggests that identities are open to continuous negotiation and influence. It is in relation to the circumstances surrounding us that we locate our sense of self:

Identifications are never fully or finally made; they are incessantly reconstituted, and as such, are subject to the volatile logic of iterability. They are that which is constantly marshalled, consolidated, retrenched, contested and, on occasion, compelled to give away (Butler 1993, 15).

Queer theory sees heterosexuality as a dominant, nonetheless unstable system that is dependent upon individually constructed performances of heterosexual identity, and on excluding homosexuality to maintain the very existence of this identity. As Butler claims, 'that heterosexuality is always in the act of elaborating itself is evidence that it is perpetually at risk, that is, that it "knows" its own possibility of being undone' (1991, 23). Even though queer theory started off by predominantly conceptualising sexualities in ways which conceive of sexual power as 'embodied in different levels of social life, expressed discursively and enforced through boundaries and binary divides', it problematises and interrogates areas which normally would not be seen as the terrain of sexuality': that is, queer theory offers queer readings of other identities, too, as 'identities are always on uncertain ground, entailing displacements of identification and knowing' (Stein and Plummer 1996, 182). Boyarin et al. (2003, 8-9) propose that 'if queer theory is to be more than a fancy way of saying more of the same - then it is necessary to work at the in-between spaces in which no one difference is elevated above all others'. In order to recognise the cross-cutting multiple social relations, they suggest establishing links and finding connections between Jewish cultural studies and queer theorising and between Jew, queer and LGBTIQ, which I discuss in Chapter Two, without closing down differences between, among and within each point of comparison. This constructive proposal appears highly relevant to the Romani/queer proximity.

Framed in this way, non-normative queer theoretical concepts and queer theory as a proposition offer an opportunity to read Romani identities in different, non/anti-essentialist ways; an opportunity to queer $(\mathrm{y})$ Roma, so to speak. Employing queer theoretical concepts in relations to conceptualisations of identities makes it possible to take essentialism out of the equation. What emerges, as a result, is the possibility to see previously essentialised identities - be they sexual, gender, ethnic/'racial' and so on - in relation to dominant social norms. It is relevant since debates 
around queer and queerness resemble arguments in ethnic/'racial' communities, in which 'boundaries, identities and cultures are negotiated, defined and produced' (Nagel 1994, 152). Therefore, queer theoretical concepts also have the potential to critically examine and take apart the notion of Romani ethnic identity, the Romani minority and the Romani community as fluid collective identities.

Some scholars have critiqued queer theory for overlooking and maintaining structural and epistemological silences on racism, classism and transphobia ((charles) 1993; Cohen 2005; Haritaworn 2007), for having a tendency to neglect the workings of asymmetrical hegemonic power relations (Yekani et al. 2010) and to gloss over the institutional character of sexual identity and the shared social roles that sexual actors occupy, consequently constructing 'an undersocialised "queer" subject with little connection to the empirical world and the sociological forces that shape sexual practice and identity' (Green 2002, 522). Others have challenged what they see as the radical deconstructionism of queer theory, referring to its capacity to shake terms and concepts such as 'gay,' 'lesbian' or 'coming out' (Castle 1993, 13). Importantly, Ferguson (2004) and Oswin (2008) have argued that despite queer theory's call for anti-identitarian politics, some queer theory is not exempt from creating its own regulatory regimes, and the politics of normalisation. Additionally, certain queer scholarship has been critiqued for failing to include bisexual and trans people, as well as non-white subjects (Puar 2002, 2007; Ferguson 2004; Oswin 2008). Queer theorists gradually started to question the dominance of white subjects in queer theory texts (cf. Eng et al. 2005). These critiques resonate with earlier lesbian of colour scholarship on multiple relations of oppression (Combahee River Collective 1982 [1977]; Lorde 1984; Anzaldúa 1987). As a result, new strands of queer theory have emerged such as queer of colour critique. Ferguson describes it as an 'interrogat[ion] of social formations as the intersections of race, gender, sexuality, and class, (...) made up of women of color feminism, materialist analysis, poststructuralist theory, and queer critique' (Ferguson 2004, 149).

Queer of colour theorists have proposed alternative conceptualisations of identity, challenging the argument made, for instance, by Hall and queer scholarship that identifications are made 'through the relation to the Other, the relation to what it is not, to precisely what it lacks, to what's been called its constitutive outside' (1996a, 4; original emphasis). Anzaldúa (2002) outlines new forms of relational, inclusionary identities based on affinity, modelling a flexible process for personal and collective identity formation through inclusion rather than exclusion:

[m]any of us identify with groups and social positions not limited to our ethnic, racial, religious, class, gender or national classifications. Though most people self-identify by what they exclude, we define who we are by what we include - what I call a new tribalism. (Anzaldúa 2002, 243) 
Queer of colour critique is a critical, interdisciplinary, heterogeneous response to the prevailing white ethnocentrism of queer theory scholarship; and the cis- and heterocentrism of ethnic/'racial' and cultural studies. Queer of colour critique makes up for this deficiency: it tries to understand, dissect and unpick 'the ways in which discourses of sexuality are inextricable from prior and continuing histories of colonialism, nationalism, racism, and migration' (Reid-Pharr 2002; Eng et al. 2005; Gopinath 2005, 3), resulting in a 'clash of civilisations' (Fassin 2006; Gardner and Fassin 2013). In this vein, questioning the centrality within queer theory of those queers located within centres of privilege, Tucker (2009) argues that being 'knowingly queer' is a privilege that is not available to all queers. This includes queer Roma, some of whom strive for basic survival in the face of antigypsyism, homophobia and transphobia. As we shall see in Chapter Three, queer Roma do not always have the choice to queer(y) or playfully dismantle the very same structures that threaten their lives.

This section has examined why and how concepts emanating from queer theory and queer of colour critique are useful theoretical tools that help resolve the essentialist/social constructionist dichotomy and impasse in Romani Studies. In what follows, I explore the conflicted relationship between intersectionality and queer theory, especially Puar's (2005) concept of queer assemblages. Having already gone through the pros of both, I first outline several cons of each of the two analytics with a view to proposing to employ their combination - queer intersectionalities - when attending to conceptualisations of Romani identities.

\section{Intersectionality or queer assemblages?}

Intersectionality has been critiqued for omitting to interrogate power relations around class (Skeggs 1997), disability and transgender; and for failing to interrogate the nature and extent of white-normativity's investment in how hegemonic oppressions and social hierarchies mutually reinforce (Erel et al. 2008). Another critique questioned intersectionality's emphasis on Black women's experiences of subjectivity and oppression (Nash 2008, 10). Some scholars have argued that understanding intersectionality as 'overlapping axes of oppression' suggests that they are detached from each other (Cooper 2004, Puar 2005). For others (Razack 2006; Combahee River Collective 1977), 'interlocking systems of oppression' is a preferred conceptualisation. Additionally, there has been an under-development of sexuality in the application of intersectionality; at the same time, intersectionality has been underdeveloped within queer theory. Commenting on the potentials and limitations of applying intersectionality, and the possibilities of critiquing and extending it beyond the 'mantra' of race, class and gender to consider sexual absences and advances (Puar, 2007), Taylor et al. (2010) express the following concern: 
sexuality is apparent within scholarly work on 'intersectionality' as a spoke on the 'intersectional wheel', but these intersections are often minimally gestured towards rather than empirically substantiated, demonstrated and 'delivered'; the formalistic addition and repetition of 'intersectionality' leaves out the intimate interconnections, mutual constitutions and messiness of everyday identifications and lived experiences. (...) A binary framework persists in theorising gender and sexuality: while some theorists foreground sexuality as the category through which gender is constructed (Rubin, 1989), others have positioned gender as the pivotal category through which sexual identities and subjectivities are produced. (Jackson 1999; Taylor et al. 2010, 2).

Perhaps most importantly, the main critiques of intersectionality (Cooper 2004; Puar 2005, 2007, 2012; Erel et al. 2008) focus on intersectionality's reifying fixed identity categories attached to the neoliberal nation state, sexual difference and re-inscribing the centrality of white women's dominant subject positioning, always producing 'an Other, and that Other is always a Woman of Color (...) who must invariably be shown to be resistant, subversive, or articulating a grievance' (Puar 2005, 128). This is a key claim highly relevant to Romani identities that have tended to be conceptualised through a foregrounding of ethnic identity, thus reifying ethnic difference. Notwithstanding these critiques, intersectionality still offers possibly the most viable and comprehensive analytic for theorising the workings of asymmetrical hegemonic power relations.

Coming from queer theory, Puar (2007) believes that intersectionality becomes 'a structural container that simply wishes the messiness of identity into a formulaic grid (...) relying on the logic of equivalence and analogy between various axes of identity' $(2007,212)$. Puar advocates for a move from intersectionality to assemblage (agencement in French), first introduced by Deleuze and Guattari (1988). They define the concept as 'a multiplicity [that] has neither subject nor object, only determinations, magnitudes, and dimensions; (...) there are no points or positions (...) such as those found in a structure, tree, or root' $(1988,8)$. Deleuze and Guattari (Ibid, 88) employ the term assemblage to 'highlight the way in which material content (bodies, actions, passions) (...) are linked rhizomatically (...), emphasis[ing] both temporality and spatiality: elements are drawn together at a particular conjuncture only to disperse or realign (Murray Li 2007, 265). A queer assemblage can then be understood as a non-normative notion

[which] resists (...) intersectional and identitarian paradigms (...) in favor of spatial, temporal, and corporeal convergences, implosions and rearrangements. Queerness as an assemblage (...) deprivileges a binary opposition between queer and non-queer subjects. (...) [T] here is no 
entity, no identity to queer (...). As opposed to an intersectional model of identity, which presumes that components - race, class, gender, sexuality, nation, age, religion - are separable analytics and can thus be disassembled, an assemblage is more attuned to interwoven forces that merge and dissipate, time, space, and body against linearity, coherency, and permanency. (...) [A]ssemblage, in its debt to ontology and its espousal of what cannot be known, seen, or heard, or has yet to be known, seen, or heard, allows for becoming/s beyond being/s. (Puar 2005 121,127, 128; [my emphasis])

Queer assemblage characterises links and relationships between constitutive categories of identification that do not assume either an overarching system, structure, groupness or a common set of roots. Applying this analytic to conceptualisations of Romani identities helps to facilitate an understanding of identities as rhizomatic, intuitive, fluid as opposed to fixed, stabilised and anchored in and by the essentialised groupness of Romani ethnicity.

\section{Queer intersectionalities?}

We have seen that there are many critics and many defenders of intersectionality, just like there are many proponents and many opponents of queer theory. Simultaneously, for our purposes, both intersectionality and queer assemblages are suited for attending to the vast diversity of Romani identities, shaped by historical, social and cultural scripts, canons and contexts, as well as by the lived experiences of queer Roma. Given the benefits offered by both analytics, I believe it is useful to consider how they can be made to work together.

Previously, Muñoz (1999) used both queer theory and intersectionality in his conceptualisations of disidentification made by 'minoritarian subjects', discussed in Chapters Two and Five: the notion that queers of colour rework and reconfigure majority society's hostile and exclusionary cultural scripts and values to survive. Importantly, coming from the perspective of queer of colour critique and recounting the works of Anzaldúa and Moraga, particularly This Bridge Called My Back: Writings by Radical Women of Colour (1981), Muñoz espouses an intersectional optic in relation to monocausal paradigms, which 'are established through the reproduction of normative accounts of woman that always imply a white feminist subject and equally normalizing accounts of blackness that assumes maleness' (1999, 8). Muñoz borrows both concepts from Crenshaw, thus locating his conceptualisation of disindentification amidst queer theorising and intersectionality. Disidentification emerges as a strategy enabling intersectional readings of the process of de-constructing, reconstructing and negotiating dominant scripts and normativities. More recently, Erel et al. $(2008,271)$ have proposed an 'intersectionality perspective' for critical queer theorising and research practice; Rahman (2010, 
956) has suggested that 'queer intersectionality is simply the necessary tautology: intersectionality is inevitably disruptively queer, and queer must be analytically intersectional'; Browne et al. (2017) have argued in favour of intersectional feminist queer research and methodologies; and Yekani et al. (2010) have argued in favour of employing 'queer interdependencies' in the hope of

emphasis[ing] that each category such as gender or race is always already intertwined in multiple frameworks of inequality (...) [which] allows us to address the conflicting racialising and sexualising processes within a category (...) without assuming a hierarchy of inequality or an essentialist understanding of these categories (Yekani et al. 2010, 7980 ; original emphasis).

In my use of queer intersectionalities, changing the singular form to 'intersectionalities' in line with Yekani et al.'s 'interdependencies' helps to account for the variety of asymmetrical hegemonic power relations - be they social-economic, cultural or political - that contribute to constructing and configuring specific subject positions. Whilst I maintain the term 'queer' in its non/anti-normative, non/anti-essentialist, non/anti-identitarian and fluid sense, the term 'assemblage' is implied in my use of 'queer intersectionalities'. To make up for the formal absence of assemblage when employing queer intersectionalities, I contextualise this use by referring to both assemblages and intersectionalities.

Queer intersectionalities can be understood as a middle ground (not always in the middle!) between intersectionality and queer assemblages. Queer intersectionalities allow us to capture the workings of social normativities and binary orthodoxies, which are the attendant manifestations of asymmetrical hegemonic power relations and the resulting social normativities: white-normativity, heteronormativity, cisnormativity and patriarchy. Queer intersectionalities benefit understandings of identities as fluid assemblages that are not anchored in the notion of fixed 'groupness'. Instead, identities unfold and flow discursively and keep becoming across space and time in a rhizomatic way. Queer intersectionalities join intersectionality with critiques of identity, thus making it possible to speak to the workings of interlocking axes of inequality and all the categories of identification participating in and contributing to the 'process of becoming/s beyond being/s' (Puar 2005, 128) whilst not assuming the supremacy of one axis of inequality over another, and not re-inscribing marked essentialist differences embedded within and constitutive of social norms and binaries. Queer intersectionalities help to facilitate understandings of identities that attend to the multifaceted, nonnormative, fluid nature of Romani identities that are in a constant dialogical relationship with asymmetrical hegemonic power relations.

Having provided this theoretical backbone to understanding the lived 
experiences of queer Roma, I now move on to discussing the methods and theory-informed methodology.

\section{Between methodology and theory: Critical perspectives on non-Romani researcher positionality and reflexivity}

This book is based on my doctoral thesis (Fremlova 2017). ${ }^{14}$ The qualitative, ethnography-informed doctoral investigation involved 24 participants from North America (US, Canada), Scandinavia, Western (the UK, France), Southern (Spain), Central and Eastern (Belgium, Germany, Austria, Czech Republic, Hungary) and Southeastern Europe (Serbia, Romania, Bulgaria). They came from a variety of national groups and sub-groups (for example, Rumungro, Sinti, Romani Gypsies, Travellers, Gitanos, Kale); age groups (between 18 and 47); religious groups; sexual and gender identities (lesbian, gay, bi, queer, straight; male, female, cisgender, transgender, intersex, nonbinary) and social classes. The book does not claim to be representative of all queer Roma: many of the participants came from more privileged backgrounds and social positions, spoke multiple languages, had access to the Internet and were able to travel abroad. This is an important limitation and an aspect of the participants' intersectional positioning within their respective societies in terms of class and social status that need to be acknowledged. I recruited the participants through my contacts with queer Roma with whom I had cooperated since 2009. For reasons related to safety, the participants were given pseudonyms and references to specific places - and in one case to a country - were removed, so that the participants could not be identified.

The methods for the research were designed to ascertain, unpack and understand the lived experiences, insights and views of queer Roma. Boylorn (2008) defines lived experience as follows:

a representation and understanding of a (...) research subject's human experiences, choices, and options and how those factors influence one's perception of knowledge. Lived experience speaks to the personal and unique perspective [of a research subject] and how their experiences are shaped by subjective factors of their identity such as race, class, gender, sexuality, religion, political associations, and other (...) characteristics that determine how people live their daily lives. Lived experience (...) acknowledges (...) how separate life experiences can resemble and respond to larger public and social themes, creating a space for storytelling, interpretation and meaning-making. (...) [L]ived experience (...) privileg[es] experience as a way of knowing and interpreting the world. (Boylorn 2008, 489-90)

The above description illustrates the importance of the complex, multifaceted identities of queer Roma, fluidly shaped by intersectional 
experiences of structural inequalities and social norms for qualitative social science research and knowledge production. Espousing a qualitative approach to collecting data from a variety of sources and using several data collection methods such as focus groups, interviews and participant observation allowed me to assemble very rich data on the lived experiences of queer Roma. Simultaneously, this manner of data collection 'also encourag [ed] reflexivity about how research is assembled' (Fox and Alldred 2015, 408). The data were generated through two focus groups and participant observation held in August 2015 and 2016 during the first and second international Roma LGBT conference, at a number of conference events and two Prague Pride marches. The first focus group involved five Romani gay men and one Romani lesbian woman; the second one involved three Romani lesbian women. Between September 2015 and November 2016, I conducted 14 in-depth semi-structured interviews with 15 participants. They included three Romani lesbian women; one Romani bi woman; one Romani queer-identified, straight woman; two Romani trans men; one Romani intersex person; two Romani/Traveller bi men; one Romani queeridentified man; and four Romani gay men. The first focus group and 11 interviews were conducted in English. Only three participants were native speakers. The rest were non-native speakers of English, hence the very specific, and at times colloquial, wording of the individual quotes that I have kept. The second focus group and three interviews were conducted with Czech-speaking participants in Czech since it is my mother tongue. I recorded and transcribed the focus groups and interviews, kept a research diary and took field notes.

In analysing the data, I used thematic, theory-driven analysis (Braun and Clark 2006, 13) at a latent level, sensitive to queer assemblages and intersectionality. Latent thematic analysis looks beyond individual themes by examining the underlying ideas and assumptions. This approach to data analysis enabled me to develop a theoretically informed methodology 'socially located, positional knowledge that can be deepened and marshaled for theory construction' (Timmermans and Tavory 2012, 172) - attuned to my positionality and reflexivity as a non-Romani queer researcher (Fremlova 2018). It is a way of conducting qualitative research that 'nurtures theory formation without locking it into predefined conceptual boxes' (Tavory and Timmermans 2014, 4) and allows the researcher not to succumb to producing overly descriptive accounts without thinking theoretically about the data. The more I kept engaging with the data, the more it became obvious that the participants' intersectional experiences shaped their fluid identities in a queer, non-normative manner. As part of this twoway, abductive, reiterative process, the data helped me to rethink theory, particularly in terms of the relationship between intersectionality and queer assemblages. This eventually resulted in the decision to read them as one concept: 'queer intersectionalities'. In line with Hall's insistence on the importance of theory, which is 'exactly like a box of tools' (Deleuze, cited in 


\section{Understanding Romani identities}

Scott 2005, 10), a way of opening up questions and understanding rather than an endpoint, and, therefore, necessarily shifting (Grossberg 2007), the theoretical insight, which, allowed me to see empirical phenomena from the social world that I may have otherwise glossed over. At the same time, the empirical account pushed the theorising in new, unexpected directions. Within and across the datasets, there were also frequent references to how the participants' experiences of oppression, and especially antigypsyism, played out in different environments, social settings and material realities.

\section{A queer approach to ethics, the 'field' and ethnography- informed research}

As mentioned in the introduction to this book, I have been involved in Roma-related causes, advocacy and research since the early 2000s and in LGBTIQ Roma activities and research since 2008. This resulted in a particular level of entanglement in a delicate network of social relations with many of the research participants. It was important for me as a researcher to acknowledge that the emotional and affective aspects of these social relations and interaction with the participants were an important factor. Thanks to the realisation that I exercised a 'significant influence on the development of the research and the engagement of the participants' (Curtin and Fossey, 2007, 92-3), I became aware that this could potentially influence the analysis and interpretation of data (Strauss and Corbin, 1998; Creswell 1998; Creswell and Miller 2000). I also came to recognise that it was not just my background and commitment to social justice and equality, but also my emotional attachment to the 'cause' and the participants, which was a driving, motivational force behind the research, giving meaning to the emotional experience. I knew I had a duty to be transparent about that influence by 'bring[ing] [my] preconceived beliefs into the dialogue' (Harry, Sturges and Klingner 2005, 7). I did that by disclosing those aspects that I was aware of to the research participants, along with aspects of my background, including my non-Romani ethnicity. As a result, over the course of the fieldwork, I assumed an overt researcher position that moved between the role of 'participant as observer' and 'observer as participant'. At every stage of the research, I informed the participants of the exact nature and purpose of the research, of what exactly I intended to do and why. This degree of openness and transparency was of vital importance in terms of the research ethics of the researcher-researched relations, particularly with respect to maintaining my pre-existing social relations with the research participants built on trust, as well as building new ones. Queer(y)ing the ethics of conducting social science research that strives to not reify or reinforce existing normativities, social divisions and power relations became 'not merely a management tool for methodology but a methodological tool for the constitution of methods itself' (Detamore 2010, 182). Consequently, 'queer ethics' as method came to sit at the core of the research. It was within 
the context of researcher-researched relations that critically examining ethics, as well as my queer researcher positionality and reflexivity, became constitutive of the methodology.

While researchers are required to adhere to their respective ethical protocols, they still exercise a significant degree of flexibility with respect to how exactly they do ethics in the 'field'. In my previous research with, for and on Roma, I tended to perceive my role as a messenger. I often asked myself many questions pertaining to the social positioning and privilege associated with who gets to emit, carry and receive the message, as well as to the context this transmission takes place in. As Jackman reminds us, 'researchers must recognise the role of the ethnographer as mediator and interpreter of cultural text' $(2010,116)$. Rooke (2010) cites 'the assumed stability and coherence of the ethnographic self'. She recalls the 'considerable criticism ethnography has been subject to due to its epistemological underpinnings and its representational conventions'; and its trajectory from its earlier colonialist, imperialist, ethnocentric versions to postmodern critiques of ethnography. These have led to what is referred to as an interpretative turn: recognising that ethnography is more than mere cultural reportage, relaying the truth or 'reality' of a situation, stressing its role as a cultural construction of both self and the other (Rooke 2010, 25, 27, 28). Ethnography, according to Rooke, is 'methodologically untidy, (...) filled with ontological, epistemological and ethical dilemmas' (Ibid, 27, 28). My use of ethnography-informed research in my methodology entailed the introduction of 'a queer sociological ethnographic perspective that brings together queer theories of sexual subjectivity and an ethnographic approach to researching identity categories and the practices which generate them (...) [to] counter the tendency towards high abstraction and [over] reliance on theory' (Ibid, 26) with a view to illuminating complex and abstract concepts such as queer assemblages.

As a research methodology, this reflexive, contemplative process implies a close link between researcher positionality, ethics and the 'field'. Queer(y) ing ethics and ethnography-informed research allows for the reconceptualisation of the 'field' or 'fieldwork', as well as for the emergence of alternative types of relations between the researcher and the researched. These alternative, non-normative, non-hierarchical, assemblage-like relations help re-orient the researcher's positionality, including through their use of reflexivity. The study of queer assemblages entails a more radical, albeit less clearly defined reorientation and repositioning of researchers in relation to conducting research: ethnographies of queer assemblages have the potential to study sexualities and experiences. They also help to facilitate an understanding of identities as the rhizomatic, intuitive, fluid workings of queer assemblages, characterising links and relationships between constitutive categories of identification that do not assume either an overarching system, structure, groupness, or a common set of roots (Puar $2007,212,215)$. Theoretically and methodologically, this is highly relevant 
to conceptualisations of Romani identities as we have seen so far. The properties and traits of queer assemblages as both a theoretical concept and a methodology inherently benefit queerness, or non-normativity, thanks to the critical challenges they pose to ways in which social norms are deployed and maintained. For example, the binary orthodoxy within Romani Studies research and scholarship, where Roma have tended to constitute the 'researched' while non-Roma have been the 'researchers', can be critically examined and challenged by queer assemblages, as well as by other concepts such as 'critical whiteness' (Roediger 1991; Frankenberg 1993, 1997; Levine-Rasky 2002; Vajda 2015). According to Vajda:

until such time that non-Romani people are willing and able to examine their own racialised identity, even those non-Roma who are committed to dismantling the discrimination experienced by Romani communities will be unable to play a powerful role in this process; whereas those non-Roma who are indifferent, resentful of or actively hostile to Roma could be persuaded to budge from their positions through a deeper understanding of the history of their own identities and how these are formed and performed in the present $(2015,48)$.

The above proposition is very queer in respect of whiteness as a social norm. In practical terms, the proposal means that a critical whiteness researcher does not have to be Roma. It implies, though, their ability to critically examine their own non-Romani, or white privilege and challenge it accordingly at an academic, political and social level. Following the same logic, a queer researcher does not have to be LGBTIQ. However, if they are heterosexual and cisgender, it implies their ability to critically examine their own heteronormative and cisnormative privilege and challenge it accordingly: academically, politically and socially.

\section{Insider/outsider research?}

In my non-normative, queer take on ethnography, the researcherresearched relations were influenced by our common identification and belonging as LGBTIQ. Importantly, the choice of research methodology was informed by the nature of the information that I needed to elicit in order to understand the lived experiences of queer Roma and to inform the theoretical considerations regarding the multifaceted identifications made by queer Roma. Ultimately, my ability to collect the data was contingent upon my positionality and reflexivity as a researcher who is simultaneously on the outside and on the inside.

My own experience of being a researcher who is non-Romani and queer and conducts qualitative research with queer Roma supports the notion that the boundaries separating the insider/outsider status can be somewhat blurred. Rather than conceiving of it as a binary opposition, it is helpful to 
conceptualise the researcher's positionality as a continuum (Breen 2007; Trowler 2011). 'Insider research' - or the study of one's own social, cultural group, community, or society (Naples 2003) into which the researcher is enmeshed and 'imbricated (...) and possesses an a priori intimate knowledge of the community and its members' (Wilkinson and Kitzinger 2013, 251) - has flourished in recent years but spans over four decades (Thorne and Paterson 2000). Insider research has been conducted across the humanities and social sciences, often with members of marginalised and underprivileged groups and communities that are sometimes referred to as 'hard to reach', such as ethnic/'racial' and sexual, gender minorities. Insider researchers may share multiple cultural traits, identities and/or profound experiences with the community they study or perhaps but a sole category of identification (Chavez 2008). For instance, in feminist research, Yost and Chmielewski (2013), who self-identify as bisexual women, have investigated bisexual women, exploring their own 'dual roles [that] blurred the lines between researcher and participant' (242). Insider positionality then refers to 'the aspects of an insider researcher's self or identity which is aligned or shared with participants' (Chavez 2008, 475). Additionally, insider researchers may be confronted with methodological and ethical issues regarding access, bias, objectivity/validity and confidentiality that may be deemed irrelevant to outsider-researchers (Breen 2007; Greene 2014, 3-6). Such a positionality located 'within' may affect the type of data gathered, as well as data analysis and interpretation.

Researchers may occupy a wide range of positions on the insider/outsider spectrum: indigenous-insider, indigenous-outsider, external-insider and external-outsider (Banks 1998). ${ }^{15}$ Nonetheless, as Naples (1996) points out, 'insiderness or outsiderness are not fixed or static positions, rather they are ever-shifting and permeable social locations (...)' (140). While the typology itself may be too prescriptive, restrictive, and at times problematic, it does serve as a useful illustration of the wide range of positions one may occupy on the insider/outsider spectrum. This suggests that neither the insider nor the outsider has 'a monopoly on advantage or objectivity' (Chavez 2008, 476). Or, indeed, as Hellawell (2006) argues, one does not have to be a member in order to have or gain knowledge of the specific community under investigation.

Within the social world, the researcher's positionality vis-à-vis power relations may be seen by some as an essentialist, pre-existing, alwaysalready-produced condition. It may seem like something that existed prior to the researcher starting the investigation, or even before the person becoming a researcher. While this may be true of natural sciences, in the course of conducting social science research, researcher positionality develops and unfolds discursively, in relation to others, especially the researched. Therefore, positionality, which is underpinned by identities reconstituted through relations between people, particularly researcherresearched, places and things, is relational, context dependent, fluidly 
shifting on a spectrum or continuum, where one pole may be seen as representing insiderness and the other outsiderness.

There are undeniable benefits to insider research, as shown by feminist, queer, critical whiteness and other research. This is the case, especially when researching historically misrepresented groups and communities such as Roma. In Romani Studies, a subject field with a long colonialist legacy, Romani researchers have been severely under-represented, leading to epistemic invisibility, or even erasure enacted at times through non-Romani research ethnocentrism. Yet, whether the researcher is a member of the group/community under investigation or not, their identity cannot be regarded as a sole - albeit important - criterion qualifying or disqualifying them as an epistemological insider/outsider to write with legitimacy and authority about all topics related to the social group or groups with whom they share the same identities and identifications.

The researcher's cultural, ethnically-located identity is reflected in their discursive, spectrum-like positionality vis-à-vis power relations. This, in turn, impacts all aspects of the research process, including the interaction and relations with the researched. Using my own experience of being a nonRomani queer researcher conducting research with queer Roma, I demonstrated that despite being an outsider as a non-Roma, it was through my queer, insider and neither-of-the-two positionality that I was able to negotiate the relations between myself as the researcher and the participants as the researched. This means that the social locations of insiderness/outsiderness do not exist as a binary opposition, nor are they static, but evershifting, complementary and permeable. Reflexivity then entails an ability to critically examine the nature of these shifting ethical terrains as part of an ongoing research process, whereby the researcher tries to understand themselves, their researcher identity, and the researcher-researched relations by viewing their work with a contemplative eye.

\section{Critical reflections on non-Romani researcher privilege}

As a non-Romani researcher, I have worked on Roma-related issues for two decades. On a personal level, I am an individual with long-term emotional attachments to many Roma. This includes queer Roma, who have been either colleagues, acquaintances, close or good friends of mine. When starting to conduct this research, my personal and professional backgrounds came together. I was aware of beginning to walk a thin line separating the notion of being an outsider as a non-Roma and an insider as a lesbian. At the same time, as a researcher, I was neither of the two. I had to critically examine how my own privilege played out in different contexts. In the UK, I am perceived as a middle-class, white, Eastern European female researcher whose white privilege is perhaps not so obvious. One of the reasons may be my migrant status of an EU citizen made uncertain by the implications of Brexit or the fact that I am not a native speaker of English. 
However, my position in relation to privilege changes when I am in my home country, the Czech Republic, where a substantial part of the fieldwork took place. There, I am perceived as a middle-class, non-Romani Czech female researcher working in the UK who passes as straight. Despite the disadvantaging factors of being a woman who is openly lesbian, I still exercise much privilege due to my social status and my white, non-Romani origin. This inadvertently impacts on my researcher positionality.

Ultimately, my being queer in my everyday personal life does not automatically qualify me to speak on all matters related to LGBTIQ issues. By extension, this means that in the academic world, my queer identity cannot be regarded as a pass, qualifying me as a researcher to be an 'epistemological insider' (Brubaker 2017) who, by default, can write with legitimacy and authority about all LGBTIQ-related topics. I also had to acknowledge that for me as a queer woman, a non-Roma and simultaneously a researcher, involvement in the research was not the same as for the queer Roma research participants. I was a non-Romani researcher who was asking queer Roma to share their lived experiences with me for the purposes of my doctoral research. This was a key factor in a situation where a large portion of academic research on Roma has been done by non-Roma. Consequently, there may have been a perception that all non-Romani researchers were advancing their careers on the back of Roma. Additionally, at times, the impact of some research on Roma has been detrimental to Romani communities: for example, the aforementioned research by Jakoubek (2004) or Jakoubek and Poduška (2003) within the very specific Czech and Slovak contexts. These considerations became critical aspects of my positionality and reflexivity as a non-Romani researcher. Still, the notion that I am openly queer, non-Roma, acknowledging openly that Romani identity is an identity that I do not and cannot claim, came to represent a fundamental link between me as a researcher and the queer Roma research participants.

This thin line separating epistemological outsiderism and insiderism enabled me to work towards becoming closer to some of the queer Roma. There were a small number of research participants who found my position as a non-Roma problematic. This was mainly due to perceptions and assumptions about my origin made as a result of my alignment with Romarelated causes and my involvement in the LGBTIQ Roma movement. I have always been open about being non-Roma heritage, have never been elusive about it, never pretended to be Roma or been taken for Roma. However, none of the written information sent to potential participants in the initial stages of the research contained an explicit reference to my non-Romani origin. Consequently, unless the research participants had known me before, they had no way of knowing whether I was non-Roma or Roma. Upon eventually meeting me for the first time in person, a few were unpleasantly surprised when I said I was non-Roma. This realisation led me to appreciate that indeed, my non-Romani positionality as a researcher was an issue. 
One of the research participants illuminated my understanding of some of the ways in which assumptions about my ethnicity and the eventual realisation I was not Roma. They helped me to see that there was a link between my non-Romani identity and some of the participants' prior experiences of antigypsyism, which was key to the subsequent interaction. The following example will illustrate what I mean. I planned to hold a focus group with four self-identified queer Roma. I had identified and contacted them several weeks before the event where the focus group was to take place. When I approached the potential participants on the day of the focus group, I reiterated that participation was voluntary. One of them started asking me about the guiding questions and why I was asking specifically about Roma. I explained that I was asking only those people who selfidentified as Roma and LGBTIQ. The person said they felt that the questions were formulated as if to suggest the sexuality of Roma was different. I explained that it was not my intention and stepped away for a bit. When I came back, it was clear that the participants were still discussing the guiding questions but did not want to take part in the research. I respected their decision. About two months later, I received the following message from one of them, along with permission to use it:

I just wanted to tell you that I was thinking a lot when I wasn't sure to do the interview or not. I am sorry. It's not very easy to trust 'white' people. Too often, we get abused from them or I wasn't sure what happens exactly with the information you get. It was not personal. And I still thinking of that. I don't understand, I felt very bad. It's not easy for us. This paranoia is very deep with white people (anonymous).

My ethnic identity was the element linking the queer Roma's reluctance and suspicion with lived experiences of anti-Romani racist abuse from nonRoma. Looking back, I can appreciate that the responses were understandable, especially when taking into account their lived experiences of antigypsyism which I discuss in Chapter Three. As someone who has experienced homophobia first-hand, I can also conceive of a situation where I might make the assumption that someone co-organising an LGBTIQthemed event is LGBTIQ. Consequently, my interaction with them might have been impacted upon finding out that they are straight. Though it is not possible to prevent these situations from happening, for all of the above reasons, in my subsequent postdoctoral research, I have been including a reference to my non-Romani identity in initial communication with new research participants to avoid any potential misunderstanding.

A researcher well-versed in queer theory and critical whiteness has an opportunity to avoid reproducing social paradigms and narratives by espousing a critical approach to conducting social science research. This may entail the researcher's sensitivity to, for example, Roma participants' experiences of antigypsyism or LGBTIQ participants' experiences of 
homophobia or transphobia, which are likely to play a role in subsequent interactions with the researcher. This, in turn, enables the researcher to critically examine their privilege by being reflexive and reflective of their positionality within social normativities. By pondering the role their positionality plays in the research process, they can thus help establish research processes and protocols that provide rigorous academic insight, as well as understand, endorse and promote the principles of social justice.

\section{Notes}

1 Sex is not a binary (Fausto-Sterling 2018, 2019). '[A]ccording to Rubin, human societies begin with sexed bodies and produce gender. According to Butler, human societies begin with gender and impose it on human bodies as sex' (Halperin 2014, 452).

2 Thinking about my own sense of identity, I realize that it has always depended on the fact of being a migrant, on the difference from the rest of you... the colonized subject is always "somewhere else": doubly marginalized, displaced, always other than where he or she is, or is able to speak from' (Hall [1987] 1996c, pp. 114-15, original emphasis). This displacement, dislocation from the 'centre', from the 'norm' and the resulting desire to critically examine and to challenge essentialised notions of identity, to write 'the margins into the centre, the outside into the inside...' (quoted in Jaggi 2000), to find a space for the 'others' in the national imaginary were key to Hall's theorising of identities and difference.

3 Here, Okely (1983) refers to Edward Said's Orientalism, published in 1978. Orientalism is a practice of making 'the other'; a 'set of mind' that creates 'social distinctions' (Buchowski 2006, 466). As an analytic, it provides one with a looking glass that makes visible the often dichotomic ways of dividing past and present societies into 'us' and 'them'. This, in turn, produces social difference and hierarchical power structures and relations.

4 Other scholars such as Willems (1997); Lemon (2000); McGarry (2010, 2017); van Baar (2010, 2014), Brooks (2015) have made similar observations.

5 McGarry (2017) refers to antigypsyism as Romaphobia: 'Romaphobia places an emphasis on how non-Roma construct Roma as a particular identity group, distinct from the majority. (...) Romaphobia is a complex of ethnic discrimination and prejudicial attitudes that target groups and individuals based on assumptions of inferiority. (...). These generalizations are harmful because they reduce all Roma to negative attributes and characteristics simply because they are Roma. Instead of 'that Rom is a criminal', we hear 'all Roma are criminals'. The jump from the individual to the collective is achieved through the negative ascription of group identity' $(2017,95)$.

6 The European Roma Institute for Arts and Culture (ERIAC) is an institution created in joint partnership between the Council of Europe and the Open Society Foundations to strategically and sensitively convey and represent heterogeneous issues of Romani culture, identity and politics. https://eriac.org

7 Internal divisions within intersectionality scholarship with respect to the additive and constitutive approaches have resulted in differences of opinion as to how many social divisions there are, who defines them, and whether or not they should be included into intersectional analysis. The debates have also touched upon intersectionality's inability to consider 'the spaces in-between' (YuvalDavis 2006, 202). Butler (1990) apparently "mocks the "etc." (...) [as she] sees it 
as an embarrassed admission of a "sign of exhaustion as well as of the illimitable process of signification itself"' (Yuval-Davis 2006, 202). Yet, Yuval-Davis appeals to defences of intersectionality by Fraser (1997) and Knapp (1999), concluding that critique similar to Butler's is 'valid only within the discourse of identity politics where there is a correspondence between positionings and social groupings [as] [t] his is the way additive/fragmentation models of social divisions operate' $(2006,202)$.

8 A paraphrase of the title of Kóczé's paper Missing Intersectionality: Racel Ethnicity, Gender, and Class in Current Research and Policies on Romani Women in Europe (2009), and Jovanovic and Daróczi's paper Still Missing Intersectionality: The relevance of feminist methodologies in the struggle for the rights of Roma (2015).

9 "Queer" was the word commonly used in Britain, and to a lesser extent in other English-speaking countries, until the almost universal adoption of "gay" after emergence of gay liberation in 1969, to describe both homosexuality as a condition and homosexual people themselves. It had a long lineage, used across class and cultures, though more generally among men. By the 1950s and 1960s to say "I am queer" was to tell of who and what you were, and how you positioned yourself in relation to the dominant, "normal" society. Queer was a generalized description of otherness and an emerging identity. It signaled the internalization of a particular set of meanings about homosexuality. Like common alternative words such as "bent," it signaled the general perception of same-sex desire as something eccentric, strange, abnormal, and perverse. Many of the gay liberation generation gladly abandoned use of the term after 1970 because it was seen as a signifier pression, and certainly none of the new generation of writers exploring sexuality in the 1970s or 1980s would ever have described what they were as queer anything. That spoke to a different era. So the retrospective labeling of the historical work that was beginning in the 1970s as "queer" is at the very least anachronistic.'

'The second definition of queer, referring to the rise of new forms of lesbian, gay, bisexual, and transgender militancy in the late 1980s (especially in the Un States but also elsewhere), signals a remarkable return of the repressed as part of new manifestations of grassroots activism. The immediate stimulus was anger among young activists at the ways in which the AIDS crisis had been neglected by conservative administrations in the United States and elsewhere, but beyond this was a yet more radical challenge to what was seen as the assimilationist and ethnicizing politics of the gay movement as it had consolidated in the 1980s. Queer activists sought "a more thorough resistance to regimes of the normal", going beyond the limited forms of toleration that, they claimed, was the limit of the mainstream gay movement's ambition. The rhetoric reflected a deep sense of political and cultural alienation at the direction of gay politics, which led to a reappropriation of the stigmatizing term "queer" as a confrontational gesture. What was strikingly different from earlier uses of queer, however, was the reversal of the term's meanings. It had shifted from being a negative, individualizing description to a signifier of collective agency and militancy, as represented by Queer Nation and Act Up! in the United States and Outrage! in Britain, both countries that had seen sharp moves toward conservative moral politics in the 1980s. The new queer politics was by intention at least a politics of the streets, but it also fed into a wider cultural politics, notably in a new queer cinema. Its implications for the practice of history were, perhaps, more ambiguous.'

'On the surface, at least, there are close affinities between this revived activism and the new theoretical directions indicated by the third definition of 
queer. Both radically questioned the fixity and arbitrariness of lesbian and gay identities and endorsed a politics of subversion, dissidence, and transgression. They pointed, however, in different directions. Queer theory was a new language in the academy rather than on the streets.' (Weeks 2012, 525-6)

10 'Queer' has a number of important dimensions: temporality, turning queer into action, a verb (Butler 1993, 223); spatiality in terms of 'where queer plays out and ways to makes make it an active proposition so that it re-creates experimental space' (Probyn 1996, 14); as well as movement (Kosofsky Sedgwick 1993): 'The word 'queer' itself means across -it comes from the Indo-European root - twerk, which also yields the German quer, Latin torquere (to twist), English anthwart (1993, xii).'

11 As Weeks (2012) puts it: 'The often-unacknowledged lineage of queer theory lies in social constructionism, in poststructuralist theory, in the of Jacques Derrida, and in the analyses of discourse and power of Michel Foucault. But whereas the earlier works had been, as we shall see, largely historical and sociological in focus, queer theory was originally much more closely aligned to literary theory and philosophy, although its influence soon spread rapidly back, if sometimes uneasily, into sociology, as well as into critical theory, cultural studies, postcolonial and critical race studies, human geography, and even psychology and biology' (Weeks 2012, 526).

12 'Whatever the continuing restrictions of post-gay life, in most Western countries they are accompanied by growing openness, toleration, and opportunity. Queer theorists often attack the teleological tendencies of early gay history, allegedly written as if there were an inevitable pathway from oppression to light, a sort of Whig interpretation of queer history. Here instead is a sort of inverted teleology that seeks escape from the neat categories of the present in a more indeterminate past where queans and respectable queers and young working-class lads cruised the same streets and public lavatories, and people were able to evade easy categorization. In the process there is a danger that the reality of power, domination, oppression - and resistance - gets lost' (Weeks 2012, 527).

13 Romani Studies and the Roma rights movement have followed a similar trajectory as scholarship and activism has been shaped by Roma's historic and modern experiences of exclusion, marginalisation, discrimination, persecution and annihilation. This has had implications for essentialised conceptualisations of Romani identity, which have been challenged by social constructionists.

14 In the concluding chapter, I also refer to some insights from my subsequent postdoctoral research on visual self-representations.

15 According to Banks, indigenous-insider possesses the values, perspectives, behaviours, beliefs, and knowledge of their respective community; indigenousoutsider is perceived by the community as an outsider due to having assimilated into mainstream/outsider culture; external-insider is socialized into mainstream/ outsider culture, rejecting the cultural values of their community; and externaloutsider is a visitor, interested in learning more about the group, they are not a part of as they are socialized into a community different from the one they study and have only a partial understanding and appreciation for its cultural values. 


\section{2 'Perverse' and 'deviant' queer sexualities, genders, ethnicities and 'racialities'}

This chapter explores what are, within the European context, often considered two of the most stigmatised and pathologised collective social, ethnic/'racial', sexual and gender identities - Roma, queer and their intersections. It considers the construction of gendered and sexualised, or sexed, ethnicities/'racialities', as well as the construction of ethnicised and 'racialised', or 'raced', sexual and gender identities. Seeing identity formation as a process whereby identity is constantly reshaped and reconstructed in and across social processes and contexts, the chapter also discusses the prism of negative social valuation of Romani identity that has come to be seen as pathological, deviant, perverse and abject. Just like non-normative sexualities and gender identities are often closets for queer people, Romani identity has become a kind of ethnic/'racial' closet due to being a negative, socially stigmatising marker for many Roma.

\section{Ethnicisation and 'racialisation' of Roma}

As we have seen thus far, historically, antigypsyism has been at the core of mistreatment of Roma by non-Roma. Since Roma arrived in Constantinople between the 9th and 11th centuries and in other parts of Europe in the 14th and 15th centuries, non-Romani individuals, communities and societies have largely ostracised and marginalised Roma. This has been reflected in the names non-Roma gave to Roma. Throughout Europe's history, dominant populations have called Roma various names, often based on the lack of information majority society had about Roma and, at times, on direct hostility towards Roma. The names included, among others, the term 'Tsigan' - and regional variants of Tsingan, Cingan, Zingar, Cigany, Cikan, Cigan, Zigeuner - originating from the Byzantine Greek 'Atzinganoi/Atsigános' to refer to a group who was most likely Roma and who appeared on the mountain of Athos around 1068 (Horváthová 2002, 11). These exonyms included the term 'Gypsy', too, which is rarely spelt as 'Gipsy' (along with the French variant 'Gitan' or the Spanish 'Gitano'), deriving from the word 'Egyptian' (Hancock 2002, xxi). Scholars believe that this was because due to the darker complexion, Roma

DOI: $10.4324 / 9780367822699-2$ 
were erroneously seen as foreigners, having come from Egypt (Hancock 2002, Lee 2013). Alternatively, the term 'Gypsy' was used to refer to an area called Little Egypt, or Egypt Minor in the Venetian colony of Modon (present-day Methoni) in the Peloponnese peninsula where some Roma were settled for substantial periods of time (Fraser 1992, 50; Clébert 1961, 20; Liégeois 1986, 28-29; Horváthová 2002; Matras 2014). It would take another five centuries for Roma to organise, mobilise at a transnational level and adopt the endonym 'Roma', sometimes spelt as Rroma, ${ }^{1}$ at the first World Romani Congress in London in 1971 for the purposes of selfdetermination and recognition.

From the outset, the term 'Gypsy', which was imposed on Roma by the respective majority societies, had negative connotations. Roma were also called Heidens (heathens, pagans) in Dutch. The misperception and the attendant mislabelling of Roma went hand in hand with anti-Romani measures and laws introduced and maintained by the Church, the state and trade guilds in the 16th, 17th, 18th and 19th centuries. As we have seen in the introduction, these measures stigmatised Roma even further as vagrants, parasites, unwanted outcasts, outlaws and criminals. Complementing the mislabelling and mistreatment of Roma by non-Roma, and the ensuing wholesale stereotypical vilifying and stigmatising conceptualisations of Roma as an ethnic group was the romanticisation and objectification of Roma. Following the publication of Grellman's thesis in 1783 and the foundation in 1888 of the Gypsy Lore Society, academic discussions were underway about the Indian origin of Roma based on evidence that the Romani language is of the Indo-Aryan family of languages. In the 19th century, romanticised literary (for example, Maupassant, Hugo, Mácha, Borrow, Arnold, Dickens, Eliot, the Brontë sisters), visual representations (e.g. Van Gogh's 1888 Encampment of Gypsies with Caravans near Arles; Morland; Nonell; Sully; Harvey; Modigliani) and musical renditions of 'Gypsies' (for instance, Dvořák, Janáček, Verdi, Liszt, Bartók, Bizet, Strauss) constructed an image of Roma as 'bon sauvage' that has persisted well into the 20th and 21st centuries. Combined with the different, externally imposed exonyms, these representations of Roma (McGarry 2014), created by non-Roma, have incorrectly endorsed a wholesale association of Roma with both positive and negative stereotypes.

Non-Roma have associated Roma with romanticising images of nomadism, unchained freedom, passion, voluptuousness and exoticism (Mayall 2004, 1; Oprea 2004, 1), 'a welcome anachronism in modern society' (Mayall 2004, 2) on the one hand; and, on the other, with more sinister ones, portraying Roma as criminals, thieves, vermin, undesirable, anti/asocial, work-shy, foreign elements (Liégeois 1983; Hancock 2002; Horváthová 2002; Baloun 2019). As Cortés (2021) puts it,

antigypsyist language interweaves, in viscous interaction, moral degradation, racial minority and criminal allusion. The Gypsy [...] would be 
eternally bad $[\ldots]$ by nature, and therefore immutably guilty: such is the racist framework from which the archetype of the 'Gypsy' springs. Of course, antigypsyism endorses exceptions, and the dominant society keeps celebrating them. But after compliment to every exception, there is that (bad) shadow in the background: how much is this subject worth, who, despite being a Gypsy, is good, and therefore innocent, perhaps against their nature and culture. (Cortés 2021)

These representations of Roma have engendered homogenising stereotypes portraying Roma as a genetically bound, deviant group. In the 20th century, nation states pathologised Roma, consistently excluding Roma from equal citizenship, deliberately maintaining the negative ascription of Roma identity and actively constructing Roma as a deviant 'other', 'risky people' (van Baar and Vermeersch 2017) that threaten the fabric of the nation (McGarry 2017, 245); and as a separate, 'inferior', 'deviant' race (Balibar 2009, x; Rostas 2019). In the most recent history, a different image of Roma has been created, whereby Roma have been increasingly described as 'unproductive' and 'useless' citizens, blamed for and responsible for their own poverty (McGarry 2017, 81), who deliberately confine themselves to Roma ghettos and settlements due to their 'unwillingness to integrate' (Vincze 2013, 2014); a 'problem' associated with negative social phenomena (Vermeersch 2006) and with European societies' ills such as mass unemployment, poverty, ill-health, discrimination, social exclusion and, more recently, the spread of COVID-19. Thus is created a 'backward' (Schneeweiss 2018; Rostas 2019), 'uncivilised race' (Vincze 2014, 74); 'an inferior class of non-humans, who threaten the formation of a desired territory of "our own" inhabited by the desired community (by "us") composed of people who deserve belonging to it' (Vincze 2013, 239). This means that throughout history, the assumed difference that non-Roma have perceived in and attributed to Roma, whom they have defined as 'Gypsies', has always been ethnicised and, effectively, 'racialised'.

In Chapter One, I discussed the theoretical underpinnings of Romani identity. I touched upon the nexus of ethnicity and 'race'. The chapter demonstrated that Romani Studies scholarship on Roma has often viewed Roma through the lens of ethnicity/'race': this has resulted in the discipline getting caught in the trap of cultural essentialism by ethnicising and 'racialising' Roma. The chapter also signalled new approaches to conceptualising Romani identities in Romani Studies: hybridity, superdiversity, critical race theory, intersectionality and, to a limited extent, queer theory. We have seen that ethnicity/'race' is a socially constructed category, a discursive, contextual, relational and at times material unit of meaning that is constantly reconstructed and redefined in different periods of time, in different regional, political, socio-economic and cultural contexts. It is grounded in the discourse of nationalism, racism - and, in the case of Roma, in the specific form of racism targeting Roma, antigypsyism - 
and colonialism. It is operationalised through 'racial' difference where 'race' has become a category of difference that refers to assumed or perceived differences between people (Balibar and Wallerstein 1991, 48-49). This dynamic entails and legitimises the asymmetrical and unequal power relations between the coloniser and the colonised, insiders and outsiders, the norm(al) and the abnormal, or the 'other' that deviates from that norm. Ethnicisation and 'racialisation' are discursive practices and processes whereby immutable boundaries that differentiate between $u s$ and them are constructed, which are then used to fix and naturalise hierarchical, asymmetrical hegemonic power relations between them (Anthias and YuvalDavis 1992; Rattansi 2007; Goldberg 2009; Yuval-Davis et al. 2017a). What is key to the process of ethnicisation/'racialisation' is that these boundaries are constructed around the presence of ethnic/'racial' boundaries rather than around the existence of an 'essence' (Barth [1969] 1998). As part of this dynamic, it can be any one physical or social feature, or signifier, for example, skin complexion, the shape of the skull, accent, social status, lifestyle etc, which are then called upon to construct these boundaries between groups of people.

'Race' is a material semiotic and topological object that is 'enacted in situated practices as a set of relations'; although the concept of 'race' often invokes the notion of genetic inheritance, 'race' can neither be reduced to the body or biology, nor to ideology (M'charek 2013; M'charek et al. 2014, 468; Plájás et al. 2019). While racial science was deeply embedded within the process of building modern nation states (Schmidt 2020), 'race' was integral to racial theories and eugenics in the 19th and 20th centuries (Turda 2014; Saini 2019). Additionally, 'racial anthropology ultimately provided intellectual justification for policies such as forced sterilization, loss of civic rights and genocide' (Hutton 2010, 153) for the purposes of the Nazi race theory and ideology in the 20th century. 'Race' is internal to all social processes: therefore, it is important to examine 'race' and ethnicity separately, too.

The term 'race', which started to be used in English during the early 20th century, became a taboo in Europe following the atrocities associated with the Second World War and the Holocaust. Roma were subjected to essentialist notions of 'race' under the rule of Nazis and their national collaborators: for example, Czech guards serving in the Roma, or so-called Gypsy camps at Lety and Hodonín near Kunštát under the Nazi Protectorate of Bohemia and Moravia, where Roma were gathered before they were transported to Auschwitz. During the Holocaust, an estimated 220,000 (Milton 1991) to 1,500,000 Roma (Hancock 2005; see also Kenrick and Puxon 2009; Stauber and Vago 2007) were exterminated as an 'inferior race' alongside millions of Jews, gays, the mentally and physically challenged, political prisoners and others considered 'racially unnatural' (Hutton 2005) and anti/asocial. In the period preceding the Holocaust, the Nazis took blood samples from Roma, measured their facial characteristics 
(N.B. a reconstruction can be seen in the Museum of Romani Culture, Brno, Czech Republic) and 'racially' cleansed or 'de-loused' towns and villages.

In spite of - or perhaps because of - this historical experience of 'race', across Central and Eastern Europe, and post-communist Europe in particular, 'race' continues to be regarded as belonging exclusively to Western discourses of coloniality and imperialism. Indeed, many Eastern European nations are eager to exclude themselves from them. Although 'race' and racism are seemingly non-existent, in reality, they have survived and are embedded in many Eastern European societies, thus remaining 'perhaps the most poorly articulated factor in the relationship between official ideologies and people's fantasies during and since communism' (Imre 2005, 83). Instead of seeing post-colonialism and post-socialism as intertwined phenomena, some scholars still distinguish between Western Europe - which is allegedly marked by colonialism and racism - and Eastern Europe, deemed to be marked predominantly by nationalism, socialism and ethnic violence. Simultaneously, while 'race' is used to prevent the Holocaust from being repeated (Banton 2012), it is also denied (Lentin 2005, 2011, 2015). Lentin describes the 'race idea' as follows:

The race idea, which invokes theories of genetic inherency as legitimatory props in situations of domination predicated on either the annihilation of the population conjured as racially other/inferior or the extraction of their servitude (or, later, their labour) becomes dislodged from discussions of blood or skin or hair or bone. It pertains even when those visible differences are actively denied as significant $(2015,1402)$.

According to Lentin, 'race' is confined to the moment of the Holocaust and is extended to other extreme instances of racial rule such as Apartheid and Jim Crow whilst it is considered debatable in relation to other, less iconic, instances of racial governmentality - thus allowing it to be foreclosed. This approach leads to the narrowing of the problem of 'race' and racism to the history of quite a specific stream of racial thinking, the Nazi racial ideology, at the expense of other, less visible, though perhaps equally salient ways of racial thinking, including those of Czech and Slovak provenance (Herza 2019, 2020). Additionally, to avoid 'race', societies and governments often refer to the so-called Roma question as a matter of culture: a biopower based on an assignment to 'race' (Fassin et al. 2014). Many aspects of this racial thinking are related to the 'racialisation' and the racist treatment of Roma throughout Europe, which I outlined briefly in the introduction. The continued existence of 'race' and race categories in census data, research and scientific literatures (Lipphardt 2012); the recent revival and resurgence of the race science (Saini 2019) along with the proliferation of scholars openly advocating for it; the rise of racism, racially motivated hate crime, including hate speech, alongside other manifestations of 
intolerance such as xenophobia, homophobia; and a growing emphasis on and foregrounding of the essentialist notions of biological givenness and the natural fuelled by populists shows that race still matters (Lentin 2020); or that it has never stopped to matter.

\section{'Stigmatised' and 'deviant' identities: Sexual and ethnic/ 'racial' difference}

Taking into consideration the historical experience of Roma being enslaved from the 14th century until 1855 in Moldavia and 1856 in Wallachia and the racial theories and eugenics of the 19th and 20th centuries, from which the Nazi ideology stemmed and developed, it is worth remembering that before and during the Holocaust, Roma, Jews, Slavs, LGBTIQ people including queer Jews (Shneer and Aviv 2002; Hájková 2013, 2020) and queer Roma, as well as other minority groups were persecuted due to the so-called pathology, deviance and deficiency of their identities. They were targeted for extermination because of who they were: that is to say, due to their assumed ethnic/'racial' and sexual difference. Since there appears to be no detailed account of the nexus of social arrangements, processes and discursive practices, through which modern Romani and LGBTIQ - or queer identities have emerged and been constituted by each other, it may be of use to consider how sexual and 'racial' difference were mutually constituted in the case of the Jewish sexual difference. There has been a long-standing notion that Jews embody non-normative sexual and gender categories, attributing softness to Jewish men, and manliness to Jewish women - or female sexual inverts - who were paradoxically seen as being at once too much and not enough of a woman. Boyarin et al. (2003) illustrate the Jewish-queer proximity, which is highly reminiscent of the Romani-queer proximity:

[T] he circuit Jew-queer is not only theoretical but has had - and still has - profound implications for the ways in which Jewish and queer bodies are lived (...) and have died. (...) While there are no simple equations between Jewish and queer identities, Jewishness and queerness yet utilise and are bound up with one another in particularly resonant way. This crossover also extends to modern discourses of antisemitism and homophobia, with stereotypes of the Jew frequently underwriting pop cultural and scientific notions of the homosexual. $(2003,1)$

The rationalisation of Jewish 'racial' difference, which came to be deeply embedded within mainstream non-Jewish societies, was all the more powerful for being drawn through stereotypes of an assumed sexual difference. Popular and scientific literature featured claims insinuating the existence of Jewish male's sexual difference from other men. Modern Jewishness became as much a category of gender as of 'race': it is the Jewish male's difference, 
deviance or divergence from normal masculinity - that is, an inability to embody and perform proper masculinity - that was the indelible evidence of the 'racial' difference of Jews as a group from non-Jews (Boyarin et al. 2003). In a manner that is highly resonant with Romani ethnicity being sexed and Romani sexuality being 'raced' and perceived as deviant, abject, perverse, or pathological, Boyarin et al. go on to argue the following:

Because homosexuality was initially characterised as a matter of sexual, or gender, inversion (a characterisation that understood the 'bad' object choice as effect not cause), the Jew's gender trouble was seen to bear more than a family resemblance to the homosexual's sexual inversion. Significantly this crossing went both ways, for a cluster of nineteenth century stereotypes of the Jew came to circle around the homosexual as well. (...) [I]t is not just that the modern Jew was being secularised and homosexualised - the 'homosexual' whom scientis sexualis and its various practitioners were so busily identifying and diagnosing, was also being 'raced'. (2003, 3-4)

As we have seen thus far, historically, Roma, Romani ethnicity and Romani sexuality have been marked as fundamentally different and distinct from the non-Romani norm; and stigmatised, pathologised and marked out in ways similar to how Jews, Jewishness and Jewish sexuality have been marked out and misrepresented. These misrepresentations are also reminiscent of how discourses on Black sexuality are used to articulate theories of 'racial' difference (Ferguson 2004); and of white Americans' stereotypical attitudes to African American sexuality. This includes, for example, the misguided notion that African Americans hold 'more permissive attitudes to extramarital affairs', 'have a more naturalistic attitude towards human sexuality' or 'the myth of Black sexual superiority' (Staples 1978, 1986, 2006). Black sexuality has been historically misrepresented in the popular imagination and in scientific literature as 'bestial', 'animalistic', and subject to damaging, often contradictory stereotypes of the (enslaved) Black man being 'super-potent'; a 'rapist, obsessed with having sex with white women', yet 'more feminine than white men'; and stereotypes of the (enslaved) Black woman 'wanting to sleep with and responding enthusiastically to all sexual advancers' (Samuels 1999, 43). As Hancock (2008) observes, around the time of the publication of Grellmann's 1783 book about Roma, newly emergent sciences were focusing on differences amongst non-Whites by identifying social and moral distinctions between groups, their essential markers of difference and grounding them in nature and science. 'Race' and sexuality came to be seen as measurable, permanent, categorised and medicalised - hence rationalised - differences; they were applied across various non-White ethnicities and incorporated into emerging discourses on 'race' and sexuality. Describing the perceived sexual difference in Romani men, Hancock (2008) writes that Romani male who 
had been enslaved in the Balkans were seen as a threat to white womanhood (2008, 184). As regards Romani female sexuality, Charnon-Deutsch argues that the danger of the Romani woman, who is a threat to the family, social system, the nation, and sexuality itself since she can 'castrate' men, and her 'racial' difference were represented as reduplicating the seductive danger of her sexual difference (2004, 240-241). Codur (2011), who writes about artistic representations of Romani female sexuality during Romanticism, remarks that 'Gypsy women have continuously aroused all kinds of fantasies revolving around the repressed desired of transgression of sexual norms' $(2011,6)$ while Okely (1983) claims that 'in England, a stereotype of the Spanish Gypsy is often thought to be typical, and is often depicted in popular paintings: a black-haired girl in décolletage, with flounced skirts and swaggering walk, hand on hip... sexually available and promiscuous in her affections' $(1983,201)$. Thus, the ethnic/'racial' difference that non-Roma have attributed to Roma has also been gendered, as well as sexed/sexualised and aged.

For instance, in interwar Czechoslovakia, as well as Slovakia and Transcarpathian Ruthenia, between 1927 and 1938, as part of resolving the so-called Gypsy question through assimilation, Romani children taken from Roma families were identified by authorities as vagrant and streamed into Gypsy schools in accordance with the Czechoslovak law on Wandering Gypsies adopted in 1927 (Baloun 2018, 175-77; Baloun 2019). This practice has continued well in the second half of the 20th century and the 21st century, with the European Court of Human Rights issuing the ground-breaking judgement in the matter D.H. and others versus the Czech Republic in 2007. The ruling found the disproportionate assignment of Romani children to special schools without an objective and reasonable justification amounted to unlawful indirect discrimination in violation of the European Convention on Human Rights. In its judgement, the Court required the Czech Republic to adopt measures to end discrimination against Roma in the education system. In September 2014, the European Commission initiated infringement proceedings against the Czech Republic for the government's failure to implement the judgement. ${ }^{2}$ In what Henschel (2019) describes as 'a striking example of the diffusion of antiRoma discourses into perceptions of psycho-social deviance and into the performance of state child care in socialist Czechoslovakia', the 1950s and 1960s psycho-medical discourse of defectology was heavily influenced by centuries-long racist prejudice towards the 'true nomadic Gypsy'. Romani children's so-called defective condition and deviant behaviour were framed as typical of the Gypsy environment whilst the ethnic/'racial' attribute 'Gypsy' served as an explanation of the mental and behavioural abnormalities caused by flawed education and care, considered typical for Roma. Additionally, gender and ethnicity/'race' were used to help establish the diagnosis and affected the treatment of behavioural difficulties: defectologists and other practitioners considered sexually deprived girls and 
Gypsy children as the 'embodiment of deviance'. The long-established racist views regarding Roma were transformed during socialism whilst adding increased importance to the notions of taming the 'savage Gypsies'; and of the body of the nation allegedly being threatened by the unwilling and unfit Gypsy population, whose cultural backwardness and high birth rate were believed to be linked to the genetic degradation of Roma and the country's population (Henschel 2019, 1, 2, 8, 9). In Czechoslovakia, the alleged high birth rate of Roma was subject of eugenic regulation - the coercive sterilisation of Romani women - by the communist state. Cases of coercive sterilisation of Romani women were first reported in 1978 by the dissident group Charter 77; the last known cases are from the early 2000s. Yet it took another 27 years for the Czech government to officially admit this. In his report published in 2005, that is almost two decades after the fall of Communism, the Czech Republic's public defender of rights acknowledged that the transition to democracy did not see an end to these practices; in fact, complaints were still being made. In 2009, the Czech government issued an official statement of apology; In 2009, the Czech government issued an official statement of apology and in August 2021, it finally adopted a law to compensate Romani women who had been sterilised coercively and without informed consent. ${ }^{3}$

Sexuality, gender identity and ethnicity/'race' are distinct and separate categories of identification: 'there are clearly good historical reasons for keeping "race" and "sexuality" and "sexual difference" as separate analytic spheres' (Butler 1993, 123). As such, these identities entail distinct histories, materialities and experiences, particularly when it comes to oppression. The distinct processes of oppression, exclusion and stigmatisation based on marked essentialist ethnic/'racial', sexual and gender difference may have some parallels; yet, the identities, lived experiences and historical legacies cannot be equated. For example, Haslanger's (2012) analysis focuses on gender and 'race' in relation to group-based oppression common to groups that have formed due to oppression. She examines how 'social norms, symbols, identities and such are gendered or raced' $(2012,7)$. In doing so, she interrogates patterns of social relations that constitute women, including trans women who are 'presumed to have female biological features observed or imagined, presumed to be evidence of a female's biological role in reproduction' (Haslanger 2012, 230) as gendered and subordinate to men. Haslanger also investigates social relations that constitute people of colour who are 'socially positioned as subordinate [to Whites] along some dimension (economic, political, legal, social, etc.) and are "marked" as a target for this treatment by observed or imagined bodily features presumed to be evidence of ancestral links to a certain geographical region' (2012, 236) as 'raced', or 'racialised'. At a physical, bodily level,

what can be seen, what qualifies as a visible marking, is a matter of being able to read a marked body in relation to unmarked bodies, 
where unmarked bodies constitute the currency of normative whiteness. (Butler 1993, 125)

In this binary opposition, the former, the marked is 'thus reduced to the function of an accident as opposed to the essentiality of the latter' (Laclau 1990, 33). To echo Hall's words, both are 'constructed through, not outside difference, (...) through the relation to the Other, the relation to what it is not, to precisely what it lacks' $(1996,4-5)$. Queer sexual and gender identities and Romani ethnic/'racial' identities can thus be understood as marked terms in contrast to the unmarked normative terms 'heterosexual', 'cisgender' and 'non-Roma/white'. Effectively, this means that oppression on the grounds of ethnic/'racial', sexual, gender or any other identity is always based on the binary opposition between the unmarked norm and the marked deviation.

In Chapter One, we saw that heterosexuality, and, by extension, whiteness and cisgender identities, are dominant, yet unstable social orthodoxies aware of constantly being at risk (Butler 1991); and that heteronormativity, cisnormativity and white-normativity therefore depend upon individually constructed performances of heterosexual, cisgender and white identities by excluding and othering those identities perceived as non-normative, marked, to maintain their own existence. At a theoretical level, thanks to their non-normative (queer) nature, marked identity categories have a potential to be subversive to dominant orthodoxies. However, it is precisely due to the historic stigmatisation and pathologisation at the core of antigypsyism, homophobia and transphobia that non-normative sexuality, gender identity and ethnicity/'race' need to be concealed; other times, they can be revealed. Like stepping in and out of the closet.

\section{Ethnic/'racial' identities, the closet and passing}

Having outlined some of the possible ways in which Romani sexuality, similar to Jewish sexuality, has come to be seen as stigmatised due to being marked as different, deviating from the sexual norm of non-Romani, white sexuality, it is now time to turn to the aforementioned notion of Romani identity being a closet and how that links to another survival strategy used by queer people to protect themselves from homophobia and transphobia: passing. In her Epistemology of the Closet (1990), a key queer theory scholar, Kosofsky Sedgwick, makes the following connections, as well as distinctions between the closet of gay identity and the closet of Jewish and Romani identity (Kosofsky Sedgwick uses the term 'Gypsy'):

Vibrantly resonant as the image of the closet is for many modern oppressions, it is indicative for homophobia in a way it cannot be for other oppressions. Racism, for instance, is based on a stigma that is 
visible in all but exceptional cases (...); so are the oppressions based on gender, age, size, physical handicap. Ethnic/cultural/religious oppressions such as anti-Semitism are more analogous in that the stigmatized individual has at least notionally some discretion - although it is never to be taken for granted how much - over other people's knowledge of her or his membership in the group: one could 'come out as' a Jew or Gypsy, in a heterogeneous urbanized society, much more intelligibly than one could typically 'come out as,' say, female, Black, old, a wheelchair user, or fat. A (for instance) Jewish or Gypsy identity, and hence a Jewish or Gypsy secrecy or closet, would nonetheless differ again from the distinctive gay versions of these things in its clear ancestral linearity and answerability, in the roots (however tortuous and ambivalent) of cultural identification through each individual's originary culture of (at a minimum) the family. $(1990,75)$

The closet is a powerful analytic tool providing an opportunity for an indepth insight into the workings of social norms and hegemonic power relations, dominated by the heterosexual and homosexual binary. In particular, this concerns the concealment/disclosure, denial and oppression of non-normative (queer) sexual and gender identities. Kosofsky Sedgwick (1990) uses the closet of queer - or as she terms it, gay - identities as a metaphor for similar workings of discrete forms of identity: in this case, ethnic/'racial' identities. She believes that these discrete forms of ethnic/ 'racial' identity work along the lines of 'ancestral linearity and answerability.' In the case of discrete queer sexual/gender identities, there tends to be no link with the 'originary culture of the family'. Thus, Kosofky Sedgwick suggests that there is an assumed binary opposition between the somehow less obvious, unancestral queer closet and the ancestral ethnic/ 'racial' closet. Underpinned by various degrees of visibility, the ethnic/'racial' closet and the queer closet are constructed in distinct ways, leading to specific constructions of ethnic/'racial' and sexual/gender identities. Some of the manifestations of the queer closet and the ethnic/'racial' closet may be somewhat similar: a 'knowing by not knowing' commonly associated with the closet (Tucker 2009, 10). However, their specific configurations and the resulting distinct cultural meanings differ contextually, materially and relationally: that is, at specific times, in specific spaces and communities. Writing about the queer Gypsy, Baker $(2002 ; 2015)$ points out that sexual identity formation and ethnic/'racial' identity formation differ fundamentally. While the former denotes a politics driven by and associated with particular desires, the latter is usually seen through an essentialist lens as predetermined at birth (Ibid, 88). Similarly, Shneer and Aviv (2002) show that for Jewish non-converts, Jewish identity is derived biologically, whereas queer identity is derived from non-biological social networks. Nonetheless, queer Jews have been redefining the balance between biological and chosen families by pushing their biological families to broaden 
their self-definitions (Shneer and Aviv 2002, 11). As Chapters Three, Four and Five will demonstrate, similar dynamics have occurred in the families and kinship structures of queer Roma.

There are some problematic aspects of theorising the closet in an ethnocentric, predominantly white sense and applying it to all queer people indiscriminately. Tucker (2009) sees the closet as just one way of conceptualising the heterosexual and homosexual binary that only works in a very narrow epistemological framework. The closet allows us to examine the workings and reproduction of a particular heterosexual and homosexual binary within Western culture in the process of identification as/with (Kosofsky Sedgwick 1990, 61). It also functions as a 'means of personal identification' (Halperin 2002), bringing a particular subject position - the queer subject - into being through enacting power. The closet is based on the notion of the Western queer subject - informed by the Foucauldian conception of the medicalised homosexual - that persists in a strongly oppositional relationship to heterosexuality. Consequently, its own identity can only be authentic when it is situated in open, semi-public opposition to heterosexuality. This presents a series of issues when attempting to understand queer sexualities in societies and communities where the heterosexual and homosexual binary may have been constructed in the context of specific realities as in the case of the specific, 'raced'/'racialised' configuration of black, coloured ${ }^{4}$ and white gay sexualities in Cape Town's District Six under Apartheid (Tucker 2009). There, despite measures limiting the movement of non-whites, the relative openness due to the hybridity of its inhabitants coming from across Africa and South Asia made up for a particularly eccentric social fabric in which coloured gay men, particularly queer effeminate men and cross-dressers, were able to enact their queer identities (Tucker 2009, 74-78). This is reminiscent of another study (Fremlova et al. 2014), in which a local Romani community in Serbia lived in a shantytown where most men had either died in the Yugoslav war, were in prison or were not present for other reasons. The community depended exclusively on smithery and other manual labour provided by two lesbian Romani women accepted by the community despite living together openly. The confluence of these specific contextual, relational and material circumstances, coupled with the history of the location, contributed to a specific construction of the heterosexual and homosexual binary, and hence to a specific negotiation of sexualities. These two examples illustrate an aspect of the importance of this spatial, temporal and material specificity, which consequently impacts on a particular negotiation of sexualities. This specificity also means that queer sexualities configured under those circumstances may relate to heterosexuality differently. Therefore, people may choose to come out in ways that are not necessarily the same as the sexual liberationist notion of coming out of the closet of 'inauthentic secrecy': such use of the closet as an analytic fails to acknowledge the specificity of nonWestern under-privileged queer individuals, communities and societies 
(Tucker 2009, 8-11). As Chapter Four will show, these contextual, temporal, material and, indeed, ethnocentric considerations are highly relevant to the lived experiences of queer Roma coming from various cultural traditions across and outside of Europe. The sexual, gender and ethnic/'racial' identities of queer Roma, which get constructed and negotiated under specific circumstances, including through the queer and ethnic/'racial' closet discussed in Chapter Four, significantly impact on queer Roma's sense of belonging (or not), visibility, identifications and disidentifications as discussed in the following sections and in Chapter Three, Four and Five.

From the second half of the 19th century, African American authors in the United States (US) wrote about the phenomenon of 'racial' passing 'as a way of investigating the complexities and contradictions of the category of race (...) in terms of the black/white divide' (Rottenberg 2003, 435-50). The term 'passing' denotes a process, often a protective survival strategy, whereby a person belonging to what is often understood as a nonnormative, stigmatised ethnicity/'race', sexuality or gender identity takes on the privileging guise of the ethnic/'racial', sexual or gender identity norm. This means that they can pass as non-Roma, white, straight and cisgender, often to avoid expressions of antigypsyism and its intersections with homophobia, transphobia and sexism. ${ }^{5}$ According to Ginsberg (1996), passing is about the creation or imposition, adoption or rejection of identities and the attendant rewards or penalties within social normativities. Passing also refers to the act of moving from one category of identification to another; and to crossing identity boundaries. It is also about 'the boundaries established between identity categories and about the individual and cultural anxieties induced by boundary crossing' (Ginsberg 1996, 2). As Chapter Four will show, this movement may entail more than just one category of identification. Thanks to these qualities, passing can also be considered a transgressive, subversive - hence queer - process that destabilises dominant hegemonic power relations, social and cultural norms and binary orthodoxies. Passing - whether in terms of one's ethnicity/ 'race', sexuality or gender identity - involves a certain degree of 'destabilisation, transgression, mimicry, rupture, hybridity, breakage, travesty, masquerade, iterability, performativity, citationality, camouflage' (Ahmed 1999, 89). The person involved in the act of passing moves, or crosses consciously, semi-consciously or unconsciously from one social position, determined by their perceived or actual belonging with, in or to an identity, over to another: often from a non-normative, minoritarian (Muñoz 1999) social position over to a normative, majoritarian one.

The distinctive and separate nature of sexual and gender identity on the one hand and ethnicity/'race' on the other has implications for the fundamentally different ways in which ethnic/'racial' passing is operationalised under whitenormativity as opposed to sexual/gender passing under heteronormativity and cisnormativity. At the same time, both ethnic/'racial' passing and sexual/ gender passing are subversive to the dominant normativities in that the 
maintenance of white-normativity, heteronormativity and cisnormativity relies on the presence of non-normative (queer) ethnic/'racial', sexual and gender identities. Examining Nella Larsen's 1929 novella Passing and commenting on the societal and institutional constitution and reconstitution of whiteness through blackness, Butler (1993) notes that 'it is only through that disavowal [of blackness] that [...] whiteness is constituted, and through the institutionalization of that disavowal that [...] whiteness is perpetually - but anxiously - reconstituted' (1993, 126). In response to her own invitation to consider 'how and where we might read not only the convergence [of sexuality, sexual difference and ethnicity/'race'], but the sites at which the one cannot be constituted save through the other' (1993, 123), Butler offers a queer reading of Passing. She bases her queer reading on Larsen's linking of queerness - where queerness refers to

an array of meanings associated with deviation from normalcy with a potentially problematic eruption of sexuality (...). As a term for betraying what ought to remain concealed, "queering" works as the exposure within language - an exposure that disrupts the repressive surface of language - of both sexuality and race. (...) [Q]ueering is what upsets and exposes passing; it is the act by which the racially and sexually repressive surface of conversation is exploded, by rage, by sexuality, by the insistence on color. (1993, 130-131)

Drawing on Butler's politics of drag (1990), where the queer drag parodies, and thus subverts, the assumed biological givenness, naturalness - or essentialism - of heterosexual and cisgender identities, the above quote by Butler (1993) could be paraphrased as follows. Where heterosexual and cisgender identities depend on non-normative sexualities and gender identities for their (re)constitution, whiteness depends on the disavowal of ethnic/'racial' identities of colour, including Romani identities, for their (re) constitution. In that sense, the very essence of passing - whether it relates to ethnic/'racial', sexual or gender identities - is non/counter-normative, transgressive, and hence queer in line with the understandings of queer and queerness discussed in Chapter One.

Sexual passing, and particularly ways in which gay men and lesbian women pass as straight, is associated with double-coding linked to the presence of hyper-masculine 'skinhead' gay men and hyper-feminine 'lipstick' lesbians in everyday straight spaces (Bell et al. 1994). The physical appearance of their identities has the potential of appearing and being perceived as heterosexual: the ability to pass as straight, hyper-masculine men and hyper-feminine women affords protection from homophobic violence. Being able to pass entails deriving the privileges that come with heterosexuality, producing spaces that can be interpreted as straight and having an opportunity to transgress sexual norms: 
[T] he last thing any straight person expects skinheads to do is to hold hands in public, or to gently kiss. When this happens, people notice. By behaving in this way the gay skinhead can disrupt or destabilise not only a masculine identity but heterosexual space. Can you ever be sure again that you can read the identity of others or the identity of a space? And if not, then how can others read you? (...) The lipstick lesbian is the feminine desiring the feminine, breaking the last stable concept of heterosexuality. Whilst butch-femme seemed to outsiders to reinforce the validity of the heterosexual original, the lipstick lesbian, with her subtle mixing of heterosexual signifiers within a feminine disguise, reveals that the heterosexual 'original' was, as Butler (1990) argues, only an imitation after all. (Bell et al. 1994, 36, 42)

Passing is a political, strategic, transgressive and subversive response to white-normativity, heteronormativity and cisnormativity's symbolic, as well as actual violence towards ethnic/'racial' identities that are not white or non-Roma and sexual and gender identities that are not heterosexual or cisgender. Thanks to passing, it is not clear whether individuals who may be perceived as white or non-Roma are actually white or non-Roma; nor is it evident whether masculine men and feminine women navigating everyday spaces are heterosexual, cisgender or queer. Visibilities, along with acceptance and inclusion on the one hand and rejection and exclusion of non-normative ethnic/'racial', sexual and gender identities on the other, impact not only on queer Roma's sense of belonging, but also on the adoption of protective survival strategies - and queer Roma's ability to do so - such as passing explored further in Chapter Four, which will also demonstrate their significant impact on belonging and the identifications and disidentifications that queer Roma make with the respective categories of identification.

\section{Belonging}

Just as identity is essentially a contested concept, so is the notion of belonging in, with or to that identity or any number of identities that one may - or, as we shall see shortly, may not - identify with. Belonging is fraught with tension: its dynamics apply differently to different groups under different circumstances. Belonging may become articulated, formally structured and politicised especially in situations where it is threatened (YuvalDavis 2011, 4), including when belonging is associated with group identities that may have been or continue to be stigmatised. We have established that the negative social valuation of Romani ethnic identity is propelled by antigypsyism that sits at the root of neoliberal democracies (McGarry 2017). As a result, Romani identity has become a socially stigmatised and stigmatising marker for many Roma. In turn, this impacts on how Roma, including queer Roma, may or may not belong. 
Belonging is often considered a naturalised part of everyday practices (Fenster, 2004): yet, it is by no means straightforward, clear cut or neatly delineated. Often associated with feelings of safety and security or lack thereof, belonging is not a taken for granted, objective, factual reality that is either good or bad. Belonging is a dynamic, discursive, affective process shaped by hegemonic power relations that often exist and manifest themselves in inequitable ways. Belonging encapsulates 'the ways in which individuals and groups are caught within wanting to belong, wanting to become' (Probyn 1996, 19). Belonging can be associated with the desire that individuals have to belong and the knowledge of the impossibility of ever really and truly belonging', as well as with 'other manners of being and desires for becomingother' (Probyn 1996, 5-6). Indeed, the dynamic nature of belonging may symbolise the constant oscillation between sameness and otherness (Theodosiou 2011), often creating tension as a result. The desire, or the wish to belong epitomised by this dynamic 'movement of and between categories' thus challenges and defies 'a certain logic of identity [politics], which proceeds through division and designation, ultimately producing polarisation' (Probyn 1996, 9-10). Probyn (ibid) develops this subversive dimension of belonging by introducing the concept of 'outside belongings', posing it against identity politics. Thus, she creates an analytic space in which it is possible to conceive of belonging outside of the divisive nature of categorising, allowing for the coexistence of different forms of social relations and different modes of belonging. The concept of 'outside belongings' renders visible the forces that constitute the delineation of what is inside and what is outside, where belonging is situated as the threshold separating the public from the private and the personal from the common. Outside belonging is highly relational as it is performed with the experience of being within and inbetween sets of social relations (Probyn 1996, 9-10, 12,13). This subversive dimension of belonging will be discussed more in detail in Chapter Five.

Roma are citizens of nation states, 'recognised as national and ethnic minorities as legally constitutive of and belonging to the state and nation' by the post-communist democracies that have sprung across Central and Eastern Europe in the aftermath of the end of communism in 1989 (McGarry 2017, 22; original emphasis). This is so in the vast majority of cases: that is with the exception of those persons of Romani ethnic heritage who are stateless due to conflict or as a result of not having been issued with personal identification documents. Some states, such as France that does not recognise any minorities, do not recognise Roma as an ethnic/'racial' minority. However, recognition as a member of an ethnic/'racial' minority is not straightforward and does not yield benefits only. As McGarry aptly observes, being recognised as belonging to an ethnic minority means being marked as different from the national ideal - and the social norm - and can result in stigmatisation and potentially persecution (McGarry 2017, 22). Notwithstanding, when it comes to Roma, belonging is a very complex notion fraught with historical, as well as modern contradictions. 
With respect to belonging to the dominant nation state, it becomes apparent that the parameters and modes of belonging have always been determined and regulated by majority, non-Romani societies. Particularly in the case of Roma, belonging has historically had a series of challenging connotations. For instance, under slavery in $19^{\text {th }}$ century Wallachia and Moldavia, Roma belonged to - were owed by, hence the property of - a non-Romani master (Achim 1998, 31). Modern modes of Romani belonging can be seen as being no less problematic. As discussed earlier in this chapter, through ethnic/'racial' visibility, which served as a proof or demonstration of belonging, Roma were issued with special passes because they were believed to belong with vagrants, tramps and criminals in the 1920s in Czechoslovakia. Belonging with Roma in the 1930s and 1940s in Europe meant an almost certain death sentence in Nazi concentration camps. The nexus and conflation of Roma and nomadism (Baloun 2019) has reinforced the belief, including at the policy level, that Roma do not belong to a 'nervous sedentarized state' (Clark 2004, 244) and need to be managed by it. The visible 'presence of domestic or migrant Roma in public spaces is considered to be a security risk and is sufficient to allow the authorities to take special measures, including eviction, confiscation of property and ethnic/'racial' profiling through fingerprinting' (van Baar $2015,77)$. Writing about antigypsyism in relation to 'the constellation of belonging, space and identity [...] mediated in a highly racialized environment, where the subjective articulations of belonging are frequently denied' McGarry $(2017,74)$ demonstrates how Romani communities have been highly visibilised, or hyper-visible, and used by nation states to generate ideas of solidarity, belonging and identity among non-Roma. Fostering majority, non-Romani society's sense of belonging came at the price of excluding, marginalising and demonising Roma. Moreover, Roma have never expressed a territorial claim to an originary state as opposed to, for instance, the territorial claim to Israel made by Jews. Consequently, negative perceptions of Romani communities as not (worthy of) belonging and not wanting to belong to mainstream society anyway since they 'apparently enjoy' being excluded and marginalised into settlements, camps and ghettos, separated from non-Roma (Szalai 2014, 21) have fuelled powerful negative stereotypes about Roma in spite of Roma having resided on European territory since before the creation of nation states (McGarry 2017, 43). Roma have thus been construed as a problem that is simultaneously pan-European and non/un-European, which has severe implications for belonging.

Mobilising around fixed identity categories is the basis for political power, but also the basis of oppression: this represents a 'queer dilemma' (Gamson 1995); or more generally an 'identity dilemma' (McGarry and Jasper 2015), as we have seen in Chapter One. In response to exclusion, stigmatisation, marginalisation and discrimination, Roma and Roma rights activists have been claiming equal rights, equity and equality of access and opportunity, 
and protection from discrimination, thus asserting the notion of belonging in, with and to the dominant national identities. While this rights-based approach achieved a number of positive legal changes, for instance, in the field of education, it has resulted in reinforcing the difference between Roma and non-Roma. As for the insider concept of Romani identity and belonging, the notion of Romanipe(n), also spelt as Romipe(n), encapsulates the idea of common belonging as Roma that all Roma allegedly share: a common culture and cultural practices such as elements of religion, habits, purity laws and a set of beliefs. As diverse and heterogeneous as the cultural and linguistic identities of the various Romani communities, groupings, subgroups are, so is the concept of Romanipe(n). Not all Roma necessarily share the same understanding of Romanipe(n). In fact, some may not subscribe to Romanipe(n) at all. All of these factors impact greatly on the sense that Roma make of belonging both in terms of belonging to the dominant national identity of a given nation state - one that may be hampered by experiences of exclusion that exacerbate the struggle for acquiring a sense of belonging (Anthias 2006) - and of Romani identity.

Belonging can also be associated with ordinariness, as discussed by Browne and Bakshi (2013) in relation to queer commonplace ordinariness:

Commonplace does more than allowing for LGBT people to be inplace, who once were out- of-place. It goes further to transcend this binary. When you are commonplace, you are not only 'in place', but common to the place itself. Place can then be shared or inhabited in common, as well as collectively created in ways that do not necessarily impose normative agendas. (...) Our conceptualisation of ordinariness, through considerations of being or becoming commonplace, enables moves beyond the binaries of marginalisation/inclusion, normalisation/ queer. However, it does not exist in opposition to critiques of normativity. Rather, ordinariness can be strived for and sought because people continue to feel out of place in new sexual and gender landscapes and seek to be included (...). The potential of commonplace is the possibility that anyone can become ordinary and this challenges the power relations that idealise particular normalised lives. (2013, 191)

The concept of the everyday or ordinariness has been applied in Romani Studies, too (Tremlett and McGarry 2013; Tremlett 2014a, 2014b, 2017; McGarry 2017). Tremlett, who has written (2014a, 2014b, 2017) and done art-based research (2014) on the everyday ordinariness of Roma people's lives, proposes that a conscious effort be made by non-Roma to accurately understand Roma by going beyond the historically constructed prejudiced stereotypes about Roma while also addressing the history of oppression that has resulted in negative and distorted imagery portraying Roma. Importantly, she argues that 
if 'Roma' is foregrounded as the subject, even a non-stereotypical approach can reproduce 'difference' (from a supposed 'norm'). 'Roma' is thus, at the moment, still strongly linked to a notion of ethnicity that is seen as different and racialized. (Tremlett 2017, 1)

In a 2014 exhibition entitled 'The Roma - from "extra" to "ordinary", Tremlett sought to show "how Romani lives are not so different from those of everyone else, with a focus on the banal and everyday, rather than the sensational. ${ }^{6}$ Tremlett (2014a) also demonstrated how the United Kingdom (UK)-based Channel 4 reality show Big Fat Gypsy Weddings used essentialist and essentialising TV imagery of Roma as different by nature of being portrayed as extraordinary despite claims made by the series that it offers a unique insight into at the lives of ordinary members of a marginalised community. Tremlett and McGarry (2013) opined that majority society discourses 'labelling Roma as "a" group (...) often [produce] negative images' $(2013,8)$. As a result, social divisions are reinforced, along with the image of the so-called Roma problem as if Roma were a community which is a bearer of problems, collapsing the group. They go on to suggest this status quo in society as well as in academia can be challenged and changed through very detailed, thorough, empirical research on the everyday lives of Roma and making comparisons with people from nonRomani backgrounds.

Ordinariness can thus be understood as a form of belonging, or as belonging as ordinary that is available to Roma, too. As discussed above, ethnic/'racial' identities and sexual/gender identities are separate and distinct with very different histories, historical legacies, materialities and experiences that cannot be equated. At the same time, as we have seen in this chapter thus far, when considering the distinct processes of oppression, exclusion and stigmatisation, there are some parallels between the closet of queer - that is, sexual and gender - identities and the closet of Romani ethnic/'racial' identities that come to intersect, impacting on how queer Roma feel they may or may not belong. Simultaneously, dominant patriarchal and heteronormative conceptualisations of Romani identity as being exclusively ethnic/'racial', which have been critiqued by Romani intersectional feminists and queer scholars discussed in Chapter One (see also Fremlova and McGarry 2018), has impacted on how Roma who are not male, heterosexual or cisgender feel they can, cannot or do not belong. Intersectional critique in Romani Studies can be seen as having slowly paved the way for the inclusion of issues pertaining to sex, sexuality and gender identity. Nonetheless, until quite recently, sexual and gender identities have been omitted, at times avoided by Romani Studies scholarship. This has led to the invisibilities of queer Roma, and particularly of Romani lesbian women and trans people. In turn, all of these partial or full exclusions, silences and erasures have consequences for how queer Roma may identity or disidentify with the groups that they supposedly belong or do 
not belong in, with or to. Before discussing identification and disidentification, I explore non-normative queer and ethnic/'racial' visibilities.

\section{Non-normative queer and ethnic/'racial' visibilities}

In Chapter One, we have seen that some sociologists and demographers refer to Roma as a 'hard to see' (Stewart 2010,1) or 'invisible' (Okely 2010) minority. So far, this chapter has established how visibilities are linked to antigypsyism and the ethnic/'racial' closet by virtue of 'a stigma that is visible in all but exceptional cases' (Kosofsky Segdwick 1990, 75); and how hypervisibility has played a role in excluding Roma from dominant hegemonic modes of belonging to the national identity groups. Indeed, historically, ethnic/'racial' visibility and being 'dark skinned' (Yuval-Davis et al. 2017a, 2017b) or 'too dark' were understood and employed as a proof or demonstration of belonging by repressive totalitarian regimes to assimilate, forcibly settle, persecute or to annihilate Roma: many aspects of these practices have persisted until today. In that sense, Romani ethnic/ 'racial' visibility has been turned into hyper-visibility, making Romani identity both stigmatised and stigmatising. According to McGarry (2014, 2016, 2017), the issue for Roma is that visibility is outside the control of Roma since nationalist parties, other groups, and indeed, nation states construct Roma as a 'plague', a 'disease' and a 'parasitic' community threatening the fabric of the nation (McGarry 2014, 2017), with negative attitudes fuelled by relentless negative coverage in the media. Even though Romani communities are present in the public sphere, others, including media and politicians, have determined this positioning and modes of belonging in order to serve political ends. Simultaneous, the invisibility of Roma as ordinary, full-fledged citizens in everyday life 'suggests a refusal of recognition within broader social, cultural and political discourses which could mean that a community does not exist, indeed is actively denied existence by the majority' (McGarry 2016, 272). Therefore, when it comes to Roma, the relationship between belonging and visibility is very delicate and needs to be unpacked as such.

Visibility matters: 'it suggests a presence in public life and recognition of existence as the first step' (McGarry 2016, 272). Visibility has consequences for acceptance and appreciation of difference, which 'depends on the way particular groups [within communities] have developed elsewhere' (Tucker 2009, 5). Writing about Roma and queer visibility in relation to pride parades, McGarry (2016) argues that Romani and LGBTIQ communities attempt to appropriate public space, through which the process of visibility is mediated, in order to control the very process of visibility and the attendant cultural codes; visibility brings communities and identities into the open, requiring others to take notice, shaping social identities and affirming Romani and queer identities (McGarry 2016, 272). Visibility therefore renders visible what was previously invisible; it renders hyper-visible what 
was previously somewhat visible. Visibility gives an opportunity for group acceptance by enabling individuals to make themselves known to the wider community (Tucker 2009). This establishes an important link between visibility, acceptance, safety and 'the possibilities of enacting LGBT identities in taken for granted, indeed ordinary ways, [which] is more than an absence of abuse' (Browne and Bakshi 2013, 135-136; see also Browne, Bakshi and Lim 2011). Those who are hyper-visible due to having an identity that is perceived as stigmatised, such as Roma and queer Roma, may not feel safe though.

Visibility makes it possible to recast what are often conservative, as well as stigmatised and pathologised conceptions of ethnic/'racial', sexual and gender identities by bringing the very identities into the context of a particular space, time and materiality. As McGarry (2016) notes, visibility is important for individuals and groups who want to affirm their belonging, including through pride parades as a means to publicly celebrate their individual and collective queer or Romani identities. Such visibility performs the belonging of Roma and queer individuals to wider society, thus providing an opportunity to control the narrative of collective identity maintenance by invoking solidarity and attempting to change the meaning and content of a stigmatised identity by challenging dominant negative stereotypes (McGarry 2016, 270). However, to be queer and visible - in some cases hyper-visible as Roma - may mean to be or to become objectified and 'to have enmeshed oneself at some point within wider systems of control that allow for visibility and invisibility' (Tucker 2009, 18). In the case of queer Roma, that may mean enmeshing oneself within systems of hegemonic oppression such as white-normativity, heteronormativity, cisnormativity and patriarchy. As we have seen, the societal consequences of being visible or hyper-visible - acceptance, inclusion, rejection, exclusion, partial acceptance or partial inclusion - within different spaces governed by social normativities have repercussions not only for queer Roma's sense of belonging. They also impact on the sense of safety experienced by queer Roma regarding the ability to come out as both Roma and queer; or lack thereof, which may result in adopting survival strategies such as the closet or passing, discussed above.

\section{Identification and disidentification}

All of the four concepts investigated above - visibility, belonging, the closet and passing - are interrelated with the process of identification. They impact significantly on the identifications and disidentifications made by individuals, particularly by 'minoritarian subjects' (Muñoz 1999) such as queer people of colour, including queer Roma, whose ethnic/'racial', as well as sexual and gender identities have been marked as different, deviating from the norm, stigmatised and pathologised and who are thus located outside dominant social groups. As such, minoritarian subjects encounter 
numerous obstacles while attempting to enact identifications by virtue of the 'minority identifications [often being] antagonistic to other minoritarian positionalities' (Muñoz 1999, 8). In the introduction to her Epistemology of the Closet, Kosofsky Sedgwick writes of identification as follows:

What, then, would make a good answer to implicit questions about someone's strong group- identification across politically charged boundaries, whether of gender, of class, of sexuality, of nation? It could never be a version of 'But everyone should be able to make this identification.' Perhaps everyone should, but everyone does not, and almost no one makes more than a small number of very narrowly channelled ones. (...) After all, to identify as must always include multiple processes of identification with. It also involves identification as against; but even did it not, the relations implicit in identifying with are, as psychoanalysis suggests, quite fraught with intensities of incorporation, diminishment, inflation, threat, loss, reparation, and disavowal (1990, 59-60, 61; original emphasis).

The various processes of identification (with/as) are by no means straightforward or easy. Additionally, there is no uniform way of identifying. As both Kosofsky Sedgwick (1990) and Muñoz (1999) observe, identifications are fraught with what are often conflicting intensities, and structured by and through multiple sites of identification. Yet, they tend to be 'accessed with relative ease by most majoritarian subjects' (Muñoz 1999, 5). Those outside dominant, or majoritarian, society and norms find these processes much more difficult in the face of 'the power and shame of queerness' (Ibid, 5), where queerness can be understood as both sexual, gender and ethnic/ 'racial' non-normativity. Due to not being able to identify with majority society's paradigms, codes, values, meanings and norms and in order to survive in what are often hostile and exclusionary social setting, minoritarian subject, including queers of colour, rework and reconfigure them. Muñoz calls this process disidentification:

Disidentification is meant to be descriptive of the survival strategies the minority subject practices in order to negotiate a phobic majoritarian public sphere that continuously elides or punishes the existence of subjects who do not conform to the phantasm of normative citizenship. (...) Minority subjects (...) must work with/resist the conditions of (im) possibility that dominant culture generates. (...) Their emergence is predicated on their ability to disidentify with the mass public and instead, through this disidentification, contribute to the function of the counterpublic sphere. (...) To disidentify is to read oneself and one's own life narrative in a moment, object, or subject that is not culturally coded to 'connect' with the disidentifying subject. It is not to pick and choose what one takes out of an identification. It is not to willfully 
evacuate the politically dubious or shameful components within an identificatory locus. Rather, it is the reworking of those energies that do not elide the 'harmful' or contradictory components of any identity. (...) The process of disidentification scrambles and reconstructs the encoded message of a cultural text in a fashion that both exposes the encoded message's universalizing and exclusionary machinations and recircuits its workings to account for, include, and empower minority identities and identifications. Thus, disidentification is a step further than cracking open the code of the majority; it proceeds to use this code as raw material for representing a disempowered politics or positionality that has been rendered unthinkable by the dominant culture. $(1999,4,6,7,12,31)$

Disidentification is 'a hermeneutic, a process of production, and a mode of performance' (Ibid, 25). It is an everyday practice of survival and transformation, since, according to Muñoz, minoritarian subjects cannot ever fully overcome the damaging components of hostile, often violent normative cultural scripts. Instead of trying to triumph over such components, minority subjects continually rework and transform them. Describing how artist Marga Gomez transforms damaging, seemingly homophobic images of lesbians into 'powerful and seductive sites of self-creation' (Ibid, 4), ${ }^{7}$ Muñoz explores the paradox of her identification with 'very depressed, very gloomy' lesbians to explain how disidentification - a remaking of identification - works. He also gives a powerful, hypothetical example of 'the queer revolutionary from the Antilles, perhaps a young woman who has already been burned in Fanon's text by his writing on the colonized woman' (ibid 9); and subsequently by Fanon's dismissal of a homosexual component in colonial identity formation. Muñoz suggests that

a disidentification with Fanon might be one of the only ways in which she is capable of reformatting the powerful theorist for her own project, one that might be as queer and feminist as it is anticolonial. Disidentification offer a Fanon, for the queer and lesbian reader, who would not be sanitized; instead, his homophobia and misogyny would be interrogated while his anticolonial discourse was engaged as a still valuable yet mediated identification' (ibid 9).

Muñoz's account of disidentification follows the trajectory that moves from a world that is damaged and damaging to minoritarian subjects towards describing 'a utopian blueprint for a possible future': a vision for 'performers, cultural workers, and activists who are not content merely to survive' (ibid 200). His queer intersectional approach articulates how normative social dynamics and structures built on and around nation, class, ethnicity/ 'race', sex/gender, sexuality and gender identity etc and their intersections are enmeshed into identities: so much so that 
our prescribed 'public' scripts of identification and our private and motivating desires are not exactly indistinguishable but blurred. (...) Queer are not always 'properly' interpellated by the dominant public sphere's heterosexist mandates because desire for a bad object offsets that process of reactionary ideological indoctrination. In a somewhat analogous fashion, queer desires, perhaps desires that negate self, desire for a white beauty ideal, are reconstituted by an ideological component that tell us that such modalities of desire and desiring are too selfcompromising. We thus disidentify with the white ideal. We desire it but we desire it with a difference. The negotiations between desire, identification, and ideology are a part of the important work of disidentification. (Ibid, 15)

As Chapter Five will show, for some minoritarian subjects such as queer Roma, disidentification is a survival strategy that works both within and outside the normative scripts of dominant societies. For others, disidentification may not always be an adequate form of resistance. Sometimes, resistance may have to be pronounced and direct; other times, minoritarian subjects need to follow a conformist path to survive. Disidentification thus sits located within dominant hegemonic normativities. As a non-normative positionality, it does not require one to align with or against social norms, thus bypassing the assimilationist/separatist dualism.

\section{Conclusion of Part One}

Part One has been a probe into post-modern, poststructuralist conceptualisations of identities and identifications. It has taken the reader on a journey exploring various angles of how we understand identities, how these understandings are underpinned by social conventions and norms, and how else it is possible to understand identities when we are willing to change the prism through which we are looking. This exploration started in Chapter One with Hall's conceptualisations of collective social identities and new ethnicities and continued through understandings of Romani identities in Romani Studies to theoretical concepts such as hybridity, super-diversity and intersectionality that cross-cut ethnicity/'race', sex/gender, sexuality, gender identity, class, social status, age and other categories of identification. Some of these categories have been also applied in Romani Studies. The chapter then went on to examine scholarship associated with queer theory, queer of colour critique, as well as recent intersectional approaches to critical queer theorising, particularly in relation non/anti-normative, non/anti-identitarian and non/anti-essentialist queer theoretical concepts: the chapter considered their applicability and relevance to understandings of ethnic/'racial', sexual and gender identities. To this effect, Chapter One proposed to apply queer intersectionalities when theorising Romani identities. Queer intersectionalities benefit understandings of Romani identities as fluid becomings 
that are not anchored in the notion of fixed groupness or marked essentialist difference and attend to the asymmetrical hegemonic power relations that participate in the construction of Romani identities. The first part of Chapter One provided a springboard for a methodological reflection in the second part on conducting qualitative research informed by ethnography and thematic analysis sensitive to queer assemblages and intersectionality. The methodology consisted of critically examining - or queer(y)ing - the ethics of doing social science research, queer ethnography and non-Romani queer researcher positionality and reflexivity in relation to social normativities and social privilege.

Elaborating on the notion that certain, historically persecuted queer (non-normative) ethnic/'racial' and sexual/gender identities came to be seen as perverse, pathological, deviant and socially stigmatised and stigmatising markers for their bearers, this chapter examined the construction of ethnicised and 'racialised' - 'raced' - sexual and gender identities; and the construction of gendered and sexualised - sexed - ethnicities/'racialities'. It went on to interrogate the concepts of belonging, visibilities, including hyper-visibility, passing, identification and disidentification, demonstrating that the closet, passing and disidentification are subversive, transgressive strategies used by minoritarian subjects to respond to the dominant cultural scripts of social normativities.

In what follows, that is Chapters Three, Four and Five, I explore the insights emanating from analysing the lived experiences of queer Roma through the lens of queer intersectionalities. Part Two of the book demonstrates what it looks like to operationalise the proposition to employ queer intersectionalities when theorising Romani identities framed by the lived experiences of queer Roma. As I develop the different thematic aspects of queer intersectionalities, I draw on various elements of the data as examples of my theoretical arguments. The empirical material is mobilised in a way which still allows us to see and feel the individual queer Roma behind the stories.

\section{Notes}

1 http://rroma.org/en/.

2 'Brussels probes Czech Republic over Roma', The Financial Times, 26 September 2014, accessed 13 September 2020, http://www.ft.com/content/61c25bca-455 8-11e4-ab86-00144feabdc0.

3 'Illegally sterilised Czech women to be offered compensation', The Guardian, 4 August 2021, accessed on 4 August 2021, https://www.theguardian.com/globaldevelopment/2021/aug/04/illegally-sterilised-czech-women-to-be-offeredcompensation.

4 Here, 'coloured' refers to the 'descendants of inter-racial sexual ties and unions between the first whites from Europe, their slaves from Indonesia, Madagascar, Mozambique, Angola, Bengal, South India and Sri Lanka, and the original inhabitants Khoi-khoi pastoralists and San hunters' (Tucker 2009, 71) 
5 In her article on passing, Horváth (2010) makes some rather problematic statements with respect to Romani ethnic/'racial' identity, sexuality and passing, showing limited engagement with queer theory and the literature on passing.

6 'The Roma - from "extra" to "ordinary"', Portsmouth Research Portal, 19 June 2014, accessed on 13 September 2020, https://researchportal.port.ac.uk/portal/ en/activities/the-roma--from-extra-to-ordinary(d8cd06c9-a6b6-4c4d-922f-7881 03de0a6b).html.

7 I want to briefly consider a powerful moment in her performances that demonstrates disidentification with mainstream representations of lesbians in the media. From the perch of her bed, Gomez reminisces about her first interaction with lesbians in the public sphere at the age of eleven. Marga hears a voice that summons her down to the living room. Marga, who at this age has already developed what she calls "homosexual hearing," catches the voice of David Susskind explaining that he will be interviewing "lady homosexuals" on this episode of his show Open End. Gomez recounts her televisual seduction:

[I] sat next to my mother on the sofa. I made sure to put that homophobic expression on my face. So my mother wouldn't think I was mesmerized by the lady homosexuals and riveted to every word that fell from their lips. They were very depressed, very gloomy. You don't get that blue unless you've broken up with Martina. There were three of them. All disguised in raincoats, dark glasses, wigs. It was the wigs that made me want to be one.

(...) Gomez luxuriates in the seemingly homophobic image of the truckdriving closeted diesel dykes. In this parodic rendering of pre-Stonewall stereotypes of lesbians, she performs her disidentificatory desire for this once toxic representation. The phobic object, through a campy over-the-top performance, is reconfigured as sexy and glamorous, and not as the pathetic and abject spectacle that it appears to be in the dominant eye of heteronormative culture. Gomez's public performance of memory is a powerful disidentification with the history of lesbian stereotyping in the public sphere. The images of these lesbian stereotypes are rendered in all their abjection, yet Gomez rehabilitates these images, calling attention to the mysterious erotic that interpellated her as a lesbian' (Muñoz 1999, 3). 


\section{3 'We're here, we're Roma and queer!'}

This chapter first begins by exploring the key role that antigypsyism plays in the lived experiences of queer Roma. Secondly, it goes on to examine queer Roma's lived experiences at the intersection of antigypsyism, homophobia, transphobia, sexism and other forms of oppression. The chapter considers the queer intersectional specificity this confluence of oppressions engenders for queer Roma. Thirdly, the chapter looks at how the most immediate social group - the family, which is located within the broader social fabric of communities - impacts on the lived experiences of queer Roma. Two cross-cutting themes are woven through the chapter: gender and visibility. Gender is explored in relation to the societal position of women, men and trans Roma, particularly in terms of the inequitable asymmetrical power relations impacting on the position of Romani lesbian women, bisexual and trans people and gay men. Gender identity is considered with respect to ways in which trans Roma may be ethnicised/'racialised', sexed and gendered as opposed to cisgender non-Roma. Underpinned by the discussions in Chapter Two, this chapter goes on to consider ethnic/'racial' and queer visibility, invisibility and hyper-visibility. Developing the crosscutting theme of visibility in this chapter will then serve as a springboard to exploring visibility, invisibility and hyper-visibility in relation to the closet, passing and commonality discussed in Chapter Four.

\section{Navigating antigypsyism}

In the course of the second international Roma LGBT conference held in Prague, Czech Republic in August 2016, I observed a panel that brought together 11 queer Roma. The participants talked about their experiences of being discriminated against as Roma by non-Roma in LGBTIQ spaces and agreed that hiding their sexuality was easier than hiding their ethnicity. A number of participants discussed an incident from 2014 when they had been denied access to a gay club in Prague. I was at the scene of the actual incident at that time. The club manager asked the queer Roma to produce club cards - which none of us had because they did not exist - in order to be let in. However, the club manager did not ask non-Roma, including myself,

DOI: $10.4324 / 9780367822699-3$ 
to produce the card. Subsequently, another Romani gay man and I intervened, informing the club manager that he was engaging in illegal behaviour amounting to racial discrimination in the provision of goods and services by not allowing a group of people in on the grounds of their 'race'. During the aforementioned panel session in 2016, a Czech Romani gay man in his early thirties, who had experienced the incident in 2014, expressed his opinion as follows:

I found the club manager's behaviour discriminatory and unacceptable. However, as a Roma, I have become used to being denied access to gay clubs, as well as to other expressions of antigypsyism by non-Romani gay men. (Lada)

The racist incident at the gay club, specifically aimed at the queer Roma, was then used creatively as the basis for a play, for which several of the queer Roma who had not been let into the club wrote the screenplay. The play was performed as part of Prague Pride 2016 festival week and the event was open to the general public. Afterwards, members of the audience were asked to step in and change the main protagonist's actions that could have hypothetically altered the gay club manager's conduct. A number of spectators gave it a try: the first person was a non-Romani woman who believed that providing a list of guests would have helped. The second person, a non-Romani man, opined that because all the queer Roma who had not been let into the club had a dark complexion, they should have pretended to be Spanish. In his opinion, the queer Roma could have passed as Spanish, thus avoiding the anti-Romani behaviour by the club manager. The third person was a Romani man who suggested that the queer Roma should have called the Commercial Inspectorate or the Czech Police because private establishments have a duty to display the conditions, under which they let guests into clubs. In the discussion that followed between members of the audience and the actors, some of the queer Roma expressed discomfort at the idea of having to pretend they were Spanish. One nonRomani woman who participated in the discussion introduced her intervention by saying that she lived in the area in Prague where the club is located and had a good experience of interacting with African Americans but not Roma. She was of the opinion that not letting the queer Roma in the gay club was not an act of racism since the club may have had a bad experience of having Romani guests in the past. She believed that was why the management of the gay club did not let the queer Roma in. She was challenged by other members of the audience - Roma and non-Roma alike who claimed that although she said she was not racist towards African Americans, that did not mean that she did not have racial prejudice towards Roma. They went on to claim that both the club manager's actions and her condoning such practices were examples of prejudicial conduct whereby a whole group of people perceived as Roma is assigned a negative group 
identity on the grounds of allegedly displaying similar physiognomic, behavioural, social or other traits: or antigypsyism. The incident from 2014, as well as the responses by some of the non-Romani members of the audience at the re-enactment of the incident in 2016 were clear indications and reminders that queer Roma experience and deal with antigypsyism frequently in very specific ways that are not always accounted for by dominant LGBTIQ discourses and in a variety of settings and environments, LGBTIQ and heterosexual alike. These repeated references to expressions of antigypsyism by non-Romani LGBTIQ individuals and communities demonstrate that queer Roma experience anti-Romani racism even in spaces and environments generally thought of as inclusive and accepting, as illustrated by the following quotes:

My LGBT friends say: 'We like you, you're not shy, you're not ashamed that you are Roma.' And I ask: 'Should I be ashamed because I'm Roma?' But they clearly thought that Roma must be ashamed of this ethnic origin. (Ana)

For example, the application, Grindr, you go on the site and there, French people say 'ah, it's a Gypsy and he's gay, disgusting' you know. (Constantin)

In the first narrative, Ana, a middle-aged Romani lesbian woman who hails from Serbia, points to the notion that some non-Romani LGBTIQ people see Romani identity as a stigmatising negative group identity. In the eyes of a non-Romani person who valuates Romani ethnic identity negatively, a Romani person should be ashamed of being Roma. The quote suggests that it was perhaps surprising to the LGBTIQ acquaintances of Ana's that she was not ashamed of being Roma. In the second account by Constantin, a Romani gay man in his mid-twenties who is originally from Romania and now lives in France, gay users of the dating application are said to have associated Romani ethnic identity with feelings of disgust, effectively indicating that they were excluding Romani gays as potential dates or sex partners due to their ethnic identity. Both quotes convey negative, biased or stereotypical attitudes by the non-Romani LGBTIQ people at issue towards Roma as an ethnic group.

The above experiences from non-Romani LGBTIQ settings also show that queer Roma experience this specific form of racial bias independently of homophobia and transphobia. This means that Queer Roma experience antigypsyism in ways that are very similar to non-LGBTIQ Roma's experiences as evidenced through research on antigypsyism (Van Baar 2010, 2011, 2014; McGarry 2010, 2013, 2017; Ljujic, Vedder and Dekker 2012; Agarin 2014; Vrabiescu 2014). The notion of there being a variety of nonRomani settings, including LGBTIQ ones, in which queer Roma have to navigate different manifestations of racism towards Roma, means that the 
contextual dimension of social and geographical settings is crucial to the lived experiences of queer Roma, as Chapters Four and Five will show in relation to the closet, passing, and queer belonging, respectively.

Antigypsyism and the attendant social stigmatisation play a pivotal role in the lived experiences of queer Roma. Because of its widespread, deeprooted nature, many queer Roma experience antigypsyism as a pre-eminent form of oppression. These experiences thus come to impact on their lives in a manner that is more acute, immediate, tangible. Indeed, some queer Roma's experiences of antigypsyism are such that they eclipse all their other experiences of oppressions, as illustrated by the following quote:

Paradoxically, the people whom I used to know as a child are more shocked by me living with a Romani woman than by the fact that I've transitioned. People regard homosexuality as something better and with a more positive outlook, or they don't see it as such a big issue as opposed to Romani identity. And the kind of questions I get because she's Romani, whether she works at all. Even though I carry what I believe to be a typical Czech Romani surname, or perhaps it's not visible that I'm Roma or I don't present myself that way because I don't have a Romani accent. I don't know. But [until I met my girlfriend,] I'd simply never been discriminated against based on my Romani identity, I'd never experienced being told by someone that something isn't possible because I'm Roma but because I'm trans. (Dominik)

Dominik is a Romani trans man in his mid-twenties. In his story, he juxtaposes his experience of being accepted as a trans man by his non-Romani friends and acquaintances with his experience of being condemned by the very same people for going out with a Romani woman. Additionally, he dwells on the comparison between what he considers to be a more favourable public perception of being gay or lesbian on the one hand and being Roma on the other. Dominik's account indicates the presence of some problems around being trans which have not gone away. However, in his experience, these problems have been eclipsed by problems relating to Romani ethnic identity. Although both Romani and gay/lesbian identities have been historically stigmatised and stigmatising, Dominik believes that in this day and age, it has become less stigmatising and often socially more acceptable to be an LGBTIQ person. However, being Roma is still seen as something much more stigmatising, negative and often not accepted.

Another important aspect of the above quote is Dominik's reference to a sense of his evolving identity, agency and his recently found, heightened awareness of his own Romani identity. Prior to starting the relationship with his Romani partner, he had not self-identified or, indeed, had not been identified by others as Roma. Dominik now experiences his Romani ethnic identity in a more immediate way through his Romani partner and through the relationship with her. His sense of what being Roma is or means is 
informed by his new experiences, including by those of antigypsyism that he and his girlfriend have experienced together. His partner makes the following observation about this change in Dominik's perception of his Romani identity:

As a Romani woman, I experienced my classmates at primary school wanting to pour bleach over me and all manner of other things. And today, [gestures inverted commas with her index fingers] 'thanks' to me, my boyfriend is undergoing exactly the same. For instance, the last time something happened, a driver almost hit us with his car at the crossroads. That was our last experience. All of a sudden, he is starting to see it. He also said that he simply either didn't want to admit it or he wasn't aware of it but now, with me, he's experiencing all of these things. (Jolana)

Jolana's description of the horrifying experience at a Czech primary school not only illustrates the degree of anti-Romani racist hatred that some nonRoma, including primary school children and teenagers, feel towards Roma. It also captures the essence of antigypsyism and its primary manifestation, which operates through Romani ethnic/'racial' hyper-visibility, with specific reference made by non-Roma to skin colour. In Jolana's account, her non-Romani classmates at primary school deemed her skin to be black or too dark; consequently, they wanted to 'whiten' it with bleach. Now that Dominik has been associated with Jolana and is perceived as Roma, he is exposed to similar expressions of antigypsyism. As a result, he experiences antigypsyism in similar ways. Coming back to Dominik's narrative, his ethnic identity, now associated with and through his Romani girlfriend's ethnicity, has become a problem for his non-Romani friends and acquaintances. Thus, antigypsyism has become a more immediate priority for him: Dominik's experiences of antigypsyism have come to eclipse his experiences of transphobia. Even though both of them have to navigate very specific queer intersectionalities as a Romani trans man and a Romani woman who are in a non-heteronormative (queer), albeit straight relationship, it is still important to take into account the overarching experiences of antigypsyism that impact on their lives. The fluid, assemblagelike becomings of both Dominik's and Jolana's ethnic/'racial', sexual and gender identities unfold against the backdrop of interlocking axes of oppression (antigypsyism, transphobia and their intersection) and the workings of binary social norms such as white-normativity, heteronormativity and cisnormativity.

Experiences of antigypsyism also define the lives of those queer Roma who experience ethnic/'racial' hyper-visibility due to non-Romani people's centuries-long association of certain physiognomic features with being Roma. As discussed in Chapters One and Two, Roma are stigmatised because of Romani ethnic identity being stereotypically associated with 
particular lifestyles, as well as with either romanticising or vilifying (mis) representations. Given this widespread blanket negative social valuation of Romani ethnicity by non-Roma, in practical terms this means that Roma, who are ethnically/'racially' hyper-visible, cannot hide their Romani identity - or 'a stigma that is visible in all but exceptional cases' (Kosofsky Segdwick 1990, 75). The following quote conveys a similar sentiment in terms of how the Romani person has experienced antigypsyism; and the role that his ethnic/'racial' hyper-visibility has played in the anti-Romani bias and prejudice that non-Roma held and displayed towards him:

In school in Romania, my classmates or others never said my name. They said 'Tzigan'. They call me Tzigan, Gypsy. And then, there was 'crow', it's a bad word. Crow is black. It's insulting. Or they also called me negrut, blackie. That was the good way. They were friends close to me, I was only a little bit darker than them, that's why. But it was not discrimination because it was like something good but the others they were racist, calling me a crow, or Tzigan. (Constantin)

Constantin's story depicts two different situations. In each of them, the antigypsyism that he had experienced in the school setting in Romania gets normalised whereby the hyper-visibility of his blackness would be regularly called upon as deviating from whiteness as a norm. This is done both in a friendly - if one can use that term - and a hostile manner by non-Roma referring to him as 'blackie' in the former case, and as 'crow' in the latter. Having experienced such scales of antigypsyism, Constantin can tell the difference between 'good' and 'bad' antigypsyism. Just like in Jolana's case, it is the Constantin's skin colour that marks him out and defines him as the black other; a 'Gypsy' without a name. This behaviour and linguistic verbalisation consolidate the normalisation of antigypsyism as an acceptable form of conduct in society, reaffirming the dominance of white-normativity and calling into being - or interpellating (Althusser 1971; Butler 1997) - the 'subordinated' Romani subject who has been thus ethnicised/'racialised'.

The issue of the hyper-visibility of specific physiognomic features associated with Romani ethnic identity as the basis for identifying Roma also comes up in the following quote. Kerttu, a Scandinavian Romani lesbian woman, talks about her experiences of being easily identifiable as a Romani woman.

When we went to the gay bars I was always hiding, so we ran in and out from there. At that time, there was not so much black hair people and I had long hair also, people were always asking where I come from. I couldn't be invisible. Nowadays it's not the same as it was in that time: now we do have more different kind of colours in population, ethnic groups. I never ever talked with my sisters and brothers that I go there. Even today, it's not so easy to talk with my sisters. Basically, it was and still is a kind of taboo. (Kerttu) 
Kerttu refers to her experience of going to gay bars as always hiding: she ran in and out of there because she could not be invisible due to her ethnic hyper-visibility. Here, her hyper-visibility may refer to the dynamics of ethnic/'racial' hyper-visibility in relation to anti-Romani attitudes. Due to her black hair, as Kerttu puts it, which stood out in a predominantly white Scandinavian country, Kerttu was anxious that she could be easily identified as Roma by non-Roma: they could potentially associate Kerttu with a negative group identity. Her ethnic hyper-visibility precluded her from blending in as ordinary at the gay bar (for a discussion on ordinariness, see Chapter Two). Additionally, Kerttu's queer visibility as a lesbian, which, according to her, is still seen as a taboo in her Romani family and community, was exacerbated by her association with the gay setting. Kerttu refers to her hyper-visibility in connection with her anxiety about being identified by other Roma within such a small group: hence her fear of being outed as a lesbian due to her association with the gay setting. Here, Kerttu's fear of a possible expression of antigypsyism in response to her ethnicity intersects with her fear of a homophobic response to her sexuality.

\section{Living at an intersection of identities}

This section examines how the intersection of antigypsyism, homophobia, transphobia, sexism and other forms of oppression impact the lived experiences of queer Roma. Informed by the discussions in Chapters One and Two, it considers the non-normative intersectional specificity that queer Roma experience as both Roma and queer. While some queer Roma experience antigypsyism as a pre-eminent form of hegemonic oppression that eclipses their experiences, other queer Roma experience antigypsyism at the intersection of ethnicity/'race', sex/gender, sexuality and gender identity, as illustrated by Arpad:

The fact that I'm Gypsy - or Roma - and gay has negative impact mostly in my private life. The biggest part was for me in the two things together, to put all the information that I got in my 28 years in the right place, like prejudices from both sides. First, for my Roma identity at school, from my classmates, for example, what I got, how to handle it; and then about my gayness. When I came out, my Gadzo friend told me: 'it's ok but you aren't the one getting fucked? What would your father say?'. He freaked me out with this. Now, after I put all the information in the right place, all the comments from kids at school, and when my father who's Roma called gay people 'faggot' regularly, you reach the level of pride and you start to feel inner peace. (Arpad)

Arpad's story details the anti-Romani and homophobic abuse that he was subjected to from a young age. He elaborates on the negative impact this intersectional abuse has had on his identity. As a result of both his ethnic/ 
'racial' and sexual identities being stigmatised, Arpad has been grappling with the attendant intersectional stigmatisation: or what could be termed 'intersectional essentialism'. Echoing the discussion in Chapter Two, Arpad's narrative also demonstrates that the processes of oppression, exclusion and stigmatisation associated with non-normative ethnic/'racial', sexual and gender identities are distinct and separate. Nonetheless, they have some important parallels that come to intersect with each other, thus creating a queer intersectional specificity unique to queer Roma. The intersection of sex/gender, ethnic/'racial', sexual and gender identities also impacts on the queer intersectional specificity experienced by Romani lesbian women as discussed by Ana:

I had to come out as Roma because I'm light-skinned and I lived outside of the Romani settlement. Then I had to come out as a lesbian. Roma lesbian and LGBT people have a big issue with how to identify themselves from early childhood until their older age. All the time, we question our identity. There is a clear gender difference between the position of women and men in the Roma community. It is easier to be Roma gay than Roma lesbian because there are specific roles for women. If she's lesbian, she also must behave as a Roma woman: stay at home. Freedom to move is not something that she got, she's not educated, she'll be stuck in her house in the Roma community. It is so much harder to find partner if you're Roma lesbian in the settlement. The testimonies of those women show life of solitude, loneliness. They don't want to have a partner in the Roma community. [Not wanting a Romani partner] applies also to Roma gays because everyone will know. But men can do whatever they want, they can go outside, they can go somewhere, even in the park and they will find another nonRomani guy. But it is so hard to be Roma lesbian woman. Some Romani lesbian women are forced to marry. They didn't have right to react; they had to be married. Violence against women is present; it's not a 'Roma thing' but it exists in Roma communities as well. If they're lesbians, they were beaten up because of sexual identity. Because of invisibility of lesbian Romani women, it's obvious that they live their lives as hidden lives. They don't want to show themselves as lesbians and therefore gay men are more visible. This is a male world and it is like in the majority and in the Roma community, it's no different. It is easier to be a gay man because of power. (...) We [lesbians and gays] are not the same, we don't have the same experiences. I can't define myself as a gay woman: I'm not gay. That is why I don't use 'gay woman'. I'm first of all radical feminist. We have such a different life actually because gay men have privilege. (...) Being lesbian or gay doesn't mean that gender roles in your community don't apply any more. They apply, plus you have something more: a label that you're different because of sexual orientation. (Ana) 
Here, Ana talks about the specificity she has experienced as a Romani lesbian and also refers to the experiences of other Romani lesbian women. Ana is very sensitive to the gender disadvantage that lesbians, including Romani ones, are subjected to under patriarchy, in this male world. In order not to perpetuate asymmetrical hegemonic power relations within language, she is most careful not to use the expression 'gay women' when referring to lesbian women who, unlike gay men, are underprivileged by nature of being sexed and gendered as women. Ana discusses the specificity of Romani women's gender role within some Serbian Romani communities, which may restrict some Romani women with respect to education and professional career. In Ana's opinion, irrespective of whether or not the Romani woman fulfils the heteronormative societal norm in terms of her sexuality, her sex/gender - that is, being born and socialised as a woman, a female - determines society's expectation of her. She is expected to be confined to the household, to be invisible and to exercise her freedom to an extent decided by men. If she is perceived to trespass the patriarchal social norm and the heteronormative sexual convention, confinement to the household or other means of social control such as forced/arranged marriage may be used. This means that the importance of visibilities is key to the queer intersectional specificity experienced by Romani lesbian women. Romani lesbian women's existence becomes invisible, coded, or implicit rather than explicit, hidden or not quite visible. The invisibilising effect on Romani lesbian women is a complete lack of opportunity to find a female partner, lack of freedom to act upon lesbian sexuality, and increased social isolation. In this account of Romani lesbian women's queer intersectional specificity, it is sex/gender as well as invisibility, which determine the different treatment Romani women are afforded, resulting in Romani lesbian women's lived experiences being distinct from those of Romani gay men.

Ana's reference to instances of forced or arranged marriage, which is employed as a means of social control to limit the Romani lesbian woman's visibility and to avoid potential social or physical contact with another woman, is complemented by a similar narrative by a Romani gay man living in Germany. Below, Antonio talks about his experience of arranged marriage:

I'm in my late thirties, I have two children, my son is 21 and my daughter is 20 . I have two grandchildren. I was very young when I was married because my family was traditional. They know from their parents and then it goes to the next level in the next generation. That was normal for my family. (....) I was going to school and I was with other non-Roma. It was very difficult for me to live this life that my parents wanted to give me. I know it's very important to know who you are. Because in my situation, my family gives me a different identity, the identity from a husband, from a father, a traditional Roma man. That's good but that is not my identity. I'm a gay man, I want to live a gay life 
with my husband and normal life but only in the relationship with my husband and with my child. That was my way. (Antonio)

Forced or arranged marriage is a global phenomenon that affects individuals from non-Romani, as well as Romani families and communities (Oprea 2004; Kóczé 2009; Bošnjak and Acton 2013). Antonio's story further develops the role that the intersection of sex/gender and sexuality plays under heteronormativity and patriarchy. Not only does Antonio's account show that gay men, too, can be underprivileged by virtue of being vulnerable to arranged marriage. It also demonstrates that conservatism in close-knit, insular families and communities often serves to preserve the hegemonic workings of heteronormativity and patriarchy most often associated with opposite-sex marriage. This means of social control has an adverse impact particularly on women and non-heteronormative family and community members, including men.

Sex/gender, sexuality and gender identity also intersect with ethnicity/ 'race' in additional ways, producing very specific, 'racialised' dynamics. In the following quote, German Romani trans man in his early twenties, Markus, talks about his experiences as a Romani trans man.

I had to pick up a paper from my old school, I needed it for my next final test because I needed a signed copy, so I went there and said: 'Hey, I need this' and the woman behind the desk looked at me from the foot to the head and said: 'What do you want?' I said: 'I called several times. I need this paper otherwise I can't do my exam.' 'Out of here, I'm not doing anything for you.' I didn't understand at all, she totally freaked out, she said she will call the cops if I'm not leaving the building. It was super racist. I didn't understand it and then I met a friend of mine. They said to me 'yeah, well, it's easy honey, you are a trans guy but you are not a white trans guy. So, you are from the eroticised, fetishized southern-looking person to the bad guy with a lot of hair and dark huge eyebrows and maybe a terrorist, so they are afraid of you'. It's so obvious that I didn't come up with the idea, I was like 'what was it?' and then 'oh yeah, that it is'. (Markus)

In this account, it is the specific intersection of Markus's sex/gender, gender identity, ethnic/'racial' hyper-visibility associated with his physiognomic features and gendered masculine demeanour that were said to have been perceived by the female admin officer as potentially threatening or aggressive. Here, Markus's experience shows that as a person who is perceived as a cisgender man of colour, his sex/gender has been ethnicised/ 'racialised' differently to his previous experiences as a person who used to be perceived as a woman of colour. This instance of 'racialisation' resulted in unfavourable, discriminatory treatment that put him as a man of colour at a bigger disadvantage than a woman of colour. In the white-normative 
environment described by Markus, his ethnicity/'race', sex/gender and gender identity intersected in a very specific, ethnicised/'racialised' way, thus creating a queer intersectional specificity.

The testimonies in this section have helped to demonstrate that queer Roma's lived experiences of asymmetrical hegemonic power relations and the attendant queer intersectional specificity are crucial to queer Roma identities. Queer Roma are in a constant dialogue with the external discursive practices of the social world, including through their families and communities. These key relational aspects of the lived experiences and the attendant queer intersectional specificity of queer Roma are explored in the following section.

\section{Family, kinship structures, community and queer Roma}

Family, kinship structures and community are key social safety nets (San Román, 1975; Okely, 1975; Stewart, 1997; Gay y Blasco, 1999; Martin and Gamella, 2005; Cahn, 2009; Tesăr, 2012). Many queer Roma who had families depend upon them, at times entirely. Yet, within the dominant heteronormative social fabric, families often reproduce and impose the workings of heteronormativity and patriarchy on queer Roma. The following quotes by Antonio and Ana expand on the notion of queer Roma's dependency on their families, including for livelihood, economic resources, safety, survival and protection from antigypsyism:

The problem is when you live in this Roma system, you don't have much more possibility to go out of this life because when you go out of your family, you don't have anything anywhere to rescue you. It's very important that young people know that when you live in so difficult a system, the Roma system, it's very hard to find the right way in the other system of the Gadje, the non-Roma. (Antonio)

One of the main problems is that LGBTIQ Roma are really poor economically and they need economic empowerment. They need - I don't know - small businesses but in the way that they need some kind of independency because they depend on other people a lot and because of that, they live their lives in fear because they depend on their parents or if they're in marriages or from social welfare and they cannot be what they are because of it. And they need security, they don't feel secure in this world. Even in the settlement or out of the settlement. They don't have money, they need money; they don't have clothes, they don't have information or even passports. Roma community is really in a bad situation but Roma LGBT are in deep shit. It's something being LGBT Roma community makes you totally vulnerable to everything. (Ana) 
Antonio discusses the vulnerability of queer Roma in relation to and within both the Romani and non-Romani social systems. Queer Roma may have to leave the heteronormative Romani family structure, which may not be compatible with what queer Roma need, including a neutral environment in which queer Roma can realise and enact their sexuality and gender identity. Queer Roma may also be made to leave as a punishment for being LGBTIQ. Leaving or having to leave the Romani family comes at the expense of being left to their own devises, being alone in a society unknown to them or having no-one and nothing to help or rescue them, especially if things go wrong (for instance in a situation of material deprivation such as unemployment, homelessness and other difficulties). Ana makes a very important point about the economic and material precariousness and extreme social and personal vulnerability of many queer Roma in some of the Romani families and communities in Serbia. All of these factors, but acceptance/rejection, inclusion/exclusion and the attendant vulnerability in particular, result in queer Roma's feelings or safety and security - or lack thereof - in their respective environments. In the previous section, Ana elaborated on the reasons why queer Roma - and Romani lesbians in particular - feel a lack of safety and security. This is compounded by experiences of abuse, violence or threats of intersectional abuse. Family relationships and dynamics therefore play a crucial role in informing the lived experiences of queer Roma; and in shaping queer Roma's ability - or lack thereof - to negotiate and enact their queer identities. It is through these relational experiences with nuclear and extended families that queer Roma made sense of ethnic/'racial', sexual and gender identities, as discussed by Veronika, a Czech Romani lesbian woman in her mid-thirties:

Mum is Czech and dad is Romani. This actually made me see my ethnicity as a taboo and I didn't know how to handle it. With our dad, we didn't know that back then, but there was domestic violence, so I kind of understood that it wasn't entirely kosher, but when you're growing up in it, it really becomes normal. Now I'm grateful that they got divorced. I tried to reconnect with him but mum took it really badly, as a betrayal. Initially I lied to her when I went to see him, my aunt or cousin. For the past three years or so, this has changed, so regarding the issue of identity, I speak with her about these issues and she simply started to respect that my opinion is different. When I was born, mum was 18 and all of her family left her [because of her decision to be with a Romani man]. She was stigmatised in that town, so everything that her parents had predicted happened, as it were: that it wouldn't work out, that there would be alcoholism and that he wouldn't look after us, that he wouldn't be working. Since mum doesn't come from an intellectual family, she took it very hard: she fell in love, she got hurt by that love plus she wasn't happy in that relationship because he was cheating on her, didn't look after us, beat 
her terribly and she was terrified at the thought of her or us not surviving it. So it is understandable that afterwards, she simply didn't want to hear about any 'Gypsies' ever again. Mum didn't see us as Roma, we were hers only, which is bizarre, isn't it? So, my coming out at 17 was a bit of a surprise for my mum, she turned it against herself: no man was around, meaning that she didn't give us a happy childhood and teenage years. She also entertained the thought that it has to be related to 'bad blood, the Romani blood,' that it is some sort of a 'stray, degenerative gene'. (Veronika)

It is possible to observe that the negative light in which Veronika saw her own Romani ethnic identity was informed by her mother's difficult relationship with her father. Veronika's ethnic identity ended up being stigmatised in ways similar to the stigmatisation experienced previously by her mother for marrying a Romani man. In Veronika's case, though, her stigmatised ethnic identity intersects with her stigmatised sexuality: her mother irrationally associated Veronika's 'bad Romani gene' with her nonheteronormative sexuality. This example of intersectional stigmatisation is reminiscent of the account by Arpad in the previous section. Both stories demonstrate the crucial role that families and parents play in the sense that queer Roma make of their non-normative ethnic/'racial' and sexual identities due to the negative valuation of these identities; and in the identifications that queer Roma make.

Within the heteronormative cultural script of majority societies, some Romani families may reproduce the workings of heteronormativity and patriarchy and impose them on queer Roma. However, others may not abide by these social norms, or they may simply enable and validate the existence of LGBTIQ family members, as shown in the following testimonies from a bi Traveller in his late forties based in the United Kingdom (UK) and three Czech Romani lesbian women in their 30s:

In my family, there are a couple of gays and I know of two lesbians. I remember my mum had gay friends. (Jolana)

My mum had sexual contact with women; she has a tattoo of a woman on her lower back. (Gabriela)

My mum and dad separated and my mum went into a relationship with a woman that involved her going back to live in a trailer. (Michael)

Our Romani family had a female family member, S., who from a certain point in time asked to be referred to by a male name. When I was a kid, I didn't know that he had been a woman. I realised that in my adulthood. These days, when I've tried to speak to her about it, I found it was impossible. She doesn't want to discuss the topic or if she 
ends up discussing an aspect of it, she tells these stories about how many women she had where she lives, all of them were straight. I don't really know what happened or how it happened. It's not important. What matters is that there's such a person in our family. Also, there's my cousin who is gay. There's also this rumour that one of my father's brother's is possibly in the closet. He's a very effeminate man. In his marriage, the gender roles are reversed. My aunt is very masculine, she reads the newspaper. Uncle does the washing, he hangs the washed clothes, cooks, opens the door when someone rings the doorbell. $\mathrm{He}$ always wears his cute little apron and stockings. (Veronika)

All of the above stories point to the presence of non-heteronormative, queer family members in the families of Jolana, Gabriela, Michael and Veronika across several generations. Veronika's story in particular also points to how, in Romani households made up of opposite-sex partners or spouses that is, a woman and a man, gender roles may be performed, switched up or even swapped outside the constraints of heterosexual norms. By contrast, some conservative Romani families at times perceive being lesbian, gay or bi as socially unacceptable or unnatural while they may view transitioning from female to male or vice versa more favourably. In the following quote, Dominik details his Romani family's positive response to his transition:

My mum was terrified because she didn't know how my Romani dad's side of the family would take it. They see being gay as something bad. But they took it really well because they wanted me to be ok, healthy and happy, irrespective of who I would become. This helped me tremendously in terms of deciding to transition, this kind of family support. The Romani part of my family takes it as if I've been cured. For them, this alternative is better than me being a homosexual. At least for my grandparents and his side of the family. All over the world, the man means more than the woman, so I've been improved, or upgraded in their eyes, as it were [laughter]. I don't try to talk them out of it if it's better for them this way or if they justify it to themselves like this. They treat me normally, so I accept it. My father has become so tolerant that he told me that he would be OK if I brought a man home. (Dominik)

While Dominik's Romani family members perceived lesbianism as a stigmatised identity, they accepted his transition from female to male. Having his family's full acceptance and support was a key factor that facilitated his transition. In this patriarchal world, they understood his transition as an improvement. Dominik's becoming a man who is attracted to women also meant that he was cured of lesbianism. Dominik also dwells upon his father's acceptance of his gender identity and potentially his sexuality: that is, his father's openness to the possibility of Dominik being in a gay relationship. Dominik's gender identity, sexuality and ethnicity have 
intersected in a specific way, enabling him to pass and to be accepted as a man. Comparing Dominik's experience of transitioning with that of Markus in the previous section, we can see that the two Romani trans men have been gendered and ethnicised/'racialised' differently, depending on the social settings they have navigated. In Dominik's case, his Romani family saw his manhood as a privileging 'upgrade'. By contrast, Markus's ethnicity/'race', sex/gender and gender identity intersected to his disadvantage: his ethnicised/'racialised' masculinity as a man of colour in a whitenormative environment was seen as a threat.

Dominik's non-normative gender identity and his gender transition are important also for another reason: one of his coming-outs as a trans man was made by his partner. In the following quote, Jolana describes her experience of outing Dominik:

Dad is a bit macho and doesn't like the idea of two men being together. Mum used to have gay friends but dad was glad because they weren't a threat. And when I started having gay friends, dad said mum had brought it into the family. But he knows he can't hold a grudge against my gay friends because they really helped me. Initially, when I told dad about Dominik being born as a girl, he was shocked. And naturally, I told him immediately: 'Now he's a man and he's been a man since childhood, it's just that he was born into the wrong body and there are so many of us'. And I said 'look, dad, I haven't chosen my chronic illness either, so knowing that you can really understand that it is not the person's fault, is it? ... that they are born this way. I apologised to him for placing an even bigger burden on his shoulders after everything we have been through as a family. It took him about two days to digest the information. But he accepted it. And I even said to Dominik after I had told dad: 'I actually came out!' [laughter] So now I belong with the $\mathrm{Q}$ [queer] group, too. (Jolana)

It is evident that Dominik's gender identity as a trans man was more acceptable for Jolana's dad than being gay. Jolana's experience of being ill was instrumental to her father's acceptance of Dominik's gender identity since they led to the presumption that Dominik's embodied limitations were okay because he was in the 'wrong body' (Stryker 1994; Halberstam 1998). Additionally, by outing Dominik, Jolana effectively revealed her sexuality to her father. Jolana's sexuality, which had been heteronormative until then, became queer, non-normative in a relational manner: through her relationship with Dominik. In a sense, both Dominik and Jolana have been in a constant, fluid process of multiple becomings through each other. Dominik has become Roma through Jolana; and Jolana has become queer through Dominik.

The topic of conservative attitudes to same-sex relationships, discussed by Dominik and Jolana, is explored by Kerttu. In the following quote, she talks about her family's response to her sexuality. 
Mum was very happy when I was together with my Romani girlfriend, visiting her. She was calling me often and always asking 'how is she?' She never ever turned against me. So that was kind of really funny because she was really traditional. Somehow, I think my biological mum was happy that I had a Romani girlfriend and she got to know her well during those years. The only person who I have been able to talk to about my lifestyle, my identity, is actually my sister. But the first time I really wanted to talk about that, I was already 40 something and she had problems with her husband and so on. Suddenly my way of living came into the picture and she turned it against me. The atmosphere of what we have now is ok, we are friends, we are sisters, we see each other, but basically, I don't talk about the feelings which I have for my partner at all. She has grown up with our parents and at some point, religion came into the picture, and you know what the Lutheran church and other churches say about homosexuality: it's against our religion to have this kind of relationship. She was talking about those things and somehow, I don't know because at the same time she's saying 'you're my sister, whatever you do, it's fine.' I can't trust her anymore. (Kerrtu)

Kerttu describes the difference between her conservative mother's acceptance of her sexuality and her religious sister's negative attitude towards homosexuality, as she puts it, shaped by the church. Kerttu's mother's cultural conservatism was not an impediment to her acceptance of Kerttu's lesbianism. However, her sister's religious conservatism echoes some of the ways in which conservatism works to preserve heteronormativity and patriarchy, including through opposite-sex marriage discussed in the previous section. Thus, within her Romani family, Kerrtu has experienced lack of acceptance from her sister and acceptance from her mother. Kerrtu's experiences show that certain types of conservatism within Romani culture can be accepting of queer (non-normative) sexualities and gender identities.

The issue of acceptance of queer Roma identities is also explored by Zoltan, a Hungarian gender-queer Romani man in his late twenties, in relation to his queer hyper-visibility. In the following quote, he dwells on his hyper-visibility as a very effeminate gay man from a very young age.

Sometimes I'm noticed as a female, from people on the street. For me, being gay was a very obvious thing from the age of five. One Christmas I asked my parents for a barbie doll and they bought it for me. They also bought me a train in the hope that maybe I would play with it. One and a half years ago, I went to my family, I asked everybody to sit down in the living room: they knew what I wanted to tell them. My mother told me 'why didn't you tell me before?' And I told her 'because I didn't want to hurt you.' My mother replied: 'I also was so scared that I will hurt you if I will tell about it because I know you are a very sensitive boy.' From my deceased father's side, everybody's dead unfortunately. 
On my mother's side, we have a very big Gypsy family. For years, they've been asking 'do you have a girlfriend?' and I always said 'no'. From a certain point, they just finished the questioning: it was obvious for everybody what is going on. It was just like 'you're fine'. They're not very well educated and what I really think is it's easier for them to accepting someone. They are simple people in a good way. Whilst we were in the garden, my godfather asked me 'do you have a girlfriend ever?' and I just told him 'no, I won't.' And he just winked at me and said in silence 'son, it's ok'. So that was it. I think it's not necessary to talk about it more until I have found a sweetheart that I can introduce to them. Probably they will be surprised by my [masculine] type of boys but they would accept it very easily, I think. (Zoltan)

From a very young age, Zoltan's parents were accepting of his queer sexual and gender identity and queer hyper-visibility. When he eventually came out as gay to his mother and sister in his mid-twenties, they accepted him. Zoltan goes on to discuss the positive, accepting response by his extended Romani family, to whom he never directly came out. Zoltan makes an interesting point about the extended family's lack of education impacting positively on their acceptance of his hyper-visible queer sexuality and gender identity. Contrary to a common belief where education tends to be often cited as a key factor enabling liberal thinking with respect to queer sexual and gender identities, in Zoltan's case, lack of education was not necessarily a hindrance to the acceptance of queer identities, and of those that are hyper-visible in particular.

The hyper-visibility of some queer sexual and gender identities is also addressed by Teresa, a Romani queer, fluidly gendered woman in her midthirties living in Austria. In the following quote, she talks about how her family responded to her sexual and gender identity:

I went to my parents and grandfather and said: 'hey, when we're going to hospital? You have to change my gender'. [chuckles] I was only five. They didn't really take it seriously because I was so small. Many of us we're getting a second name, like a Romani name. This is a very old tradition because we had to survive, so we had an official name for the whites. My grandmother gave me this name and the name is male. They never said e Teresa, 'e' is for female, they said: 'o Teresa'. So, all my family, I'm used to be like in a male article from the beginning. They also said: 'Teresa is muskaraca'. Muskaraca is like male-ish. These typical things that I hated of girls, I was really like a typical boy. But really, they took it - what was interesting - quite normal. But I think they were not so worried because they don't have any idea of being trans, they just took me like I was. My parents, they were really good with it. I want a toy gun and they bought me a gun. And I wanted sport shoes or boxers and high heels when we were older. It was like 'ok, 
[male name] is like that'. But I think they never took it really seriously before my puberty. At 15 or 16, I was really afraid that my parents would find out. This was a big deal. They wanted me to get married and this was like 'wow, no way' and I was really behaving like one catastrophe. Then my mother suddenly said that she wanted to speak with me. A neighbour saw me and my girlfriend kissing on the street and told my mother. She was asking me if this is true and I said: 'yes, and what if it would be true?' And she said: 'Then you're not my daughter anymore because it's nothing to do with our community and this is a big shame.' And then I said: 'Ok, then I'm not your daughter anymore'. I took my stuff and left. It took many years that I started to talk to them again. (Teresa)

Both Zoltan and Teresa touch upon two issues: how parents may understand their children's queer hyper-visibility; and how queer hyper-visibility plays out through the life course. In the above narrative, Teresa discusses her experience of being hyper-visible as queer from a young age. Despite being accepted and encouraged by her family to be her tomboyish self as a child - something that was also reflected by her Romani nickname - Teresa believes that she was too young for her family to understand what her being queer was. Both Zoltan and Teresa's stories signal that their parents were aware of the sexual and gender difference: Zoltan wanted to be a girl and Teresa wanted to be a boy. Within the heteronormative matrix, Zoltan and Teresa's queer visibility as children made them hyper-visible. Zoltan and Teresa's queer hyper-visibility has played out differently for each of them: Zoltan's family remained accepting of his hyper-visible queer identity through his teenage and adult years. In Teresa's case, her family's conservative views on lesbianism being un-Romani and shameful - and the cooption of heteronormativity into what constitutes supposedly authentic Romani ethnic identity - played a crucial role in Teresa's mother disowning her for some time. Teresa's account indicates that her family's views have changed over time: they eventually came to take her back and accept her. However, leaving the family for a period of time as a result of rejection is a traumatic experience in and of itself. It may also come at the expense of being left alone in an unknown and hostile society, particularly in situations of material deprivation, unemployment or homelessness. Supported by Jolana, Constantin and Kerttu's stories about ethnic/'racial' hyper-visibility, Zoltan and Teresa's experiences of queer hyper-visibility help build our understanding the role hyper-visibility - whether ethnic/'racial' or queer plays in accentuating the assumed non-normative ethnic/'racial', sexual and gender difference of queer Roma vis-à-vis white-normativity, heteronormativity and cisnormativity.

Queer Roma and their families and kinship structures are located within the broader fabric of communities. This impacts on and exacerbates the queer intersectional specificity that queer Roma experience. Just like in the 
case with families, communities are safety nets key for livelihood, survival, socio-economic and material security, safety and protection from antigypsyism. Yet, the function of communities is distinct in that they often tend to operate as super-structures in relation to families and individuals, exerting authority and social control particularly in terms of hegemonic power relations, moral conventions and social norms. They tend to provide a safety net for individuals, groups, kinship structures and families. However, planted within the dominant heteronormative social fabric, communities often reproduce and impose the workings of patriarchy, heteronormativity and cisnormativity. As such, they can be bastions of conservatism, policing identity as in the case of Romani ethnicity having been historically associated with heteronormativity (Fremlova and McGarry 2018) and preserving hegemonic power relations, for instance the workings of patriarchy critiqued by Romani intersectional feminists in relation to virginity tests, forced/arranged marriage, Romani women's rights and Romani women's social and political participation (Oprea 2004; Kóczé 2009, 2011; Brooks 2012; Gelbart 2012; Schultz 2012; Jovanovic and Daróczi 2015; and others). Communities can also be a source of social control and punishment, especially in situations where individuals, families and other kinship structures are deemed to be in breach of social conventions and norms. In such cases, individuals, families or groups of people can be ostracised or excommunicated as in the case of queer Roma (Fremlova and Georgescu 2014; Baker 2015; Jovanovic and Daróczi 2015).

As we have seen in Chapters One and Two, historically, Roma have been essentialised as poor and uneducated. This has been the case especially in relation to Romani communities that have been conflated with the 'Roma problem' (Vermeersch 2006, 182). Having been associated with being a bearer of problems as a community (Tremlett and McGarry 2013, 8, 10), for some Roma, association with Romani communities can be stigmatising. All of these relational, as well as material and contextual aspects of community dynamics therefore contribute to defining queer Roma's lived experiences. They play a crucial role in shaping queer Roma's ability to navigate and negotiate their queer intersectional specificity. Queer Roma make sense of their ethnic/'racial', sexual and gender identities through relational experiences within communities such as acceptance, inclusion (Fremlova et al. 2014), rejection and exclusion, as discussed by Michael:

At the time my mum and dad separated, my mum, who identified as pansexual, went into a relationship with a woman that involved her going back to live in a trailer. So that raised a lot of questions and a lot of conversations within the family. What was interesting of course was watching people's reactions to that, particularly men within the community because there was a kind of failure to understand almost what was going on 'cos it's like if my mum had left my dad for another man, then the men just would have gone round and beat the guy up. 
But because she left my dad and moved out and went to live with another woman - that as a response to that situation wasn't deemed to be an appropriate way to act. So, it then raised some quite interesting discussions. Leaving my dad, that's quite a big statement to make and that was almost thirty years ago, so that's a long time ago. But as I say it has kind of affected the future course of the relationships and I'm in touch and communicate with my mum's family. (Michael)

In the above account, Michael reflects on how his family failed to understand and accept his Traveller mother's queer identity. This 'big statement' - her breach of the heteronormative social script - was also rejected by the Traveller community, resulting in Michael's mother permanent exclusion from her family and community. At the same time, the community's rejection and subsequent exclusion saved her partner from a violent retaliation.

Rejection can be either permanent or temporary, as described by Ana:

In the beginning it was hard, some of my friends who are Roma said to me that I'm crazy because I'm in a relationship with a woman and what Roma community will think and say about it. But at that time, I was outside the Roma community because I grew up surrounded by the majority and I didn't care about it. But now, politically, when I explain myself, and I speak about my identities, I say I'm lesbian. Publicly, in front of Roma communities. First, they said that there is nothing like gay or lesbian [she laughs] in the Romani community but now they act like they respect it but still I hear behind my back that they are gossiping about it. (Ana)

The context of Ana's breach of the heteronormative social script was different to the situation of Michael's mother: there was no community for Ana to be excluded from as she had not grown up or lived within the Romani community. In spite of being accused of insanity and reproached for being lesbian - something that the interlocutors thought the community would deem improper, and just like in Teresa's case, un-Romani - Ana she did not care. Ana's lesbian sexuality gradually came to be accepted by the Romani communities that she engages with; or at least seemingly, or partially, because she is aware of rumours about her. In the following narrative, Aleko, a Bulgarian Romani gay man in his thirties who now lives in Belgium, expresses a similar experience in relation to his Romani community knowing he is gay. At the same time, he acknowledges that people may have an issue with him being gay.

A few weeks after I came out to my parents, they went back to Bulgaria but they asked me not to say it in the community in the village. They said: 'for us, it's okay, we're gonna live with it. But we don't think the 
community will accept it'. In the community, many people know I'm gay. No one talk about it. It's interesting because as I told the story with the guy who committed suicide, when the community knew that he's gay, often you can hear people joking about him, saying: 'look, the guy who sleeps with guys'. Maybe there are rumours but I never heard them, neither my parents. I think that's something to do with my social status. 'Cos more or less I'm a key person in my community, a person with knowledge. It's a small community which relies on its key people. There's a Roma guy who's passive gay and it's well known that he's gay. His daughter is a social worker and he's recognised as one of the leaders in the community. I mean now I make the link that actually the position you get in the majority society helps a lot for the perception in your own community. I had a boyfriend who comes also from a Muslim community and his sisters realised that he's gay and the question they put to him was 'are you receiver or giver?' And he said: 'I'm a giver' and that was well accepted. But if you're a receiver, it's really a problem. (Aleko)

Aleko dwells on the role of social status as a major factor impacting on community acceptance - or lack thereof - of a person who does not conform to heteronormative sexual and gender norms. In his account, this relates particularly to gay men who are perceived as 'passive receivers'; hence their gender is deemed female/feminine. Within patriarchy, 'female' and 'feminine' represent a marked - hence lesser - category as opposed to the unmarked - neutral - category 'male' or 'masculine'. To explain the workings of social status, Aleko gives examples of two passive gay men considered indispensable. Their communities accepted them because of their social status as key community leaders within the Romani communities, which was enhanced by their social status within non-Romani communities. This means that in this case, community acceptance was contingent upon local power relations: that is, acceptance happened for hegemonic reasons. Aleko gives the example of another passive gay man whose social status was low. In this case, he was not accepted; in fact, he was ridiculed and shamed as 'the guy who sleeps with guys'. Aleko's narrative demonstrates that the nexus of local power relations, social status, ethnicity/'race', sex/gender, sexuality and gender identity plays a key role, at times functioning as a mitigating factor, determining whether or not queer Roma get accepted, rejected, or at times shamed by their respective communities. A similar idea that some passive gay men (receivers) who do not occupy a position of power get shamed, or indeed slut-shamed was expressed by Bruno, a middle-aged Spanish Romani gay man:

When somebody in the community is visibly gay and is very effeminate, then, he's the bitch of the community. You have a lot of married guys that go and fuck this guy. She may be discrete [he chuckles] but all the 
people know. I think this example very clear shows the position of the community. (Bruno)

The more the majority society, for example, Serbian or Montenegro society, is conservative, the more obvious is the division into active and passive, butch and femme. It's not specific for Roma. Roma people just took lots of prejudice from their surroundings and adapted that one. that's the reason why [being an active gay] is more acceptable. (Ana)

Bruno's statement expands on the notion that slut/femme-shaming as a form of social control and stigmatisation that guardians of conservatism impose on the person for breaching the patriarchal, heteronormative convention. Complementing Bruno's is Ana's account of the impact of majority society's normative workings on Romani communities. These social dynamics apply to any group(ing) that insists on maintaining clear identity boundaries irrespective of their ethnic/'racial' background. As Zoltan explains in the following quote, femme shaming occurs due to breaches of norms in gay communities:

I can talk about the Hungarian gay community and the global situation. The gay feminine shaming is a living thing in the gay community. What I experienced many times in gay clubs: the stereotypical muscular gay guys are just throwing themselves about in the club and don't give a shit about me. Skinnier guys than me are coming to me and calling me 'bitch, princess, diva'. And I just tell them 'ok, honey, you have no idea how big a diva I can be if I want to'. Feminine shaming is also in the gay culture and yes, I've experienced it many times. (Zoltan)

Some Hungarian guys are handling us as 'specialty' [he gestures inverted commas with his fingers]. They see a 'Roma bull' in us. First, you take it as a compliment but after a while, it starts changing your identity. For example, you start to act more masculine because you see that more people like it. Then you realise that you don't enjoy it at all because you are simply another person. (Arpad)

In interactions with the majority, we are part of the exotic sexual safari. A lot of Gadzos like to fuck with a Rom because 'the Rom is more passionate'. I don't know how many romantic stories are in their head. But it's very similar for Roma women: the majority have the idea that Roma women are more voluptuous. (Bruno)

Sexuality is very important for many gay men. When you are single, you go on grinder, Romeo, gaydar. You can have sex when you want. 'Active' is when you look like an Arab, black, slave, with a big cock. That's a dangerous fantasy, a game for many gay non-Roma. (Antonio) 
While Zoltan's story shows that in some gay circles, masculine or neutrallooking gay men -the 'good gays' - sometimes treat gay femmes as bitches or sluts that give gays a bad name, Arpad, Bruno and Antonio's accounts point to the presence of damaging ethnic/'racial' stereotypes, objectifying and fetishizing Roma. The narratives echo some of the fundamental premises of homonormativity (Duggan 2002; Richardson 2004, 2005; O'Brian 2007 ) in relation to how asymmetrical hegemonic power relations crosscut and intersect with ethnicity/'race', sex/gender, and sexual and gender identities. Homonormativity, and homonationalism (Puar 2007) in particular, puts some gays and lesbians at an advantage while disadvantaging and marginalising other ethnicised/'racialised', classed, gendered and sexed queers (Seidman 2002; Hines 2007, 2010; Taylor 2007, 2010; Bryant 2008; Lim and Browne 2010; Taylor et al. 2010; Browne and Bakshi 2013). As a result of this dynamic, in the gay community, too, femininity in gay men is often frowned upon and shamed, placing gay femmes at the bottom of the social ladder. To escape the stigma associated with femininity in both heteronormative and homonormative settings and in order not to lose their social standing, some gay Roma feel the need to 'butch up' their masculinity, as expressed by a Hungarian gay Roma in his early thirties, Balint:

I know many gay Roma and usually they are well educated. When they go home to their own community, I mean the Roma camp or settlement, they are kind of role models in their own community. They always say it's better to look like a real man than a feminine man. If they look feminine, they cannot be a role model to the children or the Roma settlement anymore. So, this is also interesting because even the community, they guess or know that they're gay but the male has to look male. He has to have a beard, muscles and nice clothes, stuff like this, so dressing queer, let's say, then you can lose your role model and your position in the Roma community. (Balint)

As Balint's narrative shows, some Romani communities accept gay men. In this respect, class and status play an important role impacting on community acceptance of a person who does not conform to sexual and gender norms. In the case that Balint refers to, this concerns particularly those gay men perceived as passive: their gender expression, which is associated with femininity, can hinder community acceptance. The potential risk consists in the gay man's loss of his social status. The workings of the nexus of local power relations, social status, class, ethnicity/'race', sex/gender and sexuality inform the social dynamic as per Aleko's previous account.

A person's social status and class are still a source of privilege that may either engender acceptance or alleviate some of the psychological pressures associated with lack of acceptance, even persecution, as expressed by Kerrtu: 
I had three things why some Roma started to discriminate me. One was that I grew up for my first 7 years in children home. Second thing was that I didn't fit in the traditional Roma community because I have my active sport things, and I was also wearing trousers. And the third thing was of course the worst thing, I didn't have a husband and children. I was not acting the way they think lesbians are. They were confused. They think if I have had a really bad childhood and bad things happened with men, that's why I turned lesbian. But there's no reason in my case. Actually, my childhood was not so bad and I've had very nice boyfriends also. When I was working on Romani issues, there were a couple of Roma who were so much against me that they made my life with my partner living hell. We left our home country twice to be able to live how we wanted. It was really bad. I have not been working on Romani issues since I came back from abroad, so I cut all professional ties. After that I have been accepted. My saving point in that hell was that my biological Roma family was so-called good family in this country, known and respected in Romani community. The second saving point was and still is that I have a bit darker colour on my skin, curly long black hair in that time and brown eyes. I knew my relatives and traditions. And thank God I am Roma from both sides. Small things but so important. Surely saved my life during that decade of discrimination! I have decided only 10 years back that I am what I am and I do what I have to do and I want to do it but I don't need to care what they think about me and it took almost 20 years to come this long. (Kerrtu)

Kerrtu details the extent of discrimination and persecution she experienced from within the Romani community due to her sexuality and other traits considered un-Romani such as doing sports, wearing trousers or not having a husband or children. Romani lesbian women are thus perceived as subverting and disrupting conservative conceptions of womanhood and femininity. However, it was her family's class and social status that afforded her a level of acceptance. Both Kerrtu and Aleko's cases demonstrate that it is the privilege they have enjoyed as a result of their social status that impacts positively on acceptance, also enabling their non-heteronormative, queer visibility. In turn, the increased visibility has helped to validate Kerrtu's identity as a Romani lesbian woman. Identity validation as a form of acceptance was also important to Andrea, an American bi Romani woman in her 30s. In the following account, she explains how she initially felt her bisexual identity did not go together with her Romani identity:

My Romani identity was deepening at that point and I couldn't really imagine how that would go together with a bisexual identity. I was attracted to women before I was attracted to men, so it's all still a part of my sexual being ever since I can remember. I can't tell you now what 
are the factors that led to me not being in a same-sex relationship but I think it was a bunch of factors. I remember being on my campus and thinking like I really did want to be with another woman but because I wasn't that kind of social? I wasn't gonna go to a club and so it was sort of like a complete lack of opportunity, so there was that. It just didn't come up for me for whatever reason in the same way it would have if I had actually been actively dating somebody. But I did have this strong feeling that it just wouldn't fly. Not from my mother but just from everybody else. It just would not be something that I would bring up with my family members, with just anybody. I certainly didn't know really any other Roma who were in same-sex relationships. Fast forwarding from that to what's going on now, I mean not just Romani LGBTIQ pride but all the visibility on Facebook, I really think I have a whole bunch of acquaintances and some friends who are Romani and definitely gay, lesbian, bisexual. It is this affirmation of just all those things: being publicly Romani, and sort of not really publicly bisexual because of being in a monogamous heterosexual relationship. I think this advance and having my own set of identities validated this way makes it more likely that I can be more vocal in situations that I previously would have been silent. Like if I'm with a bunch of male Romani delegates and something homophobic comes up. And just riding the wave of this movement right now and also being older and more mature, I wouldn't be silent anymore, I'd call them out and be like 'don't be homophobic around me, just stop'. (Andrea)

Andrea explains how her conflicting ethnic/'racial' and sexual identities were alleviated by the recently emerged queer Romani visibility. The point she makes about visibility is similar to the one made by Kerrtu. For her, too, queer Romani visibility has been a principal factor enabling the validation of her intersecting identities as a Romani bisexual woman. This validation has enabled her to speak up and challenge homophobic language and conduct, hence undermining homophobia within the hegemonic dominance of heteronormativity and patriarchy, which is explored in Chapter Four.

\section{Conclusion}

In this chapter, we have seen that due to the negative social valuation of Romani ethnic identity that lies at the root of antigypsyism, non-Roma often stereotypically associate Roma with stigmatising conceptions of Romani ethnicity. This happens through Romani ethnic hyper-visibility that marks out and precludes Roma from belonging as ordinary and blending in just like everyone else. Indeed, queer Roma experience antigypsyism in a variety of settings, including LGBTIQ ones: there, queer Roma are often ethnicised/'racialised'. Antigypsyism thus emerges as a preeminent form of oppression. Although antigypsyism often eclipses other 
experiences of oppression, it is not the only form of oppression queer Roma experience: some experience stigmatisation of the intersection of nonnormative (queer) ethnic/'racial', sexual and gender identities.

We have seen that queer Roma are part of the wider society, Romani family, kinship and community structures. This means that the lived experiences of queer Roma are relational, unfolding through and around nuclear and extended families and communities. In the face of persisting antigypsyism, the social marginalisation and socio-economic poverty of Roma in majority societies, many depend upon these key social units for safety, livelihood, survival and protection from antigypsyism. Within the heteronormative social script of the majority, this creates a particular vulnerability and a queer intersectional specificity for queer Roma within both Romani and non-Romani communities.

As complex as family and community relationships can be, they add another layer of complexity to the lived experiences of queer Roma: this includes acceptance, inclusion, rejection and exclusion. These relationships impact fundamentally on the agency and ability of queer Roma to enact non-normative sexuality and gender identity. Conservatism within some Romani families and communities may engender rejection: breaching the heteronormative norm may result in permanent exclusion from the community. Conversely, some Romani families accept their trans children's non-normative gender identity but may at times reject those who are gay or lesbian. Importantly, this chapter has also demonstrated that Romani families and communities can be accepting of queer Roma who, through agency, enact their non-normative sexualities and gender identities, including those who experience queer hyper-visibility, at times irrespective of low levels of education. While families and communities may see nonnormative, queer sexualities and gender identities as un-Romani, over time, they may come to accept them as part of Romani ethnic identity.

Within both bon-Romani and Romani communities, structural inequalities and the workings of sex/gender result in Romani queer women's multiple invisibility. Simultaneously, some Romani gay men's experiences are also impacted by social normativities, particularly with respect to mechanisms of social control enforcing heteronormative and patriarchal social norms and paradigms. In heteronormative and cisnormative settings, sex/ gender, sexuality and gender identity intersect with ethnicity/'race', creating conceptions of what is perceived as constituting traits of authentic Romani ethnic identity in Romani women and men. Romani lesbians who do not comply are seen as undermining heteronormative conceptions of Romanipen, womanhood and femininity while Romani passive gays are seen as antithetical to masculinity. What is seen as femininity in some passive gay men sometimes results in shaming and the attendant loss of social status. The nexus of power relations, class, good social status, ethnicity/'race', sexuality and gender identity plays a significant role enabling acceptance. Good social status is a privilege that may validate the identities 


\section{4 'We're here, we're Roma and queer!'}

of queer Roma by alleviating some of the strain associated with rejection, engendering acceptance and enhancing visibility. Thus, certain intersections of queer identities are enabled and validated while others are made hard or impossible. In the case of some Romani trans men, ethnicity/'race' gets sexed and gendered while sex/gender is ethnicised/'racialised' in either unfavourable or favourable ways, depending on the environments that they navigate.

The identities of queer Roma are in a permanent process of becoming, informed by asymmetrical hegemonic power relations in a dialogical and discursive way, within a variety of settings, including Romani families and communities; and non-Romani LGBTIQ and straight communities. In that sense, they are socially constructed, not essentially given. Queer Romani identities are shaped in an assemblage-like way, against the backdrop of the interlocking axes of oppression, inequality and social normativities: whitenormativity, heteronormativity, cisnormativity and patriarchy. Thus, the material, relational and contextual specificity of the lived experiences of queer Roma is brought into effect.

\section{Note}

1 Vladimir Tismaneanu, an acclaimed Eastern European scholar at the University of Maryland, posted a meme late on April 10 in which Roma were compared to crows, a widely used, derogatory expression in Romanian for Roma and Africans. 'Depiction of Roma as Crows Exposes Deeper Racism within Romania', 16 April 2020, accessed 29 September 2020, https://www.rferl.org/a/ depiction-of-roma-as-crows-exposes-deeper-racism-within-romania/3055 8933.html. 


\section{Visibility in spaces between difference and sameness}

This chapter explores queer Roma's lived experiences in relation to visibility in spaces between difference and sameness. It builds on the theoretical considerations in Chapter Two pertaining to marked essentialist ethnic/ 'racial' difference lying at the root of the negative social valuation of Romani ethnicity and the notion of stigmatised, closeted, deviant, perverse and pathologised Romani ethnic identities. This chapter further expands on the link between the closet of ethnic/'racial', sexual and gender - or queer identities. It also draws on the analytical insights from Chapter Three in relation to the queer intersectional specificity experienced by queer Roma vis-à-vis the attendant ethnic/'racial' and queer visibility, including hypervisibility and invisibility, within non-Romani society, LGBTIQ communities and Romani families and communities. The chapter first considers queer Roma's visibility and the resulting ethnic/'racial' and queer closets as survival strategies responding to and protecting their users from antigypsyism and its intersections with homophobia, transphobia and sexism. The chapter then goes on to explore another aspect of the closet, which may also be considered a separate strategy rendering its users invisible: ethnic/ 'racial' and queer passing. Finally, the chapter introduces the notion of strategic sameness not only as an extension of passing, but also as a subversive queer positionality that unsettles and challenges binary social norms and normativities.

\section{The closet}

Chapter Two established that the closet is as a powerful metaphor and a useful analytical tool. It enables conceptualisations relating to the concealment or disclosure of queer sexualities and gender identities in relation to the hegemonic workings of heterosexual and cisgender identities as normative social scripts. Notwithstanding its importance, the closet also entails some problematic aspects. We have seen that its ethnocentrism suggests there is or should be only one true way of liberating oneself from the constraints of heteronormativity and cisnormativity. As an analytic, the closet does not always acknowledge the relational, contextual and material 
specificity or the resulting social positioning of various Western, as well as non-Western queer individuals and communities outside the assumed ethnic/'racial' centre. For example, the expectation that all queer people will come out of the closet in order to be considered authentic and honest about who they are somehow seems to indicate that those who do not or cannot come out of the closet are considered somehow inauthentic and dishonest. As this chapter and Chapter Five will show, these considerations are particularly relevant to the lived experiences of queer Roma coming from across and outside of Europe.

In the previous chapter, we saw that ethnic/'racial' and queer visibility are directly linked to queer Roma's experiences of antigypsyism and intersectional stigmatisation of ethnic/'racial' and queer identities. Therefore, ethnic/'racial' and queer visibility may be understood as closely associated with the ethnic/'racial' and queer closets. Depending on the context, when availing oneself of the protective nature of the closet, one steps in or out of the closet. In the following quote, John, a United States (US)-born Romani gay man in his mid-forties, elaborates on his experience of the Romani ethnic/'racial' closet and the gay closet.

My mother taught me that being Roma is something that you hide. Being Roma and being able to hide it because my family come from what used to be Czechoslovakia, I grew up in North America and I moved to the Czech Republic in the 1990s. And nobody knew that I was Roma at work. And my mother told me never to tell anybody. And for me this is very strange in the US, in a multicultural society, everybody is happy to be Irish American, Italian American. It's a multiple identity; I could be in the closet as a Roma, I could be in the closet as a gay person. Gradually I got to know people but it was only a few years ago that I attended a conference: Roma intellectuals who were very open-minded and LGBTIQ friendly - they weren't LGBTIQ themselves - and this kind of made me at ease in my own skin, that I can be who I am, doesn't matter where, whether it's in another Roma setting. It took me a long time to come to this point, and for me it's a fundamental part of my identity but it took a long time for me to reconcile these two issues. (John)

John's testimony echoes what Hancock expresses as follows: 'I know of very few [Roma] who weren't warned as children to keep their ethnicity to themselves outside of the community' $(1998,3)$. The generational experience of employing the ethnic/'racial' closet that John talks about refers to the ability of some Roma to render their Romani identity invisible. The protective aspect of his mother's decision to hide the family's ethnicity can be seen as a survival strategy used as protection from antigypsyism. It can also be understood as an ability to hide one's Romani identity, and the attendant quality of being unidentifiable as Roma by others - or passing as 
non-Roma. John's account above suggests that he availed himself of the ethnic/'racial' closet to help him navigate non-Romani social settings, particularly those which are hostile or threatening to queer Roma; and to protect him from being socially stigmatised by Romani ethnicity in those settings. His experiences of navigating ethnic/'racial' oppression seem to have informed his use of the queer closet also as a survival strategy, protecting him from homophobia in a variety of settings, including Romani ones. Consequently, for a duration, this queer intersectional specificity gave rise to John's intersectional closet, helping to render his ethnic/'racial' and sexual identities invisible until the moment he decided to disclose them: that is, after the settings changed or when he felt safe enough to do so. In John's story, the ethnic/'racial' and queer closets may be also thought of as notional spaces shielding queer Roma from the negative social valuation of their non-normative intersectional identities as different, pathological, deviating from the assumed white, heterosexual and cisgender norm; and from antigypsyism and its intersections with homophobia, transphobia and sexism.

In a similar vein, Aleko describes his experience of using the protection afforded by the ethnic/'racial' closet and the queer closet.

At school, there were predominantly ethnic Bulgarians, a few Turkish people. I was the first Roma in the secondary school. I was hiding my identity until the moment one of my teachers discovered that I'm Roma: she asked me openly a question about my identity in front of the class. My classmates started to take actions against me like moving my chair all the time, making jokes about my identity, asking why I am not black and I'm white. After a month, the school decided to move my place among the girls. For the following 3.5 years, I was sitting with the girls; the only boy who sits with girls. The experience was quite OK because firstly I was freer there and I think in a sense I was less apparent for my sexuality. It was easier accepted, for example if we go for a coffee break, I would go with a group of four girls and not with the boys. After this moment there was no real reaction. I became very visible. I didn't expect that is gonna be good; but it was a good thing. With the girls I was more open, in the beginning they were starting to ask 'B, do you like also boys?' I never said openly I liked boys but all of them guessed that I'm gay, I never had a girlfriend; it was like 'ok, we have the sissy boy here', like the best friend. At university, the problem with identity came back. It was clear that I'm not ethnic Bulgarian, I had to pretend I'm not Roma either. I was saying 'I'm a Turk as well' because the Turkish minority was better accepted than the Roma minority. But in my group, we were like 60 people and within a few months I realised that there are another three Roma. We succeeded to become a small informal group within the bigger one. And among us, we were ok with our identity, ethnicity. In the second year, there were 
ethnic Bulgarian girls from the 3rd year. And then they brought me to a gay club. They were lesbians and I realised afterwards. It was nice and I started to be part of this group also. I had a non-Roma boyfriend at university. My friends at university never talked openly about it. But they knew that I had a relation with the boy because they were seeing us always together, no one questioned it. (Aleko)

In Aleko's story, it is possible to see the intersection of the ethnic/'racial' and queer closets. Aleko, who hid both his Romani and gay identity, recounts his multifaceted experiences of being hyper-visible both as Roma and gay whilst also managing to stay invisible as Roma and gay. In so doing, Aleko demonstrates that it is possible to be hyper-visible and simultaneously in the closet, thus suggesting that one can hide in plain sight, as it were. For example, the all-female social setting enabled Aleko to be 'less apparent for [his] sexuality'. This reiterates and underlines the importance of the contextual and relational dimensions of the closet. The context in which the closet is strategically deployed is constituted and reconstituted through social relationships. This requires the queer Roma person at issue to be able to read the social settings they navigate. They need to be able to pick up on various cues and to make important choices relating to whether or not it is safe for them to come out of the closet: that is, to out themselves as Roma and LGBTIQ. Aleko's account of the closet demonstrates that there is a direct relationship between hyper-visibility, which I previously discussed in Chapter Three in relation to antigypsyism, and the invisibility afforded by the closet. Additionally, the notion of the closet being the opposite to hyper-visibility is contested by Aleko whose experiences challenge the binary of being hyper-visible/out of the closet on the one hand and being invisible/in the closet on the other. The closet can thus be understood as a notional space - both relational and contextual - in which the queer Roma person at issue constantly negotiates and renegotiates the boundary separating difference and sameness, as well as the spaces in between. The queer Romani person thus walks a very fine line delineating the spaces, in which they are read as different from or the same as the assumed ethnic/'racial', sexual or gender norm.

Both Aleko and John's stories indicate - albeit to different degrees - that at different points in time, in different social settings, they were able to avail themselves of the protection offered by the ethnic/'racial' closet. The ability to do so can be understood as a privileging factor: the often-wished-for protection afforded by the ethnic/ 'racial' closet is not available to everyone. For example, in Chapter Three, Jolana, Kerttu and Constantin described how, due to the hyper-visibility of Romani ethnic identity, they were not able to pass as non-Roma, as expressed by Constantin in the following quote:

Maybe my mind wanted to [deal with my sexuality] but my brain refused because I was afraid. I was dealing with being an orphan and 
being Rom, too. And this issue was very difficult, to accept another discrimination as being gay, too; it was too much. Exact the same thing how I suspect for the Roma discrimination. So imagine if you're worried, discriminated as Rom and then many issues and you're discriminated all the time, you hear bad things and you become very depressed and very tired, you don't feel like hearing these things so it's better to hide [being gay], protect yourself from that discrimination. I already accepted being Roma... but it's harder to come out as gay. (Constantin)

In Constantin's experience, maintaining the intersectional closet as an orphaned gay Roma also means prioritising and strategising in terms of his ability to cope. As a result of his experiences of intersectional oppression, Constantin felt that taking on the additional pressure associated with coming out as gay would be too much. Even though - or perhaps precisely because - he cannot be protected by his ethnic/'racial' closet due to his Romani hyper-visibility, he makes his sexuality go away, as it were, by maintaining the queer closet. Similar to Aleko, Constantin's story shows that some queer Roma are ethnically/'racially' hyper-visible as Roma but are able to stay invisible as queer.

Paraphrasing Kosofsky Sedgwick's (1990) analogy with racism, antigypsyism can be seen as a form of oppression based on the Romani ethnic stigma that is visible - at times hyper-visible - 'in all but exceptional cases' (ibid 1990, 75). In light of Zoltan and Teresa's experiences of queer hypervisibility discussed in Chapter Three, it is possible to argue that homophobia and transphobia, too, are based on a visible stigma. Though the queer closet does not entail the biological essentialism of 'a clear ancestral linearity' or the cultural essentialism of the family's 'originary culture' (Kosofsky Sedgwick 1990, 75), the queer stigma is visible and, at times, hyper-visible. What Kosofky Sedgwick suggests is that the queer closet is somehow less given due to being unancestral, thus involving a distinct set of factors relating to how sexual and gender identities and the assumed difference are constructed. This binary opposition of the queer and the ethnic/ 'racial' closets implied by Kosofsky Sedgwick is challenged by queer Roma's accounts of the intersectional closet. Echoing John and Aleko's experiences, the queer intersectional specificity experienced by queer Roma entails two or more categories of identification, interacting and intersecting with each other. The construction of the queer closet thus intersects with and is informed by the construction of the ethnic/'racial' closet and vice versa. The above stories add to our understanding of the queer intersectional specificity experienced by queer Roma who navigate the spaces between ethnic/ 'racial', sexual and gender difference and sameness depending on the context of social settings.

In this section, John has discussed his use of the ethnic/'racial' and the queer closets at a time when he felt he could not be visible as Roma and gay. 
In the following quote, John talks about the process of arriving at the point where he no longer needed the protection of the closet.

Now, it's just simply part of my identity, I feel comfortable with it, I am who I am and no one can take that away from me. But: it took me a long time to get to this point. And it was a lot of effort to come to this point because you have to deal with being gay. Period. Come out to yourself, come out to your friends, come out to your family. This is a self-discovery process, it is an engagement process. And I missed knowing that there are other LGBT people, I missed knowing that there are LGBT Roma. The fact that we have a group like this or if it only existed on the internet before, I feel like I'm a complete person and I can deal better in society knowing that there are other people like me. And I think it's important to see there are other people like me and I think it's important for children if they're in Macedonia or in Spain and if they're gay and they're in a Gypsy community they need to know that there are other gay Gypsies in the world, that it's not just them. This isolation is what kills people and I'm interested in being visible for those people. That's what most important because that's what was missing for me. (John)

Talking about the intersectional closet of queer Romani identities, John touches upon the consequences of invisibility and the resulting sense of social isolation of queer Roma. He draws parallels between what was missing for him in terms of contact and interaction with other queer Roma and what may be for missing for queer Roma today. While queer Roma who are vulnerable to antigypsyism and its intersections with homophobia, transphobia and sexism often feel they need the protection of the closet, its invisibilising effect makes it seem as if queer Roma do not exist. John has experienced 'this isolation [that] kills people'. Consequently, he sees his own Romani gay visibility and the visible existence of the LGBTIQ Roma movement as a process: a vehicle for validating the queer intersectional identities of queer Roma. In a similar spirit, in the following quote, Bruno makes a number of observations in relation to the invisibility of queer Roma.

It's your self-process for accepting yourself and to be in the community. It doesn't apply to Roma only, it's a general thing in the gay community. Can you imagine what it is like in Spain? There, you don't have any information, any reference, you don't know what it's like to be gay. To be gay, is it to be crazy or to wear flowers in your hair? You don't know what your position is. It's something that Roma gays need to think about more. It's true that on TV, you start to see some roles gay people play; they are married, they need to be out of the closet. And you think: Hmmm, really, can I do this? Or what is my 
position as a gay Roma? How can I have self-esteem and be selfconfident and proud of who I am and my position and not to regret it after making this step? It's for this that visibility is important. It is important to have safe space to speak because first you need to be hidden, secretive in the community, you want to speak about what you do. You are in the middle of a party and the first thing you do when you go to the bar is [he gestures looking around in a cautious way] you look if you see another Roma. If you see another Roma in the bar [he makes a frightened noise] directly you put yourself in the position of a macho but you don't like that the other people know. (Bruno)

According to Bruno, when coming to accept themselves, queer Roma often do not have a connection with other queer Roma who would reassure them that they are not the 'only gay Roma in the village' and that it is 'okay to be gay'. Consequently, queer Roma may feel isolated; they may not know what it means to be a queer Romani person. Such a stigmatised and closeted conception of one's own sexual, gender and ethnic/'racial' identity may mean that queer Roma will resort to employing the queer closet so as to protect themselves from homophobia. Bruno's account echoes John's ideas about social isolation, as well as the life stories of queer Roma regarding visibility, invisibility, acceptance and rejection in some Romani families and communities in Chapter Three. This lack of visibility, including the lack of information about queer Roma, may be more pronounced in some countries than in others; and indeed, in some insulated, rural areas in the individual counties. This specificity adds to the relational, as well as contextual complexity of how the ethnic/'racial' and queer closets are constructed.

As regards the predominantly white-normative ethnocentrism of the closet, Chapter Two touched upon the notion that queer sexualities and gender identities are constructed specifically in various societies and communities, including in some Romani communities: we saw some examples in Chapter Three. This specificity may relate to dominant heteronormative and cisnormative cultural scripts present within the context of specific social, spatial, temporal and material realities. Consequently, according to Tucker (2009), the heterosexual/homosexual binary may be constructed in quite specific ways and therefore, the closet is not always a viable strategy for every queer person. This observation is echoed by Teresa:

I don't say that I'm lesbian or queer. Part of my family is really 'from yesterday', they're still like 'but when are you going to get married?'. I would of course prefer to be like 'I'm out, I'm proud' and talk to them about it. I prefer out of the closet, definitely. But with the family, it's really different. On one hand, I'm pretty like lucky that now they kind of know it but we don't talk about it and that my girlfriend was always welcome and my parents were really warm, welcoming and also my brother knows it and is fine. The only thing that really bothers me is for 
example because my mother is always very curious to know how my [siblings] are with their partners, especially if it doesn't work. They break up or worse... and my mother is 'oh my god, what happened? Why?' And I remember for me this was like the biggest love of my life and the longest relationship with this girl, we were like four years together officially but unofficially six years. But when she broke up with me and it was for sure the most intense relationship, I was really broken and my mother didn't even ask how I am. And that really hurts. Suddenly she disappeared and my parents never asked me where she is or what happened (Teresa).

In the previous chapter, we saw how for a duration, Teresa's family's conservative views on lesbianism being un-Romani and shameful played a crucial role in her mother disowning her. Teresa's story above shows that in such complex family and community relations, coming out of the queer closet is not always the only strategy by means of which queer Roma enact non-normative sexual and gender identities. Some queer Roma may choose to stay in the closet fully or partially in order not to sever vital social, community and familial ties, bonds and relationships that they depend upon for survival, safety and protection from antigypsyism.

Chapter Three also demonstrated how, in some Romani communities, Romani lesbian women's restricted visibility contributes to rendering their non-heteronormative (queer) existence invisible, coded and implicit. Yet, as Gabriela suggests in the following quote, in some Czech Romani communities, Romani lesbians now experience a greater degree of freedom in terms of being out of the closet than before:

Back then, everyone was hiding it, weren't they? They didn't come out, so I think it's amazing now. Finally, Romani women are lesbians! And bi! At last, the news is out! The fact that they found out that they can speak up! People take it differently now, parents as well, it depends though. (...) But I think it's superb, Romani lesbian. I'm proud of it. My parents accepted it, and so did my sisters. It was a year ago, I had kept it a secret for a long time. I left home at 17 but I had to tell them, didn't I? Because it is clear, when you don't have children, you are almost 33. So, I kept thinking on it and decided I could no longer lie to them. So, I told them and all was ok. One feels relieved when you say it, when you come out as opposed to bottling it up, right? I know a Vlax Romani lesbian who moved away: she had come out and her parents shaved her head, and then she went into hiding and stuff. I have a cousin and he feels he's a woman and dresses as a woman. Her parents didn't know that she's trans. She found a boyfriend. I bumped into her at a disco and she was so unhappy. So I told her to come out to her parents; whenever she needed, I would support her by messaging her and meeting her for a chat. Recently, they had a wedding. She wore a beautiful dress. There were lots of Roma, it was amazing. (Gabriela) 
Gabriela talks about what she perceives as a positive change with respect to the acceptance of Roma who are openly queer in some Czech Romani communities. Gabriela touches upon her own experiences of coming out as a Romani lesbian and being accepted by her family. According to her, this openness to Romani queer sexualities and gender identities in some Romani communities contributes to making queer Roma more likely to come out of both the ethnic/'racial' closet and the queer closet. This, in turn, enables greater visibility of queer Roma.

The stories of queer Roma presented in this section have demonstrated that the ethnic/'racial' closet and the queer closet are closely linked with and mediated by different degrees of ethnic/'racial' and queer visibility. They function as survival strategies in response to queer Roma's lived experiences of antigypsyism and its intersections with homophobia, transphobia and sexism. We have also seen that it is possible to understand the ethnic/'racial' and the queer closets as notional spaces between difference, sameness and the spaces in between, protecting queer Roma from asymmetrical hegemonic power relations that discursively shape queer Romani identities. The following section explores another survival strategy: ethnic/'racial' and queer passing.

\section{Passing}

In Chapter Two, we saw that passing can be understood as a distinct strategy in its own right: a transgressive strategy that is inextricably linked to visibility and the closet. Passing has been touched upon in relation to the closet, which allows some queer Roma to hide their ethnic/'racial' and queer identities. Writing on passing among gay Romani Gypsies, Baker (2015) observes that

both Gays and Gypsies have historically been well placed to employ strategic 'passing', with self-protection or ease of passage determining when and where to pass as straight or non-Gypsy. Here ethnicity and sexuality mirror each other within cycles of concealment and revelation. (...) The same facility appears to be employed in relation to the sexual identities of the interviewees, suggesting that the experience of managing their Gypsy identity in early life has informed the eventual management of their Gay identity. (...) The ambiguity involved in ethnic passing is mirrored in that of sexuality. The patterns of management employed for sexual and ethnic representation combine to facilitate the Gay Gypsy's ability to remain invisible in multiple sites. These mechanisms make for a free-floating approach to identity - a facility that allows adaptation at will, but at the cost of constructive community building within this doubly alienated group (Baker 2015, 88).

The stories of John and Aleko, who passed as non-Roma by concealing their Romani ethnicity from an early age, and their capacity for this 


\section{Spaces between difference and sameness}

'ambiguity' have shown us that their experiences of queer passing mirrored their ethnic/'racial' passing. Or to put it differently: their experiences of ethnic/'racial' passing chronologically preceded and strategically informed their queer passing. In the excerpt above, Baker (2015) refers to passing as a strategy used in order not to get seen as 'Gypsy' and gay; or to pass as nonGypsy, or non-Roma - that is, white-normative - and straight - that is, heteronormative. This invisibilising effect afforded by passing enables the queer Romani person at issue to deliberately choose to conceal - or, as the case may be, reveal - aspects of their ethnicity/'race', sexuality and gender identity depending on the spaces they navigate. John's story shows that passing can also be understood as a combination of deliberate strategising and a relational and contextual reading by others. Sometimes he passed as straight, sometimes he passed as non-Roma; other times, he passed as a non-Romani straight man. Thus, depending on the social settings and environments John has navigated, he was read differently. In non-Romani settings such as the workplace, he was read as non-Romani; he was read as straight in Romani settings where the assumption was that since he is Roma, he also had to be straight; or, alternatively, that because he was gay, he could not be Roma. This enhances our understanding of the queer intersectional specificity of queer Roma with respect to how queer intersectional identities get separated and come back together; and how others define, affirm or deny them in this process of relational and contextual reading.

Even though passing can be seen as a key function, or even an extension of the closet as demonstrated by Aleko in this chapter and Andrea in Chapter Three, passing may also occur irrespective of whether the person is actually in or out of the closet. Andrea has previously touched upon her queer passing. At different points in her past, she felt that her Romani ethnicity was not compatible with her bisexual identity. In those situations, adhering, as it were, to the assumed sexual norm in terms of being read by others as heterosexual helped and protected her. Passing was a protective strategy shielding her from homophobia since she felt being in a lesbian relationship would not be accepted. In the following quote, Andrea elaborates on her ethnic/'racial' passing:

I read as white. It's not that I didn't experience anything before. I have family members and friends who don't read as white, so depending on the situation... but obviously just going out alone by myself with my husband, with my white friends, or whatever, and there's no issue. The only situations were, like, there's a rabid drugged skinhead right in my face threatening to kill some Gypsy. I know that he doesn't know that I'm Romani but it's still like a really unpleasant experience. A nonRomani friend of mine was taking a Spanish class and we went out for dinner with his classmates. It was him and a bunch of non-Roma learning Spanish and we're like at a dinner and of course they start 
talking shit about Roma so it's like the same stuff that is uncomfortable for you cos you're an ally, right. [B] ut it changed drastically having two kids who actually read as Roma 'cos I'm with them all the time, it's definitely better when we're with my non-Romani friends or whatever: they're speaking English or whatever but just having that constant onslaught of just everything. You can't get away from it: the stares and the comments and the nasty shit. Even though we're here in North America, normally I just feel like ok, whatever, just deal with it. We live in a totally brown community, all three of the schools they started here are very multicultural. But because I know we're gonna be spending six to eight weeks in Central Europe, it's like I have to I feel like I have to make sure they are on their best behaviour. And so, for years it was like I would do things that I wouldn't have otherwise done as a parent, like on the playground just make sure that you don't get in trouble, you don't give people a reason to yell at you. And also you have to look really proper and nice because the minute [my son] didn't and he got away from me on the bus last summer, and suddenly he's down on the ground 'cos somebody's pushed him down 'cos he just looked like a ragged Gypsy kid 'cos he was wearing sweatpants. We were constantly on the lookout and after many years of this, I'm realising that it doesn't necessarily make a difference. I had my daughter dressed in an Indian outfit because I felt like, you know like she totally passes for Indian, it'll be a lot better. And one of the nastiest things that's ever happened to her was when she was dressed this way cos like the woman didn't even look at her clothing, she just saw the dark face and so she treated her like a Gypsy. My daughter was three. [S]o after a while I'm like you know what? Fuck it, I'm a lot less willing now to make them be like totally... This is a strain on them either way if somebody is staring or making comments or whatever but it's also a strain on them when I'm constantly having to be policing them. I'm getting to the point where I'm just like 'you know what, you motherfuckers, you're gonna treat us like shit no matter what we do'. And I'm also slowly understanding even though I've always rationally understood - why so many Roma are just like 'fuck it, I'm gonna stop trying' (Andrea).

Here, Andrea talks about unintentionally passing - or being read - as nonRoma and openly identifying as Roma. Discussing her ethnic/'racial' passing, she provides an account of her experiences of antigypsyism. As someone who reads as non-Roma or ethnically ambiguous, Andrea encounters situations of normalised antigypsyism, including everyday antiRomani racist banter. As Andrea suggests, her initial willingness to conform to white-normativity may have been influenced by her past experiences of passing as non-Roma. In light of her negative experiences of antigypsyism, it ends up being overridden by a sense of frustration and resignation. This has been the case particularly in relation to her two children who are 


\section{Spaces between difference and sameness}

ethnically hyper-visible as Roma, hence unambiguous: they are Roma, they read as Roma and they are 'racialised' as Roma. Her perception of Romani ethnicity has an important relational dimension: through her children, it has changed due to their experiences of antigypsyism and fear for her children's personal safety. There is also a contextual dimension to Andrea's perceptions of Romani ethnicity in the different social settings; and the attendant need to pass as non-Roma for the sake of her family's personal safety, which is reminiscent of John's mother's story cited in the previous section. Based on her experiences from North America, Andrea feels relatively safer there compared with her experiences from the ethnically homogeneous and white-normative Central Europe where her children are hyper-visible as Roma. Due to her children's inability to pass as non-Roma/white, other survival strategies and protective measures are needed, such as the company of their non-Romani, North American, English speaking father; or both parents 'policing' the children's behaviour and appearance.

The issues of visibility, and of hyper-visibility, associated with passing, enter the arena once again. The above quote helps to illustrate how Andrea has had to manage her children's 'racialised' hyper-visibility in the face of different degrees of anti-Romani attitudes that make the children vulnerable to verbal and physical expressions of racist abuse. At the same time, she has been managing her own ethnic/'racial' (Romani), as well as queer (bisexual) visibility, allowing her to pass in the white-normative and heteronormative social settings as both non-Romani and heterosexual. Similar to John, Andrea passes as white and straight simultaneously or separately; or she passes as straight but is knowingly perceived as Romani and still feels safe as she says she does - in North America compared to when she is in Central Europe. This reiterates the notion that passing, as well as the closet have an important contextual and relational dimension. Additionally, the queer Romani person at issue may have the ability - and, indeed, the privilege - to pass thanks to their ethnic/'racial' or queer ambiguity. This allows the person at issue to be protected by the unmarked ethnic/'racial', sexual and gender identity categories - white and heterosexual - by virtue of being read as a part or member of white-normative and heteronormative society. A queer Roma or, within the United Kingdom (UK) context, a queer Romany Traveller passing as non-Roma, settled and straight may choose to conceal or reveal their ethnic/'racial', sexual or gender identity depending on the social settings they navigate, the people they interact with and the circumstances under which these interactions occur. This is illustrated in the following quote from Michael:

In the sort of family I come from and the families that I know, it's quite normal still for cousins and especially second cousins to marry. So, there is a very strong sort of familial base. So that was the sort of unwritten I guess - kind of expectation within the family. This went for anyone who didn't or chose not to, they stood out. And essentially that 
was around children and the connection of children to the kind of family and the extended family. Education just changed everything. Once you go down that pathway, you meet lots of new people. And it certainly enriched both my personal life and my professional life. I wouldn't be doing now what I do, if it hadn't been for that move and meeting people who have been incredibly helpful to me. But the cost is that you lose a certain connection with those that are left behind, so those that don't go to college, that live in the same area, that have the same relationships. Since I moved away to college and to university, I've always been fairly open about the fact that I'm bisexual. That's how I self-identify and see myself in that way. I became a father in my early twenties and that obviously then set a kind of course in terms of a path for life and obviously within the context of that relationship that I was in. I didn't hide who I was and that was known but I obviously decided that I wanted to be loyal and committed to that relationship so therefore I sort of turned ... I suppose the way I think about it is that you kind of, it's a bit like in June at night when you're sleeping restlessly and you move from one side to the next, I kind of saw it in that sort of way if that's a proper metaphor. So, I moved to one side of the pillow rather than the other for a duration and then when that relationship broke up in my late thirties then I was able to make other choices. I've had relationships with men and women in my adult life. I've been fairly fortunate in that within the Gadje world, I kind of pass. Sometimes my kind of Travellerness is quite easy to do that for me, but equally I think within the Traveller world I can pass in terms of my sexuality because I've been in heterosexual relationships and I've also produced children. I'm aware that isn't the case for everyone, far from it; and so in some senses I consider myself quite fortunate but I've not ignored when situations have emerged and I'm not 'not proud' of who I am and so therefore I will stand up to sort of for example where there's maybe a homophobic kind of talk and language. I have never not kind of stood up to that. And likewise, when I have been party to conversations where people will talk badly of Travellers and Gypsies, again I will stand up and I will say 'well actually do you realise those people you're speaking about, that's actually me and this is who I am. What do you think about that?' So, you choose your battles, I think it's your positionality and how you find yourself. (Michael)

Michael discusses his ability to be fairly open about being bisexual. Years ago, leaving his family and community to study in higher education enabled him to do so. Education can be seen both as a privileging factor when it comes to social norms, and, simultaneously, a distancing factor when it comes to family and community. Despite his openness about his bisexuality, Michael refers to his non-Traveller and straight passing as being 'fairly fortunate'. This echoes the notion that passing as non-Roma and straight - of 


\section{Spaces between difference and sameness}

'choosing your battles', as Michael puts it - is a privileging process. The ability and the power to choose whether to conceal or reveal one's ethnic/ 'racial' or sexual identity enables the person at issue to escape antigypsyism and homophobia under the guise of white-normativity and heteronormativity: a concept also discussed by Andrea in this chapter and in Chapter Three. Passing enables the person at issue to appear the same as the assumed non-Romani, white, heterosexual norm. At the same time, it allows them not to be or become the same as the norm: I discuss this aspect of sameness more in detail later in this chapter. Michael touches upon another aspect of passing also raised by Andrea in the previous chapter: how he uses the privilege of his non-Traveller, straight passing to challenge hegemonic oppression. In this sense, Andrea and Michael's privileged positioning in relation to sameness, epitomised by a close resemblance to the norm, are key: it informs the way in which both Michael and Andrea strategically employ their invisible ethnic/'racial', sexual and gender identities to make a personal stance against antigypsyism and homophobia. Even though Michael and Andrea come from different cultural traditions and, indeed, two different continents, they share their stances as Traveller/Romani bisexual people independently of each another. Michael and Andrea's stories of ethnic/'racial' and queer visibility further develop the notion of passing - and the closet - as notional spaces between difference and sameness. Their testimonies also add to our understanding of the queer intersectional specificity that queer Roma experience by showing identities as fluid, drawn together and apart across time and space in a constant process of becoming. All the while, these nonnormative identities can be deployed strategically and politically in order to challenge asymmetrical hegemonic power relations.

Another aspect of the invisibilising effect associated with passing is discussed by Markus. In the following quote, he discusses his experience of being a gay trans Romani man who passes as a cis straight man.

I think my passing is pretty good. I see it in reactions when I tell people who I actually am. I see how the Roma community is, what different positions, gender roles there are and that my voice is having another counting and more weight suddenly. But what I realise more and more in queer spaces is that I'm suddenly invisible. A few years ago, at the parties a lot of people came because I was this butchy type, people were like catching me and 'hey'. Or like a trans guy without such a good passing that I'm now. Suddenly the same people are ignoring me. There are some moments where it's really annoying to have the feeling that actually it's not your space anymore. I have a very good cis woman friend. We were dancing pretty close and kind of with sexual tension at a queer club. We were dancing in the middle of the crowd and suddenly I had a feeling people are looking really evil at us because they think we are a straight couple and taking their space. Because we didn't look queer enough for them. And that was an awkward feeling. (Markus) 
Markus's story suggests that his visibility as a Romani cis man has been a privileging factor in Romani spaces. As for his experiences of passing as cis and straight in queer spaces, his seemingly heteronormative and cisnormative visibility may be perceived as a transgression - what Browne et al. refer to as 'a straight invasion or heterosexualisation of queer spaces' $(2013,68)$. The attendant limited visibility, or invisibility, as the case may be, that Markus now experiences as trans and gay in queer spaces suggests that Markus's passing has caused him to be perceived as being the same as the assumed heterosexual and cisgender norm. Consequently, the conflation of Markus's queer identities with the norm has almost excluded Markus from queerness. This highlights the contextual aspect of the queer intersectional specificity experienced by queer Roma: Markus's visibility as a cis straight man of colour may be a positive thing in certain heteronormative spaces, including Romani ones, but may be a disadvantaging factor in queer spaces. Additionally, as we saw in the previous chapter, Markus's intersectional visibility as an ethnicised/'racialised' cis man of colour may also put him at a substantial disadvantage in white-normative environments.

This section has explored the phenomenon of passing as both a transgressive survival strategy and an unintentional capacity for ambiguity. The attendant quality of resembling the ethnic/'racial', sexual and gender norm may be regarded as a privilege whereby difference from the ethnic/'racial', sexual and gender norm is deliberately or unintentionally camouflaged as sameness or resemblance to the norm so that the queer Romani person is not exposed to antigypsyism and its intersections with homophobia, transphobia and sexism. These forms of oppression are the normative effects of asymmetrical hegemonic power relations that are based on marked essentialist difference from ethnic/'racial', sexual and gender norms. In Chapter Two, we saw that failure to adhere to unmarked normative identity categories such as 'man', 'male', 'masculine', 'white', 'heterosexual' or 'cisgender' is often seen as a pathological deviation. Consequently, a person or a group of people who possess these identities get marked as essentially distinct, different, deviating from the norm. The enunciation of marked essentialist difference - the delineation and policing of the boundary separating the normative from the non-normative - is often performed by those occupying positions of hegemonic power or trying to maintain control over social binaries irrespective of whether these norms are related to ethnic/'racial', sexual or gender identity. Having reflected on marked essentialist difference, the following section will consider the notions of commonality, ordinariness and strategic sameness.

\section{Commonality, ordinariness and strategic sameness}

Thus far, this chapter has considered visibility in relation to the phenomena of the closet and passing, respectively. The two previous sections have contained implicit, as well as explicit references to sameness in the sense of 
being invisible as Roma and queer by appearing the same as the nonRomani, cisgender and straight societal norm. A queer Romani person who is in the closet may not disclose their ethnic/'racial', sexual and gender identities to avoid being seen as different. In this sense, sameness has a protective quality. Yet, sameness can also have a strategic, subversive quality when it comes to dismantling marked essentialist difference, historically constructed through queer Roma's assumed deviation from the norm along biologically or culturally essentialist lines. This section will first look at queer Roma's lived experiences of bridging difference and seeking commonality across ethnic/'racial', sexual and gender difference and its intersections. It will then go on to consider queer Roma's lived experiences of commonality. Echoing some of the discussions in Chapters One and Two concerning strategic essentialism, it will explore the potential for using commonality and strategic sameness as a subversive political strategy with a view to unsettling and challenging the deployment of marked essentialist difference, on which asymmetrical hegemonic power relations are based and maintained.

Chapter Three and this chapter have demonstrated how some queer Roma have navigated and negotiated ethnic/'racial', sexual and gender difference across socially and geographically different settings. For example, John discussed being in the closet both as Roma and a gay man. In the following quote, he talks about seeing common traits between the two identities:

I thought there are many similar things between the two and I could make the link between the two, because of being in the closet on the one hand or the other hand and that there's a lot that could be learnt from each group. Roma can learn from gay people; gay people can learn from the Roma. And I am the only one who can see this, I felt, I'm the only one who can make this connection but because I'm young and insecure about myself, I didn't feel I could just go into any Roma NGO or association and be completely open about myself. And so, then I had this feeling that if I did that maybe the Roma community wouldn't accept me. It's not my family, they're other people. And so, it kind of kept me from being more engaged in the earlier stage in my life, and earlier stage in the Roma movement. (John)

Having observed analogies between the two closets, John has been able to discern a series of commonalities in his multifaceted experiences of being invisible as Roma and as a gay person, as well as being perceived and accepted as different. Based on these experiences, he has determined that mutual learning can take place between LGBTIQ people and Roma. Being the one standing in the middle, or in between, and being able 'to make this connection', John felt he had the capacity to mediate this process that involves mutual recognition and affirmation of identities. 
In a similar spirit, Veronika addresses the notion of being in between her Romani ethnic and lesbian identities.

My Romani identity is also contextually dependent. I've experienced it the most when I am with aunt. In the huge Romani family, I've found a number of people who are great and they give me a sense of family, which has actually really strengthened my identity. In my childhood, I experienced having a big family, the kind of image of togetherness and the world of women. So, it is not a construct in my head or an illusion of belonging because it really makes me feel great although the beginnings were not easy when I was trying to find a place in that family at 18 . It was hard because I felt I was different from them. Not that all Roma are temperamental or loud or they needed to spend time together in one room from dawn to dusk. Roma are not that and it is good that I had an opportunity to see this for myself, as well as the fact that it is OKAY to be me: calm, introverted. So even I had that sort of stereotype to a certain extent. I would probably identify myself as a lesbian with occasional heterosexual tendencies. And I'm from an interracial family. I'm half and half; a 'halfie' in the other areas. I am able to love or to have a meaningful relationship with a man - although it is of a somewhat different nature, not so deep - as well as with a woman. I simply understand and can navigate the Romani environment while having access to the Gadzo world. It is clear that this can only enrich you, when you can navigate it and you understand both sides. At the same time, it can be very difficult at times and I've perceived this from time immemorial, that even from a personal viewpoint, I was a mediator. (Veronika)

Veronika's story contributes to our understanding of the contextual and relational aspects of the queer intersectional specificity that queer Roma experience and its role in identity construction. Veronika's queer Romani identities have been in the process of becoming, depending on the specific settings she has navigated and the circumstances that came to dominate her life. Following her reconnection with her Romani family, Veronika reconstructed her Romani ethnic identity while searching for her sexuality. Referring to herself as 'a half-Romani lesbian with occasional heterosexual tendencies', Veronika has moved between two binary worlds simultaneously: the world of ethnicity/'race', structured by the binary opposition 'Roma/nonRoma'; and the world of sexuality, structured by the binary opposition 'lesbian/heterosexual'. Veronika refers to her ability to move between ethnicities, genders and sexualities as being a 'halfie': she possesses an intimate understanding of both social settings and is able to navigate each of them. The resulting sense that she does not belong with any one specific ethnic/ 'racial' or sexual identity is discussed in Chapter Five. 
The following accounts by Vasil, a non-binary intersex Roma person living in the US, and Michael also touch upon the idea of the queer Roma or Traveller as someone navigating two or more worlds; and seeking to create commonality by mediating mutual learning between the two social settings.

I feel that I have this opportunity to kind of be a voice that bridges the two communities that aren't normally bridged. The more we have people from intersecting and polarised communities speaking out about the possibility that you can be both Roma and LGBTIQ, the more you're gonna have people coming out and being comfortable with all their identities. (Vasil)

My mum leaving my dad for a woman has kind of affected the future course of the relationships and I still communicate with my mum's family, so it's a bit like I almost act as a gatekeeper. So, I basically act as a communication post between my mum and her brothers and so on and that sort of element to it, so it's a little bit tricky but it's manageable and it's been like that for a few years now. (Michael)

John has implicitly referred to the queer Roma or Traveller's ability to seek commonality across difference as a mediator located in between - and Veronika has done so explicitly. Michael calls this positionality being a 'gatekeeper' or a 'communication post'. Vasil, who has negotiated his set of intersecting identities, uses his queer intersectional position as a conceptual link that 'bridges two communities that aren't normally bridged.' Despite some minor conceptual differences, the four accounts - by John, Veronika, Vasil and Michael, respectively - point to the importance of seeking that which is common; or, in the opinion of Browne and Bakshi (2013), that which becomes commonplace, ordinary, unremarkable, but not normalised or complicit with normativities.

As we have seen so far, the specific construction of the heterosexual/ homosexual binary is contingent upon contextual, relational, material and historic specificities of a given society in a given location. This means that lack of acceptance of some queer Roma's sexual or gender identity by some Romani families or communities may happen in ways that are similar to or the same as those of non-Romani families and communities who reject their queer members. In the following quote, John comments on these dynamics:

My conclusion is Roma culture or Roma communities are not more or less homophobic than any other society. Basically, it's a prescript of the majority society whether it's a southern European or northern European - what the dominant influence is or there's a church influence or something like that. Roma in all their cultures and all of their diversity are not more homophobic or less homophobic than any other culture, and this is very important to emphasise. They're not more or 
less homophobic than Czechs, or Italians, or Indians, or Pakistanis; we are just the same. (John)

John's observation that homophobia is a 'prescript of the majority society' echoes what other queer Roma have said about myths and stereotypes, according to which Roma and Romani communities are innately homophobic. Such blanket, damaging statements, which are often used to ethnically/'racially' stigmatise Roma, are reminiscent of discourses that purport to challenge homophobia but stereotype certain communities as being inherently homophobic (Browne et al. 2013, Bryant 2008): or what Puar (2007) refers to as homonationalism. Importantly, John's account also speaks to the presence of commonality and sameness across sections of societies that are perceived as essentially different due to the binary ethnic/ 'racial' division between non-Roma and Roma.

The notion that some queer Roma seek commonality across difference also resonates with experiences that various queer Roma have in common with other queer people and other Roma. In Chapter Three, we saw that both queer Roma and straight Roma share a spectrum of experiences arising from being Roma; and that queer Roma and queer non-Roma share a gamut of experiences arising from being queer. As the above life stories have shown, queer Roma are located in between and at the intersection of two or more sets of identities - ethnic/'racial' (Roma) and sexual and gender identities (LGBTIQ) - although, as Chapter Five will show, some do not belong with either of them. Such a conceptualisation of commonality, and indeed, of sameness, is reminiscent of the assertion made by Browne et al. (2013) that the ordinary, unremarkable could offer a potential politics beyond homo, hetero and other normalisations/normativities through the notion of ordinariness as commonplace (ibid, 190). Commonality, that which is commonplace and ordinary, is implicitly addressed also by Michael in the following quote:

I think that that sort of relationship with my mother has been really important and it was her, a Traveller that encouraged me in education, which again kind of turned stereotypes on the head a little bit because everyone assumed that it was my dad, 'cos my dad's from a settled family. So, everyone assumed that it was that side of the family that pushed the education but it wasn't. It was very much my mum that pushed me to do well at school and to get to college. (Michael)

Speaking of his mother, Michael reflects on the widespread stereotype that Travellers are 'essentially different' from non-Travellers because they willingly do not participate in education. Contrary to this misrepresentation, it was his mother, a Traveller, pansexual woman, who pushed Michael into education. Here, the ordinary, commonplace notion that irrespective of ethnic/'racial' heritage, mothers have their child's wellbeing at heart and do 


\section{4}

Spaces between difference and sameness

so through the child's education is deployed to challenge the misconception and the stereotypical, culturally essentialist, racist myth of Travellers/Roma being innately predisposed - as opposed to non-Travellers/non-Roma - to not send their children to school.

Commonality or, indeed, sameness in the above example of parental attitudes to schooling is reminiscent, at least to a certain extent, of how Romani parents respond to their child's non-normative sexuality or gender identity. For example, in the case of Aleko, Zoltan, Jolana, Dominik and Kerrtu's parents in Chapter Three, we saw that they fully accepted their queer children. These stories show that Romani parents respond to such situations just like other parents - either positively or negatively - and provide evidence that there is no essentialist ethnic/'racial' difference as to whether a parent accepts or rejects their child for being queer. Indeed, homophobia or transphobia do not lie in the ethnicity/'race' of the parents who hold them.

In a similar spirit, Andrea elaborates on the idea that much of the current Romani Studies scholarship on - and the resulting representations of Roma are based on Roma's presumed, historically constructed essentialist difference:

It's this constant need to somehow locate us, Roma, always in some idealised past whether it's an idealised past that the academic agrees with or not, that used to be our place and they just have the hardest time letting go of that. I think the LGBT Roma movement is such a great example because it just blows the minds of a lot of academics, like 'we didn't think'. Well, I didn't think it would happen either but it is happening and I know what's happening and I think I can see it for what it is. But for the ones who were like 'no', they still have this very rigid conception of a traditional Romani community because they're the anthropologists. And again, this is my whole thing with gadzology [study of non-Romani people as opposed to Romani Studies; author's addition]. People are funded to go and find out how these 'other people' are different! They're not funded to go and find out how they're the same. And you still have this problem with academia where one of the ways they're portrayed as different is that they're allegedly stuck in the past and their culture doesn't change. It's very conservative and it's really ultimately sort of economic needs that a lot of these academics have in order to have their work funded and read and interest other people. Because if your conclusion is gonna be 'well actually the LGBT Roma movement and a lot of other stuff about Roma in many of their communities is taking the same exact trajectory as it's taken with all the other communities', well then I guess the conclusion it has reached isn't so valid in their opinion. But they can't quite get to actually the most interesting research: the research that flies in the face of the popular imagination. But nobody seems to want to do that a lot of the time so 
that's why I think this work is so hugely important and to really lay it out there and talk about the academic culture and the assumptions that people are making and try to get at why they're making them. I don't know if it's totally the same with Native Americans but I have this in my crazy doll pictures, I have this like Native American girl who just says 'Is this where you want me?' and she's in the woods and it's entitled 'nature/past' and it's like exactly all the people, including academics, need us to be surrounded by nature, and in some kind of past context even if it's 2016. (Andrea)

In the above account, Andrea refers to the LGBTIQ Roma movement as epitomising the notion that sameness is a strategic challenge to non-Roma continuously constructing and portraying Roma as essentially different. In Chapters One and Two, I discussed the concept of ordinariness (Browne et al. 2013) and strategic essentialism as a temporary measure used by marginalised groups, including Roma, in order to forge collective identity in social movements. Such a strategic deployment of sameness - or what could be termed 'strategic sameness' - has a potential to subvert normativities. Using the above quote, strategic sameness is subversive to knowledge production that constructs Roma as fundamentally distinct and different from non-Roma when in fact, as Andrea says, 'a lot of stuff about Roma in many of their communities is taking the same exact trajectory as it's taken with all the other communities'. However, this is by no means to suggest that Roma should strive to be the same as non-Roma or to assimilate.

Ordinariness, and especially its queer readings, deeply resonate with many of the life stories of queer Roma presented in this book. 'Sexual/gender dissidence was once read beyond the boundaries of the nation-state (...) where that which was once legislatively and culturally deviant was rendered somewhat ordinary' (Browne et al. 2013, 2, 190). Chapter Two demonstrated that to this day, white-normative social dynamics have not allowed Roma, who remain constructed as ethnicised/'racialised' and deviant, to even reach the status of being somewhat ordinary. Due to antigypsyism lying at the root of this historic institutional exclusion, modern nation states have systematically located Roma outside the boundary of neoliberal democracies. Such mechanisms have also been encouraged, reproduced and commercially exploited in mass popular culture and entertainment. These societal processes have perpetuated the vicious cycle, constructing Roma through marked essentialist ethnic/'racial' difference as distinct, other, extraordinary, out-of-place and not belonging. Though the concept of ordinariness is highly relevant, it is not sufficiently attuned to the queer intersectional specificity that queer Roma experience. This is why it is imperative to take into consideration concepts that are more adequately equipped for unsettling and challenging this intersectional essentialism. Strategic sameness is a concept that emanates directly from the accounts of queer Roma presented in this book so far, especially from the above testimonies about facilitating mutual 
learning processes, mediating communication, bridging communities and seeking commonality across difference.

First, it is important to clarify what strategic sameness means. Chapter Three and this chapter have demonstrated how passing as non-Roma, cis and straight can undermine manifestations of antigypsyism, homophobia, transphobia and sexism. Strategic sameness refers to a relational deployment of sameness across ethnic/'racial', sexual or gender difference; and a relational use of identities whereby links and connections are created for strategic purposes. Simultaneously, grounded in an endeavour to seek commonality across difference, strategic sameness contributes to unsettling, disrupting and challenging binary social norms and normativities that sit at the root of antigypsyism and its intersections with homophobia, transphobia and sexism discussed in Chapter Three. Just like ordinariness, strategic sameness does not read through assimilation, conformity and normalisation while working with and within social norms and binary orthodoxies (Browne et al. 2013, 11, 108). If employed politically in a subversive way, strategic sameness does not follow the assimilationist route, nor does it reproduce norms and normativities even though it may imitate or mimic them. At the same time, strategic sameness does not counter or undermine queer or queerness. In fact, here, sameness is queer by virtue of being a positionality resisting marked essentialist difference constructed along the lines of ethnicity/'race', sexuality and gender identity.

In Chapter Three, we saw that some queer Roma are hyper-visible, and therefore cannot employ strategic sameness as a queer positionality in the same way or at all - although Aleko's story demonstrated that it is possible to be simultaneously hyper-visible, in the closet and passing. If and when possible, the queer Romani bearer of strategic sameness can be seen as a subversive force both within and outside normativities, previously discussed in relation to Muñoz's (1999) concept of disidentification. Using the below insight from Gonzalez-Torres (in Katz, 2015) who spoke of his queer positionality as an HIV positive gay man, the queer Romani bearer of strategic sameness may be regarded as a 'spy', using the mimicry of social normativities and strategically deploying sameness to 'infiltrate' and thus unsettle them from within. Doing so helps to challenge social normativities and cultural scripts engendering the binary opposition between social norms and that which deviates from them.

At this point I do not want to be outside the structures of power, I do not want to be the opposition, the alternative. Alternative to what? To power? No. I want to have power. It's effective in term of change. I want to be like a virus that belongs to the institution. All the ideological apparatuses are, in other words, replicating themselves, because that's the way culture works. So if I function as a virus, an imposter, an infiltrator, I will always replicate myself together with those institutions (Gonzalez-Torres, in Katz 2015, 24) 
Strategic sameness as an extension of ethnic/'racial' and queer visibility has a potential to counter, subvert and undermine marked essentialist ethnic/ 'racial', sexual and gender difference within white-normativity, heteronormativity, cisnormativity and patriarchy. Strategic sameness is still characterised by queer paradoxes that may result in inclusions of some queers to the detriment, or exclusion of others, though. For example, Markus's story detailed his invisibility as a trans gay Romani man who passes as cis and straight in most spaces, including queer ones. It showed us that strategic sameness does not subvert social norms and normativities within queer spaces that resent heterosexualisation: that is, such spaces may require queers to appear queer and not otherwise. This means that even within spaces that purport to be queer in its counter/non-normative sense, new norms and normativities may be established and maintained, resulting in the emergence and policing of new boundaries of identities.

Coming back to Veronika, Markus, John, Michael, Andrea and Vasil, their stories have demonstrated a capacity for reconstructing ethnicity/ 'race', sexuality or gender identity both at the level of an individual, as well as a queer Romani group who shares experiences of intersectional essentialism. This process of 'becoming/s beyond being/s' (Puar 2005, 128) points to the fluid, socially constructed, non-fixed nature of identities. Just like in an assemblage, certain aspects of a queer Romani person's identity become more prominent at different times during one's lifetime, as expressed in the two quotes below:

For me, it's a bit complicated because I'm an immigrant, my mother is from Mexico, I was born in Mexico too. As for the question of Roma identity, it's complicated too because Spain is a bit conservative with the question of the cult of purity of the blood. And more when you're gay, and even more when you're from Mexico. It's for myself who I am. I am a good Roma. I am no Roma. I am half Roma. What part of me is Roma? Is this finger Roma? Or none of the fingers are Roma? What's the point of all of this? Identity is something complex, it's not possible to make measures like 'I have 1 kilo of Roma and 1 kilo of Gadzo from Mexico, 1 kilo of indigenous blood, it's not possible to talk about it like that. For me, this is identity. The question of being LGBT Roma is one part of my identity. (Bruno)

What does it mean to be Roma? To be Roma in France, in the United States or Canada? There are many different groups of Roma within France itself. There are many traditions and histories, there is not one Roma culture, there are many Roma cultures. There are people who have an identity and that identity cannot be separated: you're not 50 percent LGBT, 50 percent Roma. I'm 100 percent Slovak, 100 percent American, 100 percent Roma and 100 percent 'G'. (John) 
Bruno and John's testimonies demonstrate that each facet of their multiple identities is inseparable from, intersects with and informs one another. They also show that just like assemblage-like becomings, the process of identity construction and the highly nuanced heterogeneity of complex Romani identities unfold within the ever-present plurality of Romani cultures. As Chapter Five will show, the contextually diverse social settings that queer Roma navigate also impact the identifications and disidentifications that queer Roma make.

\section{Conclusion}

In Chapters One and Two, we had an opportunity to see how marked essentialist ethnic/'racial', sexual and gender difference has been attributed to Romani and LGBTIQ identities. Informed by these insights, this chapter has considered the ethnic/'racial' and queer closets in relation to various degrees of ethnicised/'racialised', sexed and gendered intersectional visibility. This includes hyper-visibility. Some queer Roma negotiate non-normative (queer) intersectional identities by means of employing protective survival strategies such as the closet and passing. Both the closet and passing are contextual and relational: they depend on the social settings queer Roma navigate and are constituted and reconstituted through social relationships. The closet - whether ethnic/'racial', queer or intersectional - can be also understood as a notional protective space between difference and sameness. There, the queer Romani person at issue constantly renegotiates various degrees of visibility delineating difference and sameness. The ability to step in or step out of this notional protective space is contingent upon how queer Roma read the social setting; and on how they are read within that context. Some queer Roma hide in plain sight by being ethnically/'racially', sexually or intersectionally hyper-visible and simultaneously in the closet. The stories of how queer Roma navigate the intersectional closet presented in this chapter also challenge the assumed comparative binary between the ancestral or originary ethnic/'racial' closet and the unancestral - and therefore perhaps less essentially given - queer closet.

We have also seen that due to the specific configuration of the heterosexuality/homosexuality binary, coming out of the closet is not always an option available to all queer Roma. Consequently, some queer Roma stay in the closet whereas others are partially out in order to preserve vital social relationships and safety nets, on which many depend for survival, safety and protection from antigypsyism. Within this queer intersectional specificity, just like the closet, passing - whether in terms of ethnicity/'race', sexuality or gender identity - can be understood as a survival strategy and a notional space protecting queer Roma from antigypsyism and its intersections with homophobia, transphobia and sexism. Passing, whereby one's ethnicity/'race', sexuality or gender identity is either concealed or revealed, is a privileging process enabling the queer Roma to pass as non-Roma, 
straight and cis, under the guise of white-normativity, heteronormativity, cisnormativity and patriarchy. The privileging ability to pass as non-Roma, straight and cis not only enables the queer Roma at issue to escape antigypsyism and its intersections with homophobia, transphobia and sexism; some queer Roma also use their invisible ethnic/'racial', sexual and gender identities strategically to challenge hegemonic intersectional oppression.

In order to counter marked essentialist ethnic/'racial', sexual and gender difference at the root of social normativities, some queer Roma seek commonality and sameness for strategic purposes. Strategic sameness refers to a relational use of identities and sameness across difference. Operationalised through invisibility - and in some cases hyper-visibility - associated with the closet and passing and deployed in a queer way to unsettle and challenge social normativities, within which it operates, strategic sameness is a positionality resisting social norms and binaries. It does so through imitation, not through assimilation, conformity or normalisation. Strategic sameness is configured and reconfigured alongside the workings of marked essentialist difference, which it seeks to challenge: the queer Romani bearer of strategic sameness can be seen as deploying sameness subversively to undermine marked essentialist difference.

The stories presented in this chapter have shown that contrary to racist stereotypes that construe Romani individuals, families and communities as innately homophobic, homophobia is a social prescript of majority societies: just like antigypsyism. As Chapter Three and this chapter have demonstrated, queer Roma experience and navigate manifestations of antigypsyism and its specific intersections with homophobia, transphobia and sexism. Having to deal with the pressure of antigypsyism when figuring out and enacting one's queer intersectional identities adds to the queer intersectional specificity that queer Roma experience: something that queer non-Roma, for instance, do not experience.

The queer intersectional specificity that queer Roma experience whilst seeking commonality across difference in majority societies arises from asymmetrical hegemonic power relations grounded in biological and cultural essentialism. Historically, majority societies have constructed social norms and normativities along the lines of marked essentialist ethnic/'racial', sexual and gender difference. Queer Roma experience this queer intersectional specificity precisely because individuals located within the ethnic/'racial', sexual and gender norm have historically constructed images of minoritarian subjects, including queer Roma, as fundamentally distinct, essentially different from the ethnic/'racial', sexual and gender norm and located outside social normativities. Just like an assemblage, queer Romani intersectional identities are discursively shaped and formed; separated and put back together; accepted, affirmed or rejected and denied by individuals located within these norms: the concept of queer intersectionalities helps us better understand these processes. 


\section{Queer belonging}

In this penultimate chapter, I consider the notion of queer belonging within the context of queer Roma possessing non-normative, negatively valued, stigmatised and pathologised ethnic/'racial', sexual and gender identities that are often hyper-visible; and the notion of queer belonging as a nonnormative positionality vis-à-vis the queer intersectional specificity that queer Roma experience. In Chapter One, we saw that belonging is a dynamic process reflective of the asymmetrical hegemonic power relations within which individuals are located. Belonging therefore entails other ways of being, a desire for 'becoming-other'; it signifies a wished-for 'movement of and between' categories of identification, challenging 'a certain logic of identity, which proceeds through division and designation' (Probyn 1996, 5, 9-10). For queer Roma, possessing stigmatised ethnic/'racial', sexual and gender identities that majoritarian cultures often make hyper-visible has consequences for belonging - or lack thereof - with, in or to non-Romani, heteronormative and cisnormative societies, as well as Romani and LGBTIQ communities. Whether or not queer Roma feel they belong impacts on the identifications and disidentifications made.

This chapter draws on the insights from the previous two chapters. In Chapter Three, I considered queer Roma's lived experiences of antigypsyism and other forms of social oppression associated with whitenormativity, heteronormativity, cisnormativity and patriarchy. Associated with ethnic/'racial' hyper-visibility and the negative social valuation of Romani ethnic identity by non-Roma, antigypsyism impacts on the lives of some queer Roma in a pre-eminent, stigmatising way: so much so that it often eclipses queer Roma's experiences of other oppressions. The intersection of antigypsyism with homophobia, transphobia and sexism gives rise to a queer intersectional specificity. I also looked at the associated relational, material and contextual aspects of family and community acceptance, inclusion, rejection and exclusion; and explored how these varied lived experiences inform and shape queer Roma's fluid, non-normative ethnic/'racial, sexual and gender identities and identifications that come together and apart in an assemblage-like manner. In Chapter Four, I examined the link between various degrees of ethnicised/'racialised', sexed,

DOI: $10.4324 / 9780367822699-5$ 
gendered and queer intersectional visibility, including hyper-visibility and invisibility; the ethnic/'racial' and queer closets, the intersectional closet; and passing. I demonstrated how a conscious, strategic, subversive take on passing as non-Roma and non-LGBTIQ due to being perceived the same as the ethnic/'racial', sexual and gender norm can undermine manifestations of antigypsyism, homophobia and transphobia. In the same vein, I proceeded to analyse how as mediators, bridges and in-betweens, some queer Roma seek to create commonality, and indeed, strategic sameness, in order to unsettle, challenge and subvert marked essentialist ethnic/'racial', sexual and gender difference. Strategic sameness, which does not read through assimilation, conformity or normalisation, is queer by virtue of being a positionality resisting marked essentialist difference constituted along the lines of ethnicity/'race', sex/gender, sexuality and gender identity and constitutive of social norms. Strategic sameness, therefore, has a potential to unsettle and subvert dominant normativities, within which marked essentialist difference operates. These discussions have gradually paved the way to introducing and unravelling the concept of queer belonging in this chapter.

In this chapter, I expand on the subversive quality of Probyn's (1996) concept of 'outside belongings'. I examine the lived experiences of queer Roma with a view to first sketching out what non-normative, queer belonging means as a positionality and what it entails in terms of the strategies used. In order to do so, I first look at the ways in which queer Roma experience belonging - or lack thereof - with, in or to one or both of the two main categories of identification: Roma and LGBTIQ. I explore how queer Roma experience identification with certain aspects of ethnic/'racial', sexual and gender identities while disidentifying with those dominant sociocultural scripts, values, meanings and norms that feel hostile, threatening or oppressive. I examine how queer Roma experience a sense of queer belonging; and how queer belonging poses a challenge to normative, conventional modes of belonging. I go on to discuss how queer belonging epitomises the need for creating a strategic response, reconciling some of the tensions between the two extremes of the queer identity dilemma. This refers to the tension between queerness as a non-identitarian positionality countering binary social norms and orthodoxies on the one hand; and, on the other, identity, forming the basis of queer Roma's political power and the ensuing strategic, or even political need to mobilise around it, which invariably engenders fixed identity categories and binaries.

\section{Identification, disidentification and queer belonging: Belonging with Roma and LGBTIQ?}

So far, we have established that identity is a contested concept; and that identity, including Romani identity, is not a cohesive, tangible fact. This has consequences for how individuals, including queer Roma, belong. We have 


\section{Queer belonging}

also established that queerness is a positionality that challenges and is at odds with dominant social norms and orthodoxies. Therefore, by its nature, queer is fundamentally transgressive and subversive. Queer thus destabilises, unsettles and critically challenges the normal, the legitimate, the dominant, the natural, the given. It allows us to see identity categories as arbitrary historical and social constructs that societies and other units of social organisation find necessary, viable and useful. Queer, queerness and queer theoretical concepts are therefore well-suited to do away with - in the theoretical sense of the word - those 'regulatory fictions' underlying social orthodoxies, such as heteronormativity, cisnormativity, patriarchy and white-normativity, as well as with the binary opposition between unmarked, or neutral, and marked categories of identification. Referring to Laclau (1990), Hall (1996a) and Butler (1990, 1991, 1993), we have seen that marked categories of identification are queer, subversive by virtue of being reduced to the function of an accident as opposed to the essentiality of the unmarked, neutral ones; they are constructed through difference, through the relation to what they are not or to what they lack. Consequently, marked categories of identification are transgressive and disruptive to dominant orthodoxies: hence they are non-normative, or queer. In Chapter One, I fleshed out Muñoz's (1999) concept of disidentification as a strategy whereby queer people of colour, who are outside the ethnic/'racial', sexual and gender mainstream, negotiate dominant social scripts, canons and orthodoxies. They do so by working with and within these canons, transforming them for their own purposes instead of aligning themselves with or against exclusionary practices. Applying it to queer Roma, who find themselves outside the majoritarian non-Romani ethnic/'racial' orthodoxy, as well as the heterosexual and cisgender orthodoxy, we have seen that disidentification is a strategy also available to some queer Roma who use it simultaneously within, as well as outside dominant social scripts.

In Chapter Three, we saw that queer Roma and their families are located within the broader social fabric of Romani communities, upon which they often depend for safety, livelihood, survival and protection from antigypsyism. Therefore, acceptance and inclusion in communities on the one hand, and rejection and exclusion from communities, on the other, contribute to informing the lived experiences of queer Roma, as well as to whether or not they are able to enact non-normative (queer) sexual and gender identities. As illustrated by the following quote, in Kerttu's case, it was rejection and exclusion, and especially homophobic discrimination and persecution from the local Romani community, which have been key factors impacting on her sense of not belonging with the Romani community:

I'm Roma, a woman and a [Scandinavian]: it comes in that order. It's part of my history, my parents' history. For me it's important to be part of this particular ethnic group. I know a lot about my culture, other 
European Roma's culture and language. The way of thinking, actually what comes to feelings, the way I do things, maybe moving, dancing, playing guitar, and so on. I just feel that it's me. Somehow my Romani identity is stronger now than it was maybe twenty years ago. If you are very near Romani community you can't be openly what you are. In this country, the 'culture police' treats you badly and says loudly that this and that person is not a proper Roma because he or she is living differently than they should. There was a huge argument who is and who is not a proper, real Roma 15 years back. They were also talking about kind of hair and clothes proper Romani woman should have. If you used trousers, you were not a good woman. It is the wrong way to try to save Romani culture by discriminating your own Romani people. No one has apologised for what they did to me. I can't forgive or forget. I'm unable to appreciate them and I don't respect them. I don't want to be with them anywhere. When people are against you, you don't see them like 'your own' group. You don't have to accept me, you need only to let me be who I am. We don't need to live in the same way inside the Romani community. We all know where we come from, you know your relatives and you know that you're important. The Romani community in this country is so small, everybody knows somebody in your family, so people just have this big-brother mentality for watching and telling that someone's daughter is doing this and that. But understanding is slowly growing too. After I moved abroad, many things have been much easier, clear in my head and heart. I can be what I am, if somebody asks me if I'm a gay I can answer 'well, yes and how about you?' But if you go back 15 years, maybe it was not so easy. For me, having this life, that's really a good thing but to relate the Roma and the lesbian together! It has been so much trouble. I have had so much bad things because of that combination. I don't understand why it is so important to be visible Roma lesbian? I'm happy there's a Roma LGBT movement though, so that's a good thing. (Kerttu)

Kerttu talks about her experiences of negotiating her identity as both a Roma and a lesbian. She has had to do so because of the local Romani community who policed the boundaries of authentic Romani ethnicity and womanhood, defined, for instance, by particular hairstyles and clothes as markers of identity. She also speaks of the subsequent persecution she was subjected to due to having trespassed those boundaries. Kerttu has been able to negotiate her Romani lesbian identity by coming to disidentify with the local Romani community. Kerttu is Roma but she no longer considers the local Romani community her own, nor does she belong with or to it. From her statement to the effect that her Romani identity has become stronger, we can see that irrespective of the disidentification with the local Romani community, she has maintained her identification with Romani ethnic identity. In keeping with Muñoz's (1999) concept of disidentification 


\section{Queer belonging}

as recycling, reconfiguring and transforming the majority's - in this case, the Romani heteronormative majority's - hostile codes and norms, Kerttu has transformed her sense of Romani identity in a way that makes it possible for her not to belong with the local Romani community but to be Roma nonetheless. As for Kerttu's sexuality, she sees her lesbian identity as the reason for which she has suffered persecution at the hands of the Romani community. She appreciates the recent emergence of the LGBTIQ Roma movement that has contributed to validating Romani nonheteronormative sexual identities, including her own Romani lesbian identity, but she questions the importance of being a 'visible Roma lesbian'. This indicates a certain degree of disidentification with lesbians. Yet, she has learnt to endorse and acknowledge being both Roma and lesbian. In her disidentification, she has found a strategy in terms of reconciling both identities as expressed by her statement 'I am what I am' in Chapter Three. This strategy also entails not making these identities even more visible - or hyper-visible - than they already are.

The notion that Romani ethnic/'racial', sexual and gender identities are often perceived as socially stigmatised and stigmatising plays a role in terms of the identifications and disidentification that queer Roma make. In the following quote, Martina, a Czech Romani lesbian in her mid-twenties, talks about having two intersecting stigmatised identities and reconciling them:

Being Roma and lesbian? Perhaps the only positive thing is that nothing worse can happen to you [sarcastic laughter]. (...) I've come to terms with it, who I am convenes me, but do I find a positive in it? That everyone remembers you? Perhaps that. But when you think of children, you give them a 'great' [irony] start. Like really. Romani women, two faggots at home, like that is really 'amazing' [sarcasm]. (Martina)

Reminiscent of Muñoz's (1999) account of how Marga Gomez performed disidentification with her stigmatised lesbian identity discussed in Chapter Two, Martina has come to accept who she is. She says she sees almost nothing positive about the two stigmatised identities, except for her hypervisibility as a Romani lesbian, because of which 'everyone remembers you'. Perhaps due to internalised antigypsyism and homophobia, Martina feels that her ethnic and sexual identities can potentially stigmatise her children when or if she has them. Yet, in her everyday life, Martina is an eloquent proponent of the LGBTIQ Roma movement, talking about gay parenting at key LGBTIQ events in the Czech Republic. This suggests that a certain degree of disidentification has occurred in order for her to be able to function that way. In Martina's case, her sense of queer belonging has been facilitated by both identification and disidentification. In the following quote, Ana, fundamentally questions what Romaniness, or Romanipe(n), means both on a personal and a community level: 
I don't belong to any identity. That's more like queer. I don't belong to majority because I'm Roma. I didn't belong to the Roma community because I don't live in the settlement. I found out that a lot of nonRoma around me felt also they are different because of expectations of the community. That was important to me to understand that it is okay to have that feeling. Then I spoke with Roma lesbian women and realised they also feel that they don't belong. You can say it is queer theory but I really think it's revolutionary. I think we have to counter categories. It is important to have affinity. Not identity but affinity, like Donna Haraway says. It is that feeling that you don't belong that makes us more similar to others, the basis that we do not identify ourselves as one category but like not belonging to any categories. What makes me identify myself as Roma is the discrimination against Roma because I felt discrimination on my own skin and on the skin of other Roma. This is my political statement, I'm Roma. When I realised that I'm lesbian, I just felt political about my lesbian existence. I have Romani friends, I love them, I like to dance with them, I like speaking Romanes, but deep in my heart, I don't feel that I have that feeling of being Roma. What is Romanipe? It is some kind of constructed feeling. My identifying as Roma is on purpose. Not anything else because I don't have anything in common. Being a Roma lesbian is so subversive to this imperfect society: we can smash patriarchy, homophobia and sexism. I remember one sentence on the internet when an article about a Roma lesbian organisation came out and one man said: Roma lesbians? Where is this world going? In that way, we are very subversive to the system and that is our stance. We can make a difference with our freedom if we are free and speak about different identities, that we exist and we have rights to be different. (Ana)

Ana, who attaches political significance to her identification both as Roma and lesbian, discusses how she chooses to identify with certain aspects of her ethnicity while disidentifying with others. She makes identities work together by reconfiguring those dominant cultural codes around her that she finds threatening, hostile and oppressive. Where Ana chooses to - and is able to - identify with being Roma 'on purpose', she does so as a political statement, a gesture of solidarity and a subversive act of challenging hegemonic oppression: antigypsyism. Ana effectively redefines the terms of belonging - or in this case, non-belonging - with Romani identity and community. She makes use of both identification and disidentification in order to do so. By so doing, Ana transforms the meaning of Romani ethnic identity and the dynamics of disidentifying with exclusionary and oppressive aspects of Romani ethnic belonging, which she discussed in Chapter Three. In this sense, her ability to choose to disidentify with these aspects of Romani ethnicity is a privilege. Similar to her passing discussed in Chapter Four, she can 'choose her battles': to identify or to disidentify, 
or both. As a radical feminist, her identification as a lesbian woman follows a similar pattern: it is also a political gesture challenging patriarchy, sexism and heteronormativity. Unlike Kerttu, Ana does not disidentify with lesbianism. She openly and publicly acknowledges her Romani lesbian existence within the majority and Romani society: importantly, as we saw in Chapter Three, Ana speaks about her ability to do so because she had not grown up or lived in the Romani community. Ana thus hints at the notion that living in the Romani settlement is often seen as a lived, qualifying experience and a prerequisite for Romani ethnic authenticity and belonging, as well as a limitation concerning the ability - or lack thereof - to enact non-heteronormative sexualities and gender identities due to peer pressure and mechanisms of social control. Additionally, by appealing to and mobilising around the non-normative intersection of her ethnicity (Roma), sex/gender (cis woman) and sexuality (lesbian), not only does Ana challenge white-normativity, patriarchy and heteronormativity, but also Romani lesbian women's invisibility that she discussed previously in Chapters Three and Four. Ana makes a political statement directed at the Romani communities, too, laying a strategic claim to every Romani person's freedom and right to be different, including in terms of sexuality and gender identity. Ana's plea to affinity represents a conceptualisation similar to relational, inclusionary identities based on affinity, modelling a flexible process for personal and collective identity formation through inclusion rather than exclusion (Anzaldúa 2002). Such a relational conception of increased visibility of Romani lesbian existence, solidarity, affinity and queer belonging that counters identity categories has a potential to undermine patriarchy and heteronormativity both within majority and Romani societies.

Vasil, who self identifies as a non-binary intersex trans Roma of Russian heritage, talks about his experiences and sense of queer belonging as follows:

I don't really know a lot of immigrants that continue to identify as Roma after they emigrated to North America. And I definitely don't have a Romani community out here with regard to that, to the point where actually my own family will just talk about themselves as Russian. I'm pretty vocal about my Romani identity but the average North American bear ${ }^{1}$ doesn't even know what that means. So, there is a pro and a con, the pro being that there's no stigma attached to it, the con being that people don't understand what it means. And they don't really have an understanding of my identity. It's pretty difficult to find a community out here. Communities are often polarised against one another and I feel like the only real way that we can achieve any sort of real productive activism is to have voices from communities that intersect. You have LGBTQ people for example who are in North America who place an expectation on me to hate Russia. And embrace 
US imperialism. Like there's a big component of the queer community here that is really into that. And then you have Roma people and there's an expectation that I'm going to make my trans and queer identity second to my Roma identity from going to advocate for Roma people in North America. That's not something that I'm willing to compromise on. (Vasil)

Vasil discusses his identification as Roma in a situation where there is practically no local Romani community that he can have face-to-face interaction with, participate in and be a member of. This lack of contact with the Romani community results in there being little or no direct point of reference for him. Due to this absence, non-Roma, including LGBTIQ people, are not able to grasp the meaning of Roma and Romani identity. Vasil states that this lack of knowledge impacts him in a positive way: his ethnic identification as Roma does not stigmatise him. As we have seen previously, belonging with or to Romani ethnicity can often be a source of anxiety for Roma due to the historic social stigmatisation of Romani ethnic identity. In this instance, however, Vasil's belonging with Roma is facilitated by the absence of the negative social valuation of Romani ethnic identity. Yet, as he points out, he experiences a different type of social stigmatisation as a person of Russian heritage. Vasil refers to an expectation that some Roma have of him in terms of compromising on his sexuality and gender identity as if Roma and intersex non-binary trans were mutually exclusive. Consequently, Vasil experiences a very particular queer intersectional specificity. Similar to Ana, Vasil identifies with some facets of Romani ethnic identity, sexuality and gender identity, which he sees as meaningful while disidentifying with those aspects of ethnic/'racial', sexual and gender identities that he finds oppressive and hostile. In so doing, he transforms the dominant exclusionary practices and majoritarian modes of belonging for his own strategic and political purposes.

So far, exploring the experiences of three Romani lesbian women and a non-binary intersex trans Roma, this chapter has demonstrated that the intersection of Romani ethnicity with sex/gender, non-normative sexual and gender identities constitute very particular facets of the queer intersectional specificity that queer Roma experience. This impacts the identifications and disidentifications that queer Roma make against the backdrop of four dominant normativities: white-normativity, heteronormativity, cisnormativity and patriarchy. Queer Roma often find themselves outside these dominant normativities. Reminiscent of Probyn's (1996) outside belonging, queer belonging is operationalised by both identification and disidentification. As Kerttu's case has demonstrated, her disidentification with the local Romani community does not hamper her identification as Roma; at the same time, her disidentificatory reluctance to endorse visible lesbianism does not preclude her identification as a lesbian. Aided by the 
stories of the Romani gay men who are perceived as feminine explored in Chapter Four, the above accounts of the three Romani lesbian women and the non-binary intersex trans Roma have also helped to illustrate an important aspect of sex/gender and gender identity: that women, passive gay men, trans and intersex people - by virtue of being associated with the marked categories of womanhood, including trans womanhood, and femininity - are often fundamentally subversive to white, heterosexual, cisgender and patriarchal social norms. In these instances, queer belonging has been used as a strategic alternative and a positionality transforming conventional, normative modes of belonging. These normative modes are linked with the above social orthodoxies, which govern the workings of sex/gender and gender identity present in both non-Romani and Romani societies and communities. In Kerttu's case, and, to a certain degree, in Ana's, too, heteronormativity and cisnormativity are deployed as benchmarks for measuring who is and who is not a proper Romani woman. Heteronormativity is thus co-opted into conservative definitions of what constitutes authentic Romani ethnic identity, delineating the boundaries of Romani ethnicity. However, Kerttu, Ana and Vasil's queer belonging by identification with certain aspects of Romani ethnicity and by disidentification with conservative patriarchal and heteronormative conceptualisations of Romani ethnic identity are subversive to patriarchy and heteronormativity. Not only that, their very lives and visibility, which are both queer and Romani, are transgressive and transformative in that they show not only the real possibilities but also the actual existence of queer Roma who live both within and outside white-normative, patriarchal, heteronormative and cisnormative societies. Visibility can be understood as a key mechanism that sets in motion the processes of identification and disidentification, which, in turn, operationalise queer belonging. In a somewhat similar spirit, Markus discusses his experiences of queer belonging:

I'm a gay Rom trans guy. But I don't really feel part of the Roma community. I'm a bit afraid how the Roma community will react if they know that I'm trans because I don't know how transphobic the straight hetero community will react. I'm not feeling belonging to any community. I'm pretty tired, I have to say. I would really enjoy to rest. I'm feeling much more lonely than I felt before, especially after the second transition. In general, I don't feel so comfortable with those trans things because it always gives me those 'freak labels'. I identify just as a guy. It's also really hard to see how my sex life is changing because I'm more and more attracted to other guys. I always heard stories from those friends who were doing the transition, afterwards they're just into gay guys. It's really hard because I don't have a dick and they expect me to have one. The gay community is really transphobic. They fetishize trans women as an object, and trans men are not existing because they don't 
have a dick. I think a lot of my problem is the fear how people will react if they find out that I don't have a dick. And the fear is often so huge that I don't even want to come to the point. A very good friend of mine is Roma, we can talk about a lot of things but he is a gay guy. When he goes to a gay sex club, we both have the point that we can be confronted with racist people but he has a dick, so everything is fine. You don't have to be afraid when somebody's offering a blow job and say 'hey there's nothing you can blow on'. (Markus)

Markus identifies as a gay trans Roma. His first transition from female to male happened in his late teens. Then, in his early twenties, he learnt that his biological father is Roma. He refers to this period as his 'second transition': that is transition from the non-Romani cultural heritage, in which he was brought up, to the Romani cultural heritage of his biological father. The notion of transitioning in terms of gender identity, sexuality and cultural heritage is very reminiscent of the notion that identities fluidly assemble and disassemble against the backdrop of the asymmetrical hegemonic power relations that are effects of white-normativity, heteronormativity, cisnormativity and patriarchy. Following these multiple transitions, Markus states that he has been experiencing feelings of loneliness, marginalisation, isolation and not belonging. These experiences have been exacerbated by his fear of possible homophobic and transphobic reactions from within the Romani community, as well as by his experiences of transphobia, homonormativity and exclusion within the gay community. Additionally, his gender role as a trans man has been reduced and made invisible by his queer intersectional specificity, including due to not having a penis. Despite Markus's disidentification with the communities that are associated with his ethnic/'racial', sexual and gender identities, he has maintained his identification as Roma, gay and trans.

In the following quote, Lisa, a Romani woman in her early 30s, offers a similar account of how she has experienced being the partner of a Romani trans man whose masculinity is doubted by gay Roma due to him not having a penis:

Several gay friends of mine told me that they wanted the best for me, that they had not envisaged being with a trans male for me, that they had wanted me to have my own biological children and so on. So, I am not sure how they meant it, whether they were dead serious about this, but this is how I came to understand it. The truth is that it made me really sad. I mean my own father accepted it, so what are they on about? But what took me aback the most is that, effectively, the LGB community gives the impression - at least that is how I feel - they all say that they are oppressed and suddenly here comes the trans person. Whether they are female to male, or male to female, all of a sudden, gays who feel they have been oppressed, laughed at by straight men all 
their life because they are not real men, they are snowflakes, they have been ridiculed and the trans person comes along and all of a sudden, the gays are higher up, they are the 'real men'. Do you understand? They have IT. They may be wearing high heels, but they have IT. I find that the whole world is revolving around 'cock'! It is everywhere. I find this to be a sad realisation, I must say. (Lisa)

Lisa describes her experiences of not belonging to the Romani gay community as a queer straight woman. Her account suggests that even within groups and communities that purport to represent LGBTIQ people's interests and to not abide by the heteronormative social script, the presence or the absence of a penis is judged in very heteronormative terms. In Markus and Lisa's stories, experiences of homonormative exclusions of trans people (Browne and Lim 2010; Hines 2010) are some of the key factors shaping the two queer Roma's sense of non-belonging in the groups or communities they initially sought to identify with. Following Muñoz (1999), queer belonging entails disidentification with majority groups or communities that represent the dominant ethnic/'racial', sexual and gender norm. As a strategy, it enables queer Roma and other minoritarian subjects to negotiate queer intersectional identities and to make queer identifications both within and outside social normativities.

This section has demonstrated that we can understand queer belonging as an alternative, non-normative (queer) mode of belonging that shakes up and reorganises conventional ways of belonging. In the above examples, the dimension of sex/gender was of key importance especially in terms of the queer intersectional specificity experienced by Romani lesbians, trans and intersex men. Particularly with respect to the notion of stigmatised identities, queer belonging as a strategy makes it possible for some queer Roma to disidentify with the Romani community while maintaining identification with Romani ethnicity. Furthermore, this section has shown that some queer Roma, such as Ana, choose to counter identity categories by not belonging with any identity whatsoever and by actively encouraging other relational practices such as affinity and solidarity. The situations in which some queer Roma choose to belong can be seen as purposeful, strategic, political statements: a subversive challenge posed in response to everyday asymmetrical hegemonic power relations. Marked identity categories such as 'lesbian', 'gay', 'woman', 'trans' and 'Roma' - located in direct opposition to the unmarked, normative identity categories such as 'straight', 'man', 'cis' and 'non-Roma' - are thus deployed strategically and transformatively as political vehicles challenging dominant social orthodoxies.

In the following section, I first discuss queer belonging in relation to social mobilisation around fixed identity categories. I then proceed to exploring the possibility of queer belonging as a strategic response to the identity dilemma. 


\section{Queer belonging as a strategic response to the identity dilemma}

Thus far, we have seen that queer, queerness and queer theoretical concepts can shake the foundations of identity politics: not only those of gay and lesbian politics but, by extension, also those on which Romani identity politics has been built. They pose a critical challenge to social orthodoxies, including white-normativity. What Gamson (1995) has termed a 'queer dilemma', and what McGarry and Jasper (2015) refer to as 'identity dilemma', I will refer to herein as the queer identity dilemma. The dilemma lies in the tension between queerness as a non-identitarian positionality countering binary social norms and orthodoxies on the one hand, and, on the other, the notion that identity categories, including queer sexual and gender identities, are necessary as a basis for mobilisation for political power - that is, strategic essentialism ${ }^{2}$ - but they can also become a basis for oppression (Gamson 1995). In the following quote from an interview, Zoltan dwells on several related aspects:

In the gay culture, we have one of the most stereotypical communities. We have many boxes. I am a human being but if I have to choose from the stereotypical boxes, probably I'm a twink, and also a queer and a man. So, the best thing is mixing up these boxes and create one that fits you. We can't and shouldn't completely forget about these labels because they are useful. Everybody wants to belong somewhere; and it's also the heritage, your own story and identification. Everybody's labelling when you're just going on the street. When you try to be open to others, accept it and understand it, you begin to understand your personality and recognising your own labels through the other person. After coming out, I identified myself with my own homosexuality for years and in the others' eyes, I was just a gay. I identify myself also as gender-fluid person. I was born as a transsexual child. I learnt early in my life that I cannot be a girl, but I had the feeling that I'm a girl inside. I could see that I could be a girl if I want to. I have a skinny body, a very feminine face. Many times, I was noticed as woman. I began to live like that, to wear women's clothes. I looked up the operation but then I realised that I would never do that to my body, that it would be the biggest lie in my life. I knew that this isn't me. The biggest lesson I learnt from that is I have to accept and respect my body as I am. I fully respect those persons who are making this operation but I really had my time to think about it. I feel one hundred percent man in my everyday life and sometimes there is this queer and diva stuff coming out when I'm just shaking my ass, snapping with my hands in the performance. My woman's side has just turned into queer stuff. (Zoltan) 


\section{Queer belonging}

Zoltan discusses his queer identity dilemma: he has an urge to remain true to himself and to not identify with or belong in identity categories that individuals routinely adopt. Simultaneously, he sees the usefulness of identity categories and the need to belong in them. As we saw in Chapter One, belonging is often associated with the safety and security of knowing one's place, as well as with a dynamic movement of and between categories of identification. He describes his identification as gender-fluid and queer, as well as the process of coming to disidentify with the sex/gender binary of man-woman, sexuality, or even the notion that trans people need to be fixed by surgery: all these identifications and disidentifications have allowed him to find his own way of being queer. From his account, we can see that both identification and disidentification have facilitated his queer belonging. Zoltan has been working through the externally imposed identity labels towards finding an all-encompassing queer wholeness, in which all of these categories disappear. This process may be seen as Zoltan's subversive take on conventional modes of belonging grounded in division, designation and polarisation (Probyn 1996), associated with identity and identity politics.

In Chapter One, we saw that queer and queerness are generally understood as destabilising and rejecting fixed identity categories and categorisation. In keeping with some of the critique levelled at queer theory by queer of colour critique scholars (e.g. Reid-Pharr 2002; Ferguson 2004; Gopinath 2005, 3; Eng, Munoz and Halberstam 2005), even queer and queerness may become a label and a 'formulaic grid' (Puar 2007, 212) of fixed, at times stereotypical identities exploited for political purposes. In the following quote, Markus explores this queer identity dilemma by elaborating on how queer itself has often become a label in some queer collectives:

I feel somehow included in queer but also somehow excluded because I cannot identity myself with queer anymore. I see what people make out of the label 'queer' and it doesn't have anything to do anymore with Stonewall and how all of this started. I think it's more and more academic, pretty male and you have all those gender studies and queer theory. Suddenly you see voting posters from one of the parties saying something about queer and gender and I like 'what are you using even this word for if you don't know what it means and actually where it came from?'. It's a huge party label, fashion suddenly to play with gender roles but they are people's existence. Queer for me was always the thing where you can just be who you are but also goes always together with the history, with fights, with a lot of violence against transgender people, against lesbian people, against gay people. Today I see the word 'queer' but I don't see it belong to the history. I moved out of the queer white community because I didn't feel that it's mine anymore. In the queer scene, trans guys are seen as cooler than trans women, trans women really have a hard time to be taken seriously, not 
just as a drag queen or as a fetishized person. Trans guys are not allowed to pass pretty well because you should still make visible that you are a trans guy, stay kind of queer. It's a bit in an overdosed way, with a huge sign, or a tattoo on your forehead with the transgender flag so that everybody knows you're one of us. (Markus)

Through his story, Markus offers an account of his disidentification with a particular interpretation by LGBT organisations and collectives of 'queer' that has turned into a normative, over-politicised, white-washed, empty term void of its original meaning grounded within a particular historical context. As we have seen in this chapter, Markus's identification as Roma, trans and gay in conjunction with his disidentification with the white queer community has facilitated his queer belonging. The above account shows that Markus disidentifies even further with a normative understanding of queer. Responding to the queer identity dilemma, Marcus's experiences reaffirm the notion of queer belonging as a strategic positionality countering norms and normative practices applied even in groups and communities that claim to be queer.

In a similar vein, in the following quote, Teresa, who identifies as a Romani gender-fluid queer woman, talks about her take on moving fluidly between genders:

I took testosterone for a few months. I had a half-year to train for a role as professional boxer. I put on 7 kilos in muscle. I stopped because I was not sure about this transition. If I really start to pass as a guy, I will not get roles. I got afraid and didn't want to risk it. I don't really want to be a man, I just like to be more boyish. I was planning to start again this summer with a friend of mine but we were both not 100 percent sure. I didn't like that I was starting to get a beard. It is quite strange: usually, trans men really want to pass and to have beard, so that people are not doubting about their gender. They're queer getting a beard and so proud of it, shaping it. But I hated it from the beginning and it doesn't go 100 hundred percent back if you stop it. One point why I'm not completely happy taking testosterone is that I like being in between: gender fluid. A lot of people see me like very like pretty and feminine, and also like very masculine. Often, guys ask me if I'm lesbian' and then they say: 'it's really obvious, the way you're acting and your clothes, and also you're so fucking pretty'. I think it's also a quality to present both traits. This is also why I'm an actress, playing with roles. I think it's also why I'm still doubting losing one part by taking testosterone. For me, the LGB community is completely mainstream and unpolitical and also I know that many of them vote for the right party and are very conservative. If you are lesbian but suddenly you have a boyfriend, you're out of the community. (Teresa) 
As a gender-fluid queer person, in terms of her gender expression, Teresa prefers to occupy the queer space in-between by displaying both feminine and masculine qualities. Echoing some of queer of colour critique's key objections to mainstream binary understandings of sexuality and gender identity by lesbian and gay studies, Teresa disidentifies with the conventional male/female gender binary, as well as with mainstream lesbian, gay and bi communities. She considers segments of these communities unpolitical, conservative, even leaning to the right due to the perpetuation of heteronormative binary social norms: what we have previously referred to as homonormativity or homonationalism. Her sense of queer belonging as a positionality unsettling and challenging normativities within mainstream lesbian, gay and bi communities is operationalised by disidentification with them.

Aided by the theoretical discussions in Chapter Two about marked categories of identification such as 'woman', 'lesbian', 'gay', 'trans' or 'Roma' being non-normative (queer), transgressive and disruptive to dominant social orthodoxies, so far, we have seen that non-normative sexualities and gender identities have a potential to destabilise and subvert heteronormativity, cisnormativity and patriarchy. Similarly, non-normative ethnic/'racial' identities, including Romani ethnicity, which display traits of queer and queerness as a non-normative positionality, have a potential to critically challenge, unsettle and disrupt white-normativity as a social orthodoxy. In the following quote, Veronika dwells on the subversive implications of the fluidity of her ethnicity and sexuality:

As for my identification, it is very multi-layered and fluid. First, it is based on my natural resentment to labels, second, it is influenced by my own experiences, and third, it is the analytical benefit I've gained through my studies. All of this makes me unable to express myself clearly, but it is very contextual. I don't like identity politics much but I understand that from a certain viewpoint and at different points in history, it may be a way of tackling the issue, at least to a certain extent because society still operates on the basis of these oppositional categories often based on some sort of cultural difference. So it is clear that when everyone treats you this way and labels you, in fact you don't have a solution and then emancipation must happen on the same basis or rules although for you, another aspect of your identity may be pivotal, so that is what is contextual. I find that [due to] this intersection of sexuality plus a different ethnicity, I've always been somewhere in between. I didn't belong here or there. So emotionally and intellectually, this has been challenging. But for me it is a marvellous thing because it develops me in many respects. (Veronika)

Similar to Zoltan, Veronika touches upon a key debate in queer theory: the issue of labels being oppositional categories, or binaries, structuring the 
social world. She believes that because of these binary oppositions, the social world is predicated upon and governed predominantly by identity politics. At the same time, precisely because oppression and inequality occur along the lines of binary oppositions, identity politics often functions as the basis for emancipation: a queer identity dilemma. At times, such emancipatory efforts may overlook not only the queer intersectional specificity experienced by queer Roma, but also the contextual, fluid and multilayered identifications - and, as this chapter argues, also disidentifications that queer Roma such as Veronika make. Such identifications and disidentifications are non-normative, hence queer. As previously discussed by Zoltan or Teresa in this chapter, the social world structured by binary oppositions may try to force Veronika and other queer Roma to adopt labels - to make identifications - that they are not necessarily comfortable with. Veronika has moved between two binary worlds simultaneously: the world of ethnicity/'race', structured by the 'Roma/non-Roma' binary opposition; and the world of sexuality, structured by the 'lesbian/gay and straight' binary opposition. This ability to move in between ethnic/'racial', sexual and gender identities encapsulates her queer belonging by means of both identification and disidentification.

The ever-present queer identity dilemma requires individuals, who oftentimes identify as members of sexual, gender and ethnic/'racial' groups, including queer Roma activists, to strategically negotiate the value, utility and impact of collective identity (McGarry and Jasper 2015). The Roma rights movement, too, and Romani Studies have had to negotiate numerous identity dilemmas, including the articulation of nationhood in the 1970s or the more recent negotiations of intersectional identities, including LGBTIQ identities (Fremlova and McGarry 2018). As discussed in Chapter One, the emergence of intersectional feminist discourses within the largely patriarchal and heteronormative Roma rights movement and Romani Studies scholarship has shaken the foundations, on which dominant understandings of Romani identity, seen predominantly through the lens of ethnicity, have been built. Until quite recently, omission and, at times, avoidance of sexuality in these discourses have resulted in the invisibility of the queer intersectional specificity experienced by queer Roma. In the following quote, Ana discusses the invisibility that Romani lesbian women experience in particular:

Our existence is not visible either in the Romani community, the Romani movement specially or in the LGBT movement. I'm a radical feminist, activist in Romani women's network. We have a group dealing with Romani lesbians. We gather Romani lesbians, we empower ourselves. My focus is on intersectionality, actually, between different grounds of discrimination. As Roma, we can be discriminated by gender: Romani women face multiple discrimination. Also, within Romani women group, we are discriminated based on our sexual 
orientation. It is important to figure out that we can be different and diverse inside the Romani community. We have a right to be different. (Ana)

In this chapter and Chapter Three, Ana has elaborated on the idea that Romani lesbian existence is both hidden and invisible within the rubric of Romani, as well as non-Romani societies and communities, including in the LGBTIQ movement and in heteronormative Romani women's groups. The invisibility of queer Roma on all fronts, including the Roma rights movement and Romani Studies, has led to some Roma lesbian women feeling they do not belong with, in or to the Romani community, the Roma rights movement or the LGBT movement. The general lack of visibility of queer Roma was a key factor that prompted the recent emergence of the LGBTIQ Roma movement. However, as John suggests, some actors within the Roma rights movement have been sceptical about the idea of building alliances with the larger LGBTIQ movement:

I know for a fact that it's also scary for Romani organisations because the LGBT movement is more powerful than they are and if they cooperate or build alliances, some of them even say 'we might get swallowed up by them, they might take control, we need to be careful, we need to take a step back.' And this is actually coming from people who are very open to LGBTIQ Roma or other LGBTIQ issues. They say: 'we need to keep a little bit of distance from the LGBT movement because they're bigger and more powerful than us even though we can learn from them and they can be allies.' We, LGBTIQ Roma, don't have to use the rules of everyone else, we can fit in according to our rules. It's worked for the last 800 years and we're still here. It's a queer approach. (John)

John touches upon a key tenet of queerness: that queer Roma do not have to play by anyone's rules. This is an approach that very much resembles the queer slogan 'We're here, we're queer, get used to it!'. In this chapter, we have seen that Ana argues in favour of a queer, revolutionary approach: one that counters identity categories by not belonging to any identity. In the above account, she appeals for the right of queer Roma to be different from normative social scripts. In Chapters Three and Four, we saw that the lack of visibility of queer Roma often serves to preserve the white-normative, heteronormative, cisnormative and patriarchal status quo. Making the queer intersectional specificity of queer Roma visible by asserting the right to be different from dominant societies and norms is not only a political, strategically essentialist statement but also a need. It also encapsulates the very notion of the queer identity dilemma, which is implied by both John and Ana's testimonies above: that pointing out this specificity that marks queer Roma as distinct and different from straight Roma, as well as straight 
and queer non-Roma, may turn into a 'political truth' and a potential basis for oppression. This is not to say that queer Roma, activists and advocates want to reinforce this specificity. Rather, it is to assert that if formulated along the lines of identity politics, the political power of queer Roma would be premised on difference. Yet, as this section has shown, some queer Roma take an issue with and oppose identity and identity politics. The route that some queer Roma take - that is, through queer belonging by identification and disidentification - diverges from identity politics. Queer belonging can be seen as an alternative strategy and a response to the many dilemmas posed by identity and identity politics.

The invisibility of queer Roma within the predominantly heteronormative Roma rights movement and the global, predominantly white ethnocentric LGBTIQ movement has led to some queer Roma's disappointment, disillusion and a sense of disidentification with both. Within the Roma rights movement, over the past two decades, discourses on Romani women have been exhausted. Simultaneously, ethnocentrism, paternalism, white-normativity and homonationalism within the mainstream LGBTIQ movement have hampered any meaningful dialogue, as suggested by Bruno in the following quote.

Romani organisations are starting to have some interest for the LGTBQ Roma because the discourse of the women is finished. After 25 years, it's not new. It's like them saying: 'it's not exactly my thing but we need to make new programmes and a new discourse'. I think it's only a political strategy. In reality, LGTB Roma are in the same situation of discrimination inside the community, we have the problems because some people [are] kidnapped, fight, [go] through terrible personal situations. The political discourse does not match the reality. In general, intervention with Roma people, and especially we want to speak about LGTB, is paternalistic. The LGTB movements from the majority have one idea what is emancipation, what is liberation, what is respect in the LGTB community. Sometimes it's not exactly the same in the Roma community. We have this problem of ethnocentrism. This produces toxic minority-majority relations because the perception is that the Roma is a problem and we need finish with the problem. Roma are not perceived like a human group with self dynamics. And it's for this that we need to make our own forms of fighting this problem. We need the help from the movements, not the patronising approach. I think the LGTB movement needs to evolve, something to speak about intersectionality and multiple discrimination. I think it's something general for the Roma movement, for the women movement, for the feminist, too: this problem of ethnocentrism. It's like we have one model of liberation and we need to follow this model because if you don't follow this, you are not in the good way. We need to break this toxic minority-majority relation. We need start to make in the Roma 
community strategies with other minorities, too. In [my country], we're starting work with Muslim feminists and the LGTB Muslims. (Bruno)

Bruno elaborates on the idea that due to the exhaustion of old discourses, some Romani organisations are turning to discourses on queer Roma out of necessity rather than genuine conviction. In doing so, they are often quite disingenuous because they fail to tackle the real everyday problems still facing queer Roma both outside and inside some Romani communities: issues that remain largely unacknowledged. According to Bruno, the LGBTIQ movement takes a very ethnocentric, paternalistic approach to issues relating to sexuality and gender identity. Some of these failures by the LGBTIQ movement are reinforced and exacerbated by antigypsyism perpetrated by LGBTIQ non-Roma, which I discussed previously in Chapter Three. Bruno believes that mainstream LGBTIQ organisations are reluctant to employ an alternative approach as it would disrupt the white-normative orthodoxy that lies at the heart of this 'toxic majority-minority' dichotomy.

Bruno and other queer Roma such as Markus or Antonio made similar proposals regarding the transformation and subversion of the dominant ethnocentric script of the mainstream LGBTIQ movement. The suggestions concerned in particular current alliances existing between queer Roma, collectives such as Muslim feminists, LGBT Muslims and organisations bringing together queer people of colour and people from intersecting communities with similar lived experiences. Some of these experiences are related to persistent racism and ethnocentrism in LGBTIQ organisations; the objectification and fetishization of queer Roma and people of colour discussed in Chapter Three; and the expectation of coming out of the closet of 'inauthentic secrecy' (Tucker 2009). As evidenced throughout this book, the heterosexual/homosexual binary that informs the lived experiences of queer Roma is constructed within the context of specific local, relational, temporal and material realities. Therefore, coming out of the closet is not always appropriate for queer Roma. Indeed, as we saw in Chapter Four, queer Roma choose to enact their non-normative sexualities and gender identities in ways that do not necessarily conform to these expectations. The presence of social orthodoxies and antigypsyism within the LGBTIQ movement are some of the reasons why some queer Roma disidentify with the movement but maintain their identification as LBGTIQ.

\section{Conclusion}

This chapter has demonstrated that queer belonging is a productive transformation of majoritarian exclusionary cultural practices and modes of belonging, and a transgressive, subversive non-normative positionality that queer Roma assume when negotiating queer intersectional specificity. The intersectional ethnic/'racial', sexual and gender identities that queer Roma possess can be understood as non-normative positionalities with a potential 
to unsettle dominant socio-cultural scripts. The personal testimonies presented in this chapter have demonstrated that in deploying queer belonging, queer Roma productively transform dominant conceptualisations of identities by means of both identification and disidentification. Queer Roma disidentify with hostile, restrictive or oppressive aspects of ethnic/'racial', sexual and gender belonging not only to be able to live their lives but also for political reasons: to challenge antigypsyism and its intersections with homophobia, transphobia and sexism, as well as the invisibility of queer Romani lives within the LGBTIQ movement and the Roma rights movement.

Queer Roma transform the meaning of Romani ethnic identity by identifying as Roma while disidentifying with exclusionary and oppressive aspects of Romani ethnic belonging of some Romani communities. For example, growing up and living in the Romani community or speaking Romanes are often seen as prerequisites for authentic Romani ethnicity and belonging. Non-Romani majority society's heteronormative and cisnormative scripts are used as benchmarks for measuring who is and who is not a proper Roma: wearing a skirt, having long hair for Romani women; and being or appearing masculine for Romani men. Heteronormativity is thus co-opted into conservative definitions of what constitutes authentic Romani ethnic identity, delineating the boundaries of Romani ethnicity. Queer Roma transgress these boundaries: the very lives and visibility of queer Roma, who live both within and outside white-normative, patriarchal, heteronormative and cisnormative societies, are transformative and subversive to normative conceptions of Romani ethnic identity. By doing so, queer Roma effectively redefine belonging with Romani ethnic identity and community and spell out the terms of queer belonging, making use of both identification and disidentification.

Due to persisting oppression, mobilising around the fixity of identities forms the basis for political power. However, such strategically essentialist mobilisation that fixes and stabilises identity categories goes against the idea of queer as a non-normative and non-identitarian positionality. This perpetual tension presents a constant puzzle and a dilemma: identities are unstable, but their socially constructed fixity is necessary for social and political mobilisation. Some queer Roma employ queer belonging when negotiating the specificity of queer intersectional identities against the backdrop of persisting intersectional oppression. Diverging from the Roma rights movement and the LGBTIQ movement's identity politics, queer belonging thus represents an alternative form of politics.

\section{Notes}

1 Here, 'bear' refers to a particular type of male gay sub-culture. In the male gay culture, 'bear' is often associated with larger, hairier men projecting images of rugged masculinity. 
2 In Chapters One and Two, we saw that because particular groups, such as ethnic/ 'racial', sexual/gender minorities or women experience discrimination due to who they are, they start social and political mobilisation around it. This fixes the identity category, as we have seen with heteronormative and cisnormative conceptions of Romani ethnic identity. We are currently seeing something similar in relation to trans people, and trans women in particular. Some 'gender critical' or 'gender conservative' feminists insist on womanhood and motherhood being determined by biology and sex-based rights: rights they believe only women have due to being born women and experiencing discrimination based on their sex (i.e. biological essentialism). Disregarding feminist scholarship of more than four decades, they argue that gender is an ideology that trans people use to advance their own political agenda. 


\section{Towards non-stereotypical understandings of Romani identities}

In this concluding chapter, I first recount key milestones in understanding Romani identities. I outline the main contributions that the lived experiences of queer Roma presented in this book make to how we understand Romani identities. This concerns particularly the way in which queer intersectionalities challenge some of the persisting essentialising conceptualisations of Romani identities - and, for that matter, of identities in general. The chapter then proceeds to consider the importance of innovative methods in conducting impactful transdisciplinary research and coproducing knowledge that brings about social change, and the heterogeneity and plurality inherent to the lived experiences and visual selfrepresentations of queer Roma. In conclusion, the chapter reflects on the wider implications of strategic sameness and queer belonging and proposes that applying a queer intersectional feminist approach means that both strategies can and, in fact, do complement each other. Contemplating the use of strategic essentialism and queer intersectional feminism in social movements, the book concludes by reflecting on possible future directions for the Roma rights movement.

\section{Using sexuality and gender identity to trouble the 'canon' in research on Roma}

Thus far, this book has been an exploration of the lived experiences of queer Roma. It has offered the reader rich, detailed insight into the lives and experiences of queer Roma of various ages and backgrounds, coming from multiple countries in Europe and North America. It has demonstrated that the lived experiences of queer Roma pose a fundamental challenge to essentialising, one-dimensional, homogenising and stereotypical misrepresentations of Roma. It has also shown that marked essentialist difference - whether ethnicised/'racialised', sexed or gendered - that lies at the root of antigypsyism, homophobia, transphobia, sexism and their intersections can be critically challenged, deconstructed, or queered.

Part One of the book was a probe into post-modern, poststructuralist ways of understanding identity. Drawing on Hall's conceptualisation of

DOI: $10.4324 / 9780367822699-6$ 


\section{Towards non-stereotypical understandings}

collective social identities, and new ethnicities in particular, Chapter One applied these understandings, as well as understandings of identities facilitated by hybridity, super-diversity, intersectionality and queer theoretical concepts to Romani Studies. Crosscutting multiple categories of identification such as ethnicity/'race', sex/gender, sexuality, gender identity, class, age, social status, religion and so on, these concepts facilitate understandings of Romani identities beyond an ethnic frame of reference. We have seen that queerness as a positionality and assemblage rather than entity or identity deprivileges a binary opposition between queer and nonqueer individuals. Importantly, by virtue of being non-normative, antiessentialist, applicable to ethnic/'racial', sexual and gender identities and able to challenge and disrupt dominant homogenising, normative, binary and fixed accounts of identities, queer theoretical concepts - and queer assemblages in particular - help to counter essentialising conceptualisations of Romani identities and make it possible to attend to the multifaceted fluidity of Romani identities which include queer Romani identities as well.

Chapters One and Two illustrated how non-Roma as the dominant ethnic/'racial' group have historically often romanticised and simultaneously vilified Roma, thus turning Roma into a single, incomplete story. These historically flattened portrayals and misrepresentations have led to non-Roma perceiving Roma as fundamentally distinct, different from the non-Romani majority society: they are deeply rooted within the antigypsyist matrix of modern European nation states. Effectively, such stereotypical misrepresentations of Roma have resulted in embedding marked essentialist ethnic/'racial' difference at the core of historical and modern negative social valuation of Romani ethnic identity. Through this mechanism, non-Roma associate those who self-identify or are identified as Roma with stigmatising conceptions of Romani ethnicity, most often through ethnic/'racial' hyper-visibility (biological essentialism) or certain behavioural or cultural traits (cultural essentialism). In a similar vein, we saw in Chapter Two how marked essentialist ethnic/'racial' and sexual/ gender difference has engendered the historical construction of stereotypical, stigmatising images not only of imaginary Gypsies but also of queers as fundamentally distinct and different - almost a different species of humans, or 'sub-humans' - from what is presumed to be the non-Romani, heterosexual, cisgender social norm. As part of the Nazi race science and eugenics, this dangerous thesis and belief, which has historically stood at the root of antigypsyism, antisemitism, homophobia, transphobia and other forms of persecution, had utterly devastating consequences for Roma, Jews, gays, the mentally and physically challenged, political prisoners and others considered 'racially' inferior, unnatural or anti/asocial, particularly during WW2. We must never forget that.

There is no one way of understanding the complexity of people's lives, experiences and identities, especially when it comes to historic and modern persecution. Sometimes, it seems almost impossible to conceptually 
grasp the reality that certain groups of people have been historically rejected, excluded, marginalised, maltreated, institutionally discriminated against, killed or even targeted for extermination due to being perceived as distinct, deviant, perverse, pathological, backward. Yet, if there is $a$ way, then one can come to such an epistemological and ontological understanding by employing queer intersectionalities: the notion that identities are informed and shaped by asymmetrical hegemonic power relations whilst being multifaceted, fluid, always in the process of becoming. Such an approach enables us to attend to the workings of the interlocking axes of inequality sitting at the root of asymmetrical hegemonic power relations whilst not assuming the supremacy of one axis over the other, hence not reinscribing marked essentialist ethnic/'racial', sexual, gender and other difference embedded within and constitutive of binary social norms. It also enables us to see Romani identities as not anchored in the notion of fixed groupness of ethnicity/'race'.

The lived experiences of queer Roma presented in Part Two of the book demonstrated that antigypsyism - a direct manifestation of whitenormativity present even in LGBTIQ spaces - is a key aspect of the lived experiences of many queer Roma. Importantly, in Chapter Three, we saw that though antigypsyism often eclipses these lived experiences, it is not the only aspect of the experiences of queer Roma. Within the social fabric of non-Romani society, non-Romani LGBTIQ communities, as well as Romani families and communities, queer Roma experience stigmatisation at the intersection of antigypsyism, homophobia, transphobia and sexism due to the interlocking negative social valuation of non-normative ethnic/ 'racial', sexual and gender identity. In Chapters Three and Four, we saw that his queer intersectional specificity is linked to various degrees of ethnicised/'racialised', sexed and gendered visibility, including hyper-visibility, that occurs in the notional spaces between difference and sameness: the closet and passing. If and when protected by these notional spaces, queer Roma negotiate the boundaries of visibility that delineate difference and sameness. If possible, one may choose to come out of these notional spaces depending on how one reads a given social setting and how one is read within that context. Both the closet and passing are contextual and relational survival strategies employed by queer Roma: they are constituted and reconstituted through social contexts and relationships. Despite what may be seen as a white-normative assumption that queers should come out of the closet in order to be considered truthful and honest about who they are, some queer Roma choose to stay in the closet while others are partially out in order to preserve complex social relationships that may be, and often are critical for survival in the face of structural antigypsyism that is present everywhere in society, including in LGBTIQ groups and communities. This existential dependence, at times overreliance, on Romani families and communities impacts fundamentally on the ability of queer Roma to enact non-normative sexual and gender identities. We were also able to see that 


\section{Towards non-stereotypical understandings}

the closet and passing are a privilege available only to some queer Roma. In the face of intersectional oppression, the queer Romani user is able to choose their battles by determining when it is safe to conceal or reveal their ethnicity/'race', sexuality or gender identity. Even though there is a link between the closet, passing and invisibility, the assumed dichotomy between being hyper-visible/out of the closet and being invisible/in the closet does not always apply. Consequently, it is possible for some queer Roma to be both hyper-visible as LGBTIQ and Roma and to hide in plain sight. As part of this queer assemblage, the queer intersectional identities of queer Roma are contextually and relationally separated, put back together, (re) read, (re)defined and (re)affirmed against the backdrop of interlocking asymmetrical power relations that are constitutive of social normativities.

We have seen that individuals who ethnically/'racially' self-identify as Roma make other identifications on the basis of multiple categories, including sex/gender, sexuality, gender identity, religion, class and so on. Within both non-Romani and Romani communities, the intersection of sex/ gender with ethnicity/'race' plays a key role. Structural inequalities and the inequitable workings of sex/gender result in Romani queer women's multiple invisibility. Simultaneously, some Romani gay men's experiences are also impacted by social normativities, particularly with respect to mechanisms of social control enforcing heteronormative and patriarchal social paradigms. In heteronormative and cisnormative settings, sex/gender, sexuality and gender identity intersect with ethnicity/'race', creating conceptions of what constitutes authentic Romani ethnic identity. What is perceived as femininity in some passive gay men sometimes results in shaming and the attendant loss of social status. Simultaneously, a queer Roma's high social status may be seen as a mitigating factor enabling acceptance. Thus, certain intersections of queer identities are enabled and validated while others are made hard or impossible. In the case of some Romani trans men, ethnicity/'race' is sexed and gendered while their sex/ gender is ethnicised/'racialised' in either unfavourable or favourable ways, depending on the environments that they navigate.

The lived experiences presented in Part Two of the book provide evidence that queer Roma are and have always been part of the wider Romani kinship and community structures. The notion that non-normative sexual and gender identities form a part of Romani ethnic/'racial' identity means that even Romanipe(n) can be seen as a fluid becoming beyond being as demonstrated by the lived experiences of queer Roma. These rich, multilayered stories defy and dispel the single story narratives about Roma and dominant homogenising portrayals of Roma as anachronistic and antithetical to modernity and Europeanness. This includes claims and myths about the presumed compulsory heterosexuality, homophobia and sexual backwardness of Roma. As such, the lived experiences of queer Roma pose a fundamental challenge to stereotypical, one-dimensional and essentialising misrepresentations of Roma. 


\section{Impactful transdisciplinary knowledge production at the interface between community organising, policy and academia}

The lived experiences of queer Roma explored in this book fill a significant gap in knowledge. As I discussed in the Introduction and Chapter One, the missing voices of queer Roma, many of whom feel invisible, lonely and isolated, were an important aspect of the rationale for conducting the research. It was also a key need recognised and voiced by the queer Romani participants who felt that collecting data on the lived experiences of queer Roma and making them visible and accessible to other queer Roma, as well as non-Roma would empower individuals and benefit community groups. The lived experiences of queer Roma presented in this book convey powerful messages of personal strength, bravery, perseverance, resilience and survival at a particular conjuncture in the history of the Roma rights movement in the five decades since the first World Romani Congress in London in 1971, the LGBTIQ movement and, more generally, the civil rights movement worldwide. The road to equality and acceptance has never been an easy or smooth one: every historical period has had its own sets of challenges. The past one and a half decades, during which the LGBTIQ Roma movement has emerged and mobilised, has been extraordinary and unique in both a negative and a positive sense. On the one hand, it has been marked by the aforementioned major global backlash against ethnic/'racial', sexual and gender identities, minority, human rights and equality discourses, exacerbated by the recent COVID-19 pandemic, as well as by an unprecedented level of social polarisation, disinformation and extremist right-wing propaganda spread both online and offline. On the other hand, the focus within the EU and North America on equality and antidiscrimination over the past 15 years, as well as other attendant societal phenomena and developments have made it possible for queer Roma to come out and speak out not just individually but also collectively. In the last section of the chapter, I discuss some of the future steps and directions all of this may mean for the Roma rights both as a social and political movement.

This ground-breaking societal change, which some commentators from within the queer Romani community have termed 'revolutionary' (Hejlić 2019), has taken place particularly in less conservative segments of Romani communities within a relatively short period of time: something that would have been unthinkable in the early 2000s when discourses on Romani women were taking off. Importantly, though, it has had a significant knockon effect on more conservative segments of the Roma rights movement and Romani communities. The advent and increased use of social media during this time has played a significant role. These progressive, diversifying developments have enabled queer Roma to speak openly about who they are on multiple platforms and fora, including for the purposes of the research study on which this book is based. Thanks to this openness, we are now 
able to visualise the actual lives of queer Roma and to understand not just the differences that separate queer Roma from Roma who are straight; or from LGBTIQ folk who are non-Roma. Even more importantly, we are now able to grasp the gamut of commonalities that queer Roma share with straight Roma and LGBTIQ non-Roma. Thus, we can visualise the high degree of relatability and the potential that the lived experiences of queer Roma have to speak not just to the lives and experiences of people with queer intersectional identities but also to many others.

As the case of queer Roma shows, there are several paths to challenging intersectional inequalities and bringing about social change. These include community-focused organising and feeding the outputs of local and regional initiatives into policy work and impactful transdisciplinary, transformative research. The knowledge co-produced with the queer Romani research participants has been used to support national and transnational Roma initiatives such as the Roma Civil Monitor (CEU 2017-2020); ${ }^{1}$ the 2018-2019 Open Society Foundations' Community Youth fellowships; ARA ART's project 'LGBTIQ Roma consultants' and its online counselling project 'Řeknu to/I'll say it' ${ }^{2}$ for lonely and isolated LGBTIQ Roma of all ages who struggle with their sexuality; or the publication My Story, launched in early 2020 by the Brussels-based group LGBT Balkan together with European Roma Grassroots Organisations Network. ${ }^{3}$ The outputs of the above initiatives, along with the Prague Declaration ${ }^{4}$ adopted at the first International Roma LGBT conference in 2015, and the co-produced knowledge have benefitted also non-Romani civil society organisations such as ILGA-Europe, the largest LGBTIQ organisation in Europe and Central Asia, who have been including LGBTIQ Roma panels in their annual conferences since 2016. In the area of application and policy recommendations, the information regarding the specific needs of queer Roma pertaining to multiple, intersectional discrimination has been fed into larger national and transnational policy frameworks such as the new review cycle of the implementation of the Recommendation 2010(5) of the Committee of Ministers ${ }^{5}$ and other Council of Europe departments such as the Roma and Travellers Team, the Sexual Orientation and Gender Identity Unit or the Youth Department. It has also informed policy frameworks of intergovernmental institutions such as the European Commission, especially in terms of strategies designed to tackle and redress multiple, intersectional discrimination at the national and translational level, including the EU Roma Integration Policy. Ultimately, the lived experiences of queer Roma and the Roma LGTBIQ movement 'contribute far beyond the defence of their own immediate rights towards conceiving notions and ultimately policies that transgress the division and binary opposition between Roma and non-Roma and can inform smart public policies' (Fresno et al. 2020, 22).

Including the voices of less privileged, more vulnerable queer Roma was an important limitation and a key aspect that the research, on which this book is 
based, was not able to attend to sufficiently due to methodological constraints. Having cooperated with the Czech LGBTIQ Romani organisation ARA ART on a long-term basis, I have been able to participate in a project that seeks to do just that. An example of such a national and transnational initiative is the 2019-2021 project Roma LGBTIQ go visible: supporting activities for Roma LGBTIQ minority, undertaken by the Czech organisation in conjunction with the Slovak organisation Quo Vadis and the Hungarian organisation Diverse Youth Network and funded by the European Union's Rights, Equality and Citizenship Programme (2014-2020). One of the project objectives is to analyse and evaluate the situation of underprivileged LGBTIQ Roma in the Czech Republic, Slovakia and Hungary with respect to legal and other provisions concerning multiple, intersectional discrimination. This type of initiative contributes to an acknowledgement of the particular experiences and needs of queer Roma; of the importance of addressing these specific experiences and needs within Romani communities, as well as within nonRomani LGBTIQ communities; and of incorporating and mainstreaming them into equality, anti-discrimination, gender and sexuality policy frameworks and legal provisions.

In the Introduction and Chapter One, I referred to the abundance of academic and other literature on Roma vis-à-vis queer Roma's absence from Romani Studies literature, as well as from the vast body of literature on sexualities and gender identities. As someone who has been able to access these academic spheres, I felt I had the responsibility to make the lived experiences of queer Romani participants and the knowledge co-produced together widely available. This has included publishing articles in academic journals (Fremlova 2018, 2019), the present book or through a follow-up transdisciplinary academic research project discussed below.

\section{Visualising the lives of queer Roma}

As demonstrated throughout this book, the lives of queer Roma entail a wide spectrum of rich, multiple, intersectional experiences stemming from queer Roma's multi-faceted identities. As such, these experiences do not fit the template of any one representation or, for that matter, misrepresentation. Yet, Roma and Romani identities have been seen through the non-Romani prism of single-story narratives and trapped in stereotypes, misrepresentations and myths as opposed to varied, plural, multi-layered, nuanced and accurate representations. The actual lives of Roma with multiple identities have thus been hijacked by and reduced to distorted, stereotypical images of 'Gypsies'. These 'stark, crude representations of Roma (...) become a form of power and control as identities are given essential qualities' (Tremlett 2017, 722) and epitomise the idea that '[a]ll stereotypes are inaccurate, even the positive ones' (McGarry 2014, 761). For instance, it is a popular belief shared by many, non-Roma and Roma alike, that Roma are genetically predisposed to be great musicians. That is a 
positive stereotype based on the notion there are and have been, throughout history, a good many outstanding musicians which taps into the essentialist, distorted narratives and myths nonetheless. These misrepresentations construed along strictly biologically or culturally essentialist lines have become part of the hegemonic visual language of dominant societies. They have come to eclipse and govern the everyday lives of Roma. As Hall (1997) put it,

[r]epresentations sometimes call our very identities into question. We struggle over them because they matter - and these are contests from which serious consequences can flow. They define what is 'normal', who belongs - and therefore, who is excluded. (Hall 1997, 10)

Similarly, other dominant social groups such as straight and cisgender people have claimed 'to see with universal relevance' (Haraway 1991, 188), thus establishing a dominant, normative visuality that often denies the validity of other ways of seeing or being. Specific visual depictions, or images of social categories and difference - whether constituted on the basis of ethnicity/'race', sexuality or gender identity - are thus produced, making these social categories visible (Rose 2007). Visual images can be seen as iconic symbols or signs. Just like language, visual images come to constitute meaning, often resulting in the construction and reification of dominant cultural scripts, social norms and difference by means of a visual canon. Thus, certain visualities, or ways of seeing, are mobilised, privileged and lifted above others, producing specific effects in terms of dominant, normative regimes of representations. In this binary opposition, marked categories such as Romani ethnic identity, non-normative sexual and gender identities, even womanhood or femininity are constructed and visualised in relation to their unmarked, neutral counterparts: non-Romani identity or whiteness, heterosexuality, cisgender identity, manhood and masculinity. In visualising social categories, images of difference are embedded within the wider social contexts - or social modalities (Rose 2007), cultural practices, scripts, norms and normativities. In the Introduction and Chapters One and Two, we saw that non-Roma often see Roma negatively, through the stereotypical prism of crime, deviance, anti/asocial behaviour, backwardness, inadaptability as fundamentally distinct and different from the presumed non-Romani, white norm. Consequently, this binary opposition of social representations and ethnic/'racial' relations between non-Roma and Roma has been reproduced in the realm of visual representations. There, Roma are often visualised in stereotypically negative ways. As End (2017) observes, even seemingly neutral representations of Roma may reproduce ethnicised/'racialised' meanings and visual paradigms.

Social sciences have tended to be largely text-based: text has been traditionally privileged over other data and research methods. This book is not an exception: so far, the lived experiences of queer Roma presented in this 
book have assumed the form of text, too. Yet, the need for social scientists to attend to and use visual methods in the production of knowledge on ethnicity/'race', sexuality, gender identity and, more generally, social norms is significant. This seems particularly necessary given present-day world's overreliance on and oversaturation with visual images that have come to shape and fundamentally inform how we relate to and see each other. In 2018-2019, I was faced with a methodological question when thinking about how to further enhance the impact and accessibility of the knowledge co-produced with the queer Romani participants. My concern was especially with queer Roma's experiences of antigypsyism intersecting with homophobia, transphobia and sexism, and an overall lack of visibility. In a world dominated by normative visual representations, despite the high degree of commonality, relatability and a unique potential to defy stereotypes, the lived experiences of queer Roma still remained invisible to most people, Roma and non-Roma alike. 'A picture speaks a thousand words', as the saying goes. That is why I decided to explore the idea of queer Romani visual activists and artists giving a visual form to their lived experiences through a collaborative project, and to investigate the potential of these visual renditions to challenge dominant stereotypical misrepresentations of Roma. As part of this transdisciplinary project ${ }^{6}$, queer Romani visual activists and artists created a series of photographic self-representations. This approach to co-producing knowledge enabled the queer Romani visual activists and artists not only to exercise control over the process of creating the photographic self-representations, but also to spell out, in a visual form, the terms in which queer Roma wish to be represented.

The 15 visual self-representations created by the queer Romani visual activists and artists form the basis of the photographic exhibition 'Visualising the Lives of LGBTIQ Roma'. ${ }^{7}$ The exhibition not only captures the lived experiences of queer Roma; it is also a symbolic trajectory from indoors to outdoors, from the personal and private to the public and political, from the past to the present, from the myth of the 'Gypsy' to the reality of queer Roma's lived experiences, from extraordinary in the essentialising, stereotypical sense of the word to ordinary in the everyday sense that disrupts and counters the established dominant ethnicised/'racialised' visual paradigms and binaries with respect to portraying Roma. The exhibition first opened at Aspex Gallery, Portsmouth, UK, in November 2019. Since then, it has been on display at the University of Brighton (November 2019), Brighton Museum (January 2020), virtually at Ljubljana Pride, Slovenia (September 2020) and as part of an exhibition of Czech and Slovak Romani and pro-Romani artists entitled BíLá Místa (White Spaces) ${ }^{8}$ at the Emil Filla Gallery in Ústí nad Labem, Czech Republic (September-October 2020). A number of the photographs form part of Brighton Museum's multiannual community-curated exhibition Queer the Pier $^{9}$ that highlights the rich cultural history of the LGBTIQ community, including queer Roma, in Brighton and East Sussex. At all of the above 
events, discussions regarding the lived experiences and visual selfrepresentations of queer Roma, as well as the role of impactful transdisciplinary research facilitating knowledge production at the interface between community organising, policy, academia and arts, took place with members of the audience. This included scholars, university staff and students and the general public.

Just like the lived experiences, the visual self-representations of queer Roma pose a fundamental, strategic challenge to stereotypical misrepresentations of Roma. Thanks to this quality, it is possible to challenge stereotypical misrepresentations and visual tropes directly through selfrepresentations. One way of achieving this is by juxtaposing stereotypical images of Roma with something different: something that does not necessarily have to be the opposite. For example, according to the stereotype and the visual trope, a non-Roma's future is read from tarot cards inside a Gypsy trailer (Figure 6.1).

Using this archetypal misrepresentation and inserting the figure of a present-day gay Roma, we are able to visualise the difference between a stereotypical myth and the gay Roma's highly heterogenous lived experiences in the 21 st century.

Challenges to misrepresentations can be posed contextually, by making cultural or social references. This can be done, for instance, by juxtaposing feminism with stereotypical representations; placing the Romani flag and

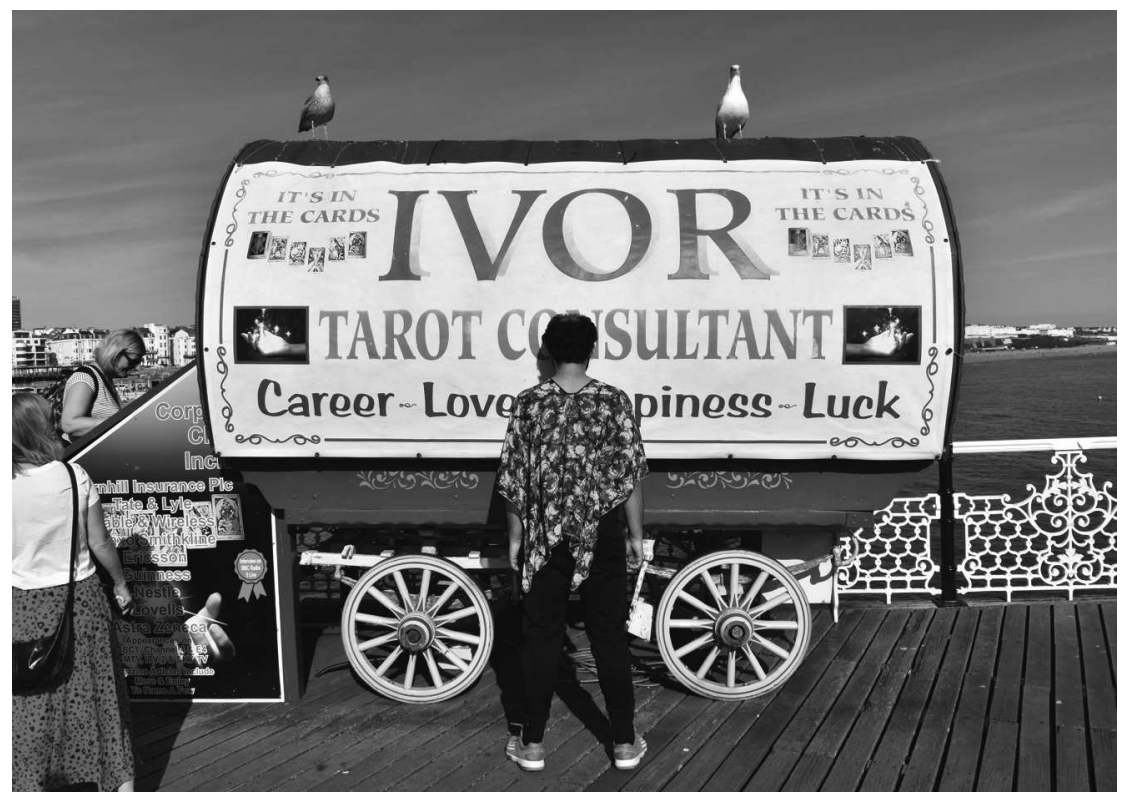

Figure 6.1 Myth and reality. 


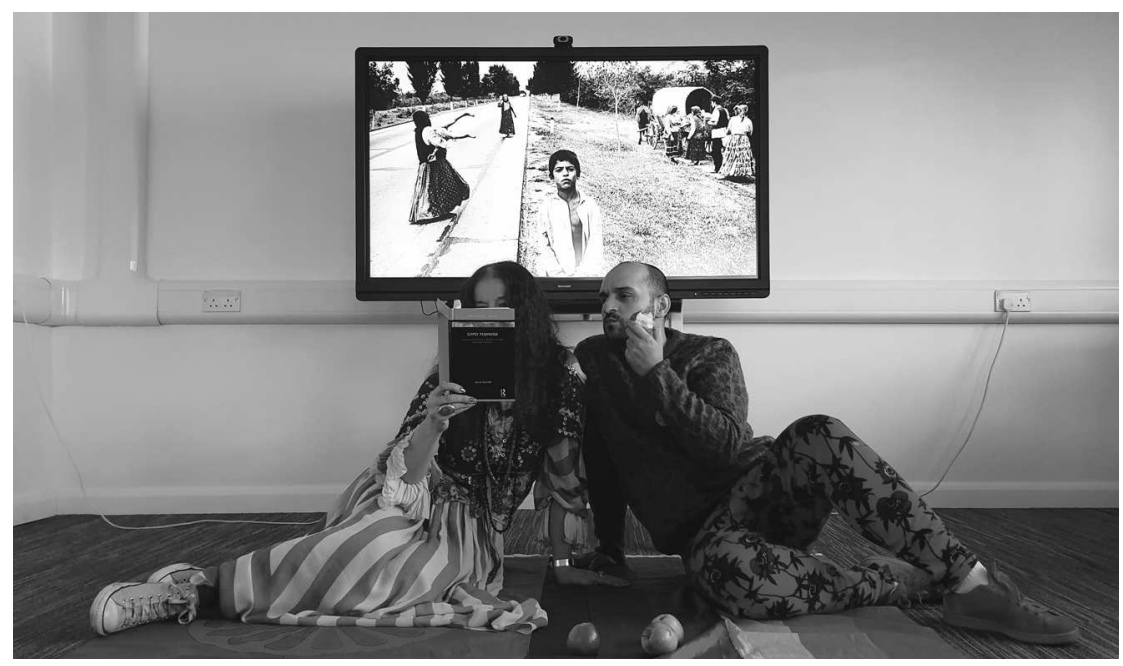

Figure 6.2 Present and past.

the rainbow flag next to each other; or through a critical use of clothing (Figure 6.2).

In Chapters Three and Five, we saw that at times, clothing is co-opted into heteronormative definitions of authentic Romani ethnic identity. Employing socio-cultural references in a critical, queer way, clothing thus becomes a personal, as well as a public, political statement of queer belonging: a means of transgressing, transforming and disidentifying with majority cultural scripts and social norms, and a tool for making the lives of queer Roma visible.

Another type of visual self-representations introduces a queer take on normalisation and assimilation, inherent to strategic sameness. Utilising stock photos as a genre symptomatic of stereotypes and social norms, impressions and imitations of presumed normalcy may be achieved by means of what the photograph portrays: for example, a happy household or a happy couple on the beach.

A queer reading is introduced by revealing to the viewer, through captions or other hints and references, that the people portrayed in these normative-looking photographs are a gay Romani couple (Figure 6.3) or cis/trans Romani couple (Figure 6.4).

Applying insight from Gonzalez-Torres (in Katz, 2015) discussed in Chapter One, the queer Romani bearer of such normalisation strategically deploys sameness to infiltrate norms from within in order to unsettle social normativities engendering the binary opposition between unmarked identity categories - or social norms - and marked identity categories that deviate from them. 


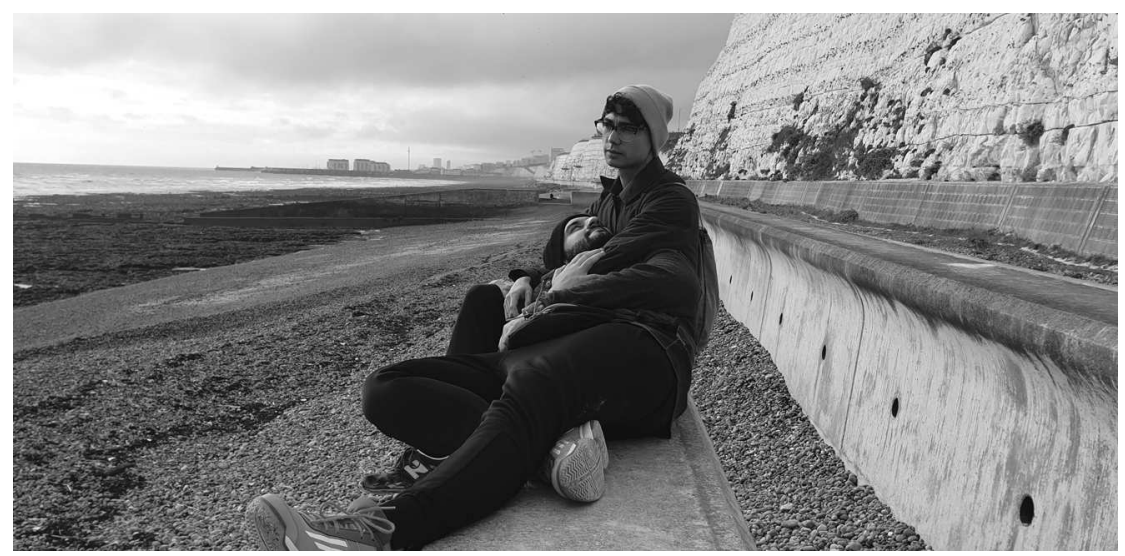

Figure 6.3 Everyday couple.

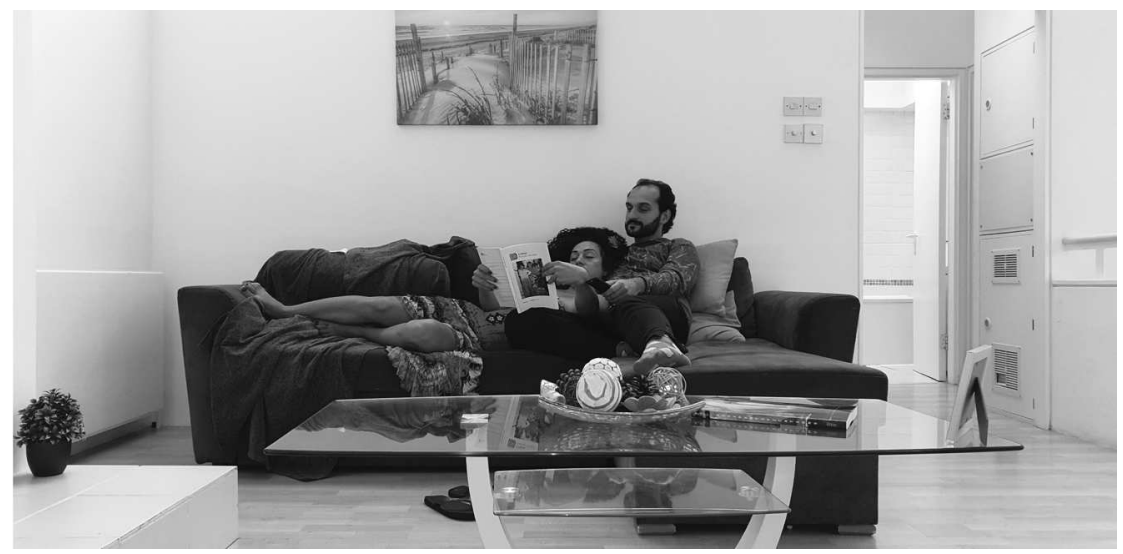

Figure 6.4 Everyday household.

Visual self-representations that do not serve another purpose can be seen as an example of so-called pure self-representations. Self-representations can be used as an efficient means of challenging oppression, but they do not have to fulfil that function. Strategically, in their design, pure self-representations do not aspire to challenge tropes, stereotypical representations and misrepresentations of Roma. ${ }^{10}$ It is frequently assumed that when portraying members of non-dominant groups such as ethnic/'racial', sexual and gender identity minorities, those portrayals will represent every single member of that group. Yet, even pure self-representations have their limits: as selfrepresentations, they do not speak for all queer Roma (Figures 6.5 and 6.6). 


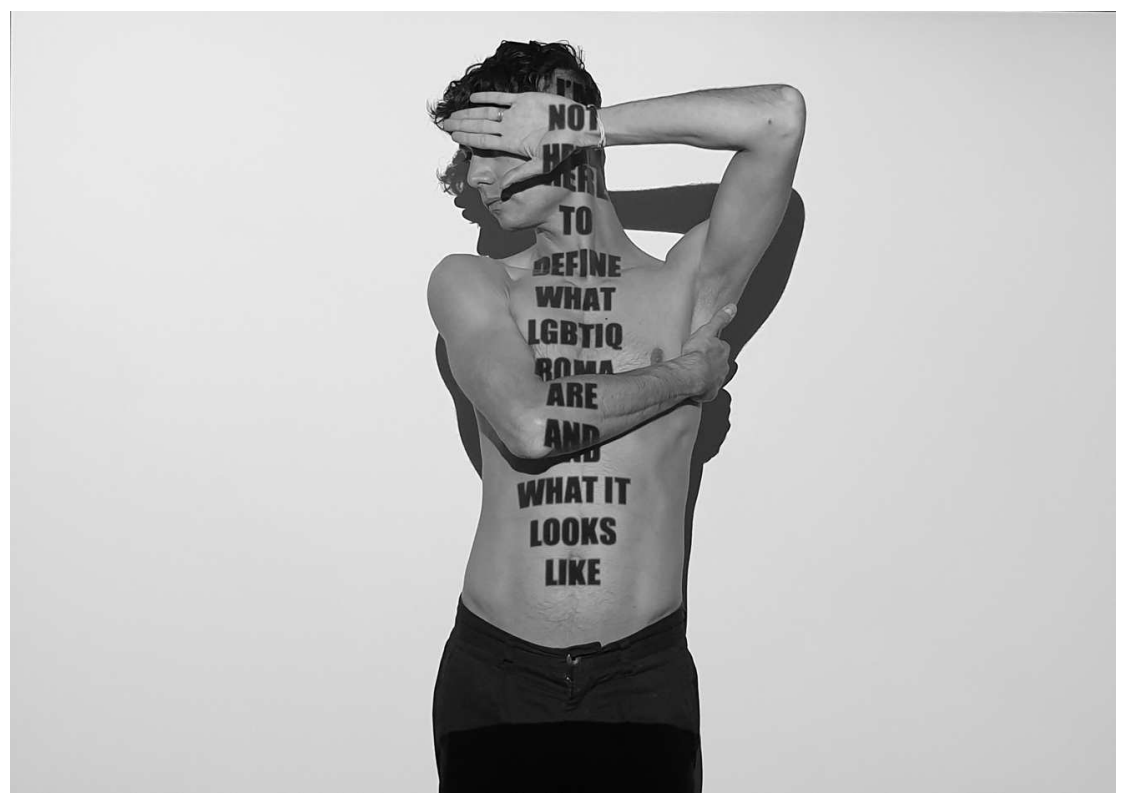

Figure 6.5 On my skin 1

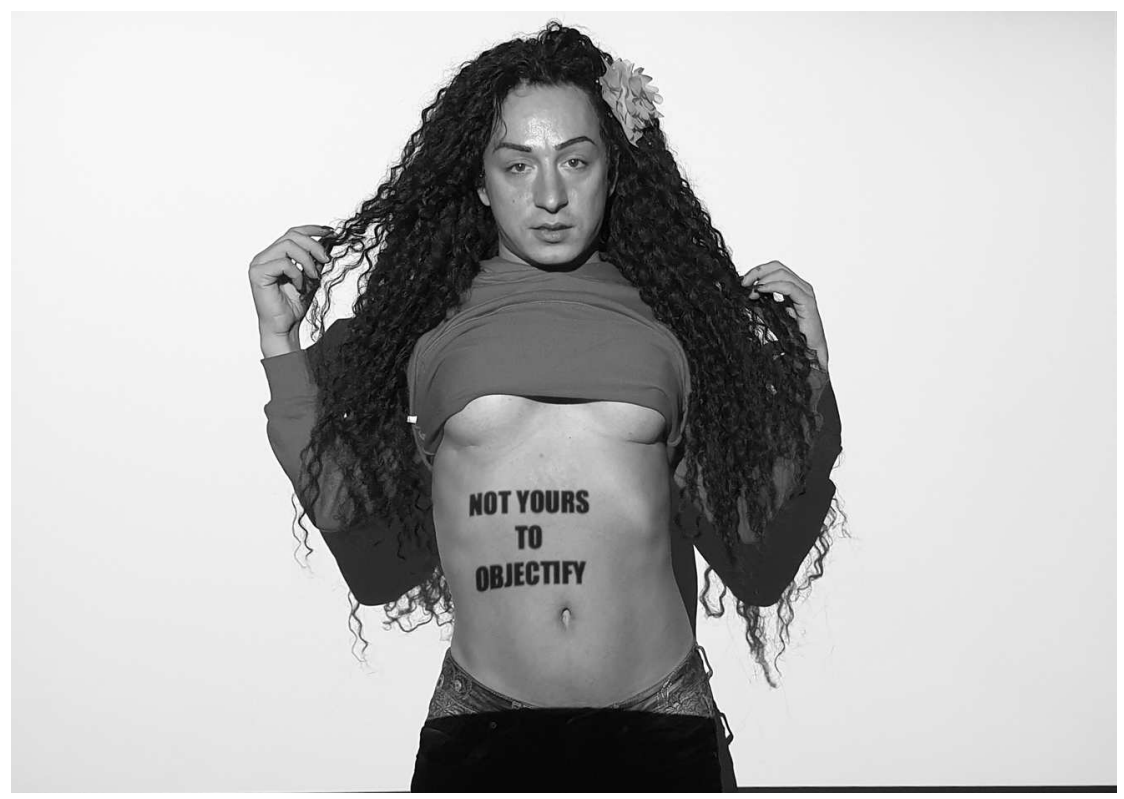

Figure 6.6 On my skin 2 


\section{Towards non-stereotypical understandings}

\section{Queer(y)ing identity politics: Avenues to new forms of queer intersectional politics}

In Chapters Four and Five, we saw that negotiating the spaces between difference and sameness leads to a positionality that some queer Roma assume in order to unsettle and counter social normativities at the heart of systemic, structural inequality. Chapter Four demonstrated that in response to marked essentialist ethnic/'racial', sexual and gender difference that lies at the root of white-normativity, heteronormativity, cisnormativity and patriarchy, as mediators, bridges, halfies and in-betweens, some queer Roma seek to create commonality, and indeed, strategic sameness as a way of negotiating queer intersectional specificity. Strategic sameness refers to a relational sense of sameness: a relational use of identities across difference whereby connections are created for strategic purposes. It is a queer positionality; as such, strategic sameness reads neither through assimilation, conformity nor normalisation. Invisibility - and, in some cases, hypervisibility - associated with the closet and passing play a key role. Deployed in a queer way unsettle and challenge dominant normativities within which it operates, strategic sameness enables its queer bearer to deploy sameness in order to resist binary social norms.

Chapter Five established that queer belonging operates both within and outside the normative scripts of dominant societies. Both strategic sameness and queer belonging may thus be seen as strategies for negotiating queer Roma's non-normative intersectional identities that are fluidly, multiply informed, shaped and discursively constructed - not fabricated, faked or fake! - by and through asymmetrical hegemonic power relations. Queer belonging by identification and disidentification is a transgressive, subversive, non/ counter-normative positionality that some queer Roma assume when negotiating queer intersectional specificity which, as we saw in Chapter One, is the result of a complex process of identification, disidentification, 'labelling, categorisation and self categorisation' (Vermeersch 2006, 3). Queer belonging is a productive transformation for both personal and political purposes of dominant, majoritarian cultural scripts and modes of belonging that are often exclusionary. This strategy allows queer Roma to identify with empowering aspects of identities that enable the enactment of non-normative ethnic/'racial', sexual and gender identities while disidentifying with those that are hostile, restrictive or oppressive or with representatives of hostile cultural scripts. This aspect of queer belonging enables a queer Romani person's disidentification with the respective communities (Romani, LGBTIQ or both) while the person may still choose to maintain their ethnic/'racial', sexual or gender identifications as Roma or LGBTIQ. Some queer Roma who have the privilege to choose to identify or disidentify do so for political reasons in order to challenge antigypsyism and its intersections with homophobia, transphobia and sexism. Invisibility and lack of acknowledgement from within a particular community play a key role in this respect. 
For example, within heteronormative social dynamics, queer Roma may experience temporary or permanent exclusion from Romani families and communities; or within white-normative and homonormative social dynamics, gender non-conforming, non-binary and trans Roma may experience exclusion from lesbian, gay and bi communities, non-Romani or Romani ones alike. Thus, queer belonging can be seen as an alternative, nonnormative mode of belonging that shakes up and unsettles conventional manners of belonging.

Chapter Five also explored the tension that exists between identity politics and queer belonging. As a non-normative positionality, queer belonging differs and diverges from the identity politics of the Roma rights movement, the LGBTIQ movement and other strategically essentialist movements that have tended to rely on an essentialist model of identity. And understandably so: this model has depended on and is stipulated by law: more specifically, antidiscrimination, equality and human rights law. In this model, a minority ethnic/'racial', sexual or gender identity is a given, fixed, static category. Strategic essentialist mobilisation around fixed identity categories and binary norms goes against the notion of queer as a anti/ non-normative and anti/non-identitarian positionality. At the same time, strategic political mobilisation around collective, unified and fixed identity categories is still very much needed for successful political resistance and legal protections given that the lives of many queer Roma are still dominated by intersectional discrimination. This is evidenced in Chapter Three, for example. There, we saw that due to structural inequality, poverty and discrimination, some extremely vulnerable queer Roma lack personal documents and basic things. This means that for disenfranchised queer Roma who are striving for basic survival in the face of systemic oppression, queer belonging may not be an adequate strategy. Sometimes, direct resistance associated with identity politics and strategic essentialism is necessary; other times, queer Roma and members of other minorities need to follow a conformist path to survive. A queer intersectional approach recognises that identity politics, queer belonging or both may be needed as strategies, depending on context.

All roads lead to Rome, as they say. Here we are, back to the ever-present essentialist v. constructionist crossroads, irrespective of whether we are referring to society, social and political movements, law or academia. In Chapter One, we saw that in the 1980s, Lesbian and Gay Studies' approach to understanding lesbian and gay identities resembled the Romani Studies essentialist/constructionist dichotomy in understanding Romani identities. In an attempt to describe and explain the conditions and the assumed ethnic/'racial', sexual and gender difference underpinning the reality of the discrimination against and exclusion of LGBTIQ people and Roma, both ended up unwittingly producing essentialised conceptualisations of a fixed, stable set of ethnic/'racial', sexual and gender identities. Though the timing was different for queer theory scholars (i.e. the 1990s) and Critical Romani 
Studies scholars (i.e. the 2010s), in due course, building on the work of and paradigm shift achieved by their respective predecessors, both have moved towards understandings of identities that are critical of essentialising conceptualisations of identities. They see identities as socially constructed, fluid and informed by hegemonic power relations. In both disciplines, the latter, poststructuralist shift has fundamentally relied on the former, essentialising approach. Therefore, it is possible to argue that they complement each other to the extent that one cannot exist without the other.

Employing the lens of queer intersectionalities as a concept that reflects and helps to reconcile the essentialist/constructionist dichotomy shows us that it is possible to understand Romani identities as non-essentialist and fluid, as well as lived, experienced within, constructed through and impacted by the discursive practices of interlocking power relations and structural inequalities. Investigating categories of identification such as sexuality and gender identity facilitates understandings of the complexity of the everyday lives of individuals who self-identify as queer Roma without reifying ethnicity/'race' as an essentialised, fixed-group concept. Identities are lived, experienced and shaped by the surrounding meanings, cultural representations, scripts, norms and codes: in that sense, they are constructed and not essentially given. Although identities may manifest differently at different points in time as the surrounding cultural meanings change, they cannot be invented or cancelled at one's will, as proponents of far-right ideologies and trans exclusionary, gender critical 'feminists' would like us to believe. Yet, the ability to identify and disidentify with certain aspects of one's ethnic/'racial', sexual, gender identities and, for that matter, other identities as demonstrated by the lived experiences of queer Roma in this book is a testament to the constructed, assemblage-like nature of all identities. Attending to the underlying power relations, binary social norms and cultural scripts of majority societies - whether non-Romani, straight or cisgender - in which queer Roma live, helps us to look at ethnicity/'race', as well as beyond it, without losing sight of it, at structural issues common to both Roma and non-Roma such as homophobia, transphobia, sexism and their intersections. Simultaneously, this approach enables us to acknowledge and investigate the specific effects that the intersections of homophobia, transphobia and sexism with antigypsyism produce for queer Roma. This commonality with and relatability to others has the potential to speak to the lives and experiences of other non-normative (queer) intersectional people.

We have also seen that the still largely heteronormative, cisnormative and patriarchal Roma rights movement has traditionally mobilised around Romani ethnic identity politics, and has often perpetuated exclusion and, at times, oppression of Roma of non-normative sexual and gender identities. Similarly, by mobilising for LGBTIQ rights and equality, the predominantly white-normative, paternalistic and, at times, homonationalist LGBTIQ movement has perpetuated exclusion and, at times, oppression of LGBTIQ 
people of colour, including queer Roma. This invisibility and lack of acknowledgement of queer Roma within the Roma rights movement and the LGBTIQ movement has led to some queer Roma's feelings of disappointment, disillusion and a sense of disidentification with both; and to an acute awareness of the limits of the strategic essentialism of identity politics used by organisations within both movements. Consequently, as we saw in Chapter Five, some queer Roma do not wish to play by anyone's rules and choose to apply a queer intersectional approach to social movements and community organising instead. As a context-dependent strategy and possibly a new form of politics, queer belonging is an example of such a queer intersectional approach that gives a powerful tool not just to queer Roma but to all people outside of dominant cultural scripts.

The above ideas concerning the limits of identity politics resonate with similar critiques that have been voiced by other Roma - not necessarily queer - from within the Roma rights movement in recent years. Especially in the EU but also elsewhere in Europe, Romani organisations have been largely weakened by lack of capacity building and an overreliance on EU funding and state budgets, at times associated with acceptance of ambiguous values and strategic dependency on public authorities (RCM 2018). An overall lack of attention paid to intersectional issues has resulted in Romani organisations being trapped and divided by two competing approaches, reminiscent of the essentialist/constructionist dichotomy in academia: one focusing on ethnicity through Roma-specific policies, the other focusing on issues related to socio-economic disadvantage and poverty. The critics have been looking through a constructively critical lens at the lessons learnt from the achievements of the movement, as well as its failures over the past 50 years since the first World Romani Congress in 1971. One such recent critique points to the limits of the use of the human rights framework by intergovernmental institutions and organisations such as the European Union, the Council of Europe and the OSCE in the aftermath of the post2008 global backlash against equality, anti-discrimination and minority ethnic, LGBTIQ, women's and human rights by far-right extremists and populists who have moved into the political mainstream. This critique indicates a need for a new politics that moves away from Roma-specific policies that are largely based on affirmative action (ERIAC 2020), ${ }^{11}$ and by extension, moving away from the strategically essentialist model, or at least to a certain extent. Such an approach would help identify new ideas and areas of activism within the Roma rights movement that open avenues for participation and action associated with the voting power or labour power of Roma. This would enable the Roma rights movement to be important and useful; and to meaningfully develop other movements such as the gender movement, the LGBTIQ movement and the youth movement (Vermeersch and Rostas, ERIAC 2020). While societies and governments cannot shy away from their duty to tackle the egregious levels of antigypsyism, the above proposition highlights the importance of enriching 
single-axis, Roma-only social policies and legal provisions with an intersectional feminist approach and embedding intersectionality at the heart of national $^{12}$ and transnational EU law, such as the proposed Horizontal Directive that seeks to equalise levels of protection across various equality grounds (Potter 2011).

Ultimately, the lived experiences of queer Roma presented in this book have also illustrated that Roma form an inseparable part of present-day, extremely complex societies. These include Romani and non-Romani families and communities; LGBTIQ and straight communities; and other 'neo-tribes and elective communities' (see Chapter One). Such modes of intersectional belonging are both a unifying and a divisive factor. In today's age of increasing social polarisation, we see more than ever before that highly politicised, weaponised topics split societies and communities down the middle. Take, for instance, Brexit; the 2020 US presidential election; trans identity; or the COVID-19 pandemic, vaccination and the disinformation spread mainly on social media. The latter has divided most people, including Roma, into two elective camps: those who do not believe in COVID; and those who are either scientists, have contracted the virus or have seen its devastating effects on their relatives, friends or colleagues. If, since the collapse of Communism, the discrimination experienced by Roma has been a 'litmus test' for democracy, then the lived experiences of queer Roma are a testament to the intersectional nature of all Romani identities; and a commonality that Roma and non-Roma share, however polarised our societies are.

\section{Notes}

1 https://cps.ceu.edu/sites/cps.ceu.edu/files/attachment/basicpage/3172/rcm-civilsociety-monitoring-report-synthesis27-2020-eprint-fin.pdf; https://cps.ceu.edu/ article/2020-01-14/roma-civil-monitors-third-cycle-ngos-focus-blind-spotsroma-inclusion-policies-27 (accessed 6 January 2021).

2 https://www.araart.cz/reknu-to (accessed 6 January 2021).

3 https://ergonetwork.org/2020/02/invitation-intersecting-realities/ (accessed 6 January2021).

4 http://www.osce.org/odihr/188136?download=true (accessed 6 January 2021).

5 https://www.coe.int/en/web/sogi/newsroom/-/asset_publisher/7fKFZd7F4Hud/ content/launching-of-the-new-review-cycle-of-the-implementation-of-the-recommendation-2010-5-of-the-cm (accessed 6 January 2021).

6 Challenging dominant representations of LGBTIQ Roma in public spaces through queer research-informed interventions https://gtr.ukri.org/projects? ref= ES\%2FS011234\%2F1; Visualising the Lives of LGBTIQ Roma 2019-2020 https://reshare.ukdataservice.ac.uk/854275/ (last access on 6 January 2021).

7 A part of the exhibition can be viewed in an online gallery at https:// qrstock.qrtv.eu. The whole exhibition is available on request. Contact the author

8 The exhibition title 'White Spaces/BíLá Místa' refers to the absence and invisibility of minorities in the majority culture. It focuses on artwork by Romani and pro-Romani artists who challenge and uncover the dynamics of dominant cultural and linguistic (both textual and visual) practices. In some cases, the 
artists offer iconoclastic and subversive reinterpretations of already established and time-tested visual and literary works of art whilst appropriating certain forms in order to draw attention to the presence of stereotypes in art in ways that are at times self-critical with respect to their own artistic processes, shifts and developments. At other times, they investigate the extent to which minority narratives - particularly those of the Roma minority - are not inscribed into the functioning of cultural and other institutions. A white space is an empty space on a map. White spaces are gaps in the history and present of culture and institutions. (Press release) 'Czech Town to See Exhibition by Pro-Romani and Romani artists Referencing the Black Lives Matter Movement', 15 September 2020, accessed 6 January 2021, http://www.romea.cz/en/news/czech/czechtown-to-see-exhibition-by-pro-romani-and-romani-artists-referencing-theblack-lives-matter-movement.

9 'The Stranger Within: Challenging Stereotypes', 9 May 2019, accessed 6 January 2021, https://brightonmuseums.org.uk/discover/2020/04/03/the-stranger-withinchallenging-stereotypes/; https://brightonmuseums.org.uk/discover/2019/05/09/ introducing-queer-the-pier/.

10 An example of such an approach to visual self-representations of queer Roma is Jozsef Marton's project 'Owning the Game'. 'Q\&A: Revolutionizing Roma Representation', 5 January 2020, accessed 6 January 2021, https://www. opensocietyfoundations.org/voices/q-and-a-revolutionizing-roma-representation.

11 Transcript of Zeljko Jovanović's contribution: 'In the Central Eastern Europe where we saw a much bigger and faster growth of Roma human rights organisations and minority rights organisations, was influenced by the fall of the Berlin Wall and all that was happening [in] the fall of communism and the regimes of that time. That was part of a larger development that was mostly Western-oriented multilateralism that established key organisations for Roma human rights. Not only the UN in the States, but also the Council of Europe, OSCE. And the role of OSCE, especially in the post-Cold War era, was critical ... and this is when Nicolae Gheorghe comes in to picture trying to use OSCE framework that was established for managing rule of law, democracy, human rights and minority rights through international agreements. That was the geo-politics of the day [key to] our movement. (...) In the $90 \mathrm{~s}$ and early 2000 s, we have the EU accession that was basically the foundation of the new European agenda that was definitely influenced by the Washington consensus and neoliberal arrangements for trade liberalisation, opening of borders, privatisation and so on. So, in that context, the World Bank has a particular role in the world as one of those institutions of the new economic world order. This is why the Open Society Foundations and the World Bank were able to nine prime ministers to establish the Decade of Roma Inclusion and build on what was already done by the Council of Europe and OSCE as multilateral institutions establishing the basis for human and minority rights. ... I don't see the contradiction or tension between them because the EU also has fundamental human rights and (...) socio-economic rights, so I think this was a development influenced by larger geo-political agendas. But what happened in 2008 is actually most critical for our discussion about the Roma movement today and the future, which is a financial crisis. The financial crisis basically marked a break in the economic affairs of the economic construction of the neoliberal order that brought about the financial crisis that made lots of people angry. With the anger of ordinary people, populism and far right rises up to a new level, to the level not only to be challenges to the power but also to take over the power. And in that context, the anger of ordinary people becomes a blockage for all the advancements that we made since the 1990 s or since 1971 . Because there was no chance 
that politicians could do something positive about Roma without paying a penalty in the next election by the votes. We also see in the last 20,30 years the rise of China that challenges the United States and the world trade conflict that goes on right now hurts also the interest of Roma because it changes the ways in which Roma, for example Roma recycling materials (...) operate, are being impoverished by the tension that come from the economic environment. We also see security changes: the way Russia influences the European Union or supports the extremist far right; we see also how Islamic terrorism influences the attitudes of non-Roma towards minorities. We see how Brexit undermines the stability of the European Union. So, all this presents a challenge for us to rely any more on human rights frameworks, for which the anger of the majority population doesn't allow any more to be respected and to be a priority. We see the undermining of multilateral institutions that we counted on, we see the undermining of the western dominance in world affairs so that they can press the national governments to do something on human rights; and most importantly, our politics and the movement were based on affirmative action and affirmative action was the basis for Roma-specific policies. I believe that the window of opportunities because of all this that has been happening is closing for Romaspecific policies, so we need to change the direction into the new Roma policies." "What do these historical junctures and moments mean? All these lessons need to tell us something. And this is the following: we need to learn that we cannot base our political advocacy, political strategy and political movement on multilateral institutions that struggle right now for their own existence. We see the attack of Russia and Turkey on the Council of Europe: so, the Council of Europe struggles for its own independence and its own existence. The European Union is attacked by its own member states: on the one side, we have Brexit; on the other side, we have Poland and Hungary challenging the fundamentals of the values of the European Union. So, everything that we knew about institutional frameworks that were on a kind of friendly basis is in question now and we cannot rely on this. Someone has said that nobody helps Roma without Roma. I would ask the question: 'why would others help Roma?'. Because this 'helping Roma' is kind of a liberal point of view which is very nice. But liberal paradigm is in question today. I would be more realistic: how do we find interests of the others in the Roma? I think this is also another element of our new politics. Interests are very simple: our demography. Our demography can be manifested, even though the important voting power that mainstream parties have been for a long time abusing. And second is labour power (...) which is critical for the European Union in the next 30, 40 years and especially getting out of the crisis because our demography and the demographic trend, our youthful and vibrant population is contrary to the trend of the rest of Europe. Europe will need our population if it wants to recover and prevent the future crisis. And this human rights strategy that we had in the past, which means we go to the international organisations to report that our governments don't implement their commitment, it doesn't work because we go there and the national governments are in the decision-making, so they will not decide because of the Roma to hurt each other because it has different arrangements. So, I see human rights activists and Roma activists shifting (...) and redirecting the strategy. We use human rights frameworks that have a moral framework, moral compass. But we are not using the same strategy of going to the international organisations. I don't think of this as an ideological question: it is a practical question. Where there is political will for Roma-specific policies, of course it is better to have the edge of something that we want to have specific for Roma. But these times show us that we need to look, for example economic recovery policy, green deal policy, security policies 
and try to articulate our specific positions in relation to the priority interest of the policy making'. Zeljko Jovanovic, 'Webinar: History of the Roma Political Movement', 20 October 2020, European Roma Institute for Arts and Culture Barvalipe Roma Online University, accessed 3 January 2021, https:// www.facebook.com/1995165164067234/videos/345142280038640/.

12 'A Draft Law Prohibiting Intersectional Discrimination Discussed by the Romanian Parliament', 11 December 2020, accessed 3 January 2021, https:// www.hdl.fi/en/blog/2020/12/11/a-draft-law-prohibiting-intersectional-discrimination-discussed-by-the-romanian-parliament/. 


\section{References}

Achim, V. 1998. The Roma in Romanian History. Budapest: CEU Press.

Act No. 117/1927 Coll. on 'wandering gypsies'/ ZÁKON Č. 117/1927 SB. “O POTULNÝCH CIKÁNECH” ZE DNE 14. ČERVENCE 1927. http:// www.holocaust.cz/zdroje/dokumenty/pronasledovani-a-genocida-romu-2/zakonze- dne-14-cervence-1927-o-potulnych-cikanech; http://www.romea.cz/cz/zpravodajstvi/domaci/uplynulo-90-let-od-vydani-zakona-o-potulnych-cikanech-z-roku-1 927-zavedl-cikanske-legitimace-s-otisky-prstu

Acton, T. and I. Klímová. 2001. 'The International Romani Union: An East European Answer to a West European Question?' In Between Past and Future: The Roma of Central and Eastern Europe, edited by W. Guy, 157-219. Hatfield: University of Hertfordshire Press.

Acton, T. and G. Mundy 1997. Romani Culture and Gypsy Identity. Hatfield: University of Hertfordshire.

Adams, T. E. 2008. 'A Review of Narrative Ethics'. Qualitative Inquiry 14 (2): 175-194.

Adichie, C. N. 2009. 'The Danger of a Single Story'. https://www.ted.com/talks/ chimamanda_adichie_the_danger_of_a_single_story/transcript

Agarin, T. (ed.). 2014. When Stereotype Meets Prejudice: Antiziganism in European Societies. Stuttgart: Ibidem Verlag.

Ahmed, S. 1999. "'She'll Wake Up One of These Days and Find She's Turned into a Nigger." Passing through Hybridity'. Theory, Culture \& Society 16 (2): 87-106.

Albert, G. 2012. 'Anti-Gypsyism and the Extreme-Right in the Czech Republic 2008-2011'. In The Gypsy Menace: Populism and New Anti-Gypsy Politics, edited by M. Stewart, 137-165. London: Hurst.

Alliance Against Antigypsyism. 2016. 'Antigypsyism: A Reference Paper'. http:// antigypsyism.eu/wp-content/uploads/2016/10/Antigypsyism-reference-paperLayouted-version.pdf

Alldred, P., and N. J. Fox 2015. 'The Sexuality-assemblages of Young Men: A New Materialist Analysis'. Sexualities 201518 (8): 905-920.

Althusser, L. 1971. 'Ideology and Ideological State Apparatuses (Notes towards an Investigation)'. In Lenin and philosophy and other essays. Translated by B. Brewster. New York: Monthly Review Press.

Andrés, R. and J. Masó (eds.). 2018. Relvisiones Gitanas. Políticas, (auto)representaciones y activismos en diálogo con el género y la sexualidad (Gypsy Rel visions. Politics, (Self)representations and Activisms in Dialogue with Gender and Sexuality). Edicions Bellaterra. 
Angelides, S. 2001. A History of Bisexuality. Chicago and London: University of Chicago.

Anthias, F. 1998. 'Evaluating “Diaspora”: Beyond Ethnicity'. Sociology 32 (3): $557-580$.

Anthias, F. 2006. 'Belongings in a Globalising and Unequal World: Rethinking Translocations'. In The Situated Politics of Belonging, edited by N. Yuval-Davis, K. Kannabiran, and U. Vieten17-31. London: SAGE.

Anthias, F., and N. Yuval-Davis. 1992. Racialized Boundaries: Race, Nation, Gender, Colour and Class and the Anti-racist Struggle. Abingdon: Routledge.

Anzaldúa, G. E. 1987. La Frontera - Borderlands. CA: Aunt Lute Book Company, San Francisco.

Anzaldúa, G. E. 1988. 'To(o) Queer the Writer: Loca, Escritora, y Chicana'. In Living Chicana theory, edited by Trujillo, C. 263-276. Berkeley: Third Woman Press.

Anzaldúa, G. E. 2002. '(Un)natural bridges, (Un)safe spaces'. In The Gloria Anzaldúa Reader, edited by Ana Louise Keating. London and Durham: Duke University Press.

Arias, D. 2002. 'Modern Gypsies: Gender and Kinship among the Calos of Catalonia'. Romani Studies 5 (12/1): 35-55. Cheverly: Johns Hopkins University.

Baker, D. 2015. 'The Queer Gypsy'. In Roma Rights 2: Nothing about Us without Us? Roma Participation in Policy Making and Knowledge Production, edited by K. O’Reilly and M. Szilvási, 87-92. Budapest: European Roma Rights Centre.

Baker, D. 2002. The Queer Gypsy. MA dissertation, University of Greenwich.

Bakker, P. and Yaron Matras. 2003. Bibliography of Modern Romani Linguistics. Amsterdam: John Benjamins.

Balibar, E. 2009. 'Foreword'. In Romani Politics in Contemporary Europe: Poverty, Ethnic Mobilisation and the Neoliberal Order, edited by N. Sigona and N. Trehan. Basingstoke: Palgrave.

Balibar, E. and Wallerstein, I. 1991. Race, Nation, Class: Ambiguous Identities. London and New: Verso.

Ball, S. J. 1994. Education Reform: A critical and Post-structural Approach. Bristol, PA: Open University Press.

Baloun, P. 2018. Czechoslovak Civilising Mission: Assimilation Practices for 'Gipsy' Children in 1918-1942. Dejiny - Teorie - Kritika Studie a eseje no. 2: 175-202.

Baloun, P. 2019. "We beg you not to equate the names of Gypsies and knifegrinders with honest traders." Itinerant Trade and the Racialisation of "Gypsies" in the Czech Lands between 1918 and 1938'. S:I.M.O.N. - Shoah: Intervention. Methods. Documentation 6 (2): 44-55. DOI: 10.23777/SN0219/ART_PBAL01

Banks, J. A. 1998. The Lives and Values of Researchers: Implications for Educating Citizens in a Multicultural Society. Educational Researcher 27 (7): 4-17. DOI: 10.3102/0013189X027007004

Banton, M. 2012. 'The Colour Line and the Colour Scale in the Twentieth Century.' Ethnic and Racial Studies 35(7): 1109-1131. DOI: 10.1080/01419870.2011.605902.

Barany, Z. 2001. The East European Gypsies: Regime Change, Marginality, and Ethnopolitics. Cambridge: Cambridge University Press.

Barrett, R. 2018. 'Speech Play, Gender Play, and the Verbal Artistry of Queer Argots'. Suvremena lingvistika 44 (86): 215-242. 10.22210/suvlin.2018.086.03 
Barša, P. 2005. 'Konec Romů v Česku? Kacírské eseje plzeňských antropologů/The End of Roma in the Czech Republic? Heretical Essays of Anthropologists from Plzeň'. Politologický časopis 1. 67-79. https://www.ff.cuni.cz/wp-content/ uploads/2014/11/Bar\%C5\%A1a_-Jakoubek.pdf

Barth, F. [1969] 1998. Ethnic Groups and Boundaries: The Social Organisation of Cultural Difference. Long Grove, IL: Waveland Press.

Bauman, Z. 1996. 'From Pilgrim to Tourist - or a Short History of Identity'. In Questions of Cultural Identity, edited by S. Hall and P. Du Gay, 18-36. London: SAGE.

Becker, H. S. 1958. 'Problems of Inference and Proof in Participant Observation', American Sociological Review 23 (6): 652-660.

Becker, H. S. 1998. Tricks of the Trade. Chicago, IL: University of Chicago Press.

Bell, D., J. Binnie, J. Cream, and G. Valentine. 1994. 'All Hyped Up and No Place to Go'. Gender, Place \& Culture 1 (1): 31-47.

Belton, B., 2005. Questioning Gypsy Identity: Ethnic Narratives in Britain and America. New York: Altamira Press.

Berná, D. 2010. 'Gitanos, Diversidad Sexual y Adolescencia'. Estudios de Juventud 89. Ministerio de Igualdad.

Berna, D. 2011a.'De muros y grietas. Análisis desde la raza, clase y género de la homosexualidad en los gitanos'. The Scientific Journal of Humanistic Studies 3 (4): $1-7$.

Berná, D. 2011b.'Construyendo Identidad. Raza y Sexualidad en los procesos performativos de construcción de la masculinidad entre los gitanos’. Facultad de Ciencias políticas y Sociología. Universidad Complutense de Madrid.

Bird, C. M. 2005. 'How I Stopped Dreading and Learned to Love Transcription'. Qualitative Inquiry 11: 226-248.

Blake, F. D. 2008. Reading Black Intimacies: Literary Studies Beyond Representational Inclusion. University of California.

Bogdan, M. Dunajeva, J. Junghaus, T. Kóczé, A. Rövid, M. Rostas, I. Ryder, A. Szilvási, M. Taba, M. 2015. Introduction: 'Nothing about Us without Us'. In Roma Rights 2: Nothing about Us without Us: Roma Participation in Policy Making and Knowledge Production, K. O'Reilly and M. Szilvási, 3-5. Budapest: edited by European Roma Rights Centre.

Bogdan, M., Dunajeva, J., Junghaus, T., Kóczé, A., Rostas, I., Rövid, M., and Szilvasi, M. 2018. 'Introducing the New Journal Critical Romani Studies.' Critical Romani Studies 1(1): 2-7.

Borrow, G. 1857. The Romany Rye. New York: Harper \& Brothers, Publishers.

Bošnjak, B. and T. Acton. 2013. 'Virginity and Early Marriage Customs in Relation to Children's Rights among Chergashe Roma from Serbia and Bosnia'. The International Journal of Human Rights, 17 (5/6): 646-667.

Boyarin, D., Ann Pellegrini, and Daniel Itzkovitz. (eds.). 2003. Queer Theory and the Jewish Question. Columbia University Press.

Boylorn, R. M. 2008. 'Lived Experience'. The SAGE Encyclopaedia of Qualitative Research Methods 2, edited by Lisa M. Given, 489-490. CA Thousand Oaks: SAGE

Bradbury, H. and P. Reason. 2003. 'Action Research: An Opportunity for Revitalizing Research Purpose and Practices'. Qualitative Social Work 2 (2): $155-175$. 
Brah, A. and A. Phoenix 2004. 'Ain't I A Woman? Revisiting Intersectionality'. Journal of International Women's Studies 5 (3): 75-86.

Braun, V. and V. Clarke. 2006. 'Using Thematic Analysis in Psychology'. Qualitative Research in Psychology 3 (2): 77-101. doi: 10.1191/1478088706qp063oa

Breen, L. J. 2007. 'The researcher "in the middle": Negotiating the Insider/Outsider Dichotomy'. The Australian Community Psychologist 19 (1): 163-174. https:// espace.curtin.edu.au/handle/20.500.11937/22045

Brooks, E. 2009. '(Mis)recognitions: Romanies, Sexualities, Sincerities'. NEVI SARA KALI, Roma Women's Journal. Publishing House of Foundation Desire: 21-29.

Brooks, E. 2012. 'The Possibilities of Romani Feminism'. Signs 38 (1): 1-11. doi: $10.1086 / 665947$

Brooks, E. 2015. 'The Importance of Feminists and 'Halfies' in Romani Studies: New Epistemological Possibilities'. In Roma Rights 2: Nothing about Us without Us? Roma Participation in Policy Making and Knowledge Production, edited by K. O’Reilly and M. Szilvási, 57-61. Budapest: European Roma Rights Centre.

Browne, K. 2006. 'Challenging Queer Geographies'. Antipode 38: 885-893.

Browne, K. and J. Lim. 2010. 'Trans Lives in the "Gay Capital of the UK”'. Gender, Place \& Culture: A Journal of Feminist Geography 17: 615-633.

Browne, K., J. Lim, and G. Brown. 2007. Geographies of Sexualities: Theory, Practices and Politics. Farnham: Ashgate.

Browne, K. and J. Nash. (eds.). 2010. Queer Methods and Methodologies: Intersecting Queer Theories and Social Science Research. Farnham: Ashgate.

Browne, K. and L. Bakshi. 2013. Ordinary in Brighton? LGBT, Activisms and the City. Farnham: Ashgate.

Browne, K., Bakshi, L. and Lim, J. 2011. 'It's something you just have to ignore': understanding and addressing contemporary lesbian, gay, bisexual and trans safety beyond hate crime paradigms.' Journal of Social Policy 40: 739-756.

Browne, K., N. Banerjea, N. McGlynn, B. Sumita, L. Bakshi, R. Banerjee, and Biswas R. 2017. 'Towards transnational feminist queer methodologies'. Gender, Place \& Culture 24 (10): 1-22.

Brubaker, R. 2016. 'The Dolezal Affair: Race, Gender, and the Micropolitics of Identity'. Ethnic and Racial Studies 39:3, 414-448. https://doi.org/10.1080/0141 9870.2015.1084430.

Brukaker, R. 2017. 'The Uproar over "Transracialism”'. https:/www.nytimes.com/ 2017/05/18/opinion/the-uproar-over-transracialism.html

Bryant, K. 2008. "In Defense of Gay Children? "Progay" Homophobia and the Production of Homonormativity'. Sexualities 11: 455-475.

Buchowski, M. 2006. Social Thought \& Commentary: The Specter of Orientalism in Europe: From Exotic Other to Stigmatized Brother. Anthropological Quarterly, 79(3), 463-482.

Budilova, L., and M. Jakoubek. (eds.), 2007. Cikánská rodina a příbuzenství/Gypsy family and kinship. Ústí nad Labem: Dryada.

Bulmer, M. 1979. 'Concepts in the Analysis of Qualitative Data'. Sociological Review 27 (4): 651-677.

Burr, V. 1995. An Introduction to Social Constructionism. London and New York: Routledge. 
Butler, J. 1990. Gender Trouble: Feminism and the Subversion of Identity. London and New York: Routledge.

Butler, J. 1991. 'Imitation and Gender Insubordination'. In Inside/Out: Lesbian Theories, Gay Theories, edited by Diane Fuss. London: Routledge.

Butler, J. 1993. Bodies That Matter: On the Discursive Limits of 'Sex'. New York: Routledge.

Butler, J. 1997. The Psychic Life of Power: Theories in Subjection. Stanford: Stanford University Press.

Cahn, C. 2009. 'Cikánská rodina a příbuzenství (review)'. Romani Studies 19 (2): 172-180. doi: 10.1353/rms.0.0014

Carlson, J. A. 2010. 'Avoiding Traps in Member Checking'. The Qualitative Report 15 (5): 1102-1113.

Castle, T. 1993. The Apparitional Lesbian. Female Homosexuality and Modern Culture. New York: Columbia University Press.

Cemlyn, S., M. Greenfields, S. Burnett, Z. Matthews, and C. Whitwell. 2009. Inequalities Experienced by Gypsy and Traveller communities: A Review - Research Report: 12. Manchester: Equality and Human Rights Commission (EHRC).

Centre for Policy Studies. 2020. A Synthesis of Civil Society's Reports on the Implementation of National Roma Integration Strategies in the European Union: Identifying Blind Spots in Roma Inclusion Policy. Roma Civil Monitor. Central European University/European Commission.

Chakraborty, M. N. 2010. 'Everybody's Afraid of Gayatri Chakravorty Spivak: Reading Interviews with the Public Intellectual and Postcolonial Critic'. Signs: Journal of Women in Culture and Society 35 (3): 621-645.

(Charles), H. 1993. “"Queer Nigger”: Theorizing “White” Activism'. In Activating Theory. Lesbian, Gay, Bisexual Politics, edited by J. Bristow and A. R. Wilson. London: Lawrence \& Wishart, 97-106.

Charnon-Deutsch, L. 2004. The Spanish Gypsy: The History of a European Obsession. Penn State University Press.

Chavez, C. 2008. 'Conceptualizing from the Inside: Advantages, Complications, and Demands on Insider Positionality'. The Qualitative Report 13 (3): 474-494.

Cho, S., Crenshaw, K., and McCall, L. 2013. 'Intersectionality: Theorizing Power, Empowering Theory.' Signs 38(4): 785-810. The University of Chicago Press. https://doi.org/10.1086/669608

Clark, C. 2004. “"Severity Has Often Enraged but Never Subdued a Gypsy”: The History and Making of European Romani Stereotypes'. In The Role of the Romanies: Images and Counter-Images of 'Gypsies'/Romanies in European Cultures, edited by N. Saul and S. Tebbutt. Liverpool: Liverpool University Press, 226-246.

Clark, C. 2015. 'Culture, Confidence and Community - the new European Roma Institute (ERI)'. http://www.crer.org.uk/crerblog/entry/culture-confidence-andcommunity-the-new-european-roma-institute-eri

Clark, C., and Elaine Campbell. 2000. “"Gypsy Invasion”: A Critical Analysis of Newspaper Reaction to Czech and Slovak Romani Asylum-Seekers in Britain, 1997'. Romani Studies 5, 10(1): 23-47. ISSN 1528-0748

Clébert, J.-P. 1961. Les Tsigans. Paris: Éditions Arthaud. 
Codur, A. M. 2011. 'Love Is a Gypsy Child Who Has Never Known any Law'. In Gypsy Sexuality: Romani and Outsider Perspectives on Intimacy, edited by J. Nirenberg. Mesa, Arizona: Clambake Press, LLC. 1-8.

Cohen, C. 2005. 'Punks, Bulldaggers, and Welfare Queens: The Radical Potential of Queer Politics?' In Black Queer Studies: A Critical Anthology, edited by E. P. Johnson and M. G. Henderson. Durham, NC and London: Duke University Press.

Coleman, R. and J. Ringrose 2013. Introduction. In Deleuze and Research Methodologies, edited by R. Coleman, J. Ringrose, 1-22. Edinburgh: Edinburgh University Press.

Collins, P.H. 2015. 'Intersectionality's Definitional Dilemmas.' Annual Review of Sociology 41(1): 20. DOI:10.1146/annurev-soc-073014-112142.

Combahee River Collective. 1982 [1977]. 'A Black Feminist Statement'. In All the Women Are White, All the Blacks Are Men, But Some of Us Are Brave, edited by G. T. Hull, P. B. Scott, and B. Smith. 13-22. New York, NY: The Feminist Press. Coming out: Life as a gay Roma http://vimeo.com/16281957

Commissioner for Human Rights. 2012. Human Rights of Roma and Travellers in Europe. Strasbourg: Council of Europe Publishing Editions. https://book.coe.int/ en/minorities/4871-pdf-human-rights-of-roma-and-travellers-in-europe.html

Cooper, D. 2004. Challenging Diversity. Rethinking Equality and the Value of Difference. Cambridge: Cambridge University Press.

Corradi, L. 2017. Gypsy Feminism: Intersectional Politics, Alliances, Gender and Queer Activism, Oxfordshire: Routledge.

Council of Europe. 2011. Roma Youth Action Plan. Available at http://www.coe.int/t/ dg4/youth/Training/Roma/2013_FEB_Roma_Youth_and_Council_of_Europe_en.asp.

Council of Europe. 2012. Descriptive Glossary of terms relating to Roma issues https://rm.coe.int/1680088eab

Crenshaw, K. 1989. 'Demarginalizing the Intersection of Race and Sex: A Black Feminist Critique of Antidiscrimination Doctrine, Feminist Theory and Antiracist Politics'. The University of Chicago Legal Forum. Feminism in the Law: Theory, Practice and Criticism1989 Article 8: 139-167.

Crenshaw, K. 1991. 'Mapping the Margins: Intersectionality, Identity Politics and Violence against Women of Color'. Stanford Law Review 43 (6): 1241-1299. doi: $10.2307 / 1229039$

Creswell, J. W. 1998. Qualitative Inquiry and Research Design. Thousand Oaks CA: SAGE.

Creswell, J. W., and D. L. Miller. 2000. 'Determining Validity in Qualitative Inquiry'. Theory into Practice 39 (3): 124-130.

Csepeli, G., and Simon, D. 2004. 'Construction of Roma Identity in Eastern and Central Europe: Perception and Self-identification'. Journal of Ethnic and Migration Studies 30 (1): 129-150. doi: 10.1080/1369183032000170204

Curtin, M., and E. Fossey. 2007. 'Appraising the Trustworthiness of Qualitative Studies: Guidelines for Occupational Therapists'. Australian Occupational Therapy Journal 54: 88-94.

Davidova, E., and D. E. Guy. 1971. 'Czechoslovakia and her Gypsies'. In Current Changes among British Gypsies and Their Place in International Patterns of Development, edited by T. Acton. Oxford. 
Davies, M. F. 1994. 'The Physical Situation' In Small Group Research: A Handbook, edited by A. P. Hare, H. H. Blumberg, M. F. Davies, and M. V. Kent. Norwood, NJ: Ablex.

De Genova, N. 2010. 'The Queer Politics of Migration: Reflections on "Illegality" and Incorrigibility'. Studies in Social Justice 4 (2): 101-126.

de Lauretis, T. 1991. 'Queer Theory: Lesbian and Gay Sexualities'. Differences 3: iii-xviii.

Deleuze, G., and F. Guattari. 1988. A Thousand Plateaus: Capitalism and Schizophrenia II. Translated by B. Massumi. London: The Athlone Press.

D’Emilio, J. 1983. Sexual Politics, Sexual Communities. Chicago: University of Chicago Press.

Detamore, M. 2010, 'Queer(y)ing the Ethics of Research Methods: Toward a Politics of Intimacy in Researcher/Researched Relations'. In Queer Methods and Methodologies: Intersecting Queer Theories and Social Science Research, edited by K. Browne and C. Nash. Farnham: Ashgate.

Detamore, M. J. 2010. Queer Appalachia: Toward Geographies of Possibility. University of Kentucky Doctoral Dissertations. 57. https://uknowledge.uky.edu/ gradschool_diss $/ 57$.

DeWalt, K. M., and Bi R. DeWalt. 2002. Participant Observation: A Guide for Fieldworkers. Walnut Creek, CA: AltaMira Press.

DiCicco-Bloom B., and B. F. Crabtree. 2006. 'The qualitative research interview'. Medical Education 40(4): 314-321.

Donald, J. and A. Rattansi. (eds.). 1992. Race, Culture and Difference. London: SAGE.

Donert, C. 2017. The Rights of the Roma: The Struggle for Citizenship in Postwar Czechoslovakia. University of Cambridge.

Doyle, S. 2007. 'Member checking with older women: A framework for negotiating meaning'. Health Care for Women International 8(10): 888-908.

Duberman, M., M. Vicinus, and G. Chauncey. 1990. Hidden from History: Reclaiming Gay and Lesbian Past. New York: Meridian.

Du Bois, W. E. B. 1903. The Souls of Black Folk. Chicago: A.C. McCLURG \& CO.

Duggan, L. 2002. 'The New Homonormativity: The sexual politics of neoliberalism'. In Materializing Democracy: Toward a Revitalized Cultural Politics, edited by R. Castronovo and D. D. Nelson, 175-190. Duke University Press.

Dunajeva, J. Kóczé, A. and Kóczé, A. Cemlyn, S. 2015. 'LGBTQIA, Feminism and Romani Studies'. Roma Rights 2: Nothing About Us Without Us? Roma Participation in Policy Making and Knowledge Production, edited by K. O'Reilly and M. Szilvási, 75-77. Budapest: European Roma Rights Centre.

Durst, J. 2010. “"What Makes Us Gypsies, Who Knows...?!”: Ethnicity and Reproduction'. In Multidisciplinary Approaches to Romany Studies, edited by M. Stewart and M. Rövid. Budapest: CEU Press.

EduRoma. 2014. 'What November Brought to Slovak Roma?' November 2014. Interview with Zuzana Kusa, Institute for Sociology. Slovak Academy of Sciences. https://www.youtube.com/watch?v=S0OEvsKIXyA\&feature=share

Elšík, V. 2004. 'Romové, etnicita a radikální konstruktivismus/Roma, ethnicity and radical constructionism'. http://ling.ff.cuni.cz/lingvistika/elsik/Elsik_2004_HO_ Etnicita.pdf 
Emigh, R. and I. Szelényi. (eds.). 2001. Poverty, Ethnicity and Gender in Eastern Europe during Market Transition. Westport, CT: Praeger/Greenwood, 193-203. End, M. 2017. 'Subtle Images of Antigypsyism: An Analysis of the Visual Perception of "Roma". Romaphobia and the Media: Mechanisms of Power and the Politics of Representations, edited by Annabel Tremlett, Vera Messing and Angéla Kóczé. Identities 24 (6): 668-683, DOI: 10.1080/1070289X.2017.1380265

Eng, D., J. Halberstam and Muñoz J. (eds.). 2005. 'What's Queer about Queer Studies Now?' Special issue. Social Text [Special double issue 23(3-4)]. Durham: Duke University Press.

Engebretsen, E. L. 2008. 'Queer Ethnography in Theory and Practice: Reflections on Studying Sexual Globalisation and Women's Queer Activism in Beijing'. Graduate Journal in Social Sciences 5 (2): 88-116.

Erel, U., J. Haritaworn, E. Gutierrez Rodriquez and C. Klesse. 2008. 'On the Depoliticisation of Intersectionality Talk. Conceptualising Multiple Oppressions in Critical Sexuality Studies'. In Out of Place: Interrogating Silences in Queerness/ Raciality, edited by Adi Kuntsman and Esperenza Mikaye, 203-230. York: Raw Nerve Books.

European Commission. 2004. The Situation of Roma in an Enlarged European Union. Fundamental Rights and Discrimination. 22 April. DG Employment and Social Affairs, Unit D3.

European Commission against Racism and Intolerance (ECRI). 2011. General Policy Recommendation No.13 on Combating Anti-Gypsyism and Discrimination against Roma Adopted on 24 June 2011. Council of Europe: Strasbourg. https:// www.coe.int/t/dghl/monitoring/ecri/activities/GPR/EN/Recommendation_N13/eRPG\%2013\%20-\%20A4.pdf

European Commission: Directorate General Justice and Consumers. 2020. 'A Union of Equality: EU Roma Strategic Framework for Equality, Inclusion and Participation for 2020-2030'. COM(2020) 620 final. European Commission: Directorate General Justice and Consumers. https:/ec.europa.eu/info/publications/ new-eu-roma-strategic-framework-equality-inclusion-and-participation-fullpackage_en

European Parliament. 2017. 'Resolution of 25 October 2017 on fundamental rights aspects in Roma integration in the EU: fighting anti-Gypsyism (2017/2038(INI)'. https://www.europarl.europa.eu/doceo/document/TA-8-2017-0413_EN.html

European Roma Rights Centre. 2007. THE GLASS BOX: Exclusion of Roma from Employment. Budapest: European Roma Rights Centre.

European Roma Rights Centre/NÚMENA. 2007. 'Social Inclusion Through Social Services: The Case of Roma and Travellers. Assessing the Impact of National Action Plans for Social Inclusion in Czech Republic, France and Portugal'. Budapest: European Roma Rights Centre. http://www.errc.org/cms/upload/ media/02/23/m00000223.pdf

European Union Agency for Fundamental Rights. 2009. The social situation concerning homophobia and discrimination on grounds of sexual orientation in Czech Republic. https://fra.europa.eu/sites/default/files/fra_uploads/369-fra-hdgso-part2 -nr_cz.pdf.

European Union Agency for Fundamental Rights. 2012. 'The Situation of Roma in 11 Member States'. https://fra.europa.eu/en/publication/2012/situation-roma-11eu-member-states-survey-results-glance 
European Union Agency for Fundamental Rights. 2018. 'A Persistent Concern: Anti-Gypsyism as a Barrier to Roma Inclusion'. https://fra.europa.eu/en/ publication/2018/persisting-concern-anti-gypsyism-barrier-roma-inclusion

Faderman, L. 1991. Odd Girls and Twilight Lovers. A History of Lesbian Life in Twentieth-Century America. New York: Penguin.

Fassin, E. 2006. 'La démocratie sexuelle et le conflit des civilisations'. Multitudes 3(26): 123-131.

Fassin, E., C. Fouteau, S. Guichard, and A. Windels. 2014. Roms et riverains. Une politique municipale de la race. Paris: La Fabrique éditions

Fausto-Sterling, A. 2018. 'Why Sex Is Not Binary'. The New York Times. https:// www.nytimes.com/2018/10/25/opinion/sex-biology-binary.html

Fausto-Sterling, A. 2019. 'Gender/Sex, Sexual Orientation, and Identity Are in the Body: How Did They Get There?' Annual Review of Sex Research Special Issue'. The Journal of Sex Research 56 (4-5): 529-555.

Fenster, T. 2004. The Global City and the Holy City: Narratives of Planning, Knowledge and Diversity. New Jersey: Pearson/Prentice Hall.

Ferguson, R. 2004. Aberrations in Black: Toward a Queer of Color Critique. Minneapolis, MN: University of Minnesota Press, 74-78.

Font-Porterias, N., Arauna, L.R., Poveda, A., Bianco, E., Rebato, E., Prata, M.J., Calafell, F., Comas, D. 2019. 'European Roma groups show complex West Eurasian admixture footprints and a common South Asian genetic origin.' PLoS Genet 15(9): e1008417.https://doi.org/10.1371/journal.pgen.1008417.

Fox, N. J., and P. Alldred. 2013. 'The Sexuality-Assemblage: Desire, Affect, Antihumanism'. Sociological Review 61: 769-789.

Fox, N. J., and P. Alldred 2015. 'New Materialist Social Inquiry: Designs, Methods and the Research-Assemblage'. International Journal of Social Research Methodology 18 (4): 399-414.

Franken, M., Woodward, A., Cabó, A., and Bagilhole, B. M. (Eds.) 2009. Teaching Intersectionality: Putting Gender at the Centre. Teaching with Gender. European Women's Studies in International and Interdisciplinary Classrooms. Athena. Utrecht.

Frankenberg, R. 1993. White Women, Race Matters: The Social Construction of Whiteness. University of Minnesota Press.

Frankenberg, R. (ed.) 1997. Displacing Whiteness: Essays in Social and Cultural Criticism. Duke University Press.

Fraser, A. 1992. The Gypsies. Oxford: Blackwell.

Fraser, N. 1997. Justice Interruptus. New York: Routledge.

Fremlova, L. 2006. 'Coping with Coercive Sterilisation'. Roma Rights 4: Romani Women's Rights Movement. Budapest: European Roma Rights Centre.

Fremlova, L. 2017. The Experiences of Romani LGBTIQ People: Queer(y)(ing) Roma, University of Brighton.

Fremlova, L. 2018. 'Non-Romani Researcher Positionality and Reflexivity: Queer (y) ing One's Own Privilege'. Critical Romani Studies 1 (2): 98-123.

Fremlova, L. 2019. 'LGBTIQ Roma and Queer Intersectionalities'. European Journal of Politics and Gender3 (3): 371-388.

Fremlova/FRANET National Focal Point. 2012. Social Thematic Study. The situation of Roma (United Kingdom). Human Rights Law Centre, University of Nottingham. http://fra.europa.eu/sites/default/files/situation-of-roma-2012-uk.pdf. 
Fremlova, L., and M. Georgescu. (Eds.) 2014. Barabaripen: Young Roma speak about multiple discrimination. Youth Department of the Council of Europe.

Fremlova, L. and A. McGarry. 2018. 'Negotiating the Identity Dilemma: Crosscurrents across the Romani, Romani Women's and Romani LGBTIQ Movements'. In The Romani Women's Movement: Struggles and Debates in Central and Eastern Europe, edited by A. Kóczé, V. Zentai, J. Jovanović, and E. Vincze. Oxfordshire: Routledge.

Fremlova, L., and H. Ureche. 2009. A Mapping Survey of A2 and A8 Roma in England (Patterns of Settlement and Current Situation of New Roma Communities in England). European Dialogue.

Fremlova, L. and H. Ureche. 2011. From Segregation to Inclusion: Romani Pupils in the United Kingdom. Roma Education Fund/Equality.

Fresno, J.-Manuel, Deyan Kolev, and Stefan Meyer. 2020. Considering the Diversity of the Roma population in a post-2020 EU-initiative for Roma equality and inclusion: Expert reports building on forward-looking aspects of the evaluation of the EU Framework for National Roma Integration Strategies. European Commission.

Gabal Analysis \& Consulting. 2006. Analysis of Socially Excluded Roma Localities and Absorption Capacity of Subjects in this Field. Prague: Gabal Analysis \& Consulting. https://www.gac.cz/userfiles/File/nase_prace_vystupy/GAC_MAPA_Socially_Excluded_ Roma_Localities_in_the_CR_en.pdf?langSEO=en\&parentSEO=documents\&midSEO= nase_prace_vystupy\&submidSEO=GAC_MAPA_Socially_Excluded_Roma_Localities_ in_the_CR_en.pdf.

Gabal Analysis \& Consulting. 2009. A Long-Term Monitoring of the Situation in Roma Localities in the Czech Republic - Czech Localities. Prague: Gabal Analysis \& Consulting. https://ohchr.org/documents/issues/housing/informalsettlements/ publicdefenderCzechRepublic_2.pdf.

Gallie, W. B. 1956. 'Essentially Contested Concepts'. In Proceedings of the Aristotelian Society New Series 56, 167-198.

Gallová Kriglerová, E., and A. Chudžíková. 2013. “There Is No Life Here”. Migration of Roma from Slovakia to Canada. In Roma Migration to and from Canada: The Czech, Hungarian and Slovak Case. Center for Policy Studies, edited by Zs. Vidra. Budapest: Central European University.

Gammon, M., and K. Isgro. 2006. 'Troubling the Canon: Bisexuality and Queer Theory'. Journal of Homosexuality 52 (1-2): 159-184.

Gamson, J. 1995. 'Must Identity Movements Self-Destruct? A Queer Dilemma'. Social Problems 42(3): 390-407.

Gannon, S. 2006. 'The (Im)Possibilities of Writing the Self-Writing: French Poststructural Theory and Autoethnography'. Critical Methodologies 6: 474-495.

Garner, S., and E. Fassin. 2013. "'Race”, Sexualities and the French Public Intellectual: An Interview with Éric Fassin'. Ethnic and Racial Studies 36 (9): 1465-1484, DOI: 10.1080/01419870.2013.791397

Gay y Blasco, P. 1999. Gypsies in Madrid: Sex, Gender and the Performance of Identity. Oxford: Berg.

Gay y Blasco, P. 2002. 'Gypsy/Roma Diasporas. A Comparative Perspective'. Social Anthropology 10 (2): 173-188.

Gay y Blasco P. 2008. Picturing 'Gypsies.' Third Text 22(3): 297-303, DOI: 10.1 080/09528820802204235 
Gay y Blasco P. 2011. 'Agata's Story: Singular Lives and the Reach of the "Gitano law"'. Journal of the Royal Anthropological Institute 17: 445-461.

Gelbart, P. 2012. 'Either Sing or Go Get the Beer: Contradictions of (Romani) Female Power in Central Europe'. Signs 38 (1): 22-29.

Gheorghe, N. 1997. 'The Social Construction of Romani Identity'. In Gypsy Politics and Traveller Identity, edited by T. Acton. Hatfield: University of Hertfordshire Press, 153-163.

Gheorghe, N., and T. Acton. 1992. 'Minority, Ethnic, National and Human Rights: Varieties of Strategy and Interest in Romani (Gypsy) Politics in Different Countries as a Case Study in the Sociology of Group Conflict'. In A Call for a New Community: Racism and Ethnic Conflicts in the Counties of the Baltic States, edited by M. Reidy and S. Udodescu, 29-36. Geneva: World Council of Churches.

Gheorghe, N., and T. Acton. 2001. 'Citizens of the World and Nowhere: Minority, Ethnic and Human Rights for Roma during the Last Hurrah of the Nation State'. In Between Past and Future: The Roma of Central and Eastern Europe, edited by W. Guy. Hatfield: University of Hertfordshire Press.

Ginsberg, E. 1996. 'Introduction: The Politics of Passing'. In Passing and the Fictions of Identity, edited by E. Ginsberg. Duke University Press Books.

Goldberg, D. T. 2009. The Threat of Race: Reflections on Racial Neoliberalism. Malden, MA: John Wiley \& Sons.

Gopinath, G. 2005. Impossible Desires: Queer Diasporas and South Asian public cultures. Durham, NC: Duke University Press.

Green, A. I. 2002. 'Gay but Not Queer: Toward a Post-queer Study of Sexuality'. Theory and Society 31 (4): 521-545.

Green, A. I. 2007. 'Queer theory and sociology: locating the subject and the self in sexuality studies.' Sociological Theory 25: 1.

Greene, M. J. 2014. 'On the inside Looking In: Methodological insights and Challenges in Conducting Qualitative insider Research'. The Qualitative Report 19 (29): 1-13.

Greenfields, M., and A. Ryder. 2012. 'Research with and for Gypsies, Roma and Travellers: combining policy, practice and community in action research'. In Gypsies and Travellers: Accommodation, Empowerment and Inclusion in British Society, edited by J. Richardson and A. Ryder. Bristol: Policy Press.

Grellmann, H. M. G. 1783. Die Zigeuner. Ein historischer Versuch über die Lebensart und Verfassung, Sitten und Schicksable dieses Volks in Europa, nebst ihrem Ursprunge. Dessau und Leipzig, 216-260.

Grill, J. 2015. 'Historické premeny štruktúry medzikultúrnych vzt’ahov. Formy spolužitia $\mathrm{v}$ prípade Tarkoviec na východnom Slovensku/The Transforming Fabrics of Intercultural Relations: The Modes of Co-Existence in Tarkovce in East Slovakia'. In Čierno-biele svety. Rómovia v majoritnej spoločnosti, 146-171. Bratislava: SAV Veda.

Groome, F. H. 1908. 'Gypsies (5: 485-490)'. In Chambers's Encyclopaedia: A Dictionary of Universal Knowledge. London \& Edinburgh: Chambers \& Philadelphia: Lippincott.

Grossberg, L. 2007. Stuart Hall on Race and Racism: Cultural Studies and the Practice of Contextualism'. In Culture, Politics, Race and Diaspora: The Thought of Stuart Hall, edited by B. Meeks. London: Lawrence \& Wishart. 
Guy, W. 2001. Between Past and Future: The Roma of Central and Eastern Europe. Xvii edn. Hatfield: University of Hertfordshire Press.

Hájková, A. 2013. 'Sexual Barter in Times of Genocide: Negotiating the Sexual Economy of the Theresienstadt Ghetto'. Signs 38 (3): 503-533

Hájková, A. 2020. The Last Ghetto: An Everyday History of Theresienstadt. Oxford University Press.

Halberstam, J. 1998. Female Masculinity. Durham, NC: Duke University Press.

Hall, S. 1989. 'Ethnicity: Identity and Difference'. Radical America 23 (4): 9-20.

Hall, S. 1992. 'The Question of Cultural Identity'. In Modernity and Its Futures, edited by S. Hall D. Held, and T. McGrew. 273-316. Cambridge: Polity.

Hall, S. 1996a. 'Introduction: Who Needs Identity?' In Questions of Cultural Identity, edited by S. Hall and P. Du Gay. London: SAGE, 1-17.

Hall, S. 1996b. 'New Ethnicities'. In Critical Dialogues in Cultural Studies, edited by D. Morley and K.-H. Chen, 440-449 London: Routledge.

Hall, S. 1996c. 'The Question of Cultural Identity'. In Modernity: An Introduction to Modern Societies, edited by S. Hall, D. Held, D. Hubert, and K. Thompson, 595-629. Blackwell Publishers.

Hall, S. 1997. Representation: Cultural Representations and Signifying Practices. London: SAGE.

Hall, S. 2000. 'Old and New Identities, Old and New Ethnicities'. In Culture, Globalization and the World-System: Contemporary Conditions for the Representation of Identity, edited by A. D. King, 41-68. Minneapolis: University of Minnesota Press.

Halperin, D. 1990. One Hundred Years of Homosexuality. New York: Routledge

Halperin, D. 1995. Saint Foucault: Towards a Gay Hagiography. Oxford: Oxford University Press.

Halperin, D. 2002. How to do the history of homosexuality. Chicago and London: University of Chicago Press

Halperin, D. M. 2014. 'Sex/Sexuality/Sexual Classification'. In Critical Terms for the Study of Gender, edited by C. R. Stimpson and G. Herdt, 449-486. Chicago, IL: University of Chicago Press.

Hancock, I. 1992. 'The East European Roots of Romani Nationalism'. In The Gypsies of Eastern Europe, edited by D. Crowe and J. Kolsti, 133-150. Armonk, New York: M.E. Sharpe.

Hancock, I. 1987. 'The Pariah Syndrome: An Account of Gypsy Slavery and Persecution'. http://www.radoc.net/radoc.php?doc=art_k_the_pariah_syndrome $\&$ lang=en\&articles=true

Hancock, I. 1988. 'The development of Romani linguistics'. In Languages and Cultures: Studies in Honor of Edgar C. Polome, edited by M. Jazayery and W. Winter, 183-223. New York: Mouton de Gruyter.

Hancock, I. 1994. 'On the Origins and Current Situation of the Romani Population in Europe and the Responsibility of the American Media to Make that Situation Known'. Report Before the Congressional Human Rights Hearing on Abuses Against Gypsies in Eastern Europe. Washington.

Hancock, I. 1998. 'The Struggle for the Control of Identity'. Roma Participation Program Reporter 1 (1): 11-20. 


\section{References}

Hancock, I. 2000. 'Downplaying the Porrajmos: The Trend to Minimize the Romani Holocaust'. A review of Guenther Lewy, The Nazi Persecution of the Gypsies. Oxford University Press

Hancock, I. 2002. We Are the Romani People. Ame sam e Rromane dzene. University of Hertfordshire Press

Hancock, I. 2005. 'True Romanies and the Holocaust: A Re-evaluation and an overview'. The Historiography of the Holocaust. Palgrave Macmillan, 383-396

Hancock, A-M. 2007. 'When multiplication doesn't equal quick addition: examining intersectionality as a research paradigm.' Perspectives on Politics 5(1): 63-79. https://doi.org/10.1017/S1537592707070065

Hancock, I. 2008. "The "Gypsy" Stereotype and the Sexualization of Romani Women'. In "Gypsies” in European Literature and Culture, edited by V. Glajar, and D. Radulescu, 181-191. New York: Palgrave Macmillan.

Haraway, D. 1991. Simians, Cyborgs, and Women. The Reinvention of Nature. New York: Routledge/Free Associate Books

Haraway, D. 1994. 'A Game of Cat's Cradle': Science Studies, Feminist Theory, Cultural Studies. Configurations 2(1) (winter 1994): 59-71

Haritaworn, J. 2007. 'Beautiful beasts. Ambivalence and distinction in the gender identity negotiations of multiracialised women of Thai descent.' Women's Studies International Forum 30(5): 391-403. https://doi.org/10.1016/j.wsif.2007.07.003

Harry, B., K. M. Sturges, and J. K. Klingner. 2005. 'Mapping the Process: An Exemplar of Process and Challenge in Grounded Theory Analysis'. Educational Researcher 34 (2): 3-13.

Haslanger, S. 2012. Resisting Reality: Social Construction and Social Critique. New York: Oxford University Press.

Hejlić, A. 2019. 'The Revolution Is Here and Now: The Revolution Is Roma, Queer, and Feminist'. https://howlround.com/revolution-here-and-now

Hellawell, D. 2006. 'Inside-Out: Analysis of the Insider-Outsider Concept as a Heuristic Device to Develop Reflexivity in Students Doing Qualitative Research'. Teaching in Higher Education 11 (4): 483-494.

Hemmings, C. 2002. Bisexual Spaces: A Geography of Sexuality and Gender. New York: Routledge.

Henschel, F. 2019. 'The Embodiment of Deviance: The Biopolitics of the 'Difficult Child' in Socialist Czechoslovakia'. East European Politics and Societies and Cultures XX (X) :1-21.

Herza, F. 2019. Sombre faces: Race and nation-building in the institutionalization of Czech physical anthropology (1890s-1920s). History And Anthropology, 1-22. https://doi.org/10.1080/02757206.2019.1629433

Herza, F. 2020. 'Colonial Exceptionalism: Post-colonial Scholarship and Race in Czech and Slovak Historiography.' Slovak Ethnology 68(2): 175-187. DOI:1 $0.2478 / \mathrm{se}-2020-0010$

Hessel, S. 2010. Indignez-Vous! Monpellier: Native Editions (French).

Hetherington, K. 2000. New Age Travellers: Vanloads of Uproarious Humanity. London and New York: Cassell.

Hines, S. 2007. Transforming Gender: Transgender Practices of Identity, Intimacy and Care. Bristol: Policy Press. 
Hines, S. 2010. 'Queerly Situated? Exploring Negotiations of Trans Queer Subjectivities at Work and within Community Space'. In Gender, Place and Culture, edited by S. Hines. London: Routledge.

Holomek, K. 2004. 'Komentář ke knize Romské osady v kulturologické perspektivě autorů Jakoubka a Podušky/Commentary on the Bookbook Romani Settlements in a culturological perspective by Jakoubek and Poduška'. Romano hangos 7 (9). http://www.romanohangos.cekit.cz/clanek.php?id_clanek=1305.

Homosexuality among Roma is still a taboo. Interview with David Berna. 23 September 2009 . Romea http://www.romea.cz/cz/zpravy/homosexualita-je-meziromy-stale-tabu

Honusková, V., and P. Šturma. 2010. Legal Study on Homophobia and Discrimination on Grounds of Sexual Orientation and Gender Identity. EU Agency for Fundamental Rights. https://fra.europa.eu/sites/default/files/fra uploads/1348-lgbt-2010_thematic-study_cz.pdf

hooks, b. 1981. Ain't I a Woman. Boston, MA: South End Press.

Horváth, K. 2010. "'Passing”: Rebeka and the Gay Pride. On the Discursive Boundaries and Possibilities of Skin Colour'. In Multidisciplinary Approaches to Romany Studies, edited by M. Stewart and M. Rövid. Budapest: CEU Press.

Horváthová, J. 2002. Kapitoly z dějin Romů/Chapters from the history of Roma. Varianty. Člověk v tísni.

Hutton, C. M. 2005. Race and the Third Reich Linguistics, Racial Anthropology and Genetics in the Dialectic of Volk. Cambridge: Polity.

Hutton, C. M. 2010. 'Nazi Race Theory and Belief in an "Aryan Race"? A Profound Failure of Interdisciplinary Communication'. The International Journal of Science in Society 1 (4): 149-156.

Hübschmannová, M. 1976. 'K jazykové situaci Romů v ČSSR (Sociolingvistický pohled)/On the Linguistic Situation of Roma in the Czechoslovak Socialist Republic (A Sociolinguistic Perspective)'. Slovo a slovesnost 3: 328-336.

Hübschmannová, M. 1979. 'Bilingualism among the Slovak Roms'. International Journal of the Sociology of Language 19: 33-49.

Identita jako jedno z romských traumat/Identity as one of Romani traumas. http:// romove.radio.cz/cz/clanek/23036

International Organisation for Migration. 2003. 'Final Report on the Project "Analysis of Contemporary Migration and Settlement of the Members of the Roma Communities from Slovakia in the Territory of the Czech Republic" (ref. OAMP-948/2003) for the Department of Asylum and Migration Policies of the Czech Ministry of the Interior'. https://aa.ecn.cz/img_upload/ea85d6c87301 f0a7507b0e8d7b873b63/analyza_migrace_rom.pdf

International Organisation for Migration. 2003. Závěrečná zpráva k projektu Analýza soudobé migrace a usazování př́islušníků romských komunit ze Slovenské republiky na území České republiky (č.j. OAMP-948/2003). https:// aa.ecn.cz/img_upload/ea85d6c87301f0a7507b0e8d7b873b63/analyza_migrace_ rom.pdf

Iovita, R. P. and T. G. Schurr. 2004. 'Reconstructing the Origins and Migrations of Diasporic Populations: The Case of the European Gypsies'. American Anthropologist 106 (2): 267-281.

Ismael, Cortés. 2021. Sueños y sombras sobre los gitanos. La actualidad de un racismo histórico. Bellaterra Edicions. 
Jackman, M. C. 2010. 'The Trouble with Fieldwork: Queering Methodologies'. In Queer Methods and Methodologies: Intersecting Queer Theories and Social Science Research, edited by K., Browne and C., Nash. Farnham: Ashgate.

Jackson, S. 1999. Heterosexuality in Question. London: Sage.

Jaggi, M. 2000. 'Prophet at the Margins', The Guardian, 8 July. https:// www.theguardian.com/books/2000/jul/08/society

Jagose, A. 1996. Queer Theory: An Introduction. New York: New York University Press.

Jakoubek, M. 2004. Romové - konec (ne)jednoho mýtu. Tractatus culturo(mo)logicus/Roma - The End of (No)One Myth. Tractatus culturo(mo)logicus. Praha: Socioklub.

Jakoubek, M. and O. Poduška. 2003. Romské osady v kulturologické perspektivěl Romani Settlements in a Culturological Perspective. Brno: Doplněk.

Jasper, J., and A. McGarry. 2015. 'Introduction: The Identity Dilemma, Social Movements and Contested Identity'. In The Identity Dilemma: Social Movements and Collective Identity, edited by A. McGarry and J. Jasper, 1-17. Philadelphia PA: Temple University Press.

Johnson, K. 2014. Sexuality: A Psychosocial Manifesto. Cambridge: Polity Press.

Johnson, K., and M. G. Guzman. 2012. 'Rethinking Concepts in Participatory Action Research and Their Potential for Social Transformation: Post-structuralist Informed Methodological Reflections from LGBT and Trans-Collective Projects'. Journal of Community and Applied Social Psychology 23 (5): 405-419.

Jovanovic, J., and A. C. Daróczi. 2015. 'Still Missing Intersectionality: The relevance of feminist methodologies in the struggle for the rights of Roma'. In Roma Rights 2: Nothing About Us Without Us? Roma Participation in Policy Making and Knowledge Production, edited by K. O’Reilly and M. Szilvási, 79-82. Budapest: European Roma Rights Centre.

Juelskjaer, M. 2013. 'Gendered Subjectivities of Spacetimematter'. Gender and Education 25: 754-768.

Kamberelis, G., and G. Dimitriadis. 2005. 'Focus Groups: Strategic Articulations of Pedagogy, Politics, and Inquiry'. In Handbook of Qualitative Research, edited by N. K. Denzin and Y. Lincoln, 887-914. Thousand Oaks: SAGE Publications.

Katz, J. D. 2015. 'How AIDS Changed American Art'. in Art AIDS America, edited by R. Hushka and J. Katz. Tacoma Art Museum and Seattle: University of Washington Press.

Kazubowski-Houston, M. 2010. Staging Strife: Lessons from Performing Ethnography with Polish Roma Women. Montreal: McGill-Queen's University Press.

Kenrick, D., and C. Clark. 1999. Moving On: The Gypsies and Travellers of Britain. Hatfield: University of Hertfordshire Press.

Kendrick, D., and G. Puxon. 1995. Gypsies under the Swastica. Hatfield: University of Hertfordshire Press.

Knapp, A. 1999. 'Fragile Foundations, Strong Traditions, Situated Questioning: Critical Theory in German-Speaking Feminism'. In Adorno, Culture and Feminism, edited by M. O'Neill. London: SAGE.

Kóczé, A. 2009. 'Missing Intersectionality: Race/Ethnicity, Gender, and Class in Current Research and Policies on Romani Women in Europe'. Center for Policy Studies Working Papers. Budapest: CEU Center for Policy Studies. 
Kóczé. A. 2011. Gender, Ethnicity and Class: Romani Women's Political Activism and Social Struggles. Budapest: Central European University.

Kóczé, A. 2015. 'Speaking from the Margins'. In Roma Rights 2: Nothing about Us without Us? Roma Participation in Policy Making and Knowledge Production,edited by K. O’Reilly and M. Szilvási, 83-86. Budapest:: European Roma Rights Centre.

Kollman, K. 2009. 'European Institutions, Transnational Networks and National Same-Sex Union Policy: When Soft Law Hits Harder'. Contemporary Politics 15 (1): 37-53. DOI: 10.1080/13569770802674204

Kovats, M. 2015. 'Commentary on the Plans for a European Roma Institute'. http:// romanistudies.eu/kovats_commentary-on-eri/

Kuntsman, A., and E. Mikaye. (eds.). 2008. Out of Place: Interrogating Silences in Queerness/Raciality. York: Raw Nerve Books.

Kurtić, V. 2013. Dzuvljarke: Roma lesbian existence (English version published in 2014). http://www.errc.org/cms/upload/file/dzuvljarke-roma-lesbian-existence.pdf

Laclau, E. 1990. New Reflections on the Revolution of Our Time. London: Verso.

Ladányi, J., and I. Szelényi. 2003. 'Historical Variations in Inter-ethnic Relations: Toward a Social History of Roma in Csenyéte, 1857-2000'. Romani Studies 13 (1): $1-51$.

Ladányi, J., and I. Szelényi. 2006. Patterns of Exclusion: Constructing Gypsy Ethnicity and the Making of an Underclass in Transitional Societies of Europe. New York: Columbia University Press.

Lamont, M., and Molnár, V. 2002. 'The Study of Boundaries Across the Social Sciences'. Annual Review of Sociology 28: 167-195.

Le Bas, D. 2010. 'The Possible Implications of Diasporic Consciousness for Romani Identity'. In All change! Romani studies through Romani eyes, edited by Bas Damian Le, and Alan Acton Thomas. Hertford: University of Hertfordshire.

Lee, R. 1998. 'The Romani Language'.https://kopachi.com/articles/the-romani-languageronald-lee/

Lee, R. 2009. 'A New Look at Our Romani Origins and Diaspora'. Toronto. http:// kopachi.com/articles/authors/ronald-lee/a-new-look-at-our-romani-origins-anddiaspora-by-ronald-lee/.

Lee, R. 2011. 'The Attempted Genocide and Ethnocide of the Roma'. http:// speakingmytruth.ca/v2a/?page_id $=638$.

Leeming. C. 2012. 'Roma Britain'. http://theromaproject.com.

Lemon, A. 2000. Between Two Fires and Romani Memory from Pushkin to Postsocialism. North Carolina: Duke University Press.

Lentin, A. 2005. 'Replacing "Race", Historicizing "Culture" in Multiculturalism'. Patterns of Prejudice 39 (4): 379-396, DOI: 10.1080/00313220500347832

Lentin, A. 2015. What Does Race Do?, Ethnic and Racial Studies, 38:8, 1401-1406, DOI: 10.1080/01419870.2015.1016064

Lentin, A. 2020. Why Race Still Matters. Polity.

Levine-Rasky, C. 2002. Working through Whiteness: International Perspectives. Albany: State University of New York Press.

Levinson, M., and A. Sparkes. 2003. 'Gypsy Masculinities and the School-Home Interface; Exploring Contradictions and Tensions'. British Journal of Sociology of Education 24 (5): 587-603. 
Levinson, M., and A. Sparkes. 2006. 'Conflicting Value Systems: Gypsy Females and the Home-School Interface'. Research Papers in Education 21 (1), 79-97.

Lewis, G. 2000. 'Stuart Hall and social policy'. In Without Guarantees: In Honour of Stuart Hall, edited by P. Gilroy, L. Grossberg and A. McRobbie. London: Verso.

Li, Tania Murray. 2007. 'Practices of Assemblage and Community Forest Management'. Economy and Society 36(2): 263-293.

Liamputtong, P. 2009. 'Qualitative Data Analysis: Conceptual and Practical Considerations'. Australian Journal of Health Promotion 20(2): 133-139.

Liégeois, J.-P. 1983. Tsiganes. Paris: La Découverte/Maspero.

Liégeois, J.-P. 1986. Gypsies: An Illustrated History. London: Al Saqi Books.

Lim, J., and K. Browne. 2009. 'Senses of Gender'. Sociological Research Online 14

Lipphardt, V. 2012. 'Isolates and Crosses in Human Population Genetics; or, a Contextualisation of German Race Science'. Current Anthropology 53 (5): 69-82

Ljujic, V., P. Vedder, and H. Dekker. 2012. 'Romaphobia among Serbian Adolescents: The Role of National In-Group Attitudes and Perceived Threat'. Political Psychology 33 (6): 911-924.

Lorde, A. 1984. 'Sister Outsider. Essay \& Speeches'. The Crossing Press Feminist Series. Freedom.

Lucassen, L., W. Willems, and A. Cottar. 1998. Gypsies and Other Itinerant Groups. London: Macmillan.

Lutz, H. 2002. 'Intersectional Analysis: A Way Out of Multiple Dilemmas?' Paper presented at the International Sociological Association conference, Brisbane, July.

Madriz, E. 2000. 'Focus Groups in Feminist Research'. In Handbook of Qualitative Research, edited by N. Denzin and Y. Lincoln (2nd ed). 835-850. Thousand Oaks, CA: SAGE.

Maguire, P. 1987. 'Doing Participatory Research: A Feminist Approach'. Amherst: The Center for International Education, School of Education, University of Massachusetts.

Mann, C., and F. Stewart. 2000. Internet Communication and Qualitative Research: A Handbook for Researching Online. London: SAGE Publications.

Markova, I., P. Linell, M. Grossen, and A. S. Orvig. 2007. Dialogue in Focus Groups: Exploring Socially Shared Knowledge. Equinox Publishing Ltd.

Marks, Sarah. 2017. The Romani Minority, Coericeve Sterilisation, and Languages of Denial in the Czech Lands. History Workshop Journal no. 84(1): 128-148. DOI: $10.1093 / \mathrm{hwj} / \mathrm{dbx} 033$

Martin, E., and J. F. Gamella. 2005. 'Marriage Practices and Ethnic Differentiation. The Case of the Spanish Gypsies (1870-2000)'. The History of the Family 10 (1): 45-63. Reprinted in Budilová, L., and Jakoubek, M. (eds.). 2007. Cikánská rodina a príbuzenství [Gypsy family and kinship]. Ústí nad Labem: Dryada.

Martínez Cruz, B. I. Mendizabal, C. Harmant, R. de Pablo, M. Ioana, D. Angelicheva Kouvatsi, H. Makukh, M. G., Netea, H. Pamjav, A. Zalán, I. Tournev, E. Marushiakova, V. Popov, J. Bertranpetit, L. Kalaydjieva, L. Quintana-Murci and D. Comas and the Genographic Consortium. 2015. 'Origins, admixture, and founder lineages in European Roma.' European Journal of Human Genetics 24(2016): 937-943. doi: https://doi.org/10.1038/ejhg.2 015.201 
Marushiakova, E. and V. Popov. 2004. 'The Roma - A Nation without a State? Historical Background and Contemporary Tendencies'. In Nationalisms Across the Globe: An Overview of Nationalisms in State-Endowed and Stateless Nations 1, edited by Tomasz Dominik Kamusella, Wojciech Burszta, and Sebastian Wojciechowski, 433-455. Europe. Poznan: School of Humanities and Journalism.

Masny, D. 2013. 'Rhizoanalytic Pathways in Qualitative Research'. Qualitative Inquiry 19: 339-348.

Mason, J., 2004. 'Semistructured Interview'. In Sage Encyclopedia of Social Science Research Methods 1, edited by M. S. Lewis-Beck, A.,Bryman, and T. F. Liao. London: SAGE.

Máté, D. 2015. 'Faced with Multiple "Values"'. Roma Rights 2: Nothing about Us without Us? Roma Participation in Policy Making and Knowledge Production, edited by K. O’Reilly and M. Szilvási, 93-97. Budapest: European Roma Rights Centre.

Matoušek, R., and L., Sýkora. 2011. 'Environmental Justice and Residential Segregation in Czechia: The Case of Roma Resettlement in the Town of Vsetín'. AUC Geographica 46 (2): 81-94.

Matras, Y. 1999. 'Johann Rüdiger and the Study of Romani in 18th Century Germany'. Journal of the Gypsy Lore Society 9: 89-116.

Matras, Y. 2002. Romani: A Linguistic Introduction. Cambridge: Cambridge University Press.

Matras, Y. 2006. 'Romani'. In Encyclopaedia of Languages and Linguistics, edited by Keith Brown. 2nd edition. Oxford: Elsevier.

Matras, Y. 2013. 'Scholarship and the Politics of Romani Identity: Strategic and Conceptual Issues'. European Yearbook of Minority Issues Online 10 (1): 209-247.

Matras, Y. 2014. I Met Lucky People: The Story of the Romani Gypsies. Penguin UK.

Matras, Y. 2015. 'Between Political Subjects and Artistic Performers: Will the European Roma Institute Really Help Europe's Roma?'. http://romanistudies.eu/ between- political-subjects-and-artistic-performers/

Maxwell, J. A. 1996. Qualitative Research Design: An interactive Approach. Thousand Oaks CA: SAGE.

Mayall, D. 2004. Gypsy identities 1500-2000: From Egiptcyans and Moon-men to the Ethnic Romany. London: Routledge.

M'charek, A. 2013. 'Beyond fact or fiction: On the materiality of race in practice.' Cultural Anthropology 28(3): 420-442.

M'charek, A., Schramm, K., and Skinner, D. 2014. 'Topologies of race: Doing territory, population and identity in Europe.' Science, Technology \& Human Values 39(4): 468-487.

McGarry, A. 2010. Who Speaks for the Roma? Political Representation of a Transnational Minority Community. London: Continuum.

McGarry, A. 2011a. 'The Dilemma of the European Union's Roma Policy'. Critical Social Theory 32 (1): 126-136.

McGarry, A. 2011b. 'The Roma Voice in the European Union: Between National Belonging and Transnational Identity'. Social Movement Studies 10 (3): 283-297. 
McGarry, A. 2013. 'Romaphobia: The Last Acceptable Form of Racism'. in Open Democracy (13 November 2013). https://www.opendemocracy.net/can-europemake- it/aidan-mcgarry/romaphobia-last-acceptable-form-of-racism

McGarry, A. 2014. 'Roma as a Political Identity: Exploring Representations of Roma in Europe'. Ethnicities 14 (6) : 756-774.

McGarry, A. 2016. 'Pride Parades and Prejudice: Visibility of Roma and LGBTI communities in Post-socialist Europe'. Communist and Post-Communist Studies 49: 269-277.

McGarry, A. 2017. Romaphobia: The Last Acceptable form of Racism. London: Zed Books.

McGarry, A., and J. Jasper. (eds.). 2015. The Identity Dilemma: Social Movements and Collective Identity. Philadelphia PA: Temple University Press.

Melucci, A. 1996. Challenging Codes: Collective Action in the Information Age. Cambridge University Press: Cambridge.

Merriam, S. B. 1998. Qualitative Research and Case Study Applications in Education. San Francisco, CA: Jossey-Bass.

Miles, M. B., and A. M. Huberman. 1994. Qualitative Data Analysis (2nd edition). Thousand Oaks CA: SAGE Publications.

Milton, S. 1991. 'Gypsies and the Holocaust; Nazi Policies Toward Roma and Sinti 1933-1945'. Journal of the Gypsy Lore Society 2 (1): 1-18.

Minkler M., and N. Wallerstein. (eds.). 2003. Community Based Participatory Research for Health. San Francisco, Calif: Jossey-Bass Publishers.

Mirga, A., and N. Gheorghe. 1997. The Roma in the Twenty-First Century: A Policy Paper. Princeton, NJ: Project on Ethnic Relations.

Mirga-Kruszelnicka, A. 2015. 'Romani Studies and Emerging Romani Scholarship'. Roma Rights 2: Nothing about Us without Us? Roma Participation in Policy Making and Knowledge Production, edited by K. O’Reilly and M. Szilvási, 39-46. Budapest: European Roma Rights Centre.

Moravčíková, D. 2020. 'The Silences and Screams of White Spaces'. https:// hranicar-usti.cz/mlceni-a-krik-bilych-mist/

Morgan D. L. 1997. Focus Groups as Qualitative Research. 2nd Edition. London: SAGE.

Morgan, D. L., and R. A. Krueger. 1993. 'When to Use Focus Groups and Why'. In Successful Focus Groups, edited by D. L. Morgan. London: SAGE.

Munnik, R. P. H. 2001. Donna Haraway: Cyborgs for Earthly Survival? In American Philosophy of Technology: The Empirical Turn, edited by H. J. Achterhuis. 95-118. (Indiana Series in the Philosophy of Technology). Indiana University Press.

Muñoz, J. E. 1999. Disidentifications: Queers of Color and the Performance of Politics. Minneapolis: University of Minnesota Press

Muñoz, J. E. 2006. 'Feeling Brown, Feeling Down: Latina Affect, the Performativity of Race, and the Depressive Position'. Signs 31(3). New Feminist Theories of Visual Culture: 675-688. Chicago: University of Chicago Press.

Mügge, L., C. Montoya, A. Emejulu, and S. L. Weldon. 2018. Intersectionality and the politics of knowledge production. European Journal of Politics and Gender 1(1-2): 17-36, DOI: 10.1332/251510818X15272520831166 
Nadin S., and Cassell, C. 2006. 'The Use of a Research Diary as a Tool for Reflexive Practice: Some Reflections from Management Research'. Qualitative Research in Accounting \& Management 3 (3): 208-217.

Nagel, J. 1994. 'Constructing Ethnicity Creating and Recreating Ethnic Identity and Culture’. Social Problems 41 (1): 152-176.

Namaste, V. K. 2000. Invisible Lives. The Erasure of Transsexual and Transgendered People. Chicago: University of Chicago Press.

Naples, N. A. 1996. 'The outsider phenomenon'. In In the field: Readings on the field research experience (2nd), edited by C. D. Smith and W. Kornblum, 139-149. Westport, CT: Praeger.

Nash, C. J. 2008. 'Re-thinking Intersectionality'. Feminist Review 89: 1-15.

Nast, H. 2002. 'Queer Patriarchies, Queer Racisms, International'. Antipode 34: 874-909.

Nirenberg, J. 2011. Gypsy Sexuality: Romani and Outsider Perspectives on Intimacy. Clambake Press LLC.

O’Brian, J. 2007. 'Afterword: Complicating Homophobia'. Sexualities 11 (4): 496-512.

O’Nions, H. 2015. 'Warehouses and window-dressing: a legal perspective on educational segregation in Europe'. Approaches to the education of Roma in Europe. ZEP: Zeitschrift fuer Internationale Bildungsforschung und Entwicklungspädagogik 38 (1): 4-10.

Okely, Judith. 1975. 'The Family, Marriage and Kinship Groups'. In Gypsies and government policy in England, edited by B. Adams, J. Okely, D. Morgan, and D. Smith, 55-88. London: Heinemann Educational Books, Ltd.

Okely, J. 1983. The Traveller-Gypsies. Cambridge. The University Press.

Okely. J. 1994. 'Constructing Difference: Gypsies as "Other"'. Anthropological Journal on European Cultures: Anthropology and Ethics 3(2): 55-73

Okely, J. 2010. 'Constructing Culture through Shared Location, Bricolage and Exchange: The Case of Gypsies and Roma'. In Multidisciplinary Approaches to Romany Studies, edited by M. Stewart and M. Rövid. 35-52. Budapest: CEU Press.

Online interview with Belén Molinuevo in Czech. 3 August 2010. Romano Vodori. http://www.romanovodori.cz/star-online/ptejte-se-belen-molinuevo-na-otaznikykolem-homosexuality-a-transsexuality/

Oprea, A. 2004. 'Re-envisioning Social Justice from the Ground Up: Including the Experiences of Romani Women'. Essex Human Rights Review 1(1): 29-39.

Oswin, N. 2008. 'Critical Geographies and the Uses of Sexuality'. Progress in Human Geography 32(1): 89-103.

Pabijanelk, K. 2018. 'From Gypsyland with Love'. Critical Romani Studies 1 (2): 168-175. 10.29098/crs.v1i2.41

Parlett, M., and Hamilton, D. 1972. 'Evaluation as Illumination: A New Approach to the Study of Innovatory Programmes. Occasional Paper No. 9, Centre for Research in the Educational Sciences, University of Edinburgh'. Reprinted in Gene V. Glass (ed.). 1976. In Evaluation Studies Review Annual 1, 140-157. Beverly Hills: SAGE Publications.

Pechová, O., and Štepánková, M. Fundamental Rights Agency. 2009. 'Homophobia and Discrimination on Grounds of Sexual Orientation and Gender Identity in the EU Member States: PART II - The Social Situation (Czech Republic)https:// fra.europa.eu/sites/default/files/fra_uploads/397-FRA_hdgso_report_part2_en.pdf 


\section{References}

Phillips, J. 2006. 'Agencement/Assemblage'. Theory Culture \& Society 23(2-3): 108-109.

Plájás, I. Z., A. M'charek, and H. van Baar. 2019. 'Knowing “the Roma”: Visual Technologies of Sorting Populations and the Policing of Mobility in Europe'. Society and Space 37 (4): 589-605.

Plummer, K. (ed). 1981. The Making of the Modern Homosexual. London: Macmillan.

Potter, M. 2011. 'The "EU Horizontal Directive". Research and Information Service Briefing Paper'. Northern Ireland Assembly. http://www.niassembly.gov.uk/ globalassets/documents/raise/publications/2011/ofmdfm/12111.pdf

Probyn, E. 1996. Outside Belongings. New York: Routledge.

Prosser, J. 1998. Second Skin: The Body Narrative of Transsexuality. New York: Columbia University.

Puar, J. K. 2005. 'Queer Times, Queer Assemblages'. Social Text 23 (3-4 84-85): 121-139.

Puar, J. K. 2007. Terrorist Assemblages: Homonationalism in Queer Times. Durham and London: Duke University Press.

Puar, J. K. 2012. "I would rather be a cyborg than a goddess": BecomingIntersectional in Assemblage Theory'. philoSOPHIA 2: 49-66. New York: State University of New York Press.

Puar, J. K., and A. Rai. 2002. 'Monster, Terrorist, Fag: The War on Terrorism and the Production of Docile Patriots'. Social Text 7220 (3): 117-148.

Puxon, G. 1973. Rom: Europe’s Gypsies. London: Minority Rights Group.

Rahman, M. 2010. 'Queer as intersectionality: theorising gay Muslim identities.' Sociology 44(5): 1-18. DOI: 10.1177/0038038510375733

Rattansi, A. 2007. Racism: A Very Short Introduction. Oxford: Oxford University Press.

Razack, S. 2005. 'How Is White Supremacy Embodied? Sexualised Racial Violence at Abu Ghraib'. Canadian Journal of Women and the Law 17 (2): 341-363.

Reid-Pharr, R. 2002. 'Extending Queer Theory to Race and Ethnicity'. Chronicle of Higher Education 48 (49): 7-.9.

Richardson, D. 2004. 'Locating Sexualities: From Here to Normality'. Sexualities 7: 391-411.

Richardson, D. 2005. 'Desiring Sameness? The Rise of Neoliberal Politics of Normalisation'. Antipode 37 (3): 515-535.

Ritchie, J., and J. Lewis. 2003. Qualitative Research Practice: A Guide for Social Science Students and Researchers. London: SAGE.

Robson, C. 1993. Real World Research: A Resource for Social Scientists and Practitioner-Researchers. Blackwell Publishers.

Roediger, D. R. 1991. The Wages of Whiteness: Race and the Making of the American Working Class. New York and London: Verso.

Roma Sovieticus: Roma Experience under Communism by Dr Ciprian Necula October 13, 2020. European Roma Institute for Arts and Culture Barvalipe Roma Online University. https://www.facebook.com/watch/live/?v=24124452 02396593\&ref=watch_permalink.

Rooke, A. 2010. 'Queer in the Field: On Emotions, Temporality and Performativity in Ethnography'. In Queer Methods and Methodologies: Intersecting Queer 
Theories and Social Science Research, edited by K. Browne and C. Nash. Farnham: Ashgate.

Rose, G. 2007. Visual Methodologies: An Introduction to the Interpretation of Visual Materials. 2nd edition. London, Thousand Oaks, New Delphi: SAGE Publications.

Rostas, I. 2019. A Task for Sisyphus: Why Europe's Roma Policies Fail. Budapest: Central European University Press.

Rottenberg, C. 2003. 'Passing: Race, Identification, and Desire'. Criticism 45 (4): 435-452.

Rüdiger, J. Ch. Ch. 1782 [1990]. Von der Sprache und Herkunft der Zigeuner aus Indien. Reprint from: Neuester Zuwachs der teutsche, fremden und allgemeinen Sprachkunde in eigenen Aufsätzen. Hamburg: Buske.

Ryder, A. 2020. 'Roma Civil Monitor: A Synthesis of civil society's reports on the implementation of national Roma integration strategies in the European Union. Identifying Blind Spots in Roma Inclusion Policy'. European Commission/ Center for Policy Studies. Central European University. https://cps.ceu.edu/sites/ cps.ceu.edu/files/attachment/basicpage/3172/rcm-civil-society-monitoring-reportsynthesis27-2020-eprint-fin.pdf

Said, E. W. 1978. Orientalism. New York: Pantheon Books.

Saini, A. 2019. Superior: The Return of Race Science. London: 4th ESTATE.

Samuels, H. 1999. African-Americans. In Sexuality in America: Understanding our Sexual Values and Behavior, edited by R. T. Fancouer, P. Koch, and D. Weis, 42-48. New York: Continuum.

San Román, Teresa. 1975. 'Kinship, Marriage, Law and Leadership in Two Urban Gypsy Settlements in Spain'. In F. Rehfisch (ed.). Gypsies, Tinkers and other Travellers. London; New York: Academic Press, pp. 169-199.

Saul, N. I., and S. Tebbutt. 2004. The Role of the Romanies: Images and CounterImages of 'Gypsies'/Romanies in European Cultures. Liverpool: Liverpool University Press.

Shmidt, V. 2020. Race Science in Czechoslovakia: Serving Segregation in the Name of the Nation. Studies is History and Philosophy of Biological and Biomedical Science 83. DOI: 10.1016/j.shpsc.2019.101241.

Schneeweis, A. 2018. 'The Imagined Backward and Downtrodden Other'. Journalism Studies 19 (15): 2187-2206. DOI: 10.1080/1461670X.2017.1331708

Schneider J., I. Kalhousková and J. Klepal. 2009. Holocaust Era Assets. Conference proceedings. Forum 2000 Foundation. ISBN 978-80-254-6406-9. http://www. commartrecovery.org/docs/PragueConferenceProceedings.pdf

Schultz, D. L. 2012. 'Translating Intersectionality Theory into Practice: A Tale of Romani- Gadže Feminist Alliance'. Signs 38 (1): 37-43.

Scott, D. 2005. 'Stuart Hall's Ethics'. Small Axe 17: 1-16.

Sedgwick, E. K. 1990. Epistemology of the Closet. Oakland: University of California Press.

Sedgwick, E. K. 1993. Tendencies. Durham, NC and London: Duke University Press.

Seidman, S. 1993. 'Identity and Politics in a "Postmodern" Gay Culture: Some Historical and Conceptual Notes'. In Fear of a queer planet: Queer politics and social theory, edited by M. Warner. Minneapolis: University of Minnesota Press 


\section{References}

Seidman, S. 2002. Beyond the Closet: The Transformation of Gay and Lesbian Life. London: Routledge.

Shneer, D., and C. Aviv 2002. Queer Jews. New York: Routledge

Silverman, C. 1981. 'Pollution and Power: Gypsy Women in America'. in The American Kalderash: Gypsies in the New World, edited by M. Salo, 55-70. Centenary College, New Jersey: Gypsy Lore Society.

Silverman, C. 1996. 'Music and Power: Gender and Performance among Roma (Gypsies) of Skopje, Macedonia. The World of Music'. Journal of the International Institute for Traditional Music 38 (1): 63-76.

Silverman, C. 2003. The Gender of the Profession: Music, Dance, and Reputation among Balkan Muslim Rom (Gypsy) Women. In Gender and Music: Perspectives from the Mediterranean, edited by Tullia Magrini. 119-145. University of Chicago Press.

Silverman, C. 2007. 'Trafficking in the Exotic with "Gypsy" Music: Balkan Roma, Cosmopolitanism, and "World Music" Festivals'. In Balkan Popular Culture and the Ottoman Ecumene: Music, Image and Regional Political Discourse, edited by D. Lanham Buchanan. M.D.: Scarecrow Press.

Silverman, C. 2012. Romani Routes: Cultural Politics and Balkan Music in Diaspora. Oxford: Oxford University Press.

Skeggs, B. 1997. Formations of Class \& Gender. Becoming Respectable. London: SAGE.

Spivak, G. C. 1987. 'Can the Subaltern Speak?' Other Worlds: Essays in Cultural Politics. London and New York: Routledge.

Spivak, G. C. 1988. 'Subaltern Studies: Deconstructing Historiography'. Selected Subaltern Studies, edited by R. Guha and G. C. Spivak, 197-221. Oxford: Oxford University Press.

Spivak, G. C. 1990. The Post-Colonial Critic: Interviews, Strategies, Dialogues. New York: Routledge.

Staples, R. 1978. 'Masculinity and Race: The Dual Dilemma of Black Men'. Journal of Social Issues 34 (1): 169-183.

Staples, R. 1986. Black Masculinity: The Black Male's Role in American Society. New York: The Black Scholar Press.

Staples, R. 2006. Exploring Black Sexuality. Lanham: Rowman \& Littlefield Publishers Inc.

Stauber, R., and Vago, R. 2007. The Roma - A Minority in Europe: Historical, Political and Social Perspectives. Central European University Press.

Stein, A., and K. Plummer. 1996. "“I Can't Even Think Straight”: “Queer” Theory and the Missing Sexual Revolution in Sociology'. In Queer Theory, Sociology, edited by S. Seidman, 129-144. Cambridge, MA: Blackwell.

Stewart, M. 1997. The Time of the Gypsies. Oxford: Westview Press.

Stewart, M. 2010. 'Introduction: Challenges for Scholarship in the Field of Romany Studies'. In Multidisciplinary Approaches to Romany Studies, edited by M. Stewart and M. Rövid. Budapest: CEU Press.

Stewart, M. 2013. 'Roma and gypsy "ethnicity" as a subject of anthropological inquiry'. Annual Review of Anthropology 42: 415-432.

Stewart, M. 2017. 'Nothing about us without us, or the dangers of a closed-society research paradigm.' Romani Studies 27( 2): 125-146. 
Stone, S. 1991. 'The empire strikes back: A posttranssexual manifesto'. In Body guards: The cultural politics of gender ambiguity, edited by J. Epstein and K. Straub. New York: Routledge.

Strauss, A., and J. Corbin. 1998. Basics of Qualitative Research: Techniques and Procedures for Developing Grounded Theory (2nd ed.) Thousand Oaks, CA: Sage Publications.

Stryker, S. 1994. 'My Words to Victor Frankenstein Above the Village of Chamounix: Performing Transgender Rage'. GLQ: A Journal of Lesbian and Gay Studies 1: 237-254.

Stryker, S. 2006. '(De)Subjugated Knowledges: An Introduction to Transgender Studies'. In The Transgender Studies Reader, edited by S. Stryker, and S. White. London: Routledge.

Surdu, M., and M. Kovats. 2015. 'Roma Identity as an Expert-Political Construction'. Social Inclusion 3 (5): 5-18.

Sutherland, A. 1986. Gypsies: The Hidden Americans. Prospect Heights, IL: Waveland Press.

Szalai, J. 2014. 'Roma Marginalization and Exclusion in a Comparative Perspective'. In Faces and Causes of Roma Marginalization in Local Contexts: Hungary, Romania, Serbia, edited by J. Szalai and V. Zentai. Budapest: Centre for Policy Studies, Central European University (CEU).

Tavory, I. and Timmermans, S. 2014. Abductive Analysis:Theorizing Qualitative Research, Chicago, IL: University of Chicago Press.

Taylor, Y. 2007. Working-Class Lesbian Life: Classed Outsiders. Basingstoke: Palgrave Macmillan.

Taylor, Y. 2010. 'The “Outness” of Queer'. In Queer Methods and Methodologies: Intersecting Queer Theories and Social Science Research, edited by K., Browne and C., Nash. Farnham: Ashgate.

Taylor, Y., S. Hines, and M. Casey. (eds.) 2010. Theorizing Intersectionality and Sexuality: Genders and Sexualities in the Social Sciences. Palgrave Macmillan.

Tesăr, C. 2012. 'Becoming Rom (Male), Becoming Romni (Female) among Romanian Cortorari Roma: On Body and Gender'. Romani Studies 22 (2): 113-140

Theodosiou, A. 2011. 'Multiculturalism and the Catachresis of Otherness: Settling Gypsies, Unsettling Gypsy Belongings'. Critique of Anthropology 31: 89-107.

Thorne, S. E., and B. L., Paterson. 2000. 'Two Decades of Insider Research: What We Know and Don't Know about Chronic Illness Experience'. Annual Review of Nursing Research 18: 3-25.

Timmermans, S., and I. Tavory. 2012. 'Theory Construction in Qualitative Research: From Grounded Theory to Abductive Analysis'. Sociological Theory 30 (3): 167-186. doi: 10.1177/0735275112457914

Tobi, Sheridan, and Lais. 2010. 'Health and Social Care Needs Assessment of Eastern European (including Roma) individuals living in Barking and Dagenham: Final Report'. Institute for Health and Human Development.

Toušek, L. 2011. 'Purification of Space: Spatial Segregation of the Roma in the Czech Republic'. RESPECT Research Project (GA no. 244549).

Toyosaki, S., S. L. Pensoneau-Conway, N. A. Wendt, and K. Leathers. 2009. 'Community Autoethnography: Compiling the Personal and Resituating Whiteness'. Cultural Studies $\leftrightarrow$ Critical Methodologies 9 (1): 56-83. 


\section{References}

Tremlett, A. 2009. 'Bringing Hybridity to Heterogeneity: Roma and the Question of "Difference" in Romani Studies'. Romani Studies 19 (2): 147-168.

Tremlett. A. 2014a. 'Demotic or Demonic? Race, Class and Gender in "Gypsy" Reality TV'. The Sociological Review 62: 316-334.

Tremlett, A. 2014b. 'Making a Difference without Creating a Difference: SuperDiversity as a New Direction for Research on Roma Minorities'. Ethnicities 14 (6): 830-848.

Tremlett. A. 2017. 'Visualising Everyday Ethnicity: Moving beyond Stereotypes of Roma Minorities'. Romaphobia and the Media: Mechanisms of Power and the Politics of Representations, edited by Annabel Tremlett, Vera Messing and Angéla Kóczé. Identities 24 (6): 720-740. DOI: 10.1080/1070289X.2017.1379927

Tremlett, A., and A. McGarry. 2013. 'Challenges Facing Researchers on Roma Minorities in Contemporary Europe: Notes towards a Research Program', European Center for Minority Rights Working Paper No. 62.

Tremlett, A., A. McGarry, and T. Agarin. 2014. 'The Work of Sisyphus: Squaring the Circle of Romani Recognition'. Ethnicities 4 (6): 727-736.

Trowler, P. 2011. 'Researching Your Own Institution'. British Educational Research Association online resource. https://www.bera.ac.uk/publication/ researching-your-own-institution-higher-education

Truth, S. 1850 [2014]. Narrative of Sojourner Truth: A Northern Slave. CreateSpace Independent Publishing Platform.

Tucker, A. 2009. Queer Visibilities. Space, Identity and Interaction in Cape Town. Wiley- Blackwell.

Tuckett, A. G. 2005. 'Applying Thematic Analysis Theory to Practice: A Researcher's Experience'. Contemporary Nurse 19: 75-87.

Turda, M. 2014. Eugenics and Nation in Early $20^{\text {th }}$ Century Hungary. Houndmills, Basingstoke: Palgrave Macmillan.

Vajda, V. 2015. 'Towards “Critical Whiteness” in Romani Studies'. Roma Rights 2: Nothing About Us Without Us? Roma Participation in Policy Making and Knowledge Production, edited by K. O’Reilly and M. Szilvási,. edited by K. O’Reilly and M. Szilvási, 47-56. Budapest: European Roma Rights Centre.

van Baar, H. 2010. 'Romani Identity Formation and the Globalization of the Holocaust Discourse'. Thamyris/Intersecting 20: 115-132

van Baar, H. 2011. "The European Roma: Minority Representation, Memory and the Limits of Transnational Governmentality". PhD Thesis. University of Amsterdam. van Baar, H. 2014. 'The emergence of a reasonable anti-gypsyism in Europe.' In When Stereotype Meets Prejudice: Antiziganism in European Societies, edited by T. Agarin, 27-44. Stuttgart: Ibidem.

van Baar, H. 2015. 'The Perpetual Mobile Machine of Forced Mobility: Europe's

"Roma" and the Institutionalization of Rootlessness'. In The Irregularization of Migration in Contemporary Europe: Deportation, Detention, Drowning, edited by Y. Jansen, J. De Bloois, and R. Celikates, 71-86. London: Rowman and Littlefield.

van Baar, H., and A. Kóczé 2020. The Roma and Their Struggle for Identity in

Contemporary Europe. Romani Studies, vol. 3. New York: Berghahn.

van Baar, H., and P. Vermeersch 2017. 'The Limits of Operational Representations: 'Ways of Seeing Roma' beyond the Recognition-Distribution Paradigm'. Intersections 3 (4): 120-139. 
Vermeersch, P. 2006. The Romani Movement: Romani Politics \& Ethnic Mobilisation in Contemporary Central Europe. Oxford: Berghahn Books.

Vertovec, S. 2007. 'Super-Diversity and Its Implications'. Ethnic and Racial Studies, 29 (6): 1024-1054. doi: 10.1080/01419870701599465

Vincze, E. 2008. 'Romani Women's Multiple Discrimination through Reproductive Control'. In Anthropo - Lenyomatok. Amprente. Imprints, edited by H. Harbula and E. Magyari-Vincze, 299-317. Cluj: EFES.

Vincze, E. 2013. 'Socio-Spacial Marginality of Roma as a Form of Intersectional Injustice'. Studia UBB Sociologica 58 (LVIII): 217-242.

Vincze, E. 2014. 'Faces and Causes of Roma Marginalization: The Case of Romania'. In Faces and Causes of Roma Marginalization in Local Contexts: Hungary, Romania, Serbia, edited by J. Szalai and V. Zentai. Budapest. Centre for Policy Studies, Central European University (CEU).

Vrabiescu. I. 2014. 'The Subtlety of Racism: From Antiziganism to Romaphobia'. In When Stereotype Meets Prejudice: Antiziganism in European Societies, edited by T. Agarin. Stuttgart: Ibidem Verlag.

Walsh, M. 2009. Gypsy Boy. London: Hodder \& Stoughton.

Walsh, M. 2011. Gypsy Boy on the Run. London: Hodder \& Stoughton.

Warner, M. 2002. Publics and Counterpublics. New York: Zone Books.

Weeks, J. 2012. 'Queer(y)ing the "Modern Homosexual”'. Journal of British Studies, 51 (3): 523-539.

Wilkinson, S. and Kitzinger, C. 2013. 'Representing Our Own Experiences: Issues in “Insider” Research.' Psychology of Women Quarterly 37( 2): 251-255. https:// doi.org/10.1177/0361684313483111.

Willems, W. 1997. In Search of the True Gypsy.London: Frank Cass Publishers.

Yekani, E. H., B. Michaelis, and G. Dietze. 2010. “"Try Again. Fail Again. Fail Better." Queer Interdependencies as Corrective Methodologies'. In Theorizing Intersectionality and Sexuality: Genders and Sexualities in the Social Sciences, edited by Y. Taylor, S. Hines, and M. Casey. Palgrave Macmillan.

Yost, M. R., and J. F. Chmielewski. 2013. 'Blurring the Line between Researcher and Researched in Interview Studies: A Feminist Practice?' Psychology of Women Quarterly 37 (2): 242-250 10.1177/0361684312464698

Yuval-Davis, N. 2006. 'Intersectionality and Feminist Politics'. European Journal of Women's Studies 13 (3): 193-209. London, Thousand Oaks and New Delhi: SAGE.

Yuval-Davis, N. 2011. 'Power, Intersectionality and the Politics of Belonging'. FREIA Working Paper Series No. 75.

Yuval-Davis, N. 2014. "Situated Intersectionality and Social Inequality." Raisons Politiques 58: 91-100.

Yuval-Davis, N., G. Wemyss, and K. Cassidy. 2017a. 'Introduction to the Special Issue: Racialized Bordering Discourses on European Roma'. Ethnic and Racial Studies 40 (7): 1047-1057.

Yuval-Davis, N., V. Varjú, M. Tervonen, J. Hakim, and M. Fathi. 2017b. 'Press discourses on Roma in the UK, Finland and Hungary'. Ethnic and Racial Studies 40 (7): 1151-1169, DOI: 10.1080/01419870.2017.1267379

Zel'ová, A., and Bačová, V. 1994. Minoritné etnické spoločenstvá na Slovensku v procesoch spoločenských premien/Minority Ethnic Communities in the Processes of Social Transformation. Bratislava: SAV Veda. ISBN 80-224-0405-5 


\section{Index}

academia 2-3, 44, 90, 175, 180, 185,187

academic discourse 30, 47, 51; scholarship 1, 3, 8, 10, 12, 30-38, 43, 47-48, 51-53, 55-56, 64, 76 acceptance 4-9, 16, 86, 91-92, 109, 111-114, 116, 118, 120-121, 131-133, 142, 144, 150, 152 advocacy 4

affinity 55, 156, 160

African American 78, 84, 99 agency 14,123

anachronism 3, 7, 73, 174

ancestral 80, 82, 129

anti-discrimination 17, 47, 177, 185

anti-essentialist 25, 31, 44, 51-54, 59, $95,172,186$

anti-identitarian 44, 55, 59, 95, 151, $161,169,185$

antigypsyism $9,11,15,16,19,27,30$, $39,42,56,62,68,72-74,81,84,88$, 91, 98, 100-104, 108, 116, 122-123, 125-127, 132-133, 137-139, 145-148, 150, 152, 155, 168-169, 171-173, 179, 184, 186-187; internalised 154

anti-Romani abuse 104, discourse 79 , laws 12, 13, 73, 79; measures 18, 19, 73 ; sentiments 2, 16, 104

anti-Semitism 82, 172

antithesis $3,7,174$

anthropology 12, 33, 34; racial 75

Anzaldúa, G. E. 55, 58, 156

apartheid 76, 83

ARA ART 19, 176-177

arbitrary 2

army 2

arts 180 assemblage $25,47,57,102,123,147$, 149-150, 172, 186

assimilation 12, 13, 40, 91, 146, 149, 181

argot 2

Atzinganoi 72

austerity 3; measures 3

Austria 60, 114, 131-132

Austro-Hungarian empire 13

authenticity $115,123,126,153,156$, $158,168-169,74,181$

backlash $18,26,175,187$

backwardness 11, 28, 74, 173, 178; cultural 80; sexual 2, 174

Baker, D. 7, 42, 82, 133-134

becoming 25, 58-60, 95, 138, 141, 147

Belgium 60

belief 2

belonging $3,4,10,20,26,42,64,74$, $84,86-92,96,122,150,152-153$, 157, 160-161, 166, 169; ethnic 50, 155-156; outside $87,151,157$; queer 9-10, 101, 151-168, 171, 184-185, 187

binary $8,29,38,41,45,53,57,82-83$, $102,128,131,139,141-142,146$, $148,151,161,164,168,173,179$, 184, 186; opposition $64,81,165$, $172,176,178,181$; orthodoxies 53 , $59,63-64,81,84,146,151-152$, $158,160,168$

biological essentialism 27, 30, 31, 49, $75,77,85,129,152,172,177$

bi $1,60,65,98,110,121,185$; bisexuality $55,134,137-138$ biopower 76

Black 8, 28, 45, 47, 48, 56, 78, 82, 102-104; blackness 85, 103 
nleach 102

bon sauvage 3, 40, 73

British Cultural Studies 25

Brexit 18, 66, 188, 190

Brubaker, R. 45, 67

Bulgaria 60, 117, 127

Butler, J. 53, 54, 80-81, 85, 152

camouflage 84, 139

Canada 60

canon 58, 171, 152, 178

Cartesian subject 26, 27, 29

categories of identification 2, 29, 42, 45, $59,80,84,86,95,129,137$,

150-152, 156, 160, 172, 186

categorisation 35, 41, 184; group 46; self 41,184

Central and Eastern Europe 5, 10, 11, $14,15,16,17,18,36,39,60,76,87$ cisgender 9, 43, 45, 60, 64, 84, 86, 88, $98,107,125,127,139,152,158$, $172,177-178,186$

cisnormativity $10,45,49,59,81$, $85-86,92,102,115-116,124,131$, 152, 158, 164, 184, 186

citizenship 40, 74-75, 87, 91

class $27,29,45,48,50,53-56,60,67$, 94, 120-121, 123, 172, 174;

classed 120

closet 4, 30, 41, 72, 81-83, 90, 92, 98, 101, 125-133, 139, 146-148, 150, 168, 173-174, 184; intersectional

127, 129-134, 148, 151; queer

81-84; ethnic/'racial' 81-84

colonialism 28, 56, 66, 74, 76

colour, of 25, 47-49, 107, 112, 139,

168, 187; skin 102-103; woman 57 coming out $4,55,82,112-114,117$,

$126,129,133,173$

commonality 98, 139-148, 151, 176,

$179,184,186,188$

communities 5, 26, 42, 108-109,

115-116, 118, 123, 125-126, 132,

$137,150,152,154,157-158,173$,

188; elective 46; imagined 27

communism 13, 40; collapse of 4,15 ,

$17,18,76,80,188$

conservatism 107, 112-113, 116, 121,

$123,132,158$

constructionism, social 30, 31, 34, 38, $43,53,185-186$

contextual 9, 27, 28, 29, 41, 74, 82-84, $92,100,116,124,125,128,131$,
134, 137, 141-142, 148, 150, 173,180

COVID-19 2, 18, 26, 74, 175, 188

Crenshaw, K. 47, 48, 49, 51

Critical Race Studies 47; theory 74

Critical Romani Studies 43, 186

Critical Whiteness 43, 64, 66, 68

c34 36, 90

cultural essentialism $3,31,38,41,42$, 45, 74, 129, 144, 172, 177

culture 3, 25-26, 29-31, 34-38, 40, $44-45,74,76,82-83,89,93-94$

Czech 99, 101-102, 109-110, 132;

lands, the 13; Republic 4, 67, 79-80, 177; Czechoslovakia 13-15, 17, 79-80, 88

danger 3

data analysis 61

data collection 61

decolonisation 43

democracy 26, 188, neoliberal 3, 15, 37, $38,40,86,145$

deregulation 3

'deviance' 8, 27-28, 33, 72-80, 125, 127, 145, 173, 178; deviation 139-140

DH and others $v$. the Czech Republic 4,79

diaspora 30,32

dichotomy $3,43,53,56,168,174$, 185-187

difference 3, 29, 35, 44, 48, 74-78, 81, 89-90, 125, 128-129, 133, 138, 140, 142, 152, 167, 173, 178, 184-185; categories of 48; ethnic $35,42,57$, 77-79, 145, 171; gender 51, 115, 171-172; marked essentialist 9, 35, 42, 59, 78, 96, 139-140, 144, 145-147, 149, 151, 160, 171-173, 178; 'racial' $35,42,75,77-79,145$, 171-172; sexual 57, 77-79, 115, 171-172

differentiation, multiple axes of 47,48 dilemma 52, epistemological 63; ethical 63; identity 52, 88, 151, 160-166; ontological 63; queer $52,88,151$, 160-166

discursive 5, 27, 54, 65, 66, 74-75, 108, 124, 133, 149, 184

disidentification 58, 84, 86, 88, 92-96, 146-148, 150-169, 181, 184, $186-187$ 
disinformation 175,188

discrimination 2, 14, 36-37, 39, 74, 88, $98,120,152,185,188$; intersectional 176,185 , multiple $6,42,176$; racial 40, 99

diversity $2,10,29,44,45$

drag 85

dualism 53, 95; duality 33

emancipation 165

empirical evidence 9, 62; material 96

enlightenment 26, 27, 40

entertainment 3, 90, 145

epistemic violence 44; invisibility 44, $66,125,149,175$

epistemological erasure 44; insider 67; silences 55

epistemology 26, 32, 173

equality $16,48,88,177,185$

essence $31,45,50,51,75$

essentialism 26, 30, 31, 34, 38, 43, 47, $53,54,65,77,90,116,144,171$, $174,177,185-186$

ethics 62

ethnic frame 3, 25, 43, 172; group 30

ethnicisation 72-75, 98, 103, 107, 112, $120,122,124,139,145,150,179$

ethnicity $2,27,28,45-50,62,68,72$, 74, 78-81, 84, 94, 98, 102, 104, 120, $126,146,151,164-165,172,174$, $178-179,186$

ethnocentrism 44, 56, 66, 84, 125, 131, 167-168

ethnoclass 40

ethnography 8, 60, 63-64, 96

everyday 3

eugenics $14,31,75,77,172$

Europe 1, 7-8, 10-14, 16, 18, 20, 31, 34-40, 45, 60, 72, 74-76, 84, 88, 174,187

European Court of Human Rights 4, 79

European Union 1, 16-19, 40, 175, 177, 187; directives 17, 188

exclusion $2,39,49,74,86,88,90,92$, 105, 109, 116-117, 123, 147, 150,

152, 155-156, 160, 169, 184, 186

excommunication 116

experiences 3-8, 11, 19, 28, 38, 45-50, 56, 62-65, 68, 80, 90; historic 77; intersectional 9, 51, 61; lived 1, 2, 6, 7, 9, 10, 20, 36, 39, 41, 42, 57-61, $67,68,84,96,98,101,108,116$,
123, 126, 150, 168, 171, 174-176, 179,188

exonym 10,72

exoticism 32, 35, 39, 73

families 4, 26, 98, 108-109, 115-116, $123,125,132,137,150,152,173,188$

female sexual inverts 77

feminism 29, 44, 47-50, 53, 58, 59, 65, 66; radical 105, 156

Fanon, F. 94

fieldwork 62-63

financial crisis 3,16

focus groups 61,68

forced marriage 105-107, 116

France 13, 60, 87

fundamental 3

Gadjo 11, 104, 108

Gamson, J. 52, 53, 161

gay $8,9,11,16,20,52-53,60,61,81$, 83, 98-100, 103, 106, 117-118, 120, 127-131, 140, 127-128, 159, 172, 180, 185; club 98-99

gender 2, 25, 28, 29, 38, 45, 48, 49, 50, 53, 94, 98, 107, 120, 151, 156-158, 163, 172, 177; disadvantage 106; roles 111

gendered 35, 36, 72, 79-80, 96, 98, $106,120,124,151$

genetics 30,31

genocide 75

Germany 60, 107

ghetto 2, 15-17, 88

Gitanos 1, 72

globalisation 26

groupness 35, 59, 63, 96, 173

Gypsy $1,10,11,13,30,32,35,45,51$, 72-74, 79, 81-82, 103-104, 172, 177, 179-180; 'Gypsy' camps 75

Gypsy Lore Society 33, 73

Gypsyologists 32, 33

Hall, S. 8, 25-29, 45, 51, 54-55, 81, $152,171,178$

Halperin, D. 11, 51-52, 83

hate crime 76

heritage $5,11,16,67,143,159$

heterogeneity 1, 2, 10, 29, 34, 44, 45, $82,89,148,171,180$

heteronormativity $10,45,49,53,59$, 81, 85-86, 90, 92, 102, 106-110, 
113, 115-118, 120, 122-124, 131, 134, 137-138, 152, 154, 156-158, $160,164,181,184-186$

heterosexualisation 139,147

heterosexuality $2,54,81,83,85-86$,

$111,125,127,137,152,158,172$,

178 ; compulsory 2,174

historic overview 11

homogeneity 2, 10, 30, 34, 39-42, 45, 171,174

homonationalism 120, 143, 167, 186

homonormativity 53, 119-120, 160,185

homophobia 2, 9, 17, 19, 56, 68-69, 77, 81, 98, 100, 104, 122, 125, 127, 133, 143-144, 146, 149-150, 152, 171-174, 179, 184, 186

homosexual 78, 111; medicalised 52, 83; modern 52

homosexuality $16,17,19,54,78$, 101,113

history 2, 12, 34, 41, 51, 72, 80 human rights $16,18,26,37,40,175$, $185,187,190$

Hungary 12, 16-18, 60, 114, 120, 177 hybridity $42,45,51,74,84,172$

hyper-visibility $9,41,88,91,96,98$, 102-104, 107, 113-115, 122, 125, 128-129, 136, 146, 149-150, 154, $172,174,194$

iconic signs, symbols 178

ideology 15, 16, 18, 27, 31, 75, 186 identification 2, 27, 41, 45, 54, 64, 83-84, 86, 88, 92-96, 101, 148, 150-169, 174, 184, 186

identities 2, 26, 41, 42, 48, 51, 55, 67, $80,91,95-96,105,111,116$, $122-123,125,143,148,150,153$, $165,169,171,184,186$; collective social 3, 26, 32, 41-44, 52-55, 91-92, 145, 156, 165, 171; contested 26, 32, 41, 86; ethnic 3, 25-30, 39, $41,45,54,81,84-85,89-90,96$, $100,105,110,125-127,151,157$; fixed $3,32,37,44,51-53,57,65,88$, 96, 151, 172, 184-186; fluid 28, 44, 55, 61, 95, 101, 112, 138, 147, 159-160, 163, 169, 174, 184; gender 2, 4, 25-28, 41, 45, 51-52, 60, 81, 85, 89-90, 94-98, 104, 109-110, 113-114, 120, 125, 132, 146, 150-151, 158, 168, 172-174, 177,
179, 184, 186; group 2, 30, 40-42, 86,100 ; individual $25,26,41,42,52$; instability of 52 ; intersecting $2,9,19$, 28, 30; national 26-28, 50, 89, 91, 94; performance of $54,78,81,84,92$, 94, 139, 154; queer 109, 114-115, 117, 124-127, 139, 149; 'racial' 1, 25-30, 41, 45, 54, 81, 84-85, 89-90, $96,105,110,125-127,172-174$, 184; Romani 8-9, 29-34, 38-42, 45, 57, 58, 63, 74, 81, 91, 95-96, 101, 121, 127-127, 133, 137, 141, 151, 153, 157, 171-172, 177, 188; sexual 25-28, 41, 51-57, 60, 81, 84-85, 89-90, 94, 96, 110, 114, 120, 125-127, 172-174, 184, 186 identity politics $161,165,167,169$, 185,187

image 10, 18, 32, 34-35, 46, 73-74, 81, 89-90, 94, 172, 178, 180; visual 178 impactful research 10, 171, 176 inclusion 18, 19, 40, 55, 86, 92, 109, 116, 147, 150, 152, 156

Indian origin $12,31,32,33,35,73$

inequalities $2,48,59,124,165,173$;

intersectional 176; structural 61, 123 , 174, 184-186

information 4

initiative 176-177

innovative research methods 5,10 , 62,171

insider 64, 75; research 65, 66

intersectional essentialism 105 , 145,147

intersectional feminism 10, 29, 47, 59, 165,171

intersectionality $41,42,47-51,56,58$, $61,74,95-96,172,188$

intersex 1, 60, 142, 156, 158

interviews, in-depth semi-structured 61 invisibility 4, 9, 90, 91, 98, 106, 123, 126, 130, 139, 147, 151, 156, 165, 184,187

Jewish 8, 27, 75, 77-78, 81-82, 172; Jewish Cultural Studies 54

Jim Crow 76

Kale 1, 60

Kaliardà 2

kinship 7, 30, 31, 41, 108, 115-116, 123,174

Kóczé, A. 38, 43, 43, 50, 107, 116 


\section{Index}

Kosofsky Sedgwick, E. 81-82, 91, 93, 103, 129

knowledge co-production 171 ,

176-177, 179; production 42-44, 51, 61,179

language, Romani 2, 11, 30, 33-34, 60, 73 ; uprooting of 14,15

lesbian 1, 9, 11, 16, 51-53, 60, 61, 98, 100, 103, 105-106, 109-111, 117, 121, 131-135, 141, 153-157, 165,185

Lesbian and Gay Studies 29, 52-53, 185

lesbophobia 9

linguistics 30, 33

literature 4

litmus test 15,188

Lubunca 1

mainstream 4

majority 2-3, 10, 14, 19, 27, 34, 37-39, $42,45,48,58,88,90,110,119,123$, 149-150, 152, 154, 156-157, 160, $169,172,181,186$

marginalisation $2,13,36,38,39,50$, $72,88,123$

materialities 9, 20, 41, 57, 62, 80, $82-84,90,92,116,124,125,131$, $142,150,168$

McGarry, A. 30, 32, 39-42, 52, 89-92, $116,161,177$

meaning $27,28,51,60,62,74,82,93$, $151,178,186$

media $3,15,26,41,91$

methodology 60-69, 96, 177, 179

migration 5, 33, 35, 56; immigration 46 minoritarian subjects $58,84,92-96$, 149,160

minority $1,2,15,18,26,29,31,34,37$, $40,52,55,77,87,182$

misrepresentations $3,30,42,103,143$, 171-172, 177-180, 182

mobilisation 2, 52, 88, 151, 160-161, 169,175

modalities, social 178

modernity $3,7,73$

Moldavia 13, 77, 88

movement, freedom of 18,105 ;

regulation of 13,14 ; social $2,4,8,10$, $18,19,26,39,130,145,154$, 165-168, 171, 175, 185-196; political $39,175,185-187$
Muñoz, J. E. 58, 84, 92-95, 146, 152-154, 160

nation state $26,27,38,74-75,87-88$, 91, 172; neoliberal 27, 57

nationalism 34, 36, 39, 56, 74, 76

Nazi atrocities 10; concentration camps

88 ; race science $27,31,172$; racial

ideology $31,76-77$; theory 75

new ethnicities $8,28,44,53,171$

nexus $88,118,120,123$; ethnicity/'race'

74 ; intersectional 8

nomadism $11,14,73,79,88$

non-binary 60, 142, 156, 185

non-European 32, 39, 88

non-citizens 39

non-normative $10,17,25,51,59,61$, 63-64, 77, 81-82, 84-86, 95, 105, $112,123,150,169,172-173$, 184-186

non-Roma 2, 9, 10, 11, 15, 30, 32, 60-69, 72, 79, 81, 86, 88, 98, 100, 108, 124, 134-135, 152, 172, 178, 186, 188

non-Romani researcher reflexivity 8,61 , 63-66, 69, 96

non-territorial 29

non-white 55,78

normalisation 52-53, 55, 58, 85, 89, 135, 142-143, 146, 149, 181, 184; normality 52-53, 77; abnormality 53,79

normativities, social $45,51,58,59,62$, $69,81,84,92,95-96,123-125,142$, $145,147,149,151,157,160,174$, $178,181,184$

notional spaces $127-128,133,138$, 148, 173

objectification 73,168

objectivity 45,65

ontology 26, 173

Oprea, A. 36, 50, 107

ordinariness 5, 42, 89-92, 104, 122, $138,143,145,179$

orientalism 11, 16, 32, 39

ostracism 116

oppression 9, 13, 36, 48, 52, 55, 62, 80-82, 88, 90, 98, 101, 104-105, 122-123, 127, 129, 139, 150, 165, 167, 186; hegemonic 56, 84, 104, 107, 138, 149, 155, 186; interlocking systems of $56,59,102,124$; 
intersectional 9, 169, 174; structural 42; , systemic 185

other $15,42,43,48,53,55,57,75,81$, $85,87,103,150$

pandemic 2

paradigm 29, 43, 47, 58, 68, 123; shift

43, 51, 53; visual 178-179

participants $60,62,179$

participant observation 61

passing $6,10,81,86,88,92,96$, 98-101, 125-126, 133-139, 146-148, 150, 155, 173-174, 184;

'racial' 84-85; sexual 85

passive gay $117,123,158,174$

paternalism 44, 168, 186

patriarchy $35,45,51,59,90,92$,

106-108, 110, 113, 116, 122,

147-148, 152, 156, 158, 164, 184, 186

persecution $2,13,37,87,91,120-121$, 154,172

plurality 10, 28, 43-44, 148, 171

Polari 2

polarisation $2,87,175,188$

policy 10, 14-15, 18, 36, 39-40, 75, 88, 175-177, 188

political science $33-34,38,40-41$

populism 26, 39, 187

Porajmos 14

portrayal 3, 7, 45, 73-74, 89-90, 145, 174,181

positionality $8,11,51,60-66,69,94$, $96,125,147,151-152,164,169$, 172, 184-185

post-modernity 3, 95, 171, 174

post-'racial' 27

poststructuralism 53, 55, 95, 171, 186

poverty $15,18,36,38,74,123,185$, 187 ; culture of 31

power relations $49,56,62,65-66,123$,

186; asymmetrical 9, 55, 57, 59, 75, 59-60, 96, 106-107, 120, 124, 133, 138-139, 149-150, 159, 173-174, 184; hegemonic $8,44,47,53,62$, 116, 140; hierarchal 53, 56, 75; , inequitable 8,98 ; interlocking 49 , 186; local 118, 120

Prague 2, 13, 98; declaration 176

prejudice 4, 79, 103-104

pride 2, 19, 61, 91-92, 98

primordial $27,30-32,35$, originary 27 , $35,82,88$ privilege 47, 56, 60, 63-67, 69, 96, 105, 111, 120, 123, 128, 137-139, 148, $155,174,184$

Probyn, E. 87, 151, 157

protection 8-9, 16, 81, 84-86, 89, 108, 116, 123, 126-130, 132, 134, 136, $140,148,152$

proximity $1-2,54,77$

Puar, J. 47, 55-59, 63, 143, 120

punishment 109, 116

purity laws 20,89

qualitative $1,60,64$

queer, meaning of $51,52,59,185$

queer assemblages $47,57,58,61$, 63-64, 96, 172, 174

queer ethics 62-63

queer intersectional specificity 98 , 104-108, 115, 116, 123, 125, 127, 129, 134, 145, 148-150, 157, 159-160, 165-166, 169, 173, 184

queer intersectionalities 56-59, 95-96, 102, 149, 171-173, 185-186, 188 queer of colour critique 51,55 queer theory $29,35,44,51,95$, 164,172

queerness 42, 51, 52, 64, 93, 139, 147, 151-152, 161, 166, 172

'race' 2, 7, 8, 15, 27, 28, 45-50, 53, 55, 74-81, 84-85, 94, 104, 120, 146, 151, 172, 174, 177, 179, 186; medicalised 78; revival of science 76

'racial' governmentality 76; persecution 10, 13; prejudice 4; purity 27

'racialisation' 72-76, 80, 83, 98, 103, $107,112,120,122,124,136,139$, $145,150,179$

'racialities' 28, 72, 96

racism 2, 28, 31, 39, 55, 56, 68, 74, 76, 81, 99-102, 129, 144, 168;

internalised 30

rejection 4, 86, 92, 109, 115-117, 131, $144,150,152$

relational 20, 26, 27, 35, 45, 55, 65, 74, 82-84, 108-109, 116, 123-124, 125, 128, 131, 134, 137, 141-142, 150, $156,168,173,184$

relations 40, 51, 66, 101, 122; race 15 ; researcher-researched 62-64; Social 9, 55, 62, 80, 128, 173

representations $3,7,10,15,28,39,60$, 


\section{Index}

$74,144,177,186$; artistic 79 ; visual $10,73,178-179$

research 4, 31, 76, 175; methods 60-62, 178

resistance $14,57,95,185$

rhizome 57

Roma 1, 11, 29, 30, 38, 72, 151, 172, 188; endonym 10, 73

Roma rights 4, 10, 19, 37, 40, 88, 165-166, 171, 175, 185-187

Romani anthem 10; flag 10, 19-20, 180; Gypsies 1, 60; Holocaust 10, 14, 27, 39, 76-77

Romani Studies 8, 29, 33, 34, 36-51, 56, 64, 66, 74, 89-90, 144, 165-166, $172,177,185$

romanticisation $3,35,36,73,103,172$; Romanticism 40, 79

Romania 60

Romaphobia 27

Romipen 31, 89, 123, 154, 174

Rose, G. 178

Rumungro 1, 60

Russia 156-157

sameness 87, 125-128, 138-139, 145, 173, 184; strategic 9, 125, 129, 139-149, 151, 171, 181, 184

Section 2816

sedentarisation $14,88,91$

segregation 4,42

self 26, 29, 54; ethnographic 63

self-identification 11, 26, 41, 174, 186

self-representation $7,10,171,181$; photographic 179-180, pure 182

Serbia 6, 7, 60, 83, 100, 106, 109

sex 4, 19, 25, 28, 45, 47, 90, 94, $106-107,120,123,151,156,172$, 174; sexed 35, 72, 78-79, 96, 98, $106,120,124,150,157-158$ sexism 9, 48, 84, 98, 104, 125, 127, 133, 146, 149-150, 156, 171, 173, 179, 184, 186; misogyny 49, 94 sexual minority 52,65 ; orientation 52 , 105 ; subject 52,53

sexualities $2,28,29,45,48,49,54,55$, $56,63,68,72-85,90,94,98,104$, 106-107, 109-110, 112, 120, 125, $129,132,141,147,151,154$, 156-157, 164-165, 168, 171, 174, $177,179,186$

shaming 118-120, 123

single story $3,30,172,174,177$
Sinti 1, 11, 60

Slavs 77

slavery $12,13,77-79,88$

Slovakia 2, 14, 17-18, 67, 69, 177

social control 2, 106-107, 116, 156, 174 ; change 171,175 ; division 48-49, 62, 90, 143, 150, 161, 176; isolation 130, 159; justice 69; norms $29,45,53,59,61,64,80,85,87$, 102, 106, 111, 116, 118-120, 127-128, 137, 139, 146, 149, 151-152, 158, 172, 178-179, 181, 184, 186; setting $62,100-101,112$, 120, 123-124, 126-129, 134, 136, 140-142, 148; status 118, 120-121, 123 ; systems 109

social sciences $26,52,61,62,65,68$ socialism 14, 15, 17, 76, 80

socio-cultural codes $91,93,154-155$, 186; references 180-181; scripts 10 , 52, 58, 94-96, 110, 117, 123, 125, 131, 146, 151, 154, 160, 166, 169, $178,181,184,186-187$; systems 28 , 29, 54

sociology 36

sociological subject 29

Spain 6-7, 35, 60, 79, 99, 118

special schools 4,79

Spivak, G. 31

statistical 5

stereotypes $3,16,30,41,73,77-78$, 88-89, 92, 100, 120, 143, 149, 171, $177,179,182$

sterilisation $14,42,75,80$

stigma 81, 103, 120, 129

stigmatisation $2,3,30,37,40,41,73$, 77, 81, 86-88, 90-92, 100-101, 105, 109-110, 116, 119, 122, 125-127, $131,143,150,154,157,160$, 172-173

straight 4, 9, 19, 43, 53, 60-61, 67-68, $84,88,124,134,160,178,186$

strategic essentialism 10, 31-32, 140, $145,161,166,169,171,185-186$

strategy $7,9,33,58,81,84,86,92,94$, 96, 125-127, 131, 133-134, 136-137, 139-140, 148, 171, 173, $176,184-185,187$

subjectivity $45,56,57,63$

subversion 9, 34, 52, 57, 81, 84-87, 96, $121,125,140,145-147,149$, $151-152,155,158,160,162,164$, $168-169,184$ 
super-diversity 42, 45, 51, 74, 172 super-structure 116

survey 5

survival 56, 58, 81, 84, 86, 92-95, 108,

116, 123, 125-127, 132-133,

136-137, 139, 148, 173, 175, 185

taboo 4, 5, 27, 51, 53, 109

television 3

territory 1

thematic analysis 61

theory-informed 60-62

threat 3

toleration 12

tomboy 115

trans $1,4,6,9,11,18,53,55,61,80$, 90, 98, 101, 107, 124, 138, 147,

158-159, 185

transdisciplinary 7, 10, 171, 179

trans-exclusionary 11, 186

transgender $7,8,17,56,60$

transgression $79,84-86,96,133,139$,

152, 158, 164, 168, 176, 181, 184

transition 15, 101, 111-112, 159

transnational 1, 6, 29, 38-40, 45

transphobia $9,19,49,55,56,69,81$, $84,98,100,102,104,125,127,133$,

144, 146, 149-150, 171-173, 179,

184,186

travellers $1,7,10,11,12,19,60,110$, 117,137

Tremlett, A. 32, 35, 38, 42, 45, 46, 89-90, 116, 177

Tucker, A. 56, 82-84, 91-92

uncover 2

underachievement 5

United Kingdom 2, 60, 137
United States 2, 60, 121, 126, 136-137, 142,175

Ursari 1

validation 110, 121-124, 130, 154, 174, 178

valuation, negative $9,30,72,86,122$, $127,150,157,172-173$

values 3

Vertovec, S. 46

vilification $3,73,103,172$

visibility $9,19,20,82,86,88,91,96$, 98, 104, 106, 115, 121, 125-126, 138-139, 148, 150, 156, 166, 173; lack of 179

visualities 178

vulnerability $15,50,107-109,123$, 130, 137, 178, 185

Wallachia 13, 77

Western 40, 44, 76, 83, 126

World Health Organisation 17

World Romani Congress 10, 73, 175,187

white $3,78,81,83,88,95,134,137$, 158, 178; women 57

whiteness 81-82, 85, 178

white-normativity $10,45,49,56,59$, 81, 84-86, 92, 102-103, 107, 112, 115, 124, 131, 134-135, 137-138, 145, 156, 161, 164, 167-168, 173, 184-186

xenophobia 77

Yenish 1 


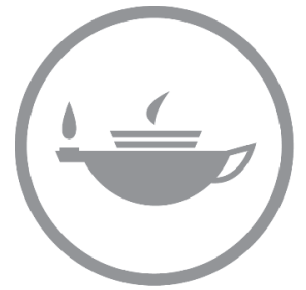

Taylor \& Francis
Taylor \& Francis Group http://taylorandfrancis.com 